\title{
CHAPTER 1.: INTRODUCTION
}

\section{I.I. AN OUTLINE OF THE DEVELOPMENT OF PEAT RESEARCH}

Since the beginning of scientific peat investigation in the first half of the last century - with interest initially centred in particular on the question of its botanical contents and the problem of its origin - innumerable publications on peat bogs and peat research have appeared (see, inter alia, Overbeck 1963, Saebo ig68). Their very number shows that there has been great interest in peat growth. The diversity of opinion among the many authors as to the relative importance of the various factors influencing peat growth (climate, mineral ground water table, vegetation processes) on the product formed (the peat), clearly demonstrates the complex character of peat growth, by which is meant the sum of the biological and also the chemical and mechanical processes which result in the accumulation of organic material.

In his extremely readable introduction to a series of lectures on peat investigation, Overbeck ( $\mathrm{I}_{96}$ ), drawing on his wide knowledge of the very extensive peat literature, divides the history of peat investigation into four periods. In his first period, extending to the middle of the 18 th century, there is, as yet, no question of scientific study. His second period - up to c. 1840 - is the one already mentioned above in the first sentence: precise observations of the stratigraphy of peat and its botanical composition lead to the classification of bogs into types and the recognition of the purely ombrogenous character of raised bogs.

Overbeck starts his third period with the work of J. STEENSTRuP (1842) and A. Grisebach (I846), and this could be defined roughly as the period during which the effect of climate on the development of peat bogs is recognised; peat bogs and organic sediments form important records, from which the development of vegetation and climate can be reconstructed. Other epoch-making investigators of this period mentioned by Overbeck are I. Geikie (I866), A. G. Nathorst (1870), A. Blytt (1876), G. Andersson, R. SERnANDer and especially C. A. WEber, whose work can be said to have had an important influence on the peat investigations of OVERBECK's fourth period, commencing in 1916 , with the rise of pollen analysis (L. von Post IgI6). This technique had, however, already been applied long before by WEBER (I893).

During the transition between Overbeck's third and fourth periods, there appeared in the Netherlands several publications 
which can be regarded as an inventory of the third period. MULDER (I9II) gives a detailed report on the state of affairs in peat investigation; VAN BAREN (I9I3) describes its history and SCHIERBEEK (1917) gives a good survey of the current knowledge of peat bogs. These publications did not, however, lead to a Dutch tradition of peat investigation, as e.g. in Germany (WeBer, Overbeck) and Sweden (Osvald, Granlund, Nilsson).

C. A. Weber's well-known opinion (inter alia 1926) that the climate has a direct influence on the nature of the peat formed, has clearly given direction to peat investigations in OVERBECK's fourth period. It was possibly because of WEBER's great prestige that less attention was paid to the vegetation processes in peat bogs, in spite of the existing extensive knowledge of the botanical composition of the peat.

In spite of the difficulties experienced by various investigators in correlating climatic fluctuations found or suspected by them, with already known fluctuations (difficulties perceptible in e.g. WEBER's "Grenzhorizont" and Granlund's "Recurrence surfaces" - contact zones between more humified and less humified Sphagnum peat) scarcely any doubt arose about the climate-dependent character of the changes observed in peat growth.

The prevailing opinion that the development of climate-and even comparatively small fluctuations in temperature and precipitation - could be deduced from peat stratigraphy, therefore endured. NrLsson (1964b) distinguishes nine RYs (recurrence surfaces) as evidence of nine temporary periods of dessication caused by climate between c. 2000 B.C. and 500 A.D. Actually, however, the large number of radiocarbon dating determinations on which NILsson bases his conclusions only shows that RYs can appear in peat at any moment in the period stated. Mirchell (I956) distinguishes four RY phases in this period, but his 24 dating determinations also reveal a regular appearance of humification levels (and not, in fact, accumulations) between c. 2000 B.C. and 500 A.D., i.e. at average intervals of about roo years.

Overbeck also divides his RYs into several groups between c. 2300 B.G. and 600 A.D. (Overbeck, münnich, Aletsee \& Averdieck 1957). Averdieck (1957 b) cannot correlate the RYs over a greater distance (Swedish peat bogs - Grosse Moor near Gifhorn). Willutzki ( 1962 ), on the other hand, does think that he can arrive at a long-distance correlation. HAYEN (1968) found a pine stump layer - often regarded as evidence of peat growth in a dry climate - in the Ipweger Moor near Oldenburg (Germany), 
which clearly cannot be seen as a synchronous level of peat growth. Osvald (1923) assumes that peat formation occurs via a cyclic succession, which he describes as the "regeneration complex". On the bog surface, hollows develop into hummocks, and hummocks degenerate into hollows. This idea is based on Sernander's hypothesis of the cyclic succession of the different parts of the vegetation mosaic of the bog surface (hummocks and hollows). In a way, this hypothesis more or less conflicts with the ideas of WeBER (Grenzhorizont) and Granlund (Recurrence surfaces), where the climate-dependent character of the type of peat formed is dominant. With cyclic peat formation, simultaneous growth of less humified and more humified Sphagnum peat in close proximity is encountered, while, from WEBER's and GRANLUND's standpoint, the bog surface forms peat with a uniform degree of humification to a much larger extent. This implies a much more homogeneous vegetation which alters clearly only under the influence of climatic changes. ERNST (1934) sees this regeneration complex in Northwest German raised bogs, where hummocks degenerate into hollows and hollows develop into hummocks on the bog surface. Du RIETZ (1950) gives a very detailed description of the vegetation dynamics in the Swedish Blängsmossen mire, where he thinks a cyclic succession can be observed. Osvald (I950) describes the hummocks-and-hollows surface of the Swedish bog of Komosse. He sees regeneration and erosion complexes as essential elements of a living raised bog surface.

Many objections to peat formation via cyclic succession have been raised; see Overbeck (1963); also Markgraf (1969).

Grosse-BraugrmanN (1968) argues that much less dynamism is present in peat-forming plant communities than is assumed by Osvald. The present author has come to a similar conclusion (CAsparie 1969).

RATCLIFFE \& WALKER (1958) give a detailed description of the vegetation of the different parts of the bog surface (river terrace, lagg, margin, hummock-hollow system) of the Scottish peat bogs of Silver Flowe. They pay a great deal of attention to the local bog hydrology, in particular to the arrangement of bog plants in relation to the water table. The mosaic of the Sphagnum-dominated hummock-hollow system, which they regard as the definitive vegetation type in the bogs investigated, remains stable. These authors, therefore, do not regard the hummock-hollow system as forming a regeneration process. Morrisson (1955, 1959), though, does see a direct reaction in peat formation to changes in precipitation. He 
also, however, points out the buffering action of the water supply and devotes attention to the water regime in relation to the mechanism of peat growth. Olausson (1957) is of the opinion that there is no question of a direct relationship between precipitation and the type of peat formed, or of cyclic succession in the Swedish bog, Roshultsmyren. According to this author, the local bog hydrology is an important factor. Schlüter (1969) quotes LANGE (1967) who sees a gradual increase in humidity from maybe even as far back as c. 2500 B.C. According to ScHLÜTER, the local ombrogenous bog hydrology is of great significance for the raised bog communities and their zoning. Ratcliffe \& Walker (1958) also come to similar conclusions in their above-mentioned study. WALKER \& WALKER (196r) believe, however, that even small variations in precipitation have an obvious influence on bog hydrology, and consequently on the type of peat which grows there.

The history of peat investigation, of which only a rough, incomplete outline has been given above, shows that special attention has been paid to the growth mechanisms of ombrogenous peat. Discussions about peat formation, then, are also based for the greater part on information from ombrogenous peat, the composition of which is very well known (e.g. Weber 1902; Grosse-Brauckmann Ig62; K. Müller 1965; SCHLÜter I969).

This is not to say that the composition of minerogenous peat is necessarily less well known (see e.g. JASNOWSKr I959; GrosseBrauckMann I963; MareK ig65; KuKLa 1965 with very detailed information about the composition of minerogenous peat), or that fen and seepage peat growths are natural biological processes. Possibly, we must look for the cause of the slighter degree of attention paid to the fen peat accumulation processes in the less easy accessibility of such peat bogs, and the impossibility of studying good sections. Apart from this, study of the development of the climate in the Holocene was an extra stimulant to the investigation of riased bogs (Weber, Granlund, Overbeck). Now that the growth processes in the peat are gradually receiving more attention (WALKER \& WALKer 196I; Du Rietz I950; JASNOWSKI and others I 968; WALKer ig65; Grosse-BrauckmanN I962, 1963, I967, ig68) - a fifth period in peat investigation? - it may be expected that, in discussions about peat growth, the growth mechanisms of minerogenous peat will begin to assume a greater importance.

In the course of the peat investigations, several peat bogs, as well as numerous prominent peat researchers, have become very widely known. Peat bogs such as Hellweger Moor, Augstumal, Grosse 
Moor near Gifhorn, Komosse, Agerøds Mosse, Roshultsmyren, Somerset Levels, may be even better known than the authors who worked on them. It may seem somewhat surprising that there has never appeared a comprehensive publication on the stratigraphy and development of the Bourtanger Moor, possibly the largest raised bog in Europe, with its surface area of, originally, c. I,60o square kilometres (BARKMAN \& WESTHOFF 1969). The reason for the lack of such a study need not be sought in the geographical situation of the bog, on the Dutch-German border, due to which the peat investigators of the one country would have been inclined to have given the honour of such an investigation to their colleagues in the neighbouring country. The very early beginning of the destruction of the raised bog (dating from the Middle Ages), and the fact that peat cutting had already continued for centuries, caused the disappearance of thelarger part of it, even before there was any question of scientific peat investigation; see also 2.I (p. I4) and 2.3. (p. I8).

Since the end of the igth centry, several studies on peat deposits from the Bourtanger Moor have indeed appeared, but almost all these dealt with a very specific aspect of the bog (VAN BEMmELEN i895, Reinders 1896 and igo2, van Zeist i955a, van Heuveln $195^{8}$ and $19^{62}$ ), or followed a predominantly pollen-analytical line of enquiry (Florschütz and others I932, Florschütz \& Wassink I 935 and 1942, Eshurs 1936, WATERBolK 1954, VAN Zeist 1955a, i955b, 1956, I959, Waterbolk \& Van Zeist i96 I, Clason i96 I, Bult 1963 , van der Spoel-Walvius ig64, de Smet \& Klungel 1965). A few field reports give some information in general terms about the stratigraphy of parts of the Bourtanger Moor (VERsLuYs ig 19, Zondervan i 925, Teunissen i 964, I965, I966). Hoogenraad (1934) analysed a few peat profiles from this bog for their rhizopod fauna.

Almost all of this information comes from that part of Bourtanger Moor east of Emmen (in the province of Drenthe), west of the Dutch-German border. Visscher (193I) published a detailed study, based on numerous stratigraphical observations, of the stratigraphy and development of the peat of the region.

In the 1960 os there existed for the last time the opportunity for a detailed study, with modern investigation techniques, of the stratigraphy and development of the peat in this region, since the last clearly decipherable peat blocks were on the point of disappearing (see 2.3., p. 18). This sufficiently demonstrates the necessity for such an investigation, the report of which appears in the following chapters. 
First of all, extensive documentation of the structure and of details of the stratigraphy were of importance for obtaining as complete a cross-section of the peat region as possible. Moreover, it was necessary to attempt to describe the development of the bog, in particular the several layers of peat, as comprehensively as was possible on the basis of the field information obtained. This was done by means of detailed investigation with several investigation techniques (pollen analysis, rhizopod analysis, analysis of macroscopic remains, ${ }^{14} \mathrm{C}$-dating, dendrochronology). In the course of the investigation we found that a description of the development in terms of peat growth mechanisms (CASPARIE 1969) was the most suitable. Every description of a peat formation ends with a final section "Stratigraphy and development" in which these growth mechanisms are discussed.

\section{I.2. AGKNoWLEDGEMENTS}

This study was set up on the initiative of Dr. W. van ZEIST, of the Biologisch-Archaeologisch Instituut of the Rijksuniversiteit of Groningen, who followed its progress throughout with great interest, and who helped, in every possible way, to put the investigation on the right track again when progress failed to materialise. Our numerous discussions have had a direct effect on the results of this investigation. Prof. Dr. H. T. WAterbolk, Director of the Biologisch-Archaeologisch Instituut, offered me ample opportunity to make use of the technical facilities in the Institute, as well as time and space to work on the material. MR. G. DELGER made an important contribution to the fieldwork. In addition, MR. H. RoELINK, the late Mr. J.van Delden, Mr. A. Meyer, Mr. K. Klaassens and Mr. J. H.ZwIER have assisted in the field-work. The working out of the field drawings and the drawing of diagrams were done by Mr. Jac. Klein, Mr. H. Roelink and Mr. B. Kuttert. Miss I. van Otterloo (now Mrs. I. Wolters-van Otterloo) assisted in several laboratory tasks. Miss J. van Dijken and Mrss G. F. Boers typed the several versions of the manuscript.

Mrs. B. M. van Der Meulen-Melrose B.Sc., of Roden(Drenthe), was willing to undertake the translation of this extensive work. I am very grateful to her for accepting the task and for the way in which she has completed the work.

I also wish to express my gratitude to DR. J. J. BUTLER who very 
kindly gave me much valuable advice concerning the translation of the technical terms.

A very large part of the area I investigated is the property of the N.V. Veenderij en Turfstrooiselfabriek "Klazienaveen, v.h. W. A. Scholten". The permission granted by the manager of this firm, Mr. D. G. S. LANDWEer (Haren) to enter the grounds, and also the pleasant contact I have had with Ir. K. Meinders (Klazienaveen), the company engineer, and with Mr. G. Hexman (Klazienaveen), the supervisor of the firm, cannot remain without mention here. The owners of the other sites I visited have also always granted me their disinterested permission to carry out investigations on their peat blocks.

Important contributions to the investigation have been made by Dr. A. V. Munaut (Louvain): dendrochronology; Prof. Dr. J. G. VOGEL (formerly of Groningen, now of Pretoria): ${ }^{14} \mathrm{C}$-dating; Drs. M. W. TER WEE (Oosterwolde) of the Geological Survey: geological information. Drs. P. Bult, Mrs. I. Wolters-van Otterloo (Amsterdam), Dr. D. Teunissen (Nijmegen) and Mrs. Drs. H. C. M. Teunissen-van Oorschot (Nijmegen) analysed some profiles. Dr. B. O. van ZanTEN (Groningen) did the determinations on a number of moss remains.

There have been discussions with many of my colleagues about the problems which arose during the investigation. Apart from those mentioned above, these included Ir. B. van Heuveln (Haren), Mr. J. Wieringa (Roden) and Mr. H. Booy (Westerbork) of the Soil Survey Institute, Dr. W. H. ZaGwijn (Haarlem) of the Geological Survey of the Netherlands, Mr. Chr. G. van LeEuwen (Bilthoven) of the RIVON and Mr. F. MODDERKolk (Beilen) of the State Forest Administration, Nature Conservancy Department, Dr. J. J. Barkman of the Biological Station at Wijster, Mr. H. Hayen (Oldenburg), Dr. G. Grosse-Brauckmann (Darmstadt)., Dr. F. R. Averdieck (Kiel) Dr. K. E. Behre (Wilhelmshaven), my Groningen colleagues Drs. J. W. Boersma, Drs. S. Bottema, Dr. J. J. Butler, Dr. A. T. Clason, Drs. O. H. Harsema, Drs. A. E. Lanting, Drs. J. N. Lanting, Dr. R. R. Newell, Prof. Dr. J. D. VAn DeR WAals, and Dutch palynologists.

During an excursion to a number of German peat bogs in September, 1964 , I had discussions with Prof. Dr. L. Aletsee (formerly of Kiel, now of Aachen) and Dr. K. Müller (Kiel) about problems concerning peat growth.

In August, 1969, and in June, 1970, I made two working trips to Poland, where, with Prof. DR. M. Jasnowski (Szczecin), 
Dr. S. Markowski (Szczecin), Doc. Dr. St. Marek (Wrocław), Dr. M. J. DABrowski (Warszawa) and the late Dr. J. Niklewski (Warszawa), I visited some splendid peat bogs, many still in an almost undamaged condition. The discussions I had with German and Polish colleagues were of great benefit to my investigation.

\section{r.3. Pollen analysis}

Much of the material presented in this study has been investigated by means of pollen analysis. Modern peat investigation is well-nigh impossible without pollen analysis. FAEGRI \& IVERSEN (I964), in their outline of the history of the Quaternary pollen analysis, point out the development in peat investigation which was partly the cause of the rise of pollen analysis.

The history of the regional vegetation in the north-east Netherlands since the Late-glacial is comparatively well known on the basis of pollen analytical information. This will be gone into very briefly in Ch. 4., p. $44 \mathrm{ff}$., A survey has been given in table II which could be made up from information from VAN DER HAMMEN (I95I), WATERbolk (1954), van Zeist (1955a, I955b, 1959), and others.

The pollen analytical investigation was directed especially towards dating particular items in the bog, drawing up correlations, and obtaining an understanding of the composition of the different types of peat. As far as the correlations drawn up are concerned, we have been constantly aware of their local character and of the errors which can easily arise from this. We have therefore made no correlation between developments in the bog that we investigated and those in other peat bogs.

We have taken the sum of the total tree pollen as the basis of the calculation for pollen percentages - except for the Late-glacial diagrams. It would perhaps have been better to have excluded the pollen of those trees which have grown in the peat - mainly Alnus, Betula, Salix (?), Quercus (?), and Pinus - from the pollen sum. This, however, raised the practical difficulty that, per sample, considerably more pollen grains would have had to be counted. The majority of the correlations concerns treeless ombrogenous peat (Sphagnum peat), so that the influence of "local tree-pollen production" is negligible. During the ombrogenous peat accumulation, trees appeared exclusively along the narrow edge of the bog.

A fortunate circumstance for the work of correlation was that the regional pollen precipitation clearly changed during the period of ombrogenous peat growth. The decline in Ulmus and Corylus, the 
increase in Fagus and Carpinus and the indicators of agriculture in the higher, sandy soils (in the Subboreal and the Subatlantic periods) are among the changes which afforded sufficient possibilities for, in our opinion, justified correlations. With the help of the ${ }^{14} \mathrm{C}$-diagram (4:3., p. $4^{8}$ and fig. 63 ) of VAN ZEIST (1955b) and some additional ${ }^{14} \mathrm{C}$-datings, several correlated levels could be assigned an absolute age.

In addition to the types of pollen originating in the regional vegetation, the representatives of the local peat vegetation were, of course, included in the pollen diagrams (as far as this was possible on practical grounds). In ombrogenous peat these were mainly Sphagna, Ericaceae, Empetrum, Gramineae and Cyperaceae, whose presence in the peat, however, should not be taken as excluding the possibility of their presence in other places. In fen peat there is a considerably richer variety of types; for this, see the parts of the pollen diagrams concerned.

\subsection{Rhizopod ANALysis}

Alongside pollen analysis, quantitative investigation of rhizopods occupies an important place in this study. By "rhizopods" is meant here the order of the testacean (i.e. with a shell) Amoeba or Thecamoeba, which, together with the order of the Gymnamoeba, constitute the subclass of the Rhizopods SENSU sTRICTO. The Heliozoa constitute another subclass of the Sarcodina or Rhizopods in a broader sense (phylum Protozoa) (Hoogenraad \& DE Groot 1940). Instead of Thecamoeba or Testacea, we usually speak of Rhizopoda (Grospretsch 1952). The rhizopod fauna occurring in many moist to wet milieus can afford further information about the peat-forming milieu, among other things.

Rhizopod shells are fairly resistant, although not to the same extent as pollen grains; shells can, however, be quite recognisable in peat sediments (especially in Sphagnum peat). Harnisch (I925, quoted by Grospietsch 1952) was able to demonstrate that the peat-forming milieu (including the humidity) has a great influence on the numbers of rhizopods and on the variety of species, and that the conditions of a peat-forming milieu, particularly its humidity, can be further determined by rhizopod analysis. He divided the associations found in various types of peat and in other moist vegetations into 5 types, according to the presence, or the absence, of the rhizopod species appearing there: 
I. The Waldmoos type, which occurs particularly in non-peatforming Sphagna and on the shores of lakes;

2. The Hyalosphenia type (after Hyalosphenia elegans and $H$. papilio), appearing especially in transition bogs and marginal areas of raised bogs;

3. The Flavum type (after Amphitrema flavum), which can be found widespread in raised bogs;

4. The Wrightianum type (after Amphitrema wrightianum), which appears in oceanic raised bogs;

5. The Tyrphoxene type, which is present in marginal areas and "dying" bogs (characteristic species: Trigonopyxis arcula).

HOOGENRAAD ( I 934) used this classification successfully in his work on the sphagnophilous rhizopods. HARNISCH (1948, I949) suggested setting out the data in absolute numbers (instead of in percentages, as is customary in pollen analysis) in the diagrams, since it is not only the variety and the relative proportions of the species present which are of importance for the interpretation of the milieu, but also the number of individuals (shells) per unit volume of peat. This method has been applied by, inter alia, Grospietsch (I952, i958), Kubitzki (ig6o), Tolonen (rg66) and Hayen (ig69). Our rhizopod diagrams also give absolute numbers per species.

In this study, only Harnisch's types 3,4 and 5 will be under discussion, since it has been almost exclusively ombrogenous peat which has been analysed. The Flavum type is characterised by the greater or lesser abundance of Amphitrema flavum and further Arcella species, Assulina muscorum, A. seminulum, Hyalosphenia elegans, $H$. papilio, Heleopera sphagni; in addition to these, there are frequently present a few specimens of species which can be considered to belong to the Tyrphoxene type. This is possibly a result of the sampling technique; the $1 \mathrm{~cm}$ thick samples represent roughly a twenty-year period of peat growth (see also Ir.48.I., p. 223); each sample, therefore, represents the total amount of fluctuations of the milieu during 20 years.

It follows from our rhizopod-moss diagrams (for the composition of these diagrams, see 2.6.2., p. 26) that the Flavum type is present in a weak form (i.e. with relatively few specimens of Amphitrema flavum) in the highly humified Sphagnum rubellum peat particularly (for the peat types, see also the following section), and in a somewhat richer form in the rather less highly humified $S$. rubellum peat, and the $S$. rubellum-imbricatum peat.

The Wrightianum type contains the species of the Flavum type and Amphitrema wrightianum, which is often present in large 
numbers. A. flavum is generally present in greater abundance in this type than in the Flavum type. The Wrightianum type is found in the fresh $S$. cuspidatum peat, the fresh to moderately humified $S$. papillosum peat, and the fresh to moderately humified $S$. imbricatum peat. Both the Flavum and the Wrightianum types are associated exclusively with Sphagnum peat.

The Tyrphoxene type contains species such as Trigonopyxis arcula, Phryganella, Bullinula indica and Hyalosphenia subflava. The Amphitremas are not present. We came across this type - in a weakly developed form - particularly in more highly humified peat growths in the fresh Sphagnum peat. We established the presence of the clearly developed form in peat from the neighbourhood of Stadskanaal (province of Groningen) (Bult 1963).

The demands which the various rhizopod species make on the milieu are generally known only incompletely. Concerning sphagnophilous species, we may observe that Amphitrema flazum strongly increases in number with increasing humidity, but that it probably does not feel completely at home in open water; A. wrightianum, on the other hand, can flourish extensively only in a very humid milieu, and attain maximum values in open water (bog pools) (HARNisch 1925, Grospietsch 1952).

HARNISCH (I949) remarks that not only increasing humidity, but also other trophic factors play a part in the increase of Amphitrema wrightianum. KuBrTzKi (1960) holds that the growth of A. wrightianum in a profile from the bog "Esterweger Dose" (Germany) can, to a considerable extent, be ascribed to increasing humidity. We think that it may be concluded from our investigation that, in any case, the milieu must be very humid for A. zorightianum, but also, in addition, strongly oligotrophic and very acid. A combination of such factors has very probably not been present in the highly humified Sphagnum rubellum peat in the area we investigated.

The appearance of tyrphoxene species in rhizopod samples is an indication of serious disturbances in the peat growth (GROsPIETsCH I952, Kubitzki i 960). "Serious disturbances in the peat growth" cannot be easily defined. Roughly, it amounts to the milieu becoming drier, less acid, and eutrophic to a greater or lesser extent, due to which the conditions for optimum ombrogenous Sphagnum peat growth disappear. Grospietsch (1952) calls the tyrphoxene species "moorfremde" species. In our investigation, the presence of more than a minimum number of inviduals of the tyrphoxene species in the peat indicates the occurrence in the peat-forming milieu of a reversal, or at least a change, of a different type than 
that usually observed during the development of hummocks and holes in Sphagnum peat. TOLONEN (1966) arrives at somewhat different conclusions; in his opinion, the tyrphoxene type is, in particular, a sign of the peat becoming drier.

\subsection{InVESTigation of PEAT types}

For investigation of the genesis of a particular type of peat or of a layer of several types of peat, as much about the composition of the peat concerned as is possible should be known. Our investigation is directed especially towards the obtaining of sufficient relevant information on the stratigraphy of the peat so that a comparatively detailed picture of its development can be drawn. Even at the fieldwork stage, as much information as possible about the composition of the layers of peat was recorded during the measuring and drawing of the vertical peat faces (see also 3.1.4., p. 35 ff.). The identification of wood remains (Alnus, Betula, Pinus, Quercus) posed no problems, nor did the identification of Ericaceae remains (particularly Calluna), Scheuchzeria palustris, Eriophorum vaginatum, Menyanthes trifoliata, Phragmites communis. Many Carex remains are found in the minerogenous layers (fen peat, seepage peat); with a few exceptions, these have not been identified. Consequently, the share of Carices in the stratigraphy of the peat layers has been only occasionally discussed in this study. The composition of only a small number of the peat samples brought back to the laboratory has been further investigated. The highly decomposed fen peat layers afforded so few identifiable remains that further macroscopic investigation - apart from pollen analysis - did not appear to be very promising. MAREK (1965), during his investigation of alder brook bogs in Poland, developed a procedure which yielded very much and very detailed information about the structure and composition of minerogenous peat layers. In our opinion, this procedure, possibly slightly adapted here and there, could have been very successful for the somewhat less decomposed fen and fen-wood peat in the area that we investigated. Since this procedure came to our knowledge too late, we have been unable to include it.

We have not ventured upon an identification of moss remains in the field. Some material from the Late-glacial Hypnaceae peat (Braunmoostorf, 6.4., p. 57 ff.) has been further identified. We have not investigated the mosses from the ferruginous seepage peat (also Hypnaceae peat, see 9.3., p. $85 \mathrm{ff}$ ) any further. A detailed picture of the development of the seepage peat deposits therefore, cannot 
be given. We have paid more attention to the composition of Sphagnum peat (Ch. II., p. I38). The circumstance that the ombrogenous part of the peat was particularly clearly exposed in many vertical (peat) faces, was, as it were, an invitation to detailed observations. Moreover, the structure and development of ombrogenous peat have many times already been the subjects of thorough investigations (e.g. Granlund I932; Grosse-Brauckmann I962; Hayen ig66; Kubitzki ig6o; Nilsson ig64; Olausson 1957; Osvald I923; Overbeck I950; I952; Overbeck, MünNich, Aletsee \& Averdieck 1957; Schneekloth ig63a, I963b, 1965, ig68; Schneider i957; Schnemder \& Steckhan 1963; Tolonen 1966; Walker \& WALKeR r96i; Weber igio, 1930), whereas, as has already been stated in I.I, p. 5, hardly a single study, based on modern methods of investigation, exists of the Sphagnum peat of the peat region east of Emmen (VAN ZEIST I955a).

According to the degree of its humification, ombrogenous peat can be roughly divided into fresh and highly humified peat, with a whole range from less humified to more humified in between.

A different classification is also possible, viz. according to the most conspicuous of the Sphagnum species in the composition: Sph. rubellum peat, Sph. cuspidatum peat, Sph. imbricatum peat, etc. and according to easily identifiable remains of Anthophyta in the ombrogenous peat: Eriophorum vaginatum peat, Scheuchzeria peat, Calluna peat etc. The objection to this classification is that it cannot always be established in the field, and that the type of peat concerned nearly always contains remains of more plant species than the one or two mentioned. Thus, Sph. cuspidatum peat will, in many cases, contain Rhynchospora alba too, while Carex limosa will undoubtedly also be present in Scheuchzeria peat. Yet we have frequently made use of the latter classification, since it was very satisfactory in our investigation. Generally a relationship exists, in the peat we investigated, between the contributing plant species and the degree of humification of the peat (given here in Von PosT's scale, $\left.\mathrm{H}_{\mathrm{I}}-\mathrm{H}_{\mathrm{o}}\right)$. Highly humified Sphagnum peat $\left(\mathrm{H}_{7}-9\right)$ is mainly Sph. rubellum peat; fresh Sphagnum peat $(\mathrm{Hr}-3)$ is almost invariably Sph. papillosum peat, Sph. imbricatum peat and Sph. magellanicum peat (which we did not find); if Sph. rubellum peat contains Sph. imbricatum, it is mostly somewhat less humified, roughly speaking: moderately humified $\left(\mathrm{H}_{4}-6\right)$; Sph. imbricatum peat and Sph. papillosum peat can also be present in a moderately humified form. Sph. cuspidatum peat is normally fresh; the presence of Sph.cuspidatum in the highly humified Sph. rubellum peat is rare. 
Peat in which Calluna and Eriophorum are abundant is mostly highly humified, (H6-9). The degree of humification of Scheuchzeria peat is somewhat more difficult to determine; this is possibly a consequence of the fact that the nature of this type of peat is frequently not purely ombrogenous in the region we investigated.

See the preceding section for the rhizopod necrocoenose present in the various types of peat.

In spite of the limited botanical information we obtained per peat-type (see, in contrast to this, Grosse-Brauckmann ig62, I963, I968, I969; MAREK 1965), we still think that we can draw justifiable conclusions from our data about the development of the bog, and, in particular, about the growth mechanisms in ombrogenous peat.

\section{GHAPTER 2,: THE PEAT REGION}

\subsection{Geographical position}

The peat region in which we made our observations, and whose structure and development will be discussed in this report, is part of the "Bourtanger Moor" (see fig. I), a raised bog which has now largely vanished as a result of intensive peat-digging. Situated between the river dunes of the Ems to the east, and the "Hondsrug" to the west, this vast raised bog formerly constituted, for a distance of about $50 \mathrm{~km}$, the natural border between the north-east of the Netherlands and part of north-west Germany.

The "Hondsrug" forms the steep western slope of an ice-marginal valley, the Hunze depression, in which the western, Dutch branch of the raised bog developed. On the higher sandy soils (cover sand, boulder clay) west of the raised bog, (the "Drenthe Plateau"), are situated a few villages such as Emmerschans, Barger Oosterveld and Nieuw Dordrecht, in the Gemeente of Emmen (province of Drenthe) close to the former margin of the bog. These villages came into existence partly through colonisation from villages somewhat further west, e.g. Emmen and Barge, and partly through immigration from, among other places, the provinces of North and South Holland.

Small groups of peat diggers settled in the Hunze depression itself, especially since the last century; originally on the bog surface, later on the peat-reclamation soils which remained after the peat digging. This resulted in villages such as Emmererfscheidenveen, on 


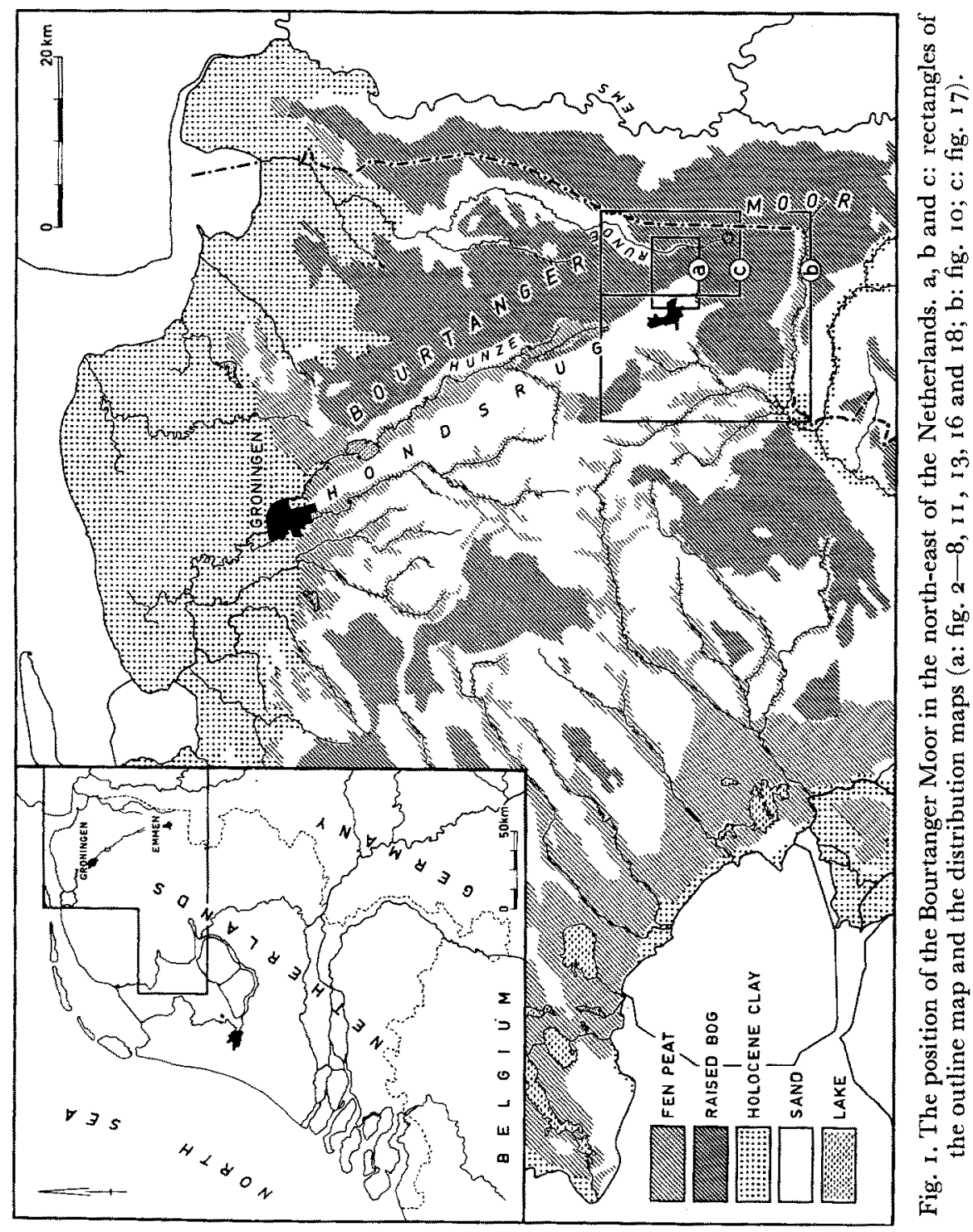


the north side of the investigation area, Barger Compascuum to the east, and Klazienaveen to the south. These villages are not, in general, limited to sand ridges in the mineral sub-soil; though this is the case with the hamlet of Berkenrode, near the former bog rivulet, the Runde (see fig. I), roughly in the middle of the investigation area. There is, in fact, nothing left in the investigation area of this formerly, on occasion, not inconsiderable rivulet. Many, especially younger, inhabitants of the neighbouring villages do not even know the position of the former river bed. As a result of renewed reclamation of the area, the aspect of this region is still changing constantly.

\subsection{ThE GEOLOGY OF THE AREA}

The Drenthe Plateau is built up of sands and gravels carried by the rivers Ems, Weser and Elbe, which deflected to the west on the approach of the land-ice sheet of the Riss Glaciation (Saalian) from the north (proglacial sand, HoL 1948; "Emmen formation", MaArleveld i 956). Ter Wee (I962) distinguishes 5 glaciation phases in the Saalian Glaciation in the Netherlands; the phases $a, b$, and $c$ already distinguished by MAARLeVELD (I958, I96I), Tromé (I959) and ZAGwiJN (personal communication), when the ice sheet invaded the Netherlands from the north (a: material from the Oslo area; b: material from Central and South Sweden; c: material from the Baltic area, deposited as glacial drift); and phases $d$ and $e$, in which ice from the northeast is thought to have advanced (Gulf of Bothnia). The depositing of boulder clay on the Drenthe Plateau is thought to have occurred during phase $d$ particularly. Part of this boulder clay is thought to be material from phase $\mathrm{c}$, pushed forward further. Phase e reached only the extreme north-east of the Netherlands, about $20-50 \mathrm{~km}$ north of the investigation area. This phase brought no glacial drift here, it only pushed forward the boulder clay of phase d. TER WEE assumes that the Hunze depression came into existence as an "ice-marginal valley" during this last expansion of the inland-ice, i.e. late in the Saalian Glaciation. The Drenthe Plateau in the north-east Netherlands, about $70 \mathrm{~m}$ high, was eroded by this to a depth of $50-60 \mathrm{~m}$ on its east side. The eastern erosion border of the plateau, the "Hondsrug", is well known, and can be traced over a distance of more than $80 \mathrm{~km}$. It runs almost rectilinearly in a north-west direction (see fig. $\mathrm{I}$ ).

It is probable that the ice-marginal valley was already partly 
filled up with fluvioglacial and fluvial deposits at the end of the Saalian Glaciation. Marine sediments were deposited in the Eemian in the northern half of the valley, peat formation occurred in the southern half. Probably even before the Würm Glaciation the organic filling was replaced by a filling in which mainly fluvial material (sand and fine gravels) was deposited. This mineral sedimentation presumably came to an end with the depositing of a fluvial loam sheet at the beginning of the Würm Glaciation. At the end of the Würm Age, the remaining depth of the valley was only ro- $15 \mathrm{~m}$, out of an original depth of $50-60 \mathrm{~m}$.

During the Würm Glaciation many cover-sand ridges were formed in the Hunze depression, which are mostly situated almost perpendicular to the erosion border (the "Hondsrug"). Such a ridge can be found in the investigation area (see fig. 3) near the village of Nieuw Dordrecht. The age of the ridge is not known. During the Würm Glaciation too, possibly towards the end of it, a drainage zone formed at the foot of the "Hondsrug" (i.e. at the extreme western side of the depression) which was the source of the present river, the Hunze. Part of its water originated in the "Hondsrug"; the valleys thus eroded are visible on the border of the "Hondsrug" as side valleys of the Hunze.

The fluvial loam sheet in the western part of the depression, and part of the fluvial sands under it, disappeared in this drainage phase, with the result that the western side of the Hunze depression is now the deeper, see the contour map, fig. 4. During the Late-glacial, organic sedimentation occurred in this drainage zone, a beginning of the organic filling up of the Hunze valley, which ended with the artificial drainage of Bourtanger Moor at the end of the Middle Ages.

We have assigned different names, according to geomorphological criteria, to the various parts of the Hunze depression in the area of our investigation, see fig. 3 . We have called the whole ice-marginal valley the Hunze depression; that part of the depression where the fluvial loam sheet and part of the fluvial sands have disappeared is called the Hunze valley (the western, deeper part of the depression), which has a steep western and a gradual eastern slope. The side valleys run into this Hunze valley, the beginning of the Hunze. There is a low spot in the cover sand ridge east of Nieuw Dordrecht which we have called the spillway, since, via this low spot, the southern part of the Hunze depression (the whole area south of this cover sand ridge) drained into the Hunze valley. We have identified the arca to the north of the cover sand ridge, east of the spillway, as the central basin of the bog. 
The contour map, fig. 4 , has been drawn from data personally collected, information available in the Biologisch-Archaeologisch Instituut in Groningen, and on the basis of bog maps.

\subsection{Description of the peat Region}

Even in prehistoric and early historic times, man has tried to make use of the bog, by, among other things, building wooden track-ways (see I I.53., p. 235) and possibly also by reclaiming the bog surface (II.50., I I.5I., p. 229 ff.). Peat was already being dug in the Middle Ages, especially along the margin of the bog. These operations probably had no more than a local effect. Peat growth, by which should be understood the accumulation of organic material especially, came to a standstill mainly, if not exclusively, due to the large-scale drainage in the interest of peat-digging from the north (the town of Groningen) at the end of the $15^{\text {th }}$ century and later.

These drainage and peat-digging activities reached the peat area east of Emmen in the latter half of the igth century.

Since the ombrogenous peat here did not so much drain in a north-westerly direction via the Hunze and the bog canals directed towards Groningen, as via the as yet but little affected rivulet, the Runde, the bog complexes east of Emmen were kept in a clearly more humid condition than further north-west.

After c. 1870 , however, the bog vegetation was seriously affected by the burning of the bog surface in the interest of buckwheat cultivation. Peat has been systematically dug in this area since shortly after the turn of the century, originally entirely by hand, later - till about 1965 - partly mechanically: the digging was still done by hand; machines were used for making the peatblocks. The drag-line was introduced as a peat-digging tool between 1962 and 1965 ; now peat-digging by hand has become rare.

The larger part of the bog had already disappeared by this time; narrow peat-blocks still remained with, in favourable cases, a length of more than $\mathrm{I} \mathrm{km}$, and with a flat, easily decipherable face. Most of our observations have been made on such peat-faces. A thickness of $10 \mathrm{~m}$ of peat - in an undrained condition - was no exception in this area; now thicknesses of 3 metres, at the most 4 , are still found. About $\mathrm{I} m$ of peat was lost due to the burning of the surface for buckwheat growing; for the rest, the decrease of the peat can be ascribed especially to shrinkage as a result of drainage.

Since the western marginal parts of the bog disappeared at an 
early stage, the western extent of the bog could not be established with any certainty; it did seem from old maps (including topographical maps, scale $1: 25,000,1902$ edition) that this limit lay to the east of Emmen, at about 20 metres above NAP. For this reason, the 20 metre contour has been taken on our maps of the investigation area as the extreme limit of westerly expansion of the bog.

Not one of the settlements on the bog surface which came into existence towards the end of the Igth and the beginning of the 2oth century (e.g. "Maneschijn" situated on our peat-face $\mathrm{H}$ ) has survived. The only reminders of the generally very impoverished existence of the peat-diggers have been preserved in a tangible form, more or less true to life, in two museums: the open-air museum, "De Zeven Marken" in Schoonoord on the Drenthe Plateau, and the peat museum village, "t Oale Compas" near Barger Compascuum.

Great social, cultural and political changes have also taken place here, simultaneous with - and partly parallel to - these great changes in the peat landscape east of Emmen. These will not be discussed in this study.

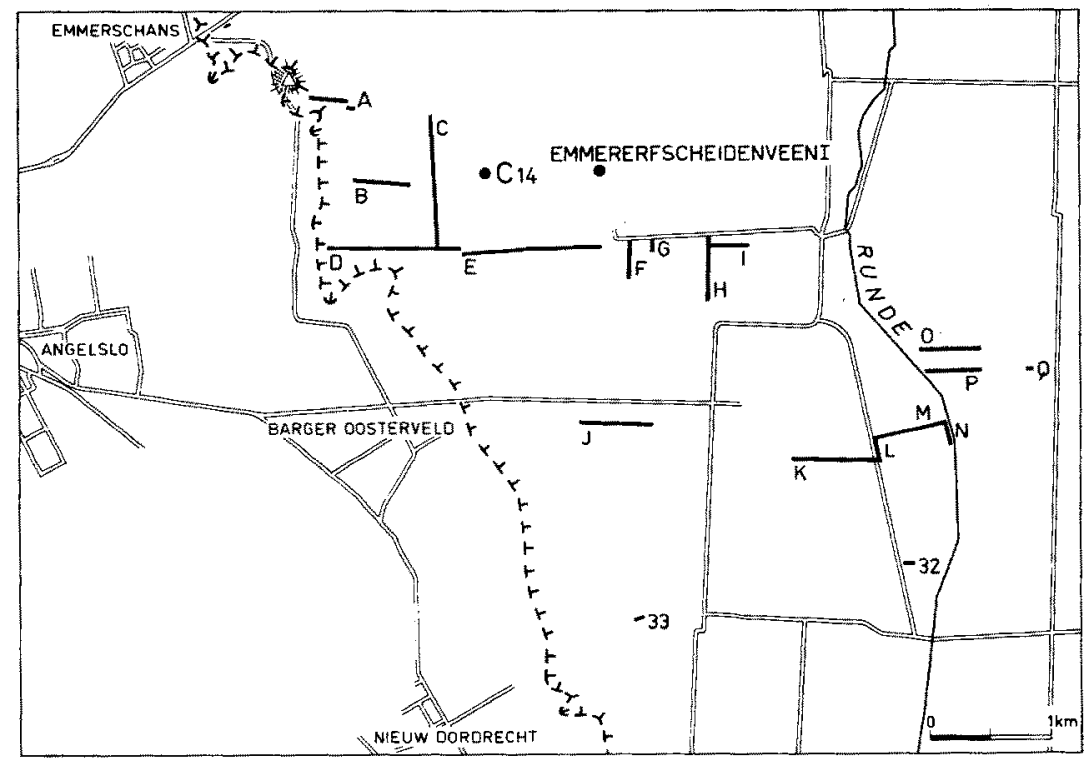

Fig. 2. Position of the vertical peat-faces $(A-Q)$ which have been drawn, the profiles of EMMERERFSCHEIDENVEEN $I$ and ${ }^{14} \mathrm{C}$ (VAN ZEIST $1955 \mathrm{a}$ and $\mathrm{b}$ ) and the sections EMmen 32 and EMmen 33. 


\subsection{Meteorological information}

The north-eastern part of the Netherlands has an annual precipitation of 700-750 mm (Bos \& NIERMEYER I955, Atlas der gehele aarde). Precipitation measurements at Uithuizen, $75 \mathrm{~km}$ to the north of the area studied, give an annual average, between the years I93 I- 1960 , of $738.0 \pm 22.0 \mathrm{~mm}$. In the "summer period", (from April to September) the average precipitation is $380.1 \mathrm{~mm}$. The driest months are March and April, with an average of 40.3 and 40.6 respectively; the wettest months are July and August, with an average of 82.1 and $83.7 \mathrm{~mm}$ resp. A mean annual temperature of $9.0^{\circ} \mathrm{C}$ has been recorded at Eelde, $50 \mathrm{~km}$ to the northwest of the area studied, in the period $1947-1965$. The coldest months are January (average temperature $0.9^{\circ} \mathrm{C}$ ) and February (average temperature $1.3^{\circ} \mathrm{C}$ ). In the "summer period" the monthly averages are: April, 7.5 ${ }^{\circ} \mathrm{C}$; May, I I. $5{ }^{\circ} \mathrm{C}$; June , I4.5 ${ }^{\circ} \mathrm{C}$; July and August, both $16.3^{\circ} \mathrm{C}$ and September, $13.7^{\circ} \mathrm{C}$; the average number of "summer days" (temperature above $25^{\circ} \mathrm{C}$ ) in June, 5 ; in July and August, each 6-7; total, 20-25 "summer days". The first "frost day" falls, on average, between ${ }_{5}$ October and i November; the last "frost day" between I and I 5 May. The average length of the frost-free period is $150-175$ days; the average number of "frost days" is 80-9o. Between the years $193 \mathrm{I}-\mathrm{I} 960$, the average number of "frost days" per winter were: in October, 2; November, 7; December, I4; January, I8; February, I6; March, I4; April, 5; the average total, 77. The average number of "ice-days" (the temperature not rising above freezing-point): December, 3 ; January, 7 and February, 6; average total, $16-17$. These data have been taken from the Atlas van Nederland (Topografische Dienst, Delft, $\left.\mathrm{r}_{963}-\mathrm{r} \mathrm{g}^{6} 9\right)$.

K. MüLLER (1965) records the following figures concerning precipitation and average temperatures at Schöninghsdorf, only a few kilometres from the area studied, in the period $189 \mathrm{I}-1930$; mean annual precipitation, $738 \mathrm{~mm}, 392 \mathrm{~mm}$ of which in the "summer period". Mean annual air temperature, 8.0 ${ }^{\circ} \mathrm{C}$. Mean summer temperature (April -September), I $2.9^{\circ} \mathrm{G}$. OverbFCK (I950) supplies a detailed table of meteorological data; he distinguishes a number of "Klimakreise" on the basis of the mean air temperature, precipitation, "frost days", mist, etc. Bourtanger Moor lies in OvERBECK's "northern Emskreis", which is characterised by a rather pronounced, but not extreme, oceanic climate. 


\subsection{Archaeological information}

The area east of Emmen, i.e. that part of the Drenthe Plateau which borders directly on the peat area studied (see fig. 1), has long been known for its many prehistoric finds. In the section "Kroniek van opgravingen en vondsten in 196I" (N.D.V. 8I) (Chronicle of excavations and finds in 1961), under the heading "Voortgezet onderzoek in het uitbreidingsplan Angelsloo, gem. Emmen" (Continued excavations in the new housing development at Angelsloo, in the municipality of Emmen), VAN DER WAALS ( 1963 ) could announce, concerning this area (in the triangle Angelsloo-Emmerschans-Nieuw Dordrecht, see fig. 2): "Numerous finds were made, spread over the terrain, which included artifacts from almost every period from the Late Palaeolithic Age to the Carolingian Period". A discussion of the prehistoric and early historic finds and traces of human settlement lies outside the scope of this investigation. We shall confine ourselves to a summing up of a number of the most important of such traces and finds from this area, without attempting to be comprehensive.

A few Middle Palaeolithic finds are known from the surroundings of Emmen. Younger Palaeolithic (Hamburg and Tjonger group) and Mesolithic finds appear, scattered over large parts of the area; these finds have not yielded a picture of the nature of the habitation, a circumstance which can be largely ascribed both to Late-glacial sand drifts (cover-sand deposits) and to later aeolian sand movements in the Subboreal and Subatlantic periods.

In the Neolithic, the area was inhabited by people of the Funnel Beaker Culture (passage graves-Dutch: hunebedden-flat-graves, arable land?) and by people of the Protruding Foot Beaker (PFB) culture (burial mounds, flat-graves, settlement remains, arable land). In the Early, Middle and Late Bronze Age, a village developed in this triangle, with large farms, accompanying arable land and burial mounds. A very large complex of "celtic fields" (enclosing the greater part of the village and triangle mentioned) and Urnfields are indications of intensive habitation in the Late Bronze and Iron Ages. Traces of habitation are also known from the Migration Period, as also from the Middle Ages (J. D. vaN DER WAALS \& O. H. HARSEMA, verbal communication). The pollen diagrams from this area (including VAN ZEIST I955a, I955b, 1959) yield similar information. It may be assumed that the area concerned has been in continuous habitation since the Neolithic, i.e. since the time of the Funnel Beaker culture. The boulder clay comes in 
this region almost to the surface, so that the soil here, in spite of its relatively high position, allowed for well-watered and comparatively fertile arable land, thanks to which an attractive settlement area could develop.

In the Hunze depression itself, on the east-west orientated coversand ridge east of Nieuw Dordrecht (see fig. 3), traces of Mesolithic occupation (hearths and microliths) have been found.

Prehistoric finds have also been made in the bog (see fig. I8); the wooden track-ways have already been mentioned (p. I8, see also I I.5., p. I 43 and I I.53., p. 235). We have at our disposal information concerning the presence of a few more wooden track-ways.
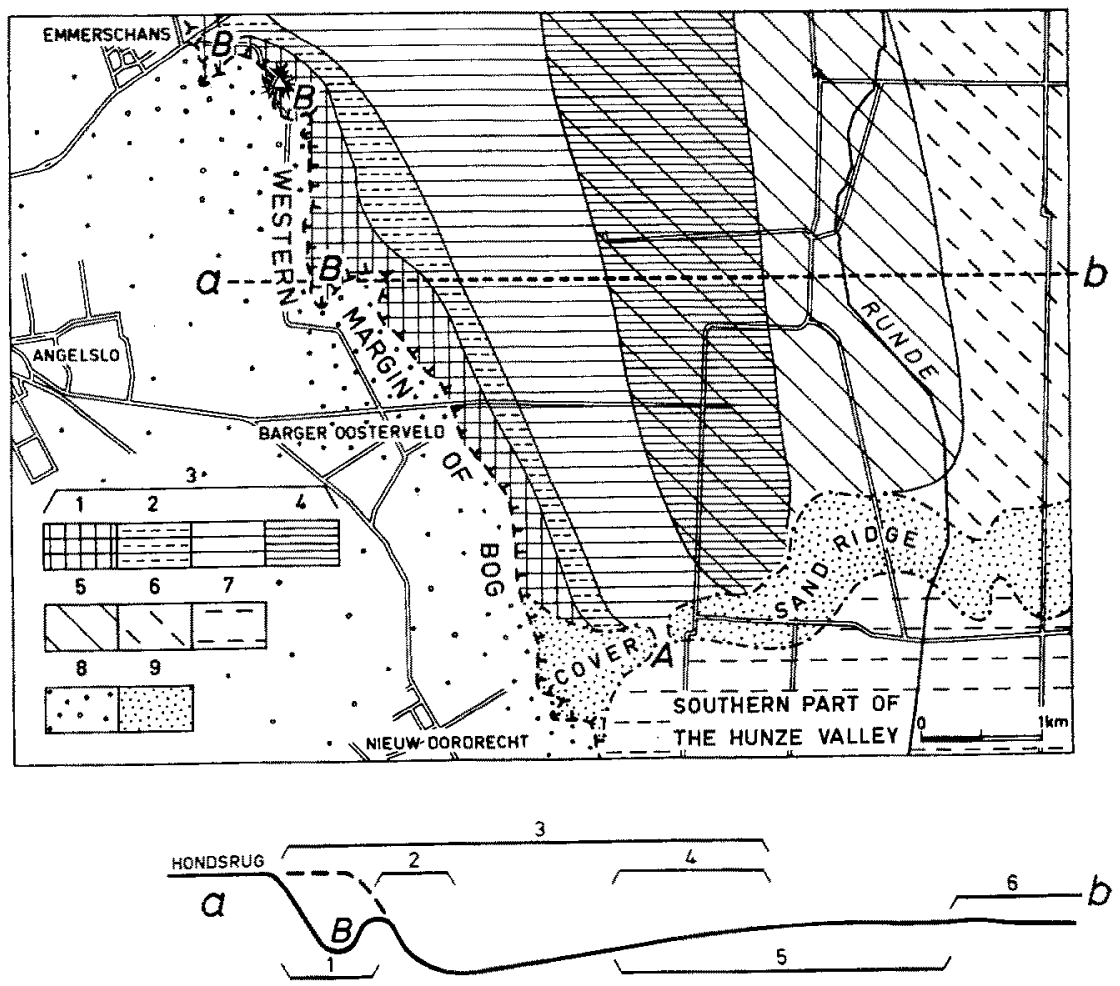

Fig. 3. The names we used for parts of the Hunze depression east of Emmen; at the bottom of the figure: simplificd cross-section of the Hunze depression along the line $a-b, I=$ slope of "Hondsrug" with side valleys $(B) ; 2=$ steep western slope of the Hunze valley; $3=$ the Hunze valley (= drainage gulley); $4=$ gradual eastern slope of the Hunze valley; $5=$ central bog area or central basin of the bog; $6=$ eastern part of the Hunze depression; $7=$ southern part of the Hunze depression; $8=$ Drenthe Plateau; $9=$ east-west orientated cover-sand ridge; $A$ : the spillway. 
VAN DER WAaLs (1964) described a number of Neolithic wooden disc wheels, a few of which come from this region. The remains of a Bronze Age wooden sanctuary surrounded by a circle of stones have been found close to Barger Oosterveld (VAN ZeIst \& WATERBolk ig6o; Waterbolk \& VAN Zeist ig6i).

GLASBERGen (I956) describes a bronze dagger which was found in the bog; BuTLER's three Bronze Age hoards from Barger Oosterveld ( $\mathrm{I}$ g6o) are, however, finds from the sandy soils. A peat body was found in 1936 in the Emmererfscheiden bog, in the extreme north of the area studied. In 1952, a leather purse with silver coins dated to c. 190 A.D., was found near Barger Compascuum (Glasbergen 1956; van Zeist i956). The place of discovery was in the extreme south-east corner of the investigation area. Many stone axes and bronze objects have come to light in the bog. Many of these objects are now in the Provincial Museum of Drenthe at Assen. W. H. Zimmermans has catalogued and worked on finds from bogs in many parts of Germany and the Netherlands. His catalogue (which is now in press) is held to be the most comprehensive concerning bog finds.

\subsection{Methods of investigation}

The following methods of investigation were employed in order to obtain the necessary information:

\subsection{Field investigation}

I. Survey; selection of the vertical peat-faces

Between 1959 and 1963 , all the vertical peat-faces which were still present in that part of the Hunze depression which lies to the east of Emmen were inspected; attention was paid to their state of preservation, to the thickness of the peat deposits, to the variety in the types of peat and to differences in the various peat deposits. In order to obtain as complete a picture of the stratigraphy of the bog in this area as possible, a number of vertical peat-faces was selected, whose stratigraphy was fairly accurately established.

2. Measuring and drawing the vertical peat-faces

After the face had been levelled, the thickness of various peat deposits was measured in places which were suitable for this. The distances between the points examined (the pits) vary rather 
widely; on the one hand, the peat-face had to be sufficiently undamaged at that spot, on the other hand, marked changes in the stratigraphy of the peat-face over a comparatively short horizontal distance sometimes made it necessary to choose pits which were close together. All the pits have been dug down into the mineral subsoil. The places measured have been plotted mainly as peat monoliths (scale I : 20), and afterwards the corresponding points (mostly transitions in peat types and/or degrees of humification) were connected with each other by straight lines. Practical considerations dictated the use of a horizontal scale of $I$ : 10oo here, which thus makes a vertical exaggeration of 50 times.

A total of 17 vertical peat-faces were measured and drawn (see fig. 2); peat-face A in September 1959; the faces C, D and E in September $196 \mathrm{I}$; the rest of the faces in the months of MaySeptember I 963 . The different types of peat which were distinguished and the stratigraphy of the faces are given in Ch. 3. (pp. 2943). The total length of the faces is more than $9.6 \mathrm{~km}$; there are almost $5^{\circ 0}$ pits; see figs. 20-33.

\section{Drawing of sections and profiles}

Parts of vertical peat-faces, bog surfaces which have been dug off, groups of stumps found in the bog, etc., have often been the subject of further investigation in the years $1962-1965$. For this, the section of the vertical peat-face or the horizontal level concerned was drawn in detail, often using a grid with $10 \times 10 \mathrm{~cm}$ squares, or $50 \times 50 \mathrm{~cm}$ squares, ("grid sections", "sections", "profiles", "levels"). Measurements were carried out on a few groups of stumps ("sections"). The position of these sections and profiles (EMmen I, EMMEN 2, etc.) has been indicated on the vertical peat-face drawings, with the exception of the sections EMmen 32, EMmen 33 and Emmen 34, which do not come from one of the I 7 vertical peat-faces drawn. For the position of these three sections see 3.1.5., p. 43, and figs. 2 and 10.

\section{4, Sampling}

Material for examination in the laboratory was collected in the following ways:

a. monoliths for pollen analysis and for rhizopod analysis

Samples were taken exclusively from vertical peat-faces. For this purpose, iron tins (length $30 \mathrm{~cm}$, cross scction $2.5 \times 3 \mathrm{~cm}$.) were 
struck vertically into the peat-face, then cut out, and afterwards wrapped in polythene. As many stratigraphical observations as possible were recorded on the tins. No core samples were taken.

b. material for macroscopic examination

Pieces from a few types of peat were cut out and packed in polythene bags. The size of these samples is recorded in the discussion of the peat type concerned.

Peat for macroscopic examination was also collected in tins.

c. samples for dendrochronological examination

For a few series of Pinus stumps, a slice of the lowest part of the trunk of the stumps was sampled, using a power saw. The thickness of the slices was c. $10 \mathrm{~cm}$.

d. samples for radio-carbon dating

Some Pinus stumps were collected in order to date the layer in which they were found. Peat samples for radio-carbon dating were obtained by digging out a block of peat, usually approx. $25 \times 25 \mathrm{~cm}$ and approx. $10 \mathrm{~cm}$ thick, after which a $2-3 \mathrm{~mm}$ thick layer was prepared. These datings have been given in table I, p. 28.

e. samples for other types of examination

Samples of various types of peat, peat minerals (including dopplerite and siderite), sand, fluvial loam, etc. were brought back, generally in polythene bags, for laboratory examination. These samples were usually cut out with a knife.

\section{Measuring on stumps}

With the use of a measuring-rule, the diameter of the trunk, including the bark, of a large number of Pinus stumps was measured immediately above the roots. In another group of stumps, the coneshaped top was sawn off, after which it was determined on which side of the tree most wood growth had occurred.

\section{Excavations of track-ways}

Large parts of the four wooden track-ways still present in the investigation area were doomed to disappear as a result of the advancing peat reclamation. We were able to excavate comparatively large sections of these track-ways: 
hurdle track-way XIV (Bou) ${ }^{1}$ ) in September-October 1962 and in June-July I 963 .

northern wooden path XVI (Bou) in September I96I, JuneAugust 1963 and May 1967 .

southern wooden path XVII (Bou) in March 1961 , June-August 1963 and May 1967 .

Neolithic track-way XXI (Bou) in March-April 1964.

7. Borings in the mineral subsoil

In April I966, the Geological Survey of the Netherlands made a bore-investigation of the stratigraphy of the Hunze ice-marginal valley (supervised by Drs. M. W. TER WEE); the field data have been put at our disposal by Drs. TER WEE.

8. Geological mapping; determining the area to be studied

Locating the spread of various types of peat and of the characteristic features in the peat deposits was done in two ways:

a. by surveying the vertical peat-faces and the mineral subsoil, b. by questioning the local population, in particular by interviewing the peat diggers.

The area studied was originally defined as "the peat region east of Emmen". The investigation area indicated in fig. 2 can be regarded as that part of the peat region concerned about which, in our opinion, a sufficiently clear picture of the stratigraphy and development of the peat deposits could be obtained by examination and enquiry. In a few cases, information about a considerably larger area was obtained; this has been indicated in fig. I by different rectangles (a: the investigation area proper, $b$ and $c$ : larger areas).

\subsubsection{Laboratory examination}

r. Pollen analysis and the compiling of pollen diagrams

I $\mathrm{cm}$ thick slices were cut from the monoliths sampled.These samples were prepared by boiling in 10 $\% \mathrm{KOH}$, filtration, acetolysis, dyeing with saffranin, after which they were preserved in glycerine (the ERDTMAN method, modified by FAEGRI \& IVERSEN 1964). Sandy and loamy samples were boiled in $50 \%$ HF before acetolysis. Also, material from rhizopod samples which had already

1) Bou is the abbreviation for Bourtanger Moor; numbering according to the system developed by HAYEN (1957), see also on p. 35 under VIII d. code for trackway numbering. 
been counted was used for pollen analysis. In this case, the $\mathrm{KOH}$ treatment was omitted during the preparation.

The tree pollen sum - the basis of the calculation of percentages for most of the diagrams - is usually more than 500. So-called Iversen-diagrams were prepared from a few Late-glacial profiles; the Cyperaceae were here excluded from the pollen sum, because they formed an important component of the local vegetation.

For practical reasons, not all the pollen types met with in the spectra have been set out in the diagrams. In general, we have reported only those pollen types which appeared in not too limited numbers, and which could yield information about dating, bog development, etc.

2. Rhizopod analysis and the compiling of rhizopod diagrams

I $\mathrm{cm}$ thick samples (principally of ombrogenous peat) were prepared by boiling in water to which a drop of $\mathrm{KOH}$ had been added. The material was then sieved and preserved in glycerine. Contrary to the usual procedure in pollen analysis, absolute numbers, and not percentages, are set out in the rhizopod diagrams, (see also I.4., p. 9, where the principles of rhizopod analysis have been discussed).

Instead of counting 5 microscopic slides per sample (see, e.g. Grospietsar I958, p. 76), we generally counted I, although sometimes $2 \frac{1}{2}$, per sample. In the diagrams we have always given the numbers per slide.

3. Determination of mosses and compilation of moss diagrams

For the preparation of rhizopod samples, a sieve was used with mesh of such a diameter, that the residue contained still recognisable remains of Sphagna and other mosses, if these were present in the starting material. The frequency with which these moss remains, mainly leaves, occurred was estimated during the rhizopod count. The frequencies obtained have been given in a scale with 5 divisions ( $1=$ rare, very few; $2=$ few; to $5=$ very many). The moss diagrams have been put next to the rhizopod diagrams, on the right, in those profiles for which both rhizopod and moss remains were determined.

4. Determination of (other) macroscopic remains.

The samples for macroscopic investigation were left immersed for a few days in $5 \% \mathrm{HNO}_{3}$, after which the material was washed through a fine sieve. The residue on the sieve was then examined 
for its seed, fruit, leaf, twig and flower content. The results have been set out in tables; the results have been given in diagram form in one case ( 17 B-macr, see fig. 87).

Wood remains, if the type could not be identified in the field, were determined using microscopic sections.

\section{Dendrochronology}

The stumps collected for this purpose were examined by Dr. A. V. Munaut, of Louvain. For the method of examination and the results, see Vogel, Casparre \& Munaut ig69 and Munaut \& Casparie (1971). This is further discussed in 10.5., p. 122.

\section{6. ${ }^{14} \mathrm{C}$-dating}

Prof. Dr. J. G. Vogel dated the wooden track-ways found in the area studied and a number of wood and peat samples; these datings are reported in the table below (table I). A comparatively large

TABLE I

${ }^{14} \mathrm{C}$-dates for peat investigation

\begin{tabular}{|c|c|c|c|c|}
\hline $\begin{array}{l}\text { No. } \\
\text { GrN- }\end{array}$ & object & $\begin{array}{l}\text { section or } \\
\text { profile }\end{array}$ & date & discussed in: \\
\hline 1087 & trackway XXI (Bou) & EMmen 33 & $2130 \pm 55 \mathrm{BC}$ & I I.5., p. 143 \\
\hline $29^{86}$ & trackway XXI (Bou) & EMmEN 33 & $215^{\circ} \pm 55 \mathrm{BC}$ & I 1.5., p. I 43 \\
\hline 4149 & trackway XVII (Bou) & EMMEN I6 & $1170 \pm 50 \mathrm{BC}$ & II.29., p. 184 \\
\hline $434^{2}$ & trackway XVII (Bou) & EMMEN 16 & $1195 \pm 55 \mathrm{BC}$ & I1.29., p. 184 \\
\hline $4^{622}$ & trackway XVI (Bou) & EMMEN I5 & $53^{\circ} \pm 4^{\circ} \mathrm{BC}$ & Ir.28., p. 184 \\
\hline 4147 & trackway XIV (Bou) & EMMEN 7,12 & $170 \pm 5 \circ \mathrm{BC}$ & $\begin{array}{l}\text { I1.24., p. I72 } \\
\text { and II.25., p. I } 72\end{array}$ \\
\hline $4^{1} 4^{6}$ & $\begin{array}{l}\text { upper I } / 3 \mathrm{~cm} \text { of highly } \\
\text { humified Sphagnum peat }\end{array}$ & EMMEN II & $1815 \pm 40 \mathrm{BC}$ & II.3, p. $14 \mathrm{I}$ \\
\hline $4^{1} 4^{8}$ & $\begin{array}{l}\text { lowermost } 1 / 3 \mathrm{~cm} \text { of } \\
\text { fresh Sphagnum peat }\end{array}$ & EMMEN II & I $800 \pm 50 \mathrm{BC}$ & II.3., p. I 4 I \\
\hline 4624 & base of hummock & EMmen I 7 & $1890 \pm 6 \circ \mathrm{BC}$ & I $1.26 .$, p. I 74 \\
\hline $4^{623}$ & top of hummock & EMMEN 17 & $540 \pm 60 \mathrm{BC}$ & $11.26, p, 174$ \\
\hline 4804 & $\begin{array}{l}\text { base of Menyanthes- } \\
\text { Betula peat }\end{array}$ & EMMEN $3^{I}$ & $2290 \pm 60 \mathrm{BC}$ & 11.17., p. 157 \\
\hline $4^{803}$ & $\begin{array}{l}\text { middle of Menyanthes- } \\
\text { Betula peat }\end{array}$ & EMMEN 31 & $235^{\circ} \pm 55 \mathrm{BC}$ & 11.17, p. 157 \\
\hline 4626 & $\begin{array}{l}\text { top of Menyanthes- } \\
\text { Betula peat }\end{array}$ & EMMEN 3 I & $1920 \pm 60 \mathrm{BC}$ & I 1.17., p. I57 \\
\hline $480 \mathrm{I}$ & $\begin{array}{l}\text { tree rings } 50-60 \\
\text { of Pinus stump }\end{array}$ & EMMEN 29 & $2410 \pm 55 \mathrm{BC}$ & $10.7 .$, p. 130 \\
\hline 4625 & $\begin{array}{l}\text { tree rings } 20-30 \\
\text { of Pinus stump }\end{array}$ & EMMEN 19 & $2490 \pm 70 \mathrm{BC}$ & I $x, 41 .$, p. 209 \\
\hline $4^{802}$ & $\begin{array}{l}\text { dopplerite on top } \\
\text { of seepage peat }\end{array}$ & EMMEN 19 & $\begin{array}{l}2650 \pm 90 \mathrm{BC} \\
\text { (minimum age: } \\
\text { acid only) }\end{array}$ & $\begin{array}{l}\text { 11.41, p. } 209 \\
: \text { treated with }\end{array}$ \\
\hline
\end{tabular}


number of datings was made of the material examined dendrochronologically; see table VIII. B.G. dates are given in this study. All the peat formed since the beginning of the Christian era has been lost by the burning off of the bog surface for duckwheat cultivation, and because of this we have not used the term A.D. in the investigation.

\section{CHAPTER 3.: THE VERTICAL PEAT-FACES}

\section{I. Description OF THE VeRTICAL PEAT-FaCES WHICH HAVE BEEN} DRAWN

\section{I.1. The terminologv and symbols used}

Originally, we used mainly descriptive field names in the drawings, for which easily established characteristics such as colour, degree of humification and wood content were used.

In the course of the investigation, however, many names have been replaced by names which indicated the nature of the peat layer concerned or its origin. Examples of this are the loess layer, which was originally taken to be a loamy gyttja, and a greasy, highly humified, charcoal-rich peat layer, which is present in many peat-faces and which we called the "Early Atlantic desiccation layer".

A great number of characteristics were distinguished during the field investigation. Later it turned out not to be necessary to use a number of these, which could be, for convenience, defined as local variations in the peat deposits. These characteristics were not, in our opinion, of essential significance, or they were more suitably placed in section drawings (grid sections, profiles).

Not all the types of peat distinguished in the investigation could be translated into symbols. On the one hand, a proliferation of symbols would not enhance the legibility of the peat-face drawings (this holds good to a considerable extent for the "intermediate deposits", see below, in this section); on the other hand, an incorrect impression of the peat type concerned might be gained by the vertical scale exaggeration used (this holds good for, among other things, the siderite lenses, the drying cracks and the erosion gullies, see below in this section). 
The symbols have been divided into groups (fig. I9) which correspond as closely as possible with the peat types, as they will be discussed in the following chapters (5.-I I., pp.. 52-25I). The composition of the types of peat will be under discussion in these chapters. Nevertheless, we shall go into the subject of this composition to some extent in the explanation of the symbols following below.

\subsubsection{Description of the symbols of fig. 19}

I. Mineral subsoil

I a. sand fluvial, white to light yellow sands, occasionally somewhat loamy, at several places with gravel.

I b. podsolised sand that part of the mineral subsoil which is in the highest position, i.e. the slope of the "Hondsrug", is podsolised.

I c. fluvial loam very finely grained to almost sandy, fluvial (Pediastrum!) loam, often somewhat humic; in some places rich in siderite, and lumpy; usually $10-25 \mathrm{~cm}$ thick, placed on fluvial sand.

II. Late-glacial deposits

II a. "Braunmoostorf" (moss peat)

generally but little decomposed Hypnaceae (moss) peat, orange on first appearance, oxidising very quickly to black; with many remains of monocotylous plants, nearly always somewhat sandy, at the base occasionally somewhat browner and, if so, more decomposed.

II b. brown gyttja

comparatively fine, somewhat sandy, brown gyitja, with numerous Phragmites rhizoms.

II c. loess layer

the thin layer of eolian loam (löss) on II b; very finely grained, here and there sandy, sometimes rather humic; often with a very thin layer of charcoal at the top.

II d. layer of twigs

thin, dark brown peat deposit, composed largely of thin, flattened twigs or trunks of (considering the pollen content) Betula. 
III. Boreal gyttja

III a. orange gyttja

very fine, in general but little sandy gyttja, composed largely of pollen; orange on first appearance, oxidising rather quickly to dark brown.

III b. grey gyttja

highly sandy, often somewhat humic gyttja, and, for this reason, sometimes difficult to distinguish from humic fluvial loam.

IV. Non-ferruginous fen peat

IV a. fen peat

generally highly humified, often sedge peat, rather compact; Menyanthes seeds visible here and there when broken open; dark orange colour.

IV b. fen-wood peat

mostly far less decomposed than the fen peat, considerably looser, usually with remarkably many wood-remains, especially Alnus, to a lesser extent also Betula; the latter often visible as fine, white bark layers; numerous Menyanthes seeds in the peat; somewhat lighter orange than the fen peat.

IV c. wood layers

present especially in fen-wood peat, although, to a smaller extent, also in fen peat, and in the ferruginous Hypnaceae peat (see $\mathrm{V} \mathrm{b}$ ); composed of remains of trunks and/or roots of, especially, Alnus and Betula; could also be called wood peat.

IV d. charcoal layers

black layers, often composed of greasy peat with bits of charcoal.

IV e. Boreal charcoal layer

as above, occurring in face $A$; with very fine charcoal particles.

IV f. Early Atlantic desiccation layer

as IV d; sometimes double; in that case, with a very thin layer of very highly decomposed fen peat in-between.

\section{Seepage peat}

$\mathrm{V}$ a. ferruginous Hypnaceae peat in general, sedge-rich Hypnaceae fen peat ("seepage 
peat"), mostly not highly decomposed; fairly compact, with desiccation cracks. Usually strongly ferruginous (red ash on burning!), often layered.

$\mathrm{V} b$. ferruginous fen peat

sedge peat, sometimes containing some wood, mostly with Hypnaceae, which produces red ash on burning. Can be distinguished from non-ferruginous fen peat by the greater degree of humification, the pitch black colour in the peat-face, and the clearly different breaking pattern on drying out.

$\mathrm{V}$ c. siderite lenses accumulations of siderite (a ferrous carbonate complex) appearing in the iron-rich Hypnaceae peat(Va), off-white when fresh, greasy (resembles clay or loam), changes to a red colour in c. 3 weeks, becomes hard and lumpy and can then be easily powdered. Sometimes thin layers of vivianite are also present in theselenses (a ferrous phosphate complex), and this is also off-white at first, changing to blue in a few days.

$\mathrm{V}$ d. seepage peat dopplerite layer the topmost $1-4 \mathrm{~cm}$ of the ferruginous Hypnaceae peat, which is filled with amorphous, to some extent resilient, slightly glossy dopplerite. Dopplerite becomes very hard on drying out, and disintegrates very easily. There is also a dopplerite filling in the drying cracks in seepage peat.

VI. Pine stump layers

VI a. pine stumps (layer)

a layer composed largely or entirely of well-preserved stumps, roots, and sometimes parts of the trunks of Pinus sylvestris. The pine stump layer present on top of the nonferruginous fen and fen-wood peat is from the "Middle Atlantic pine forest"; stumps from the "Late Atlantic pine forest" are on top of the iron-rich Hypnaceae peat.

VI b. Scheuchzeria peat

highly layered peat, composed largely of Scheuchzeria palustris remains, with, only rarely, a few pine stumps.

VI c. Pinus-Scheuchzeria peat highly layered peat, composed mainly of Scheuchzeria and Pinus remains.

VI d. Polytrichum peat peat with many remains of Polytrichum spec., black, often 
slightly shiny when dry; small quantities of this peat found especially in VI a, and, to a certain extent, also in VIc; there, however, not mentioned separately as such.

VII. Ombrogenous peat

VII a. Menyanthes-Betula peat a peat resembling fen-wood peat, in which abundant remains of Menyanthes (especially the leaves which are white on drying out) and Betula (including white bark layers) are visible; light brown colour when dry. Not regarded as fen-wood peat (IV), due to its origin.

VII b. Menyanthes remains

Menyanthes leaf remains which dry out white; not proper Menyanthes peat.

VII c. highly humified Sphagnum peat

Sphagnum peat, humification $\mathrm{H} 6-9$, with Eriophorum vaginatum and Calluna vulgaris remains. Especially $S$. rubellum, here and there $S$. cuspidatum. Subdivided in the area studied into:

a. brown-black highly humified Sphagnum peat (peat-faces $\mathrm{B}-\mathrm{E}$ and the western part of J);

b. blue-black highly humified Sphagnum peat (faces F-I, eastern part of J, and $\mathrm{K}-\mathrm{P}$ ); this distinction is not given in the peat-face drawings.

VII d. intermediate deposits

Sphagnum peat; the deposit with highly humified hummocks, hollows with fresh peat, fresh Sphagnum cuspidatum layers, with layers of moderately humified peat, lying on VII $\mathrm{c}$. A moderately humified layer $\left(\mathrm{H}_{5}-6\right)$ in the highly humified peat of face $\mathrm{C}$ has been indicated with the same symbol.

Highly humified peat: predominantly $S$. rubellum peat with Eriophorum vaginatum and Calluna; moderately humified peat: predominantly S. imbricatum and S. rubellum; fresh peat: apart from $S$. cuspidatum, chiefly $S$. papillosum and S. imbricatum.

VII e. fresh Sphagnum peat

Sphagnum peat, humification $\mathrm{H} \mathrm{I}_{\mathrm{I}}-3$, composition: see VII d. Thin layers of more humified Sphagnum peat also in this deposit; generally but little Eriophorum vaginatum and Calluna. 
VII $f$. Calluna-rich peat

predominantly highly humified Sphagnum peat (H 8-9) with very many remains of Calluna vulgaris. The dried peat is "sharp" to the touch because of the numerous Calluna stems ("sharp peat").

VII g. Eriophorum vaginatum peat

highly humified peat (H 8-9), weith very many leafsheath remains of Eriophorum vaginatum.

Eriophorum vaginatum is generally present in the moderately and highly humified peat ("flock"); the so-called "flockbrushes" (cotton-grass tussocks) have not been indicated as Eriophorum peat.

VII h. Sphagnum peat dopplerite layer

thin desiccation layer in the highly humified Sphagnum peat of the faces $\mathrm{H}$ and $\mathrm{I}$, on which level dopplerite has been deposited.

VII i. wooden trackway

VII j. anthropogenous layer

a. the charcoal-rich, highly decomposed layer in peat-face $B$, above pits $33-4 \mathrm{I}$, in the intermediate deposit; probably an overgrown agricultural layer.

b. the "buckwheat layer", created by burning the uppermost layer of deliberately dried peat for the sake of buckwheat growing. This layer has been found in most of the peat-faces; it has been drawn into face B only, above pits $5 \mathrm{O}-5^{\mathrm{I}}$

VII $k$. secondarily weathered layer

uppermost layer of Sphagnum peat, with a high root content; this layer, mainly containing Calluna vulgaris and Molinia caerulea, has not been recorded in the description of the vertical peat-faces, with the exception of face $B$. The buck-wheat layer can still be recognised at the bottom in many places.

VIII. Miscellaneous symbols

VIII a. points examined those places, called pits, where the vertical peat-face was measured and drawn. In general, observations have also been made between these points.

VIII b. contact points between 2 peat-faces the last pit of a vertical peat-face was, if possible, also 
utilized as a pit of the peat-face situated at a right angle to the former.

VIII c. sampling places indication of the place where a profile, level or section for laboratory analysis was sampled, or was drawn in greater detail.

VIII d. code for wooden trackway numbering the wooden trackways in this bog were numbered according to the system developed by HAYEN (1957):

the serial number of the wooden trackway is written in Roman numerals in front of the abbreviation for the name of the bog (in this case "Bou" for Bourtanger Bog).

\section{I.3. The position of the vertical peat-faces}

The position of the vertical peat-faces in the area studied which were drawn is given in fig. 2. The faces with northern exposure have been drawn as faces with southern exposure; the faces with western exposure as faces with eastern exposure. We drew mirror-image reproductions of the peat-faces concerned (part of $A$, part of $D$, $J, P$ and $Q$, resp., $G, H$ and $N$ ) to increase the uniformity of the peat-face drawings.

The description of the peat-faces is followed by a short description of a few sections and profiles which have been sampled from peatfaces which have not been drawn. The position of such sections is given in fig. 2, with the exception of the section Emmen 34, whose position is indicated in fig. 10 .

\section{I.4. The vertical peat-faces}

The vertical peat-faces were all composed of deposits of very well-drained, hardset peat; consequently, the thickness of the deposits was formerly considerably greater; moreover, measurements were made a few times at a place where the peat-face had subsided even more, e.g. face I (fig. 28), pit 286. The types of peat per face are named from the bottom to the top, although this has not always been mentioned.

Vertical peat-face A (fig. 20), length $350 \mathrm{~m}$

pits I-29, east-west face; pits I-23: northern exposure, pits 24-29: southern exposure. 
Subsoil: sand (Ia), in pits $\mathrm{I}-\mathrm{I} 0$ with peat podsol ( $\mathrm{I}$ b). Braunmoostorf (moss peat) (II a) on sand in the lower part (pits I 7-29). A loess layer (II c) on the Braunmoostorf, containing charcoal particles in the upper part. In pits I7-2r: sand layer tailing off into loess. On the sand layer and the loess layer between pits I 7-26, two charcoal-rich peat layers (IV e and IV f); between pits $27-29$ one charcoal-rich layer (IV f). On the topmost charcoal level: fen-wood peat (IV b) gradually changing into a very thick Pinus-Scheuchzeria deposit (VI c). Right at the top, above pits 24-29, highly humified Sphagnum peat (VII c).

Vertical peat-face B (fig. 21), length $450 \mathrm{~m}$ pits $30-5 \mathrm{I}$, east-west face, southern exposure

Subsoil: sand ( $\mathrm{I}$ a), changing in pits $30-3^{\mathrm{I}}$ and $34-3^{6}$ via a charcoal layer (IV d) into fen-wood peat (IV b). In pits $37-5 \mathrm{I}$, Braunmoostorf (II a), on top of which the loess layer (II c) with charcoal particles at many places. On the loess layer the twig layer (II d); above this, fen peat (IV a) and the Early Atlantic desiccation layer (IVf), which consists in most pits of two charcoal bands, separated by a thin layer of fen peat. Above the Early Atlantic desiccation layer, fen peat (IV b) with, above pits $38,4^{6-48}$ and 49-50, ferruginous fen peat $(\mathrm{V} \mathrm{b})$. On the fen-wood peat, the Middle Atlantic pine stump layer, with much Scheuchzeria (VI c), with, in places, several wood levels. In the highly humified Sphagnum peat (VII c) above pits $30-3 \mathrm{I}, 37-38$, and $4 \mathrm{I}$, a few pine stump layers (VI a); above pits $49-5 \mathrm{I}$, Calluna-rich peat (VIIf). On top of the highly humified Sphagnum peat above pits $30-37$, a thick deposit of Pinus-Scheuchzeria peat (VI c) and above pits 37-44, Scheuchzeria peat (VI b). Over the whole length, the intermediate deposit (VII d), which contains a weathered soil layer (VII j) above pits $33-4^{\mathrm{I}}$. Above pits $34-5^{\mathrm{I}}$ : fresh peat (VII e), on the upper side secondarily weathered (VII k) with the buck-wheat layer (VII j) here and there (including pits $50-5 \mathrm{I}$ ). Above pit 49 , a trackway ("the hurdle trackway") in the fresh Sphagnum peat.

Vertical peat-face $\mathrm{C}$ (fig. 22), length I $20 \mathrm{~m}$ pits $52-98$, north-south face, eastern exposure

Subsoil: sand (I a) with some gravel. Braunmoostorf (II a) over the whole length, on top of which the loess layer (II c) with charcoal particles and in pits $55-98$ the layer of twigs (II d). In the fen peat (IV a), which is not present in pits 53-54 and 56, some charcoal layers (IV d). On the Early Atlantic desiccation 
layer (IV f) fen-wood peat (IV d), with the exception of pits $64-70$, where the fen peat clearly contains less wood.

In the fen-wood peat, a pine stump layer (VI a) above pits $76-8 \mathrm{I}$. Above the fenwood peat between pits 84-94, some ferruginous fen peat $(\mathrm{V} \mathrm{b})$ and above pits 88-9I, Polytrichum peat (VI d); this peat, in pit 94, is also present in the Pinus-Scheuchzeria layer (VI c). On top of the fen peat in pits $65-69$, a deposit of ferruginous Hypnaceae peat $(\mathrm{V}$ a) with siderite $(\mathrm{V} \mathrm{c})$.

Over the fen peat and the ferruginous Hypnaceae peat, the pine stump layer (VI a) consisting in many places of Pinus-Scheuchzeria peat. In the highly humified Sphagnum peat (VII c) above pits $52-54$, a Pinus-Scheuchzeria layer, above pit 57 a pine stump layer, and between pits $62-66$ and 68-70, a moderately humified Sphagnum layer (VII d). In the lower part of the intermediate deposit (VII d), Scheuchzeria peat (VI b) in some places. In the fresh Sphagnum peat (VII e), a wooden trackway between pits $67-68$, the hurdle trackway.

Vertical peat-face D (fig. 23), length I roo m pits 99-I 49 , east-west face; pits 99-I4r: southern exposure, pits 142-1 49 (including pit 52 from face $G$ ): northern exposure.

Subsoil: sand ( $\mathrm{I}$ a), in pits $99-\mathrm{I} 08$ with peat podsol (I b). In pits $121-136$ and $141-143$, a predominantly very thin layer of Braunmoostorf (II a), in pits 52-I49, a considerably thicker layer of Braunmoostorf (II a). On the Braunmoostorf, the loess layer (II c). Only in pits 146 and between $147-149$, the twig layer (II d). In pits I2I, I 23-I3I, I35-I 38 and I43-I49, highly humified fen peat (IV a). In pits I I -138 and $142-149$ the (at places double) highly humified, charcoal-containing, Early Atlantic desiccation layer (IVf). Where the fen-wood peat lies on sand (pits 105-I20 and I37-I42), a charcoal-rich layer (IV d) is present at the base. At the top of the fen-wood peat above pits 123-125, Scheuchzeria-rich peat (VI b). The pine stump layer (VI a) in pits 99-I05, directly on sand; where the layer lies on fen-wood peat, at places with much Scheuchzeria (VIb). Above pits 105-Ir6, Scheuchzeria peat in the stump layer. In the highly humified Sphagnum peat (VII c), pine stump layers (VI a) at several places (pits I I3-I I4) Scheuchzeria layers (VI b) (pits I2 I123, I 28-1 29, I3 I-1 36, I37-1 39) and Pinus-Scheuchzeria layers (VI c) (pits I2I-I22, I4I-I46). At the base of the intermediate deposit (VII d), which, like the highly humified Sphagnum peat is not present in pits 99-I04, pine stump layers (pits I I3, I I 8 - I I9, 
127-128) and a Scheuchzeria layer (pits 1 $32-134$ ). Only above pits 122-I37 and I47-I49 is fresh Sphagnum peat (VII e) present.

Vertical peat-face $\mathrm{E}$ (fig. 24), length I I $30 \mathrm{~m}$ pits $150-182$, east-west face, southern exposure

Subsoil: sand (I a) with gravel. In pits $150-173$ and 182 , Braunmoostorf (II a) on sand: in pits $168-\mathrm{I} 8 \mathrm{I}$ brown gyttja (II b), lying on sand between pits $\mathrm{I} 73-18 \mathrm{I}$, tailing off into the Braunmoostorf in pits I68-I 73. The whole gyttja deposit covered by Braunmoostorf. On the Braunmoostorf, the loess layer (II c), with charcoal particles in pits $150,153-154,157-162,173,178$ and $\mathrm{I} 82$. The twig layer (II d) only in pits I 50, I 53-I $54, \mathrm{I} 57-\mathrm{I} 62$, I 75, I 77 and $179-181$. In pits $150-154$ and $157-180$, a highly humified fen peat layer (IV a) tailing off towards the east. In pits $150-181$, the occasionally double charcoal-rich Early Atlantic desiccation layer (IV f). The fen-wood peat (IV b) contains ferruginous fen peat $(\mathrm{V}$ b) at the bottom in pits $\mathrm{I} 6 \mathrm{I}-\mathrm{I} 67$ and $\mathrm{I} 69-\mathrm{I} 72$. Ferruginous fen peat is present at the top in the fen-wood peat in pits I 74-I 76 and $179-181$. In pits $169-173$, Scheuchzeria (VI b) in the fen peat. The pine stump layer (VI a) between pits I67-I 7 I with Pinus-Scheuchzeria peat (VI c). The highly humified Sphagnum peat (VII c) contains much Calluna peat at the base in pits I 50-I 55 and $157-160$, and little between pits $18 \mathrm{r}-182$. Above pit 174 some Calluna peat is present, and above pit 177 , a pine stump layer (VI a). The highly humified Sphagnum peat of this face was called "liver"-coloured peat by the peat diggers. In the intermediate deposit (VII d), Calluna peat here and there (pits I50, I59-i6o, 173 and 175 ). Between pits $165-166$, at the top of the intermediate deposit, a wooden trackway, the "southern wooden path". In the fresh peat (VII e) above pit I53, a wooden trackway: "the northern wooden path".

Vertical peat-face $F$ (fig. 25), length $315 \mathrm{~m}$ pits $183-2 \mathrm{I}$, north-south face, eastern exposure

Subsoil: sand (I a). In pits $183,187-192,193-197$ and 2052 I 2, Braunmoostorf (II a), on top of which the loess layer (II c). In pits $183-199$ and 212 , fen peat (IV a). Early Atlantic desiccation layer (IV f) present in pits I 83-185, I87-IgI, I94-I97 and 205-2II: in these pits forming at the same time the base of the iron-rich Hypnaceae peat ( $\mathrm{V}$ a) which is present in all the pits. Above pits 186 and 187 , a siderite lens ( $\mathrm{V} \mathrm{c}$ ). Transition to the highly humified Sphagnum peat (VII c) via the seepage peat 
dopplerite layer $(\mathrm{Vd})$. A few dozen drying cracks filled with dopplerite stretching from the dopplerite layer to the mineral subsoil. On the highly humified Sphagnum peat, the intermediate deposit (VII d), which, above pits I 83-I94, consists predominantly of a comparatively thick Sphagnum cuspidatum deposit. Fresh peat in most of the pits (VII e).

Vertical peat-face $\mathrm{G}$ (fig. 26), length $80 \mathrm{~m}$ pits $212-219$, north-south face, western exposure

Subsoil: sand (I a), on top of which Braunmoostorf (II a). In this, in pits $212-213$ and 219 , brown gyttja (II b). On the loess layer (II c), the twig layer (II d) with, above this, a thin layer of fen peat (IV a). The Early Atlantic desiccation layer (IV f) forms the basis of the iron-rich Hypnaceae peat $(\mathrm{V}$ a) which is wood-rich in places at the bottom (pits 212-213 and 216-216-219). On top of the Hypnaceae peat, the seepage peat dopplerite layer (V d). Several dopplerite-filled drying cracks from this level to the mineral subsoil. Above the highly humified Sphagnum peat (VII c), the very Sphagnum-cuspidatum-rich intermediate deposit (VIId), on top of which fresh Sphagnum peat (VII e).

Vertical peat-face $\mathrm{H}$ (fig. 27), length $54^{\circ} \mathrm{m}$ pits $220-276$, north-south face, western exposure

Subsoil: sand ( $\mathrm{I}$ a), on top of which gyttja; in pits $225-23^{2}$ and $25^{\circ}-254$, predominantly orange gyttja (II a), in pits $245,267-269$ and $275-276$, but little orange gyttja; in pits $220-224,232$, $244-248,255-267,270-274$, grey, sandy gyttja, (III b) exclusively, with, in most places, a thin charcoal layer (IV d) near the top. In the remainder of the pits, a small to a large quantity of this gyttja. On top of the gyttja, a thin wood-peat layer (with trunks of Alnus, Betula and Quercus, among others) of predominantly nonferruginous peat, as basis of the iron-rich Hypnaceae peat ( $\mathrm{Va}$ ), which contains many siderite lenses $(\mathrm{V} \mathrm{c})$ above pits 22I-222, $232-236$ and $267-276$. Vivianite also in the siderite lenses above pits $267-276$. A very large number of dopplerite-filled drying cracks, especially near the siderite lenses, stretching from the seepage peat dopplerite layer ( $\mathrm{V} \mathrm{d}$ ) to the mineral subsoil. In the highly humified Sphagnum peat (VIIc), above pits $264-27^{2}$, the Sphagnum peat dopplerite layer (VII h), with, above pits $264-265$, a few pine stumps (VI a). Above pits 225-232, a deposit of Eriophorum vaginatum peat (VII g) in the highly humified Sphagnum peat. The inter- 
mediate deposit (VII d) above pits 220-26r consists predominantly of Sphagnum cuspidatum peat; above pits $262-270$ it contains principally Scheuchzeria peat. There is no intermediate deposit above pits $27 \mathrm{I}-276$. In this part of the peat-face, numerous erosion gullies reaching deep into the highly humified Sphagnum peat are present. Here, fresh peat (VII e) covers highly humified, moderately humified, and fresh Sphagnum peat, which has been redeposited by erosion. On the intermediate deposit, fresh Sphagnum peat (VII e).

Vertical peat-face I (fig. 28), length $330 \mathrm{~m}$ pits 275 and $277-290$, east-west face, southern exposure

Subsoil: sand (I a), on top of which grey gyttja (III b) which, in pits2 $75-28 r$, contains a layer of orange gyttja (III a). In pits $283-290$, at the top of the grey gyttja, a fen-wood peat layer, on top of which, ferruginous Hypnaceae peat $(\mathrm{V}$ a). In this, very many, often very large, siderite lenses $(\mathrm{V} c)$ in which there is also vivianite, especially above pits $280-290$. In the Hypnaceae peat, numerous dopplerite-filled drying cracks from the seepage peat dopplerite layer $(\mathrm{V} \mathrm{d})$ to the sandy subsoil. Signs of erosion in a number of drying cracks between pits 279-282. Above pits $28 \mathrm{I}-284$, the seepage peat dopplerite surface is conspicuously domed. At the bottom of the highly humified Sphagnum peat (VII c), above pits 277-280, the Sphagnum peat dopplerite layer (VII h) with, above pit 280 , a few pine stumps (VI a). The intermediate deposit (VII d) has been affected by erosion over the entire length; built up predominantly out of Sphagnum cuspidatum peat. The fresh Sphagnum peat (VIIe) lies over the erosion-affected intermediate deposit.

Vertical peat-face $J$ (fig. 29), length $600 \mathrm{~m}$ pits $29 \mathrm{I}-336$, east-west face, northern exposure

Subsoil: sand (I a), on top of which Braunmoostorf (II a), except in pits 293-296 and $328-334$. On the Braunmoostorf, and in pits 333-334, grey gyttja (III b), on top of which, fen peat (IV a). In pits 29I-293, 297-328 and 333-335, the Early Atlantic desiccation layer (IV f), above pits 293-296, a charcoal layer (IV d) on sand, above pits $328-333$, a fen-wood peat layer (IV c). The fenwood peat (IV b) in pits $29 \mathrm{I}-335$ changes between pits $335^{-}-33^{6}$ into ferruginous Hypnaceae peat (Va) in which is situated a siderite lens $(\mathrm{V} \mathrm{c})$; near the siderite lens, some dopplerite-filled drying cracks stretching to the mineral subsoil. The Middle Atlantic 
stump layer (VI a) contains, between pits 31 7-333, Pinus-Scheuchzeria peat (VI e). Between pits $333-336$, and above the transition from non-ferruginous fen-wood peat to ferruginous Hypnaceae peat, lies a deposit of Scheuchzeria peat (VI b), covered by a thin pine stump layer (VI a). Between pits $335-336$ on the ferruginous peat, the seepage peat dopplerite layer ( $\mathrm{V} d)$. In the highly humified Sphagnum peat (VII e) between pits 293-329, several small pine stump layers, a few Pinus-Scheuchzeria layers, and some Scheuchzeria layers. Above pit $33^{6}$ a large Scheuchzeria layer is present. In the intermediate deposit (VII d), Scheuchzeria layers, generally thin, are situated, above pit 334, among others. Fresh Sphagnum peat (VII e) is present on the intermediate deposit.

Vertical peat-face $\mathrm{K}$ (fig. 30 ), length $650 \mathrm{~m}$ pits $337-384$, east-west face with southern exposure

Subsoil: fluvial loam (I c), in general somewhat humic. On top of this a layer of ferruginous Hypnaceae peat $(\mathrm{Vc})$, the basis of which consists of fen-wood, possibly non-ferruginous, peat (IV a). The seepage peat dopplerite layer $(\mathrm{V} \mathrm{d})$ at the top of the Hypnaceae peat, with the exception of pits $346,349-362,379$, where the Late Atlantic pine stump layer (VI a) is situated, and of pits $383-384$, in which Pinus-Scheuchzeria peat (VI c) covers the Hypnaceae peat. A few dopplerite-filled drying cracks stretching from the dopplerite layer to the subsoil. In the highly humified Sphagnum peat (VII c) above pits $373-383$, Eriophorum vaginatum peat (VII g). Only above pits $337-349$ are the intermediate deposit (VII d) and the fresh Sphagnum peat (VIIe) present. An erosion gulley was found between pits 337 and 338 .

Vertical peat-face L (fig. 30), length $175 \mathrm{~m}$

pits $3^{8} 4$ (from face $\mathrm{K}$ ) -389 , north-south face, eastern exposure

Subsoil: fluvial loam ( $\mathrm{I}$ c), in general somewhat humic. On top of this a layer of ferruginous Hypnaceae peat ( $\mathrm{V} \mathrm{a}$ ), with a siderite lens between pits $387-388$. Above pits $384-385$, Pinus-Scheuchzeria peat (VI c); above pits $386-387$, the Late Atlantic pine stump layer (VI a). Between pits $385-386$ and $387-389$, the seepage peat dopplerite layer $(\mathrm{V} \mathrm{d})$. Some drying cracks, filled with dopplerite, from the seepage peat dopplerite layer to the mineral subsoil. Above the Pinus peat, the Pinus-Scheuchzeria peat, and above the dopplerite layer, the highly humified Sphagnum peat (VII c). 
Vertical peat-face M (fig. 3I), length $600 \mathrm{~m}$ pits 389 (from face L) - 4 I 5 , east-west face, southern exposure

Subsoil: fluvial loam (I c), humic to some extent, with a wood layer here and there (IV c). The ferruginous Hypnaceae peat ( $\mathrm{V}$ a), with wood remains (IV c) at several places, contains large siderite lenses (V c) between pits 396-400, 403-406 and 41 2 $4^{14}$ and above pit 409 . In pits $389-39 \mathrm{I}, 396-398,400-40 \mathrm{I}$, 404-4I3 and 4I4-4r5, above the Hypnaceae peat, a pine stump layer (VI a), Scheuchzeria peat (VI b) or Pinus-Scheuchzeria peat (VI c). Above the other pits, the seepage peat dopplerite layer ( $\mathrm{V} \mathrm{d}$ ). In the Hypnaceae peat, numerous drying cracks filled with dopplerite from the top to the mineral subsoil. The Hypnaceae peat surface is noticeably domed above pits $409-415$.

In the top half of the highly humified Sphagnum peat (VII c), an extensive deposit of Eriophorum vaginatum peat (VII g). Between pits $390-4 \mathrm{I} 4$, the intermediate deposit (VII d). Above this, between pits 390-408, fresh Sphagnum peat (VII e).

Vertical peat-face $\mathrm{N}$ (fig. $3 \mathrm{I}$ ), length $\mathrm{I} 80 \mathrm{~m}$ pits $4 \mathrm{I}^{6}-424$ and $4 \mathrm{I} 5$ (from face $\mathrm{M}$ ), north-south face, western exposure

Subsoil: fluvial loam (I c), somewhat humic; very thin in pit 420; strong seepage here. On the fluvial loam iron-rich Hypnaceae peat ( $\mathrm{V} \mathrm{a})$, large siderite lenses ( $\mathrm{V} \mathrm{c}$ ) over the entire length. Above pits $4 \mathrm{I}^{6}-42 \mathrm{I}$, the seepage peat dopplerite layer ( $\mathrm{Vd}$ ), above the iron-rich Hypnaceae peat; above pits $422-424$ and 4I5, Scheuchzeria peat (VI b) and Pinus-Scheuchzeria peat (VI c). In the Hypnaceae peat very many dopplerite-filled drying cracks. Only the lowermost part of the highly humified Sphagnum peat (VII c) has been preserved.

Vertical peat-face $\mathrm{O}$ (fig. $3^{2}$ ), length $5^{\mathrm{IO}} \mathrm{m}$

pits 425-447, east-west face, southern exposure

Subsoil: fluvial loam (I c), in pits 425 and $433-434$ rich in siderite. At the bottom, in the iron-rich Hypnaceae peat ( $\mathrm{V} \mathrm{a}$ ) in pits $45^{2}-427,43 \mathrm{I}-437,44 \mathrm{I}-447$, a wood-rich peat layer (IV c). In the Hypnaceae peat many siderite lenses ( $\mathrm{Vc}$ ) between pits $425-436$; above pit $44^{1}$ a few siderite lenses, and above pit 445 , one siderite lens. The iron-rich Hypnaceae peat covered with only a thin seepage peat dopplerite layer ( $\mathrm{V} \mathrm{d}$ ). In the Hypnaceae peat, a comparatively small number of drying cracks from the seepage peat dopplerite layer to the subsoil. 
Above pits $425-445$, a thick deposit of wood-rich peat with many remains of Betula and Menyanthes (Menyanthes-Betula peat VII a). In this deposit, between pits $44 \mathrm{I}-442$, a layer of Polytrichum peat (VI d), and between pits $44 \mathrm{I}-445$, a layer of Scheuchzeria peat (VI c). On the Menyanthes-Betula peat, highly humified Sphagnum peat (VII c), and covering this, the intermediate deposit (VII d). In pits 445-447, on the Hypnaceae peat, highly humified Sphagnum peat, in which there is a deposit of Eriophorumvaginatum peat (VII g). Above this, the intermediate deposit and fresh Sphagnum peat (VII e).

Vertical peat-face $\mathrm{P}$ (fig. 33), length $465 \mathrm{~m}$ pits $448-480$, east-west face, northern exposure

Subsoil: fluvial loam (I c), in pits $453-454$ and 463 rich in siderite. On the fluvial loam layer, a wood-rich peat layer (IV c). In pits 448-473, iron-rich Hypnaceae peat (V a) with many siderite lenses ( $\mathrm{V} \mathrm{c}$ ); in pits $474-480$, non-ferruginous fen peat (IV a), in which Hypnaceae are in evidence. In the iron-rich Hypnaceae peat, a few dozen, dopplerite-filled, drying cracks, from the seepage peat dopplerite layer $(\mathrm{Vd})$ to the mineral subsoil. Above pits 448-472 Menyanthes-Betula peat (VII a). Above pits 473-480 highly humified Sphagnum peat (VIII c). The transition between Menyanthes-Betula peat and highly humified Sphagnum peat above pits $472-474$ consists of a deposit of Eriophorum-vaginatum peat (VII g). In the Menyanthes-Betula peat very many Menyanthes remains (VII b). On the highly humified Sphagnum peat that also lies on the Menyanthes-Betula peat, the intermediate deposit (VII d). Above pits 456-48o, fresh Sphagnum peat (VII e) also present.

Vertical peat-face $Q$ (fig. 33), length $30 \mathrm{~m}$ pits $48 \mathrm{I}-483$, east-west face, northern exposure

Subsoil: fluvial loam (Ic), somewhat humic. On top of the fluvial loam non-ferruginous fen-wood peat (IV b), on top of which a very indistinct dopplerite layer (Vd). Above this, highly humified Sphagnum peat (VII c), the intermediate deposit (VII d) and fresh Sphagnum peat (VII e).

\section{I.5. Some sections and profiles}

Emmererfscheidenveen I (fig. 63)

Pollen diagram by VAN ZEIST ( $1955 \mathrm{a}$ ). The place is indicated in 
fig. 2. Considering its stratigraphy: Hypnaceae peat, loess layer, non-ferruginous fen peat; (presumably ferruginous) Hypnaceae peat, highly humified Sphagnum peat, intermediate deposit (?) and fresh Sphagnum peat, originates from a vertical peat-face the character of which must have closely corresponded to face $\mathrm{G}$.

${ }^{14}$ C-Profile (fig. 63)

Pollen diagram by VAN ZEIST (1955 b). The place is indicated in fig. 2. Considering its stratigraphy: Hypnaceae peat, loess layer, non-ferruginous fen peat, fen-wood peat (with, at the base, the Early Atlantic desiccation layer), highly humified Sphagnum peat, intermediate deposit (?) and fresh peat; originates from a face the character of which must have closely corresponded to e.g. face E.

EMmen 32 (fig. $5^{8}$ )

See fig. 2. On the mineral subsoil (fluvial loam) highly humified Sphagnum peat; on top of this the intermediate deposit, over which the fresh Sphagnum peat, see also fig. 6r.

EMmen 33 (fig. 59)

See fig. 2. On the mineral subsoil (sand): Braunmoostorf, presumably a gyttja layer from the Boreal, non-ferruginous fen peat, pine stump layer, highly humified Sphagnum peat, intermediate deposit and fresh Sphagnum peat. The non-ombrogenous peat types in fig. 59 are not further specified.

Emmen 34 (fig. 60)

See fig. ro. On the mineral subsoil (sand) a Scheuchzeria deposit, highly humified Sphagnum peat, the intermediate deposit and fresh Sphagnum peat.

\section{CHAPTER 4:: \\ THE VEGETATIONAL HISTORY OF THE AREA INVESTIGATED}

4.I. InTRODUCTION

Since frequent use is made of pollen analytical correlations in this study, we shall, in this chapter, discuss a few important pollen diagrams from the Emmen bog area. The Post-glacial vegetational history of the Emmen area in particular became better known through VAN ZeIsT's studies (1955a, I955b, I959). His ${ }^{14} \mathrm{C}-$ diagram (1955b), fig. 63, will be discussed below. The Late-glacial period is, however, less well represented in his diagrams. Diagram Io-Po, fig. 73, gives a good picture of the Late-glacial vegetational 
development, and thus forms an indispensible complement to VAN ZeIsT's ${ }^{14} \mathrm{C}$-diagram, too. The diagrams 3 -Po and 3 -Po-Iv (figs. 66 and 67) will also be discussed in this chapter. Profile EMmen 3 comes from the marginal part of the bog; the diagrams show that there are some difficulties with the pollen-floristic zonation as a consequence of, among other things, local pollen production, including that of Pinus and Betula. The lithology has been given on the left hand side, as also in the other diagrams made for this investigation. The lithology will be dealt with more deeply than at this point during the discussion of the different types of peat.

As far as zonation is concerned, it may be observed that the zonation according to FIRBAS (1949) for mid-Europe, GodwIN (1956) for the British isles, and Jessen (1935) and Iversen (1941) for Denmark, are usually suitable for applying to diagrams of the north of the Netherlands. For the zonation of the diagrams which we used, the classification of JESSEN and IVERSEN was preferred, because the Netherlands, like Denmark, are situated on the eastern side of the North Sea, and have, to a relatively large extent, an oceanic climate. This classification, moreover, makes possible the use of the well-known concepts of the Early Dryas Age (I), the Allerød Age (II), etc. This zonation, with the criteria used, has been given in table II, p. 46. The ages reported are averages of the ${ }^{14} \mathrm{C}$-dates for the zone boundaries. We should point out further, that sub-division of the Boreal period into two zones is generally not possible in diagrams of our area.

The regional vegetational development which can be reconstructed from the diagrams will not be discussed here. For this, as far as the north of the Netherlands is concerned, the reader is referred to VAN Der Hammen (I95I), Waterbolk (I954) and VAN ZEIST (I955a, I955b and 1959).

The diagrams mentioned will be discussed in the order given below.

- 10-Po (fig. 73)

from section EMmen Io from peat-face C, pit 69, c. $900 \mathrm{~m}$ from the western margin of the bog.

- ${ }^{14} \mathrm{C}$-diagram (fig. 63 )

from a profile which comes from c. $400 \mathrm{~m}$ east of pit 65 from face $\mathrm{C}$ and c. $650 \mathrm{~m}$ north of pit 160 from face $\mathrm{E}$ (see also fig. 2).

- 3-Po and 3-Po-Iv (figs. 66 and 67)

from section EMmen 3 from face A, pit 29, c. $300 \mathrm{~m}$ from the western margin of the bog. 
TABle II

Zonations and periods in the Late-glacial and Holocene

Jessen and Periods Characteristics of the pollen zones (abbreviated)
Iversen

\begin{tabular}{cc}
\hline IX Subatlantic & $\begin{array}{l}\text { Higher Fagus values. Carpinus has mostly a con- } \\
\text { tinuous curve. Corylus often below 10 \%. Tilia } \\
\text { no longer forms a continuous curve. Increasing } \\
\text { non-arboreal pollen (N.A.P.) }\end{array}$ \\
\hline
\end{tabular}

VIII Subboreal

VII $\quad \begin{gathered}3000 \mathrm{BC} \\ \text { Atlantic }\end{gathered}$

$\overline{\mathrm{VI}} \quad 5500 \mathrm{BG}$

Boreal

V
IV
Preboreal

III

8900 BC
Allerød

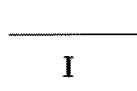

8300 BC

Late dryas

$9^{800} \mathrm{BC}$ Older dryas
Lower values for Ulmus and Tilia. Fagus often has a continuous curve with values to $\mathrm{I}-2 \%$. First occurrence of Carpinus, Plantago lanceolata and Cerealia. Transition VIII/IX: start of the increase of Fagus to first maximum and decrease in Corylus to values of $10-15 \%$.

Low values for Pinus. Relatively high values for Quercus, Ulmus, Tilia, Fraxinus, Alnus and Corylus. Sometimes Fagus present right at the top.

Transition VII/VIII: slight decrease in Ulmus and Tilia, on or just below the first Holocene presence of Plantago lanceolata, $P$. major and Cerealia.

Corylus sometimes has values as high as those of Pinus. Considerable increase of Ulmus. Low values for Alnus right at the top.

Transition VI/VII: considerable increase of Almus and decrease in Pinus.

Predominance of Pinus. Strong increase in Corylus. Quercus and Ulmus present. Transition V/VI: increase of Vlmus and Quercus.

Increasing A.P.; first Betula, then Pinus. Disappearance of many heliophilous herbs. First appearance of Corylus, Ulmus and sometimes also Quercus. Transition IV/V: first large Corylus increase and/or Pinus/Betula intersection.

Obvious increase in N.A.P. Decrease in Pinus especially. Increase in Cyperaceae and other heliophilous plants. Transition III/IV: increasing A.P.

Marked increase in A.P., initially in funiperus and Salix, afterwards in Betula and finally in Pinus, decrease in heliophilous plants. Transition II/III: sharp decrease in Pinus to low values.

Relatively high to very high non-arboreal pollen (N.A.P.) values, especially in Cyperaceae. Betula is present. Very low percentages for Pinus. Artemisia reaches a few percent. Plantago, Helianthemum and Hippophaë occur. Transition I/II: strong increase in A.P. (arboreal pollen). 


\subsection{Io-Po (fig. 73) face C, pit 69.}

A diagram, set out as an Iversen-diagram, was made of profile EMmen Io, the lowermost metre of peat from pit 69 . In Iversendiagrams, the sum of trees, anemophilous herbs and Ericales is taken as the basis for the calculations. The Cyperaceae have been excluded from the pollen sum in $10-\mathrm{Po}$, as well as in $3 \mathrm{Po}-\mathrm{Iv}$ and 2-Po (see 6.2., p. $5^{6}$ ), since these were important elements in the local vegetation, so that the Cyperaceae pollen is strongly overrepresented.

Towards the end of zone I, shortly before the start of the Allerød period, peat growth (in this case Braunmoostorf) became possible here. The transition I/II was put at the strong increase in tree pollen between spectra 4 and 5 . In the Allerød there is a clear increase in Pinus. In the diagram, the II/III transition has been put between spectra 8 and 9, at the sharp decrease in Pinus.

The first appearance of Menyanthes and Filipendula (spectra 5-7) would seem to point especially to an increase in humidity in the Braunmoos vegetations. The resumed occurrence of Equisetum (spectra 5-7) could also be an indication of a change in the milieu. This change is clearly demonstrated by the sharp decline in the Cyperaceae.

Most of the herbs present in the Braunmoostorf have disappeared at the bottom of the thin loam layer (spectrum 8), and the first pollen grains of the Potentilla type appear, a type which increases greatly in the twig layer (spectra Io and I I). Sphagnum has its first maximum in spectrum 8 . The changes in the stratigraphy are accompanied by obvious changes in the composition of the herbpollen. The disappearance of Filipendula and Menyanthes (spectra 8 and 9 respectively), just below the thin loam layer, is perhaps a very weak indication of a lowering of the water level in the Braunmoostorf and its immediate environment.

The transition III/IV can be located at the marked decline in Empetrum, the predominant pollen type in the Ericales, between spectra 10 and I I. Though the Hunze valley was not too wet in the Late Dryas Age, so that Betula could grow here, a certain increase in ground water would seem to have occurred fairly early in the Preboreal period. Typha latifolia and the Sparganium type reach relatively high values in spectrum II. The sharp decline in the Potentilla type, of whatever species, can very probably be ascribed to this increase in the ground water level. Due to this increase, 
Sphagnum must have found a good habitat in the Betula vegetation (spectra Io and I I).

The occurrence of Menyanthes and Potamogeton pollen in the spectra $1_{2-1}-I_{4}$ indicates the presence of open water in the bog here.

There is a large increase in Corylus right at the top of the diagram. For this reason, the topmost sample was placed in the Boreal period. Towards the end of the Preboreal, Pinus established itself on the bog. The Pinus maximum in spectrum I4 is largely caused by local Pinus growth, since relatively many pollen grains possessed nondeveloped air-sacks.

The fact that the peat is rich in charcoal between I $2.17-12.26 \mathrm{~m}$ +NAP can possibly be explained by forest fires. The high value for Dryopteris in spectrum $\mathrm{I} 5$ is perhaps due to the sharp expansion in Dryopteris after the fire.

\section{3. ${ }^{14}$ C-Diagram (fig. 63)}

The diagram published by VAN ZeIST ( $1955^{\mathrm{b}}$ ) has been reproduced, practically unaltered, in fig. 63 . Only for the lithology have we used our own symbols. On the extreme left the lithology and the somewhat corrected zonation of the diagram EMMERERFSCHEIDENVEEN I by VAN ZEIST (1955a) has been given. A discussion of it at this point can be very cursory, since it will be dealt with where necessary in the discussion of the various types of peat.

Peat growth began here during the first phase of the Allerød; in the period with, as yet, low Pinus percentages. In the second half of the Allerød, the Braunmoostorf was covered by a deposit which was interpreted as gyttja by VAN ZEIST and which is now considered to be a thin loess layer.

The Late Dryas and the greater part of the Preboreal are not present in the diagram. The first increase in Corylus marks the transition to the Boreal. The transition from fen peat to wood peat - undoubtedly birch carr (= fen-wood) peat - coincides roughly with the boundary between the Boreal and Atlantic. The two radiocarbon dates at the beginning of the Atlantic period suggest a stagnation in the peat growth. The fluctuating, high Betula percentages in the Atlantic section will have to be ascribed to local pollen production in the fen-wood.

The Pinus curve has two clear maxima in the Atlantic. Pinus stump layers, with which these maxima could have been correlated, have not been indicated by VAN ZErsT.

The transition from wood-rich peat to the highly humified 
Sphagnum peat will have taken place in the final part of the Atlantic. The Atlanctic/Subboreal border - marked by the Ulmus decline which can be tentatively dated at c. 3000 B.C. - is about $16 \mathrm{~cm}$ above this transition in the peat composition. The pollen-floristic border Subboreal/Subatlantic is placed at an increase in Fagus to about $5 \%$.

Towards the end of the Subboreal period, the highly humified Sphagnum peat growth changed here to the accumulation of less humified Sphagnum peat, and, from the beginning of the Subatlantic, fresh Sphagnum peat was formed.

At the place where the EMmererfscheidenveen I peat monolith was sampled, c. $1000 \mathrm{~m}$ east of the ${ }^{14} \mathrm{C}$-profile (see fig. 2), Hypnaceae peat (Braunmoostorf, 334-342 cm) was formed originally during the Late-glacial, and on top of this there is here a thin loess layer, too $(330-334 \mathrm{~cm})$. The thin charcoal layer $\left(329-33^{\circ} \mathrm{cm}\right)$ between the thin loess layer and the highly decomposed fen peat dates from the Late-glacial, as in the diagram Io-Po.

Highly humified fen peat $(300-329 \mathrm{~cm})$ was formed during the Boreal period. The highly humified wood peat $(278-300 \mathrm{~cm})$ on this fen peat dates from the beginning of the Atlantic. This wood peat changes, via a fairly thin Sphagnum rubellum layer $(270-278 \mathrm{~cm})$, into Hypnum peat $(200-270 \mathrm{~cm})$, which changes right on the Atlantic/Subboreal border into Sphagnum cuspidatum peat (I9I$200 \mathrm{~cm}$ ), the basis of the ombrogenous peat. This transition is clearly marked by a very thin dopplerite layer $(200 \mathrm{~cm})$. Towards the end of the Subboreal period, just as in the ${ }^{14} \mathrm{C}$-profile, the growth of highly humified Sphagnum peat gives way to that of less humified peat, here especially Sphagnum cuspidatum peat. Here, too, fresh Sphagnum peat was formed from the beginning of the Subatlantic period.

4.4. 3-Po And 3-Po-Iv (figs. 66 and 67 ) face A, pit 29.

Pollen diagram 3-Po (fig. 66) was made from profile EMmen 3. Since the oldest part turned out to date from the Late-glacial, spectra $\mathrm{I}-\mathrm{I} 7$ were also set out as an Iversen-diagram, see 3-Po-Iv, fig. 67. The Cyperaceae were here, as in ro-Po and 2-Po (see 6.2.), excluded from the pollen sum.

The fairly high percentages for tree pollen ( 3 -Po-Iv, spectra I-3) indicate that the forming of Braunmoostorf at this place begins not in the Older Dryas, but in the Allerød, even before the increase of Pinus. The occurrence of Menyanthes and Triglochin pollen in the 
lowermost spectra points to very moist conditions in the Braunmoos vegetation. Cyperacaeae and Equisetum are important components here. In the immediate surroundings, Funiperus will have been, at least locally, a frequently occurring shrub, which probably had to give way to Betula and Pinus (spectra $\mathbf{I}-8$ ).

Even during the Allerød, the Braunmoostorf growth came to an end with the sedimentation of the loam layer (spectra $7-10$ ). The start of the loam sedimentation took place even before the Pinus maximum.

Zones III and IV are not clearly present in the diagram. The upper limit of III was placed below spectrum I I, in which Corylus is already present. Due to stratigraphical considerations, the limit has been put at the transition from the thin loam layer to the charcoal layer. The sedimentation of loam probably did not continue for the whole of the Late Dryas, see also 10-Po. The Betula percentages, which are very high for zone III, can be explained by the occurrence of large numbers of Betula thecas in the mineral sediment, see 6.3., table IV, Emmen 3, macroscopic remains, p. $5^{8}$.

The Preboreal peat has completely disappeared except for the charcoal layer between spectra Io and 12. There is a pronounced Betula minimum and a clear Gramineae maximum present in 3-Po-Iv, spectrum I I. In 3-Po, spectrum I I, Rumex and Dryopteris reach high values. Probably, the Preboreal Betula forest which existed here was affected by fire to such an extent that it had to make way for a vegetation in which Gramineae, Dryopteris and Rumex play an important part. Moreover, pollen from Epilobium was found in spectrum II. From spectrum II onwards, Corylus appears regularly, and Alnus is present from spectrum 12. This probably concerns pollen that was deposited in the charcoal layer after the burning of the wood peat.

The IV $/ V$ transition was put at the first considerable increase in Corylus, between spectra 12 and 13 . Since the Preboreal is present in this diagram largely as a charcoal layer, the zone transition was given as a dotted line.

During the Boreal, a Betula-Pinus forest continued to grow here, and in this only a slight accumulation of organic material took place. This, together with the very highly decomposed character of the wood peat, are possible indications of fairly dry growth conditions here on the bog surface. Frangula (spectra 12-15) and Sorbus (spectra 13-I5) are likely to have grown in the bog forest. The small quantities of herb pollen in the Boreal spectra point to an 
absence of rich herb vegetation. The proportion of Dryopteris declines sharply after the fire layer. The VI/VII boundary can be located at the first increase of Alnus, between spectra 16 and I 7 . The charcoal layer between spectra 16 and 18 indicates that the Boreal bog forest was destroyed by fire. Dryopteris again attains a very high value in spectrum 17 , while the Gramineae and Cyperaceae also show an increase. The curves for Alnus, Quercus and Ulmus show remarkably higher values in spectrum 17 than in spectrum 16 , which makes a gap at the level of the charcoal-layer likely.

The VII/VIII zone boundary was placed here between spectra 34 and 35, just before the first occurrence of Plantago lanceolata and Cerealia. As has more often been observed in diagrams from this area, a clear elm decline is not present here. It is therefore not impossible that the VII/VIII boundary should be placed at a lower level.

After the break in the peat formation which occurred at the beginning of the Atlantic, carr (fen-wood) established itself in the marginal parts of the bog, and this was able to remain till well into the Subboreal. Alnus (spectra I8-27), Betula (spectra 28-34), Pinus and Betula (spectra 35-45) are successively the most important pollen producing trees here, indicating a development in the oligotrophic direction of the bog forest. Both the Alnus-Betula crossing of spectra $27-28$ and the increase of Pinus in spectra $33-34$ are accompanied by a tremendous increase in spores of Dryopteris, which could be an indication of temporary clearances in the bog forest.

Frangula, Sorbus and Hedera attain their highest values in the Alnus phase. They are possible components of the bog forest. Humulus, Jasione, a species of Papilionacaeae which cannot be further identified, and Comarum are also probably present in this forest, a fact evidenced by their having their maxima precisely in this phase. Most of these plants disappear completely or almost completely in the Betula phase. Besides the increasing oligotrophy, increasing humidity perhaps also played a part in this. Their place was possibly taken by Melampyrum, which could also retain its place in the Pinus-Betula phase, and Lysimachia. If the VII/VIII zone boundary has been placed correctly, Pinus established itself in the Betula forest towards the end of the Atlantic. This can be seen in the pollen diagram as an increase in the Pinus pollen percentage (spectra $3 \mathrm{I}-40$ ). From about $\mathrm{I} 4.30 \mathrm{~m}+$ N.A.P. many Pinus stumps are visible on the vertical peat-face. As usual, the appearance of Pinus in the peat is not accompanied by very high percentages in the 
diagram at the level concerned. Together with Pinus, Empetrum, with a very high maximum in spectrum 35 , and Sphagna establish themselves in the peat; Calluna increases slowly, Erica appears, although with very low values. Dryopteris declines shraply, while Gramineae and Cyperaceae still remain present in very low percentages. From spectrum $3^{8}$ on, Scheuchzeria palustris is present a few times in the diagram, in very low percentages, although subfossil remains are visible in large quantities on the peat-face. Above the VII/VIII zone boundary, Corylus values are generally rather low, with the exception of spectra $60-64$; however, Fagus stays clearly below I \%, except in spectrum $6 \mathrm{I}$. For this reason we have assumed that the Subatlantic is not present in the pollen diagram.

The development which started during the Atlantic - a PinusBetula forest with an undergrowth of Ericales and Sphagna - continued for some considerable time during the Subboreal. The pollen picture changes right at the top of the diagram: Betula declines sharply (spectra 59-62), while Corylus increases markedly (spectra $59-64)$.

This possibly came about due to changes in the vegetation outside the bog. In any case, the contribution of the trees occurring locally in the bog to the pollen precipitation has clearly decreased.

\section{GHAPTER 5:: MINERAL SUBSOIL}

\section{$5 \cdot 1$. INTRODUCTION}

The discussion of the mineral soil of the Hunze depression is based chiefly on data which were obtained from:

- all the vertical peat-faces,

- the diagrams Io-Po (fig. 73), 3-Po (fig. 66) and the ${ }^{14} \mathrm{C}$-diagram (fig. 63) which were dealt with in the preceding chapter,

- diagram 2-Po (fig. 65) which will be discussed in 6.2. (p. $5^{6}$ ),

- diagram 21-Po (fig. 9o) which will come under discussion in 7.2. (p. 65 ).

- a not yet published investigation of the stratigraphy of the mineral subsoil of the Hunze depression in Southeastern Drenthe, carried out by the Geological Survey of the Netherlands in Haarlem. We are much obliged to Drs. M. W. TER WEE (Oosterwolde), of that service, for the opportunity given to us to be present at the bore survey, and for permission to use the data obtained. The results have been utilised in the discussions below. 
Vertical peat-faces A--J lie on predominantly fluvial sand, on which cover-sand has possibly been deposited at places. We have not carried out an investigation of this. The highest parts, in particular the slope of the "Hondsrug", are podsolised. Peat-faces $\mathrm{K}-\mathrm{Q}$ lie on humic fluvial loam deposits. For the distribution: see fig. 5 .

\subsection{Fluvial sand}

In many places this contains some gravel. The lowest levelled topside is at I I.20 m+N.A.P. in peat-face $\mathrm{C}$, pit 69 . The highest - with the exception of the slope of the Hondsrug - occurs under peat-faces $\mathrm{H}$ and $\mathrm{I}$ at c. $13.30 \mathrm{~m}+$ N.A.P.

\subsection{Fluvial loam deposits}

The fluvial loam deposit present under faces $\mathrm{K}-\mathrm{Q}$ has a maximum thickness of $40 \mathrm{~cm}$ and lies on somewhat gravelly fluvial sand. The deposit lies between $13.30-15.10 \mathrm{~m}+$ N.A.P. In many

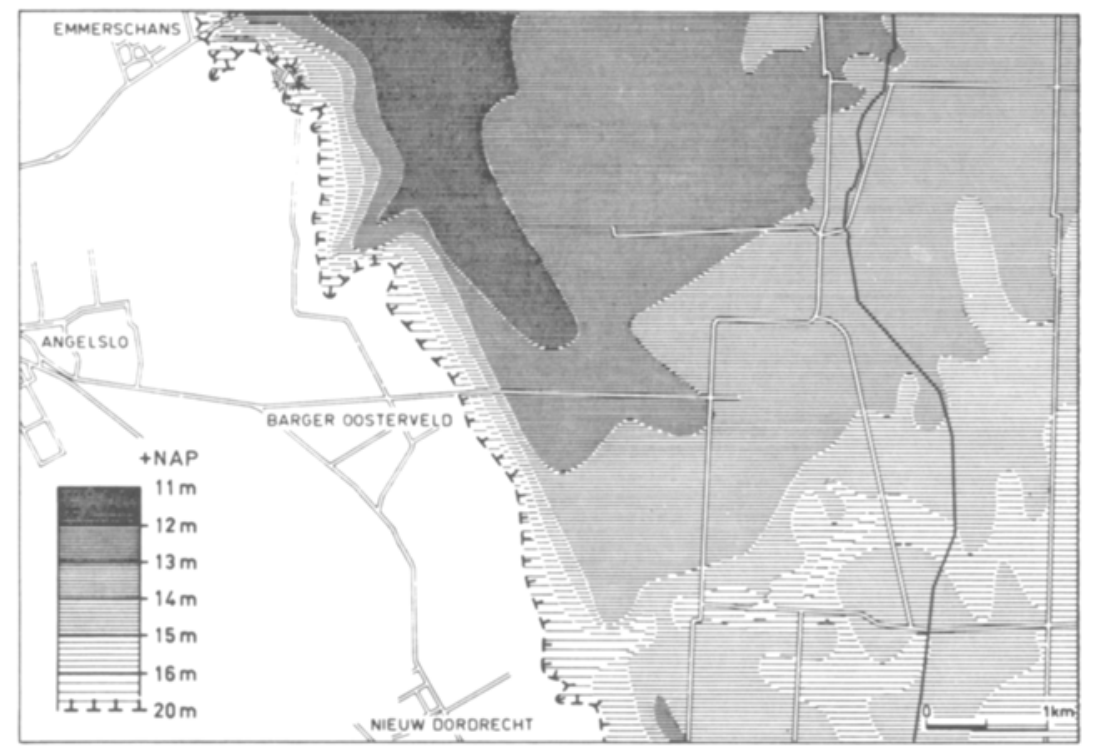

Fig. 4. Contour map of the mineral subsoil in the Hunze depression in metres + NAP (Nieuw Amsterdams Peil $=$ Dutch Datum Level; this corresponds roughly with: metres above mean sea-level). The contour lines between 16 and $20 \mathrm{~m}$ are not drawn. Heights between 16 and $20 \mathrm{~m}$ occur only on the "Hondsrug" slope, the western edge of the bog. 
places it is rather strongly humic, and often contains many root remains. In a few places (peat-faces $\mathrm{O}$ and $\mathrm{P}$, pits 425, 433-434, 454 and 463 ), it contains much siderite and vivianite. Outside the area investigated, it also appears below $13.30 \mathrm{~m}+$ N.A.P. in a northerly and easterly direction, and, here and there, above $15.10 \mathrm{~m}+$ N.A.P. in a southerly direction. The loam is very rich in siderite in many places, especially in the lower-lying parts. According to a pollen analysis (which will not be further discussed here) of this material, sampled c. $3 \mathrm{~km}$ to the north of the area studied, it would seem possible that it is a deposit dating from the Eemian interglacial.

Although the fluvial loam deposit is limited in the area studied to the eastern half (fig. 5), it appears that it extends for several kilometres to the north and to the east. It is probable that the fluvial loam deposit covered the whole of the Hunze depression, both to the east of Emmen (our investigation area) and also more to the north. Erosion which occurred later (i.e. after the Eemian) would

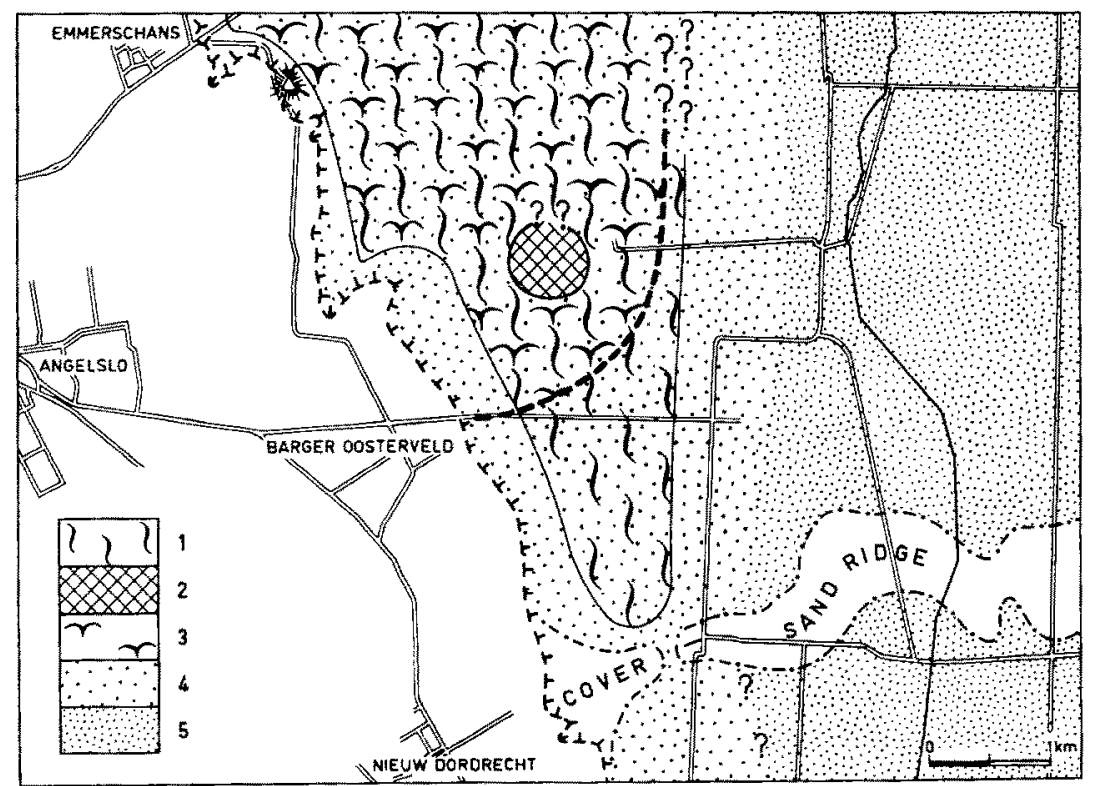

Fig. 5. The mineral subsoil in the Hunze depression and the extent of Lateglacial formations. $\mathrm{I}=$ Braunmoostorf, the end of Older Dryas and first half of Allerød; 2 = brown gyttja, first half of Allerød; $3=$ loess layer, second half of Allerød and beginning of Late Dryas; $4=$ fluviatile sands; $5=$ fluviatile loam on fluviatile sands. 
then have caused the appearance of the somewhat deeper Hunze valley (the river bed during part of the Weichselian), the northwest orientated gulley at the foot of the Hondsrug. This gulley has a steep western slope and a gradual eastern slope, which gives the Hunze depression its asymmetrical profile (figs. 4 and 3 ). Thus, all the fluvial loam below $13.30 \mathrm{~m}+$ N.A.P. in the investigation area would have been washed away.

The drainage of the c. $100 \mathrm{~km}^{2}$ southern part of the Hunze depression south of the area studied takes place through the gulley, in which, to the east of the village of Nieuw Dordrecht, there is a cross-ridge which has a spillway into the gulley (fig. 3). The crossridge can be traced in an easterly direction to outside the investigation area. It forms a barrier in the Hunze depression which had a great influence on the peat growth, see fig. 4, contour map.

A number of side valleys run into the Hunze valley proper (the gulley-like channel which can be regarded as the upper course of the Hunze) from the Hondsrug, e.g. north of the village of Bargeroosterveld and south of Emmerschans, see fig. 4, countour map, and fig. 3. Fluvial loam is not present in these side valleys either. Side valleys are present in large numbers along the entire eastern flank of the Hondsrug.

That neither the sand nor the loam can be limnic formations is apparent from the obvious NW incline of the Hunze depression, see, among other places, fig. 4 , contour map.

\section{CHAPTER 6.: LATE-GLACIAL DEPOSITS}

\section{6.x. INTRODUCTION}

The discussion of the Late-glacial deposits is based mainly on data which were derived from:

- vertical peat-faces $A-G$ and $J$,

- the diagrams 10-Po (fig. 73), 3-Po and 3-Po-IV (figs. 66 and 67) and the ${ }^{14} \mathrm{C}$-diagram (fig. 63 ) which have already been discussed in $4.2 ., 4.4$. and 4.3 . (p. $47 \mathrm{ff}$.),

- the profile EMMERERfscheidenveen I, which is reproduced beside the ${ }^{14} \mathrm{C}$-diagram (fig. 63 ),

- a pollen diagram, made by DR. D. Teunissen (Geology Department, Faculty of Mathematics and Natural Sciences, Catholic University of Nijmegen), of the profile from peat-face J, pit 327 . We are much obliged to him for the opportunity to consult this as yet unpublished diagram. 
- diagram 2-Po (fig. 65), which will be discussed below, and which comes from face A between pits 22 and 23 , about $250 \mathrm{~m}$ from the western margin of the bog.

- the analyses of macroscopic fossils of a number of samples of profiles Emmen 2, Emmen 3 and Emmen io, see tables III, IV and $\mathrm{V}, \mathrm{pp} .57-5^{8}$.

6.2. 2-Po (fig. 65) face A, between pits 22 and 23

The Iversen diagram 2-Po was made from profile EMmen 2. As in 3-Po-Iv and I0-Po, the Cyperaceae have here been excluded from the pollen sum.

The absence of thermophilous trees in spectra $\mathrm{I}$ and 2 indicates that the Braunmoostorf here dates from the Late-glacial. Corylus is present in low percentages in spectra 3 and 4 from the loam layer, while the other thermophilous trees are still absent. We consider it unlikely that this loam layer dates from the Preboreal, since no mineral deposits from this period are known elsewhere in the area studied. In the profiles EMmen 3 and Emmen 10 this layer dates from the second half of the Allerød and the first part of the Late Dryas, see 3-Po-Iv (fig. 67) and I0-Po (fig. 73). The presence of Corylus here might, in our opinion, be ascribed to contamination, perhaps caused by dessication, see also 6.6. (p. 6r) and 6.7. (p. 63). A Preboreal level (spectrum 5) and a Boreal level (spectrum 6) can be distinguished in the charcoal layer. It is not possible to check if peat formation took place here during the Boreal. Carr probably existed here during the Atlantic, with Betula in particular, but with Frangula and Sorbus also (spectra 7-9). The increase in Sphagnum (spectrum 10) is a possible indication that the bog became more oligotrophic.

\subsection{ANalyses of MaCroscopic fossils}

Emmen 2 (face A, between pits 22 and 23)

A number of samples from this profile were examined for their seed and fruit content. The results are recorded in table III, EMMEN 2, macroscopic remains. The position of the samples, height c. $4 \mathrm{~cm}$, volume c. $150 \mathrm{~cm}^{3}$, is given on the left by means of the spectrum numbering of diagram 2-Po. The type of peat is given in brackets below this. 
EMmen 3 (face A, pit 29)

See table IV, Emmen 3, macroscopic remains. Just as with EMmen 2, samples about $4 \mathrm{~cm}$ high, volume about $150 \mathrm{~cm}^{3}$, were also investigated here. The position of the samples in the profile is given by means of the spectrum numbering of 3 -Po. The type of peat is recorded in brackets alongside.

Emmen io (face C, pit 69)

A sample, height $\mathrm{I} \mathrm{cm}$, volume $7 \mathrm{~cm}^{3}$, from the profile at I I. $55 \mathrm{~m}+$ N.A.P. (just under spectrum 5 of Io-Po), was examined for macroscopic remains, see table V, EMmen ro, macroscopic remains. DR. B. O. VAN ZANTEN (Botanical Laboratory, Groningen) identified the mosses for us. For this, and for his information about the distribution of the moss species we are much indebted to him.

TABLE III

EMmen 2, macroscopic remains (only seeds and fruits)

\begin{tabular}{llr}
\hline between 8 and 9 & Betula cf. pubescens & 2 \\
(fen peat) & Epilobium parviflorum-hirsutum type & 3 \\
& Carex indet. & I \\
between 4 and 5 & Juncus cf. conglomeratus & 52 \\
(loess) & Juncus cf. effusus & 1 \\
& Typha latifolia & 45 \\
under 2 & Betula pubescens & I \\
(Braunmoostorf) & Comarum palustre & 3 \\
& Potentilla anserina & I \\
& Typha latifolia & I \\
& Carex cf. trinervis & 2 I \\
& Gramineae indet. (cf. Puccinella) & 3 \\
\hline
\end{tabular}

\subsection{Braunmoostorf}

This type of peat is present in the lower part of vertical peat-faces $A-G$ and $J$. Its occurrence is, in fact, limited to the lower-lying subsoil below I $3.10 \mathrm{~m}+$ N.A.P. and to the slope of the Hondsrug up to $14.40 \mathrm{~m}+$ N.A.P. (EMmen 2). It is, however, absent from that part of the Hunze valley where, later, during the Boreal, gyttja sedimented on the sandy subsoil (faces $\mathbf{H}$ and $\mathrm{I}$ ), viz. on the eastern slope, although the sandy subsoil here lies between 12.65 and I3.30 m+N.A.P., see fig. 4 , contour map and figs. 5 and 7. The 
Table IV

EMMEN 3, macroscopic remains

$\begin{aligned} \mathrm{l} & =\text { needles, leaves } \\ \mathrm{b} & =\text { leaf buds } \\ \mathrm{f} & =\text { flowers } \\ \mathrm{t} & =\text { thecas } \\ & =\text { seeds } \\ \mathrm{fr} & =\text { fruits }\end{aligned}$

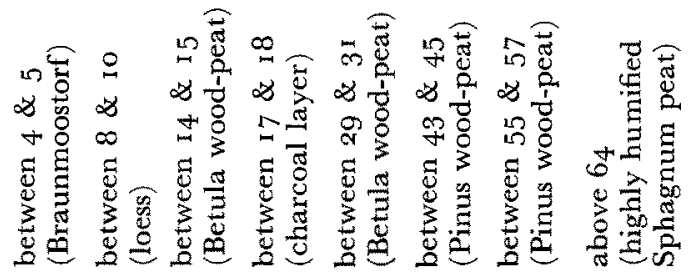

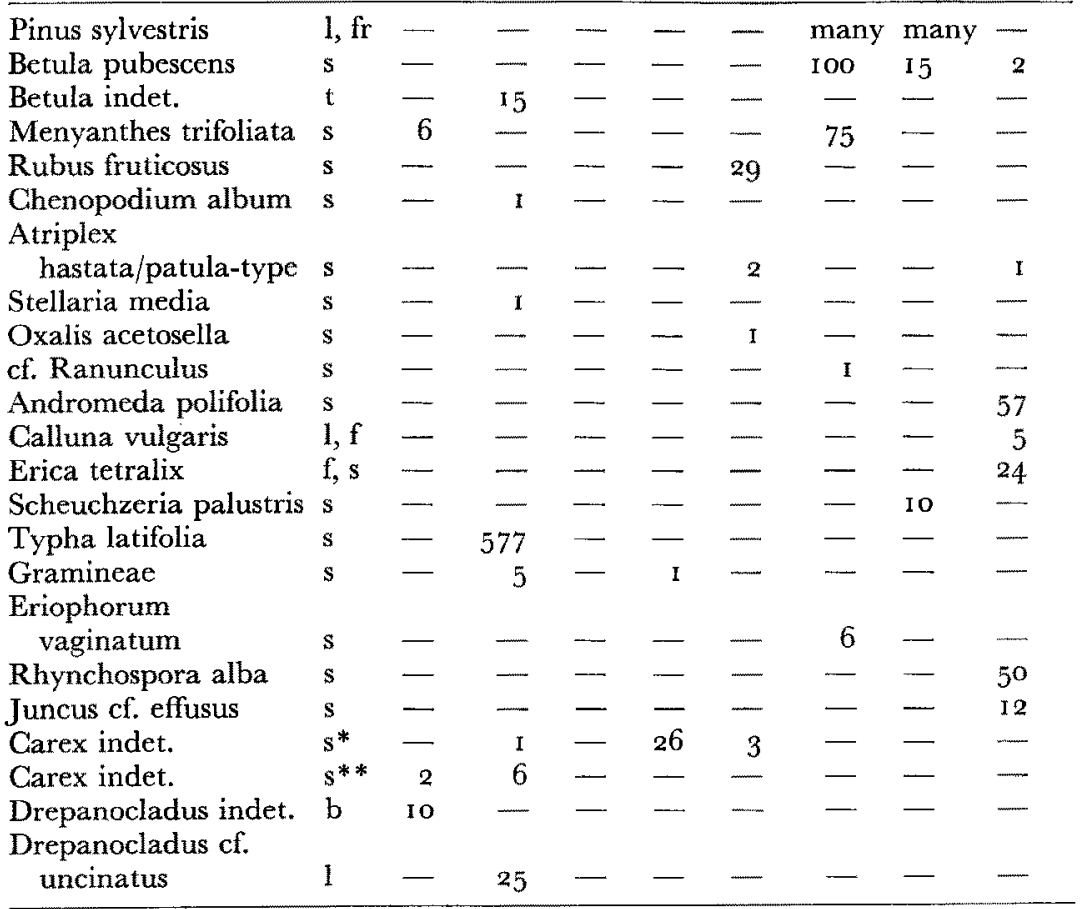

* flat ** three cornered

TABle $V$

Emmen 10, macroscopic remains

\begin{tabular}{llc}
\hline Menyanthes trifoliata & $\mathrm{s}$ & 4 \\
cf. Scirpus fluitans & $\mathrm{s}$ & $3 \mathrm{I}$ \\
Carex cf. paniculata & $\mathrm{s}$ & 8 \\
Scorpidium scorpioides & $\mathrm{l}$ & few \\
$(=$ Hypnum scorpioides L.) & & \\
Calliergon sarmentosum & 1 & many \\
$(=$ Hypnum sarmentosum Wahl. $)$ & & \\
\hline $\mathrm{s}=$ seeds, 1 = leaves & \\
\hline
\end{tabular}


start of the forming of Hypnaceae peat has been dated by io-Po (fig. 73) to the last part of the Older Dryas, shortly before the Allerød. In agreement with this, the dating of 3 -Po and 2-Po for the start of the peat growth on the higher and highest levels respectively on which Braunmoostorf appears is in the first half - the Betula phase - of the Allerød, see figs. 66 and 65 . The end may also be dated in the Allerød, more particularly in the Pinus phase; in 3-Po and probably also in 2-Po just before the Pinus maximum, in ro-Po somewhat later, at the level of this maximum, see figs. 66,65 and 73 . The Braunmoostorf layer under face $J$, which has the character of a gyttja to some extent (see also the following section), was also formed in the Allerød. The Braunmoostorf growth possibly stagnated here just before the Pinus maximum (communication: Teunissen).

The peat deposit broadly follows the contours of the subsoil (cf. faces $\mathrm{C}$ and $\mathrm{E}$ ). The absence of layering is remarkable. The present relief is, therefore, probably not exclusively secondary, but will already have been present to a certain extent during the formation of the deposit. The whole deposit is somewhat sandy; the position of several small sand lenses and the occurrence of fine gravel in the deposits of face B, among others, would seem to indicate that in-wash regularly occurred.

The mosses Scorpidium scorpioides and Calliergon sarmentosum mentioned in table V, EMmEN IO, formed important vegetations even in the Older Dryas, and, in a relatively short time, they spread, forming Braunmoostorf, over large parts of the Hunze valley. Among the mosses, Calliergon sarmentosum is especially interesting. This moss, which no longer occurs in the Netherlands, is nowadays found in Scotland and Ireland very rarely, but, more often in the Harz, the Sudeten Alps, the Riessen mountains from $530 \mathrm{~m}$, in North-Scandinavia and in Finland, where it can form massive vegetations. The present distribution can probably be regarded as its occurrence in the cool periphery of a once uninterrupted area which presumably included a very large part of Europe. Calliergon sarmentosum is, in any case, a "cool" species.

Cyperaceae occur frequently in the Braunmoos communities (2-Po, fig. 65, 3-Po-Iv, fig. 67, and 10-Po, fig. 73); besides Carex spp., Scirpus fluitans (EMmen ro), Menyanthes trifoliata (EMmen 3 and Io), Comarum palustre (EMmen 2) and Drepanocladus indet. (EMmEN 3) must have found suitable habitats here. Teunissen found an abundance of pollen of Menyanthes, Myriophyllum and Potamogeton in the Braunmoostorf of peat-face J. This over-all picture 


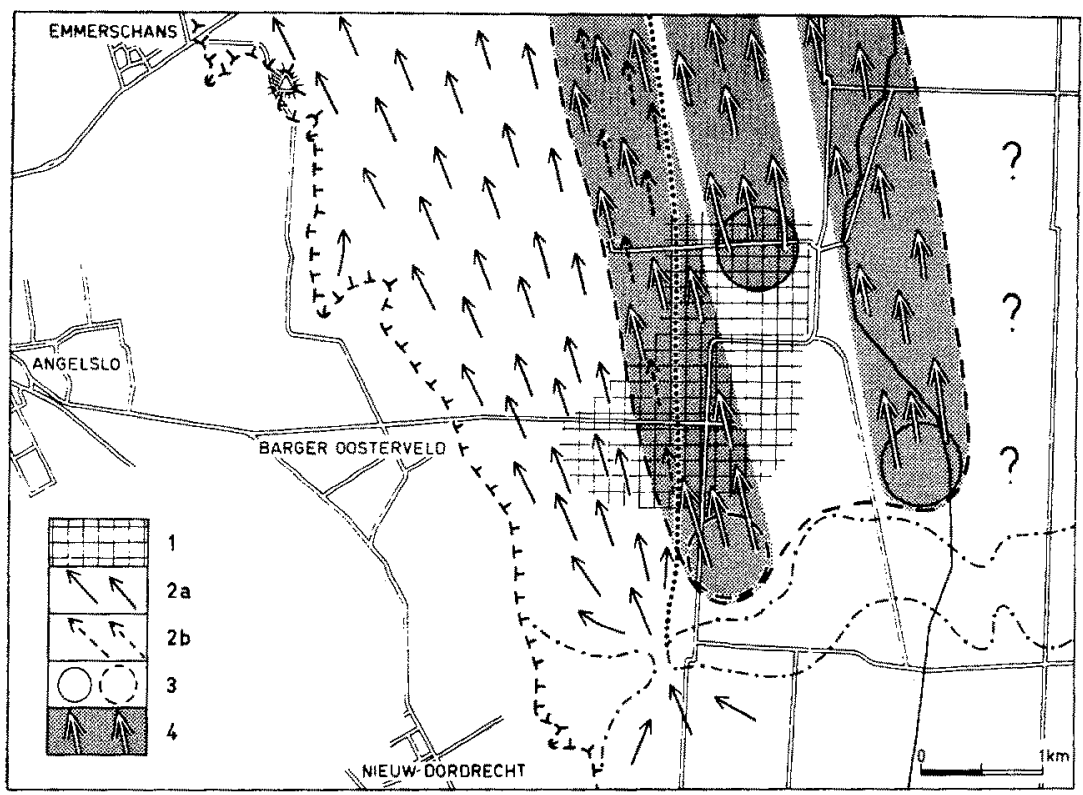

Fig. 6. Drainage pattern in the Hunze depression. The arrows give the direction and the extent of the assumed drainage courses. Also, the spread of the Boreal gyttja deposits has been plotted. $\mathrm{I}=$ Boreal gyttjas; $2=$ drainage courses for the non-ferruginous ground water: $2 a+2 b$ : drainage until the early Atlantic period, c. 5300 B.C.; 2 a: the pattern maintained since. $3=$ (assumed) seepage centres; $4=$ drainage courses for the iron-rich seepage water, from c. 5000 to 3100 B.C.

of very moist vegetations is an indication of the fact that the Hunze valley was well-watered. In so far as it was not supplied by precipitation, the water came in all probability especially from the southern part of the Hunze depression, south of the area studied. This southern part, extending to about $100 \mathrm{~km}^{2}$, drains into the Hunze valley via the spillway in the cover-sand cross-ridge east of the village of Nieuw Dordrecht; see also the preceding chapter and fig. 3. At the same time, water stagnation will probably have occurred in this drainage valley as a result of the rather irregular relief of the subsoil. During the Late-glacial, the bed of this valley north of the cover-sand cross-ridge obviously became sufficiently moist to make the establishment of Hypnaceae vegetations possible. Since on the northern side of the Hunze valley, there is no barrier which could contain the water, the vegetation itself will have caused an increasing stagnation. 
As has already been said in the first paragraph of this section, there is no Braunmoostorf deposit on the gradual eastern slope at the position of the vertical peat-faces $H$ and I. This part of the Hunze valley lies, see contour map fig. 4 , so to speak in the streamshadow of the cover-sand cross-ridge, outside the drainage pattern which is given in fig. 6 . Therefore, the eastern part of the Hunze valley will, in all probably, have had a considerably less moist soil.

A very high degree of moistness seems to have continued right to the very top of the Braunmoos vegetations. Indications of desiccation are completely absent. In 6.6. (p. 6I) the transition from Braunmoostorf formation to loess deposition will befurtherdiscussed.

The profusion of Betula seeds, as appears from table III, EMMEN 2, p. 57 , indicates that Betula pubescens was a very common tree in the higher, sandy soils along the Hunze valley during the first part of the Allerød. The tree did not establish itself in the Braunmoostorf vegetation, since wood remains are absent in this peat. See also tables EMmen 3 and io.

\subsection{BRown GytTJA}

The brown gyttja, which was found almost exclusively in peatface $\mathbf{E}$, was not examined for pollen or seed content. Deposition will, in all probability, have taken place during the Allerød, since the gyttja lies partly on a layer of Braunmoostorf (face E, pits $168-1$ 73), while it has been completely over-grown by Braunmoos communities. Its height, too, between I 1.70-I $2.65 \mathrm{~m}+$ N.A.P., supports the conclusion that it originated during the Allerød. Its position has been given in fig. 5. The lake in which the gyttja formed possibly owes its existence to extra water stagnation in the Braunmoostorf, caused by sand ridges in the subsoil (peat-face $\mathrm{E}$, pits $15^{0}-15^{8}$ ). Because of the occurrence of many Phragmites rhizomes in the gyttja, there is scarcely any possibility that there was open water for a longer time. The banks of the lake will have been formed by Braunmoos vegetation (pits $163-168$ and $18 \mathrm{I}-182$ ), which finally grew over the lake deposit.

The Allerød material examined by Teunissen (peat-face J, pit 327 ) occupied, as far as texture is concerned, an intermediate position between this gyttja and Braunmoostorf.

\subsection{LOESS LAYER}

A significant part of the Braunmoostorf deposit is covered by a very finely grained mineral deposit, see fig. 5 . We found this loam 
layer in peat-faces $A-F$, and presumably also in face $G$. It is not present on the Braunmoostorf of face J. It reaches its greatest height on the slope of the Hondsrug: face A, at $14.30 \mathrm{~m}+$ N.A.P. and face $B$ at $14.00 \mathrm{~m}+$ N.A. . Elsewhere (faces $D$ and $F$ ) it tails off on the low ridges in the sandy subsoil at a considerably lower level. The layer is thickest (up to $\mathrm{c} .20 \mathrm{~cm}$ ) on the western side in the distribution area which we reconstructed with TER WeE's assistance (see preceding chapter), and tails off north and southwards as well as eastwards. On the strength of these characteristics and the, roughly speaking, semi-circular distribution, it is our opinion that we are here dealing with an eolian deposit.

The layer can be dated in the second half of the Allerød (the Pinus phase) and the beginning of the Late Dryas. Sedimentation on the slope of the Hondsrug (2-Po, fig. 65, and 3-Po, fig. 66) probably started somewhat earlier than in the lowest-lying part (ro-Po, fig. 73) where sedimentation began just at the level of the Pinus maximum; see also 6.4. (p. 57).

The layer was considered to be a gyttja by VAN ZeIsT (I955a, the profile EMmererfscheidenveen I, his fig. 4, and 1955b, the ${ }^{14} \mathrm{C}$-diagram, his plate $\mathrm{XXX}$ ). Evidence for this conclusion includes the rich pollen content, the good state of conservation of the pollen, and the moist nature of the Braunmoostorf which changes gradually into the loam layer. Neither would the Drepanocladus leaves which we found (table IV, EMmeN 3, p. 58), the presence of Pediastrum (2-Po, fig. 65) and the frequent appearance of Typha latifolia (tables III and IV, EMmen 2, Eмmen 3) at a rather high level in the deposit appear to conflict with VAN ZEIST's view.

The layer tails off on a cross-ridge in the Hunze depression at c. Io $\mathrm{m}+$ N.A.P., approximately $3 \mathrm{~km} \mathrm{NNW}$ of peat-face A. It is clear from this that the mineral layer was deposited on a slope. Arguments against a limnic deposition include the fact that no ridges higher than about II $\mathrm{m}+$ N.A.P. are present north of the investigation area, whereas a Late-glacial lake would have had to have a water level of at least $14.30 \mathrm{~m}+$ N.A.P. (the tailing off height in face A). To this can be added the fact that Boreal deposits on sand and Braunmoostorf, respectively, occur even in faces $\mathrm{H}$, I and $\mathrm{J}$ below I $3.00 \mathrm{~m}+$ N.A.P., see next chapter. There can, in our opinion, be scarcely any doubt about an eolian origin. VAN Heuveln (Soil Survey Institute, Emmen found thick cover-sand deposits (the Younger Cover-sand B; "hopping"' sand) on the edge of the Hondsrug near Emmerschans, just west of face $A$, which he dated in the 
Allerød and the Late Dryas (verbal communication). Our loess layer is, in all probability, the wind-blown fine fraction of these sands, originating in the Hondsrug, and deposited in the Hunze depression by the then prevailing westerly winds (MAARLEvelD I960).

The absence of drying-out phenomena at the top of the Braunmoostorf and the rich pollen content in the loess layer are indications of sedimentation in a very moist milieu. The wind-blown material will therefore have been trapped in the moist Braunmoos vegetation and, as a result of this, the latter must have been smothered. This can explain both the gradual transition of Braunmoostorf to loess, and the good state of conservation of the pollen. The relative dryingout, which must have enabled the wind to carry away material, has presumably affected only a higher level, i.e. the Hondsrug. Perhaps the charcoal (only very fine, small particles) present in the loess layer comes from an Allerød forest on the Hondsrug which was destroyed by fire. The Pediastrum found in the loess (2-Po, fig. 65, 2 specimens!) has possibly been blown here by the action of the wind.

The fact that Typha latifolia managed to continue growing in the depression during this action (tables EMMEN 2 and 3 , p. $57,5^{8}$ ), is surely an indication of a certain level of humidity in the Hunze valley.

Yet there, too, where the Braunmoos vegetations were not smothered by loess sedimentation (face J), the formation of Braunmoostorf came to an end in the course of the Allerød, see 6.4., p. 57 . It is therefore probable that periods of stagnation occurred in the water supply to the Hunze valley during the Allerød, even although no desiccation phenomena can be demonstrated.

It is theoretically possible that the loess layer originated in the fluvial loam present in the Hunze depression (see preceding chapter) We do not consider this to be very likely, because the loam layer tails off towards the east and is considerably thicker in the extreme west. Moreover, there is a zone between the fluvial loam deposit and the loess layer in which both types of deposit are absent (faces $\mathrm{H}$ and I, see also fig. 5), while, $3 \mathrm{~km} \mathrm{NNW}$ of face A, Braunmoostorf covered by loess lies on ferruginous fluvial loam.

\subsection{LAYer OF TWigs}

In many places the loess layer is overlain by a layer of peat, up to about $10 \mathrm{~cm}$ thick, and resembling a pile of twigs, the twig layer. This appears in peat-faces B, C, D, E and G. It is absent in the 
highest-lying parts of the loess layer (faces $A$ and $F$, in the organic filling of the side valley of face $\mathrm{D}$, and here and there in face $\mathrm{E}$ ). The highest point is in peat-face $B$, at $14.00 \mathrm{~m}+$ N.A.P.

The layer must have been formed towards the end of the Late Dryas (cf. Io-Po, fig. 73), possibly just at the transition to the Preboreal period, during the amelioration in climate. It is the only organic formation from the Late Dryas in the area studied.

This layer lies very loosely, and apparently discordantly on the loess layer, which is an indication that it was not formed immediately after the loess sedimentation. An interval must therefore have existed between the loess layer and the twig layer, very probably a large part of the Late Dryas.

In all probability, this wood layer is the remnant of a short-lived Betula forest (see Io-Po, fig. 73, the high Betula percentages of spectra ro and I I), which was able to establish itself in the Hunze valley, even on the lowest level (Emmen 10, face $\mathrm{C}$, pit 69). It appears, too, from 10-Po, fig. 73, that an early rise in the ground water level must have occurred in the originally not very wet gulley, the Hunze valley (the river bed during a part of the Weichselian), due to which the vegetation changed quickly: Sphagna and Potentilla had to give way to Typha latifolia, Sparganium (possibly Typha angustifolia too), Equisetum and, later, Menyanthes trifoliata also (spectra I0, II and I2).

It is not clear why the Hunze river bed, through which, even in the Older Dryas, there was a considerable water flow, was much less moist for a significant part of the Late Dryas, only to become clearly moister again towards the end of this period.

The absence of the twig layer on the highest-lying parts of the loess layer does not necessarily imply that a vegetation similar to that found in the lower parts will not have been present in the Late Dryas. The thick Preboreal charcoal layer in face A, pits 26-29, lying on the loess layer ( 3 -Po-Iv, fig. 67 , spectra 1 I and I2) indicates significant peat fires, at least along the marginal parts of the bog.

\subsection{Stratigraphy AND DeVElopment OF THE LATE-GLACial DEPOSITS}

Shortly before the beginning of the Allerød, the Hunze valley became so moist that Hypnaceae vegetations (including Scorpidium scorpioides and Calliergon sarmentosum) could establish themselves in the moistest places, accompanied by Menyanthes trifoliata, Scirpus fuitans, Carexi spp. and other Cyperaceae. Large parts of the 
relatively relief-rich soil of the valley were overgrown in the first half of the Allerød by this Braunmoos vegetation (fig. 5). In the wettest places it amounted to gyttja sedimentation. Part of the Braunmoostorf deposit formed thus was smothered during the Allerød by the deposition of loess (fig. 5), due to which the peat growth here came to a stand-still. Peat formation also stagnated in the part of the Braunmoos communities not covered by loess, indicating a decrease in the water supply. The loess sedimentation probably came to an end shortly after the start of the Late Dryas, and after this no other accumulation of organic or mineral material took place in the Hunze valley, until, shortly before the end of this period, Betula established itself here in massive numbers, probably as a result of the Hunze valley again becoming moist. This increase in moisture presumably proceeded at a rather fast pace, so that the Betula forest had to make way for more moisture-tolerant vegetations as early as the beginning of the Preboreal. Peat fires occurred along the western edge of this Betula forest on loess, presumably in the Preboreal, which probably caused the destruction of part of the peat formed during the Late Dryas (the twig layer).

\section{CHAPTER 7: BOREAL GYTTJAS}

\section{I. INTRODUGTION}

The discussion of the two gyttjas sedimented in the Boreal is chiefly based on information obtained from:

- peat-faces $\mathrm{H}, \mathrm{I}$ and $\mathrm{J}$,

- diagram 2I-Po (fig. 9o), from vertical peat-face H, pit 229, which will be discussed below,

- the profile from peat-face J, pit 327 , which was analysed by Teunissen, and which has already been mentioned in the preceding chapter, 6.1., p. 55,

- the diagram by Florschütz, published by VAN Heuveln (1958), which comes from the neighbourhood of peat-face I, pits $277-278$.

\subsection{I-Po (fig. go) peat-face $\mathrm{H}$, pit 229}

The diagram concerned was made from the lowermost half metre of the profile EMmEN 21, from the area in which both Late-glacial deposits and the fluvial loam layer are absent. 
A few elements of the Late-glacial vegetation, such as Helianthemum and the Plantago major type, are present in spectrum I, from the sand, and in spectrum 2 (strongly sandy gyttja), and this indicates a possible Late-glacial origin for part of the material. The samples concerned were taken at 12.60 and $12.65 \mathrm{~m}+$ N.A.P. respectively, a level at which Late-glacial Braunmoostorf and loess are present in the western part of the Hunze Valley; see also 6.4. (p. 57). The gyttja obviously dates from the Boreal period. Probably but little vegetation existed in the shallow, oligotrophic lake: the Sparganium type only once attains a relatively high value (spectrum 4 ). The thin charcoal layer between spectra 3 and 4 is perhaps an indication of a temporary break in the sedimentation as a result of a drying-out of the shallow lake.

The sharp decline in the Sparganium type (spectra 5 and 6) on the level of the thin topmost charcoal layer (12.85-12.90 m+N.A.P.) and the disappearance of Menyanthes (spectrum 7) are indications that the lake probably dried out before the forming of seepage peat (9.5.1.) started at the beginning of the Atlantic or at the Boreal/ Atlantic transition. The many irregular pollen grains of Alnus in spectrum 7 , but especially in spectrum 8 , point to the occurrence of this tree in the fen-wood here. The change-over to fen peat is accompanied by a strong increase in Cyperaceae and Equisetum (spectrum 7). The increase of the Sparganium type at the top of the diagram indicates that a very moist peat formed here.

The pollen content of the gyttja which lies in peat-face $J$ on the Late-glacial Braunmoostorf, shows a great similarity to that of Emmen 2i (communication by Teunissen). Pinus and Betula also have high values in the section of the diagram concerned (Boreal) in peat-face J, and Corylus and Quercus show an increase. Among the herbs, Filices especially is present.

\subsection{Orange gyttja}

A particularly fine orange-coloured gyttja was found in a few east-west orientated gulleys (and therefore approximately perpendicular to the Hunze valley proper, the river bed) in the sandy subsoil of the peat-faces $\mathrm{H}$ and I. The highest occurrence of this gyttja is at $13.05 \mathrm{~m}+$ N.A.P. Underneath, the deposit is sandy. Occasionally there is a thin charcoal layer in the gyttja, e.g. face $\mathrm{H}$, pits 225-231. A thin charcoal layer forms the transition to the Atlantic seepage peat (see $2 \mathrm{l}$-Po, fig. 9o). The extent of this gyttja will be further discussed in the next section. 
The sedimentation had probably already started rather early in the Boreal; Betula is present in high percentages right at the bottom in $2 \mathrm{I}-\mathrm{Po}$; see also fig. ${ }_{3}$, the ${ }^{14} \mathrm{C}$-diagram, and the next section. The topmost $10-15 \mathrm{~cm}$ of this gyttja are not sandy. Blowing or inwash of mineral material has not taken place during the growth, which points to a dense vegetation cover of the surrounding low sand plateaux (see e.g. the sandy subsoil of peat-face $\mathrm{H}$ ).

The rise in water level, due to which water could collect in the gulleys, was only very slight. Stagnation in the local drainage, here directed westwards (see fig. 4, contour map), may have been caused only as a result of the increasing thickness of the non-ferruginous fen peat deposit in the western half of the Hunze valley, see fig. 7 , the presumable extent of the Boreal non-ferruginous peat. Mention has already been made in the preceding chapter of the absence of Late-glacial formations in the gulleys under peat-faces $H$ and $I ; 6.4$. (p. 57).

\subsection{GREY GYTTJA}

More widespread than the orange gyttja is the grey gyttja, in many places sandy to strongly sandy, which lies especially on the low sand plateaux between the shallow, orange-gyttja-filled gulleys in the region of peat-faces $\mathrm{H}$ and $\mathrm{I}$. In a more south-westwards direction, including in peat-face $\mathrm{J}$, this sediment lies on Braunmoostorf. The thin gyttja layer from a profile near face I, pits $277-278$, described by VAN HeUveln ( $195^{8}$ ) is, in all probability, this grey sandy gyttja, called humic by him. The grey gyttja lies on an average on a somewhat higher level than the orange gyttja. Its maximum height is at approximately $13.15 \mathrm{~m}+$ N.A.P. in peat-faces $\mathrm{H}$ and $\mathrm{I}$, as well as in $\mathrm{J}$. The deposition probably began only in the course of the Boreal, shortly after the start of the orange gyttja (see VAN Heuveln, I958, diagram fig. 5). The spread given by Van HeuvelN in his map (his fig. 2) agrees well with what we were able to survey, see fig. 7. It forms, in fact, the delimitation of the eastern and southeastern edge of the loess layer (see fig. 5), which was discussed in the preceding chapter. It is therefore obvious that a relationship between the presence of this loess and the formation of the grey gyttja may be assumed. In this connection, Teunissen's observation that the Boreal gyttja in peat-face $J$ is not a sandy, but a purely organic deposit, is of importance. It is possible that as a result of the presence of the loess layer, or the development of fen peat on top of this since the Preboreal period, the drainage of a presumably not very large 


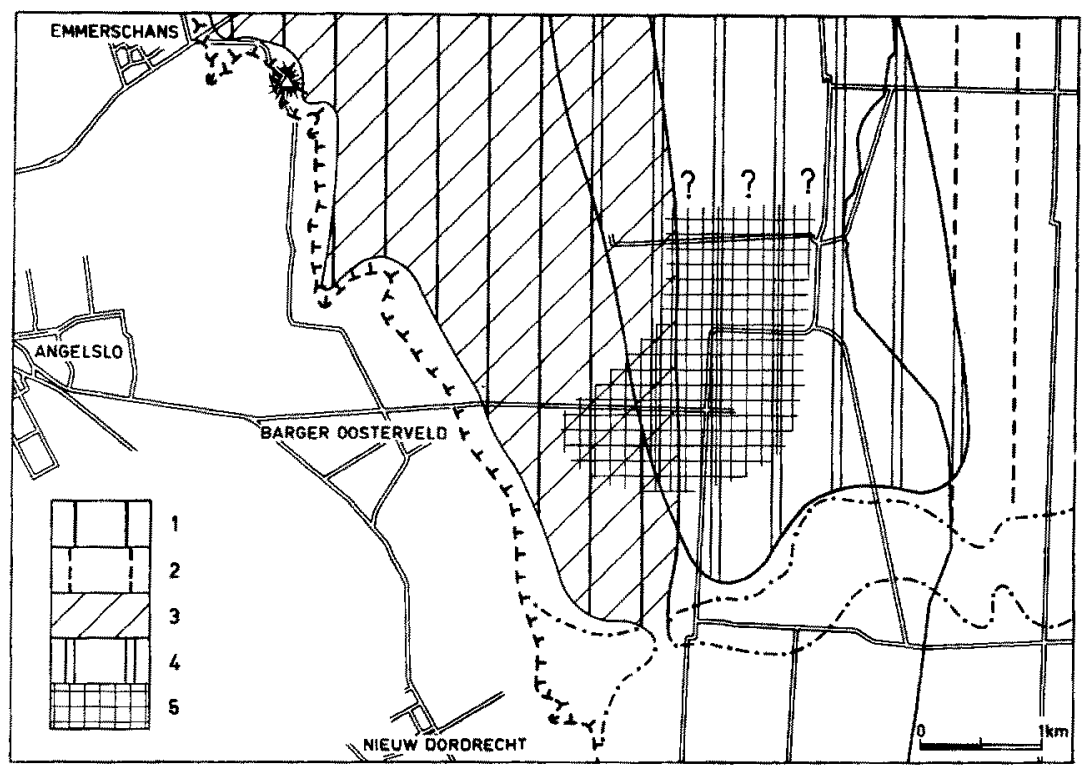

Fig. 7. Gyttja, fen peat and seepage peat in the Hunze depression: $\mathrm{I}=$ spread of the non-ferruginous fen peat after the early-Atlantic desiccation period, $c$. 5000-4500 B.C. $2=$ idem in the eastern part of the Hunze depression; $3=$ spread of the Preboreal and Boreal non-ferruginous fen peat (till c. 5300 B.C.) and of the early Atlantic pine forest (5300-4900 B.C.); $4=$ iron-rich seepage peat area; $5=$ Boreal gyttja deposits.

part of the Hunze depression stagnated, due to which an otherwise shallow lake could develop just outside the area of Preboreal and Boreal fen peat growth. At first, only the gulleys of this region will have been inundated (see preceding section), later, in the course of the Boreal, the low sand plateaux were also flooded. The western branch (peat-face J) was still overgrown with peat in the Boreal (non-ferruginous fen peat below the level of the early Atlantic desiccation layer, see fig. 7 for the spread of the pre-Atlantic nonferruginous fen peat and 8.5.2., p. 73).

In VAN Heuveln's opinion, the cause of this "Klarwassersee" (lake with open water) on the eastern and south-eastern edge of the fen peat area, is the occurrence of seepage, which may have been able to continue during the Boreal and Atlantic periods. We are of the opinion that the seepage is of a later date, see 9.4. (p. 86), and that here a more localised development is involved. The covering of the western part of the gyttja deposit (face J) by pre- 
Atlantic non-ferruginous fen peat is another argument against a lake having been created by seepage action.

VISSCHER (193I) did not identify this grey sandy gyttja as such, and called it, as well as the fluviatile loam, loamy sand.

\subsection{Stratigraphy and development of the boreal gyttjas}

Possibly as a result of fen peat accumulation in the Hunze valley, a number of shallow, east-west gulleys on the eastern slope of this valley was closed off, due to which the drainage stagnated here. In these gulleys - face $\mathrm{H}$ cuts through two of them - sedimentation of orange gyttja occurred on a limited scale, presumably early in the Boreal. During this period, the water on the eastern and southeastern flank of the fen peat which was growing on loess rose to outside the east-west gulleys, as a result of which the intervening low sand plateaux were also flooded and were covered by a thin layer of grey, sandy to humic gyttja, see fig. 7. The virtual absence of mineral material in the grey gyttja, where the latter does not lie on sand, but on Late-glacial Braunmoostorf (face J), provides evidence that blowing in or in-wash from the edge of the Hondsrug did not take place.

The rise in the water level - inundating from the gulleys the more than $\mathrm{I} \mathrm{km}^{2}$ sand plateaux - is undoubtedly the result of the stagnation of the drainage which was presumably directly linked with the proceeding non-ferruginous peat growth in the western half of the Hunze valley. The western arm of the lake was filled by plant growth during the Boreal, undoubtedly under the influence of the spreading ferruginous fen peat growth, see fig. 7 , in the Hunze valley. When all these fen peat deposits underwent a thorough and prolonged desiccation at the beginning of the Atlantic period (see 8.5.2., p. 73), or shortly before this desiccation, at the Boreal/ Atlantic transition, the gyttja growth also came to an end (see fig. 90, 2I-Po). The milieu thus formed afforded a suitable habitat for Alnus, followed by seepage peat growth. 


\section{CHAPTER 8.: NON-FERRUGINOUS FEN PEAT}

\subsection{INTRODUCTION}

The thickness and extent of the Late-glacial deposits and the Boreal gyttjas in the Hunze depression are of little quantitative significance, unlike the formations of fen peat which were enormously widespread in the horizontal plane and often of a considerable thickness. We have sub-divided the different types of fen peat into two main groups: a) the non-ferruginous fen peat, which produces yellow ash on burning, and b) the ferruginous to iron-rich Hypnaceae peat which developed as a result of seepage, and which produces a red ash on burning (seepage peat). The non-ferruginous fen peat will be discussed in this chapter. The seepage peat will be dealt with in the following chapter.

The topmost part of the fen peat is fen-wood peat. We shall use the name fen-wood peat when indicating the wood-rich nature of the fen peat.

The discussion of the non-ferruginous fen and fen-wood peat is chiefly based on information gathered from:

- vertical peat-faces $\mathrm{A}-\mathrm{G}$ and $\mathrm{J}$,

- the diagrams ro-Po (fig. 73), 3-Po (fig. 66) and the ${ }^{14} \mathrm{C}$-diagram (fig. 63), which were discussed in Chapter 4 .

- the profile EMmererfscheidenveEn I which is given beside the ${ }^{14} \mathrm{C}$-diagram (fig. 63),

- the diagram 2-Po (fig. 65) which was discussed in 6.2., see p. 56 ,

- the diagram of the profile from peat-face $\mathrm{J}$, pit 327 , made by Teunissen, see 6.I., p. 55 ,

- the diagram I-Po (fig. 64) from peat-face A, pit 6, from the marginal area of the bog which will be discussed below,

- the diagram 29-Po (fig. 98), from peat-face J, pit 328, which will be discussed in 10.7., see p. I30,

- the section EMmen I4 from peat block $\mathrm{C}$, which will be discussed in 10.3 . (p. II 7 ); see figs. 76 and 77 ,

- the fen peat part of diagram I I-Po (fig. 74), of peat-face C, between pits 68 and 69 ; the fen peat part of diagram $13-\mathrm{Rh}$ (fig. 75), of face $\mathrm{G}$, pit 64 ; the lowermost parts of ${ }_{17} \mathrm{~A}-\mathrm{Po}$ (fig. 79) and 17 A-Po bog plants (fig. 83), of section EMmen I 7, from face $\mathrm{E}$, between pits $\mathrm{I} 7 \mathrm{I}$ and $\mathrm{I} 72$. The diagrams mentioned here will be discussed in Chapter I I. Information from these diagrams and from 29 -Po which is necessary for the treatment of the non-ferruginous peat is given below. 


$$
\text { 29-Po (fig. 98, spectrum r) }
$$

In the fen peat, Betula and not Alnus must have been the most important tree. Dryopteris occurs frequently here. Sphagnum must have felt quite at home in the comparatively open forest, which points to oligotrophic, rather acid peat soil.

$$
\text { I I-Po (fig. 74, spectra I-5) }
$$

The relatively high values of the aquatic plants Menyanthes and Nymphaea (spectra 3 and 4 ) are indicàtive of an increase in the wetness of the fen peat. In spectra $I$ and 2, these types are still absent; Dryopteris and Rumex attain strikingly high values here. Right at the top, the fen peat is again probably somewhat drier (cf. spectrum 5). Calluna, Sphagnum and Cyperaceae have possibly taken the place of Dryopteris and Rumex. Alnus must have been the most important tree here.

$$
\text { I3-Rh (fig. 75, spectra I-4) }
$$

The occurrence of Amphitrema flavum in the fen peat (spectra 1-3) indicates a rather acid, oligotrophic milieu. Even before the arrival of Pinus (see also ro.3, Emmen 14), Sphagna established themselves, here, a rare development in this fen peat area.

$$
\text { r } 7 \mathrm{~A}-\mathrm{Po} \text { (fig. 79) and }{ }_{7} \mathrm{~A}-\mathrm{Po} / \text { bog plants (fig. 83), spectra I-7 }
$$

The rather high values of Sphagnum and Calluna indicate an oligotrophic, fairly acid milieu. Alnus, in view of its relatively low values, probably appeared only rarely in the immediate vicinity.

$$
\text { 8.2. I-Po (fig. 64) face A, pit } 6
$$

In profile EMmeN I, from which I-Po was made, the transition from fen-wood peat (spectra I-5) to the Pinus-Scheuchzeria peat is particularly vague. In the pollen diagram, the transition stands out as a decrease in Alnus and an increase in Pinus (spectra 5 and 6), both of which were present in the peat here. The very charcoal-rich sample 6 is strikingly poor in herb pollen. It is possible that there is a connection between a bog fire which took place at this level, and the large spread of Pinus in the peat.

\subsection{Spread of the NON-FerRuginous Fen PEAT}

The fen peat which was formed during the Preboreal and the 
Boreal has a somewhat different spread than the fen-wood peat which developed after the Early Atlantic desiccation which will be discussed in 8.5.2. (p. 73).

\subsection{Extent up to the Early Atlantic desiccation}

Preboreal and Boreal fen peat occurs in peat-faces $A-G$ and $J$ and in the profile EMMERERFSCHEIDENVEeN I (fig. 63). Its occurrence is, roughly speaking, limited to the Hunze valley where Braunmoostorf was also formed, see the map fig. 7. The top layer of this peat is formed by the Early Atlantic desiccation layer.

\subsubsection{Extent after the Early Atlantic desiccation}

The Atlantic non-ferruginous fen and fen-wood peat occurs in peat-faces $\mathrm{A}-\mathrm{E}$ and in face $\mathrm{J}$, pits $29 \mathrm{I}-335$, see the map fig. 7 . This fen peat was overgrown by the middle Atlantic Pinus forest, see 8.5.3. The difference in spread between this and the older nonferruginous fen peat is its reduced extension toward the east, see fig. 7. This will be further discussed in 8.7., p. 77 .

\section{4 . StRatigraphical aspects and DatiNg OF THE NON-FERRUGINOUS FEN PEAT}

The non-ferruginous fen peat tails off against the slope of the Hondsrug in peat-face A at $16.40 \mathrm{~m}+$ N.A.P.; this is at $15.80 \mathrm{~m}+$ N.A.P. in face $B$, and at $15.30 \mathrm{~m}+$ N.A.P. in face D. The increasing tailing-off height towards the north can very probably be ascribed to the effect of side valleys. Outside the marginal area proper, this peat type occurs in face $E$ up to $14.25 \mathrm{~m}+$ N.A.P. (in a dried-out condition, as is the case with all the heights given). The lowest level is in face $\mathrm{G}$ at $\mathrm{I} \times .80 \mathrm{~m}+$ N.A.P. (pit 6g, Emmen 1o). It dates here from the beginning of the Preboreal (10-Po, fig. 73), see 6.7. (p. 63). The non-ferruginous peat growth came to an end in the course of the Atlantic, c. $4500 \mathrm{BC}$, see following section. The fen peat at the top, i.e. above the Early Atlantic desiccation layer (see following section), is, on average, more wood-rich (fen-wood peat) than the peat at the bottom. A few black, charcoal-rich layers point to desiccation processes of the fen peat. These bands, which occur especially in the Boreal fen peat, all have a comparatively slight spread. Also, they are usually less clear than the Early Atlantic desiccation layer.

Where the fen peat lies on sand elevations on the subsoil, a black, greasy layer, usually a few centimetres thick, has formed at 
the base of the peat. This phenomenon is not indicated in the peatface drawings.

In a number of places, iron-rich or ferruginous fen peat is found in the otherwise non-ferruginous fen peat, e.g. in face D, pits ro8-119 and 137-I4I. This will be further discussed in 9.16. (p. 105).

8.5. Desiccation levels in the non-ferruginous fen peat

\section{5. . The Late Preboreal desiccation layer}

In peat-face $\mathrm{C}$, above pits $68-7 \mathrm{I}$, between $12.20-12.55 \mathrm{~m}+$ N.A.P., there is a late Preboreal ( $10-P o$, fig. 73), highly decomposed, charcoal-rich layer in the fen peat. The high Pinus percentage in the sample from this layer and the appearance of comparatively many pollen grains of Pinus with undeveloped air-sacks are indications of the presence of this tree here.

The lowest charcoal level in face A, pits $23-29$, can be dated in the Preboreal (3-Po, fig. 66). It is not impossible that we are here dealing with one and the same desiccation.

\subsubsection{The Early Atlantic desiccation layer}

In 3-Po (fig. 66), a greasy, very highly decomposed layer is present between $13.60-13.70 \mathrm{~m}+$ N.A.P., and it can be dated at the beginning of the Atlantic. A break in peat accumulation between c.5800-5100 BC, at the beginning of the Atlantic, is discernible in the ${ }^{14} \mathrm{C}$-diagram (fig. ${ }_{3}$ ). In peat-faces $\mathrm{B}, \mathrm{C}, \mathrm{D}, \mathrm{E}, \mathrm{F}, \mathrm{G}$ and $\mathrm{J}$, between $12.20-\mathrm{I} 3.30 \mathrm{~m}+$ N.A.P., a greasy layer containing charcoal is present, which is divided into two in several places (faces B, C, D and J). From its position, roughly speaking at the base of the Alnus fen-wood peat, we can conclude that there is a rather strong probability that the layer was formed shortly before or at the beginning of the Atlantic. Teunissen analysed this layer in face $J$, pit 327 , where it is present between 12.90 and $13.00 \mathrm{~m}$ above N.A.P., just at the level of the first Alnus increase. It follows from this that the layer must be an Early Atlantic formation.

It may be concluded from the Early Atlantic Pinus forest, which will be discussed in 10.9. (p. 131), that Pinus was able to continue growing on the bog surface between c. $5300-4900 \mathrm{BC}$, and that scarcely any, or no, peat accumulation took place in that period. There can, in our opinion, be no doubt that the Pinus stumps of the Early Atlantic stump group Munaut $\mathrm{D}^{\circ}$ originate from this 
desiccation layer. It should be added, however, that we have observed no stumps on the peat-faces at the level of this layer.

All these phenomena point to a thorough desiccation of the nonferruginous fen peat, which can be dated at or shortly before $\mathrm{c}$. $5300 \mathrm{BC}$.

It follows from the very regular growth of the dendrochronologically investigated trees that there was a prolonged break in the peat growth, due to which the moisture content of the forest soil remained fairly constant for more than a century (fig. I08, the years 80-215 of the floating chronology). Presumably fires will have raged several times in the Pinus forest on the bog, thus creating a charcoal-rich base. The division of the layer, found here and there, points to several peat fires with a certain time interval at the beginning of the Atlantic. The desiccation affected the whole of the non-ferruginous fen peat area in the drainage gulley (the Hunze valley) east of Emmen, which came into existence in the Preboreal and Boreal (fig. 7). The layer containing charcoal, which will be called the desiccation layer from now on, is comparatively thin, and, apart from its localised division, is uniform in character. The desiccation must, therefore, have been intense, and must have become established in a relatively short time. It seems that the supply of drainage water was completely stopped at the beginning of the Atlantic.

The Early Atlantic desiccation layer tails off in face B at about I $4.00 \mathrm{~m}+$ N.A.P. This occurs at c. $13.00 \mathrm{~m}+$ N.A.P. in faces $\mathrm{D}$, $\mathrm{F}$ and J. The layer appears in face $\mathrm{A}$ at 14.00 or $14.50 \mathrm{~m}+$ N.A.P. This last height, however, is dubious, since a charcoal layer on sand is involved here. We consider it fairly certain that the level of peat growth was not much higher than $14.00 \mathrm{~m}+$ N.A.P. at the beginning of the Atlantic period. The spillway in the east-west orientated cover-sand ridge near the village of Nieuw Dordrecht, see fig. 5 , is at approximately $\mathrm{I} 4.30 \mathrm{~m}+\mathrm{N}$.A.P. (see fig. 4 ). It is therefore probable that the cause of the Early Atlantic desiccation was a fall in the water level south of this cover-sand ridge to below the level of the threshold (of the spillway). This threshold presumably had a critical height, as it were, until some time during the Atlantic period.

The fall may even have been comparatively slight. It is possible that this fall in the water level was caused by the retention of more water in the developing peat-forming vegetation in the southern part of the Hunze depression. Deflection of the drainage pattern is not likely in the light of the topography of the subsoil of the Hunze depression. 
The thickness of the - predominantly Boreal - fen peat under the desiccation layer discussed here varies strongly in different places in the area studied. The black band lies in face B, pits $37-43$, in face $\mathrm{C}$, pits $5^{2-}-59$, in face $\mathrm{D}$, pits $120-136$, in face $\mathrm{E}$, above the sand elevation and pits $175-18 \mathrm{I}$, and in face $J$, over the whole length drawn, almost directly on top of the Late-glacial deposits or the Boreal gyttja. In face $\mathrm{C}$, pits $60-98$, a fen peat deposit of significant thickness (up to $80 \mathrm{~cm}$ ) is present under this black layer.

Whether it is here a question of a locally strongly varying fen peat accumulation in the Boreal, or that a considerable part of the Boreal fen peat in the investigation area disappeared at the beginning of the Atlantic due to fire, is not known. The position of the black layer in face $\mathrm{C}$ does not exclude the latter possibility.

\subsubsection{The Middle Atlantic pine stump layer}

The transition from the non-ferruginous fen and fen-wood peat deposits to the ombrogenous peat lying on it is formed by a Pinus stump layer; there will be a discussion in I0.3, (p. I1 7 ), I0.5. (p. I22) and I I.39. (p. 203) of the reasons we have for regarding this layer as a level of relative desiccation.

The layer itself does not belong to the complex of non-ferruginous fen peat types. The composition of the forest, the nature of the forest base, the duration of the wooded phase etc. will be further dealt with in 10.10. and IO.I I. (p. I32 ff.). The layer is present in peat-faces $B, C, D, E$ and $J$, with the exception of the most easterly part. Along the whole length of the western edge, see face A and the western part of face B, a particularly thick Pinus stump layer developed, see the next section.

The relative desiccation which brought the non-ferruginous fenpeat growth in the western half of the Hunze valley to an end, can be dated at c. 4500 BC, see I0.10. (p. 132). Apart from Pinus, Scheuchzeria palustris $\mathrm{L}$. was able to establish itself on the bog surface after it had become drier, see Ir.39. (p. 203). This points to a less thorough desiccation of the bog than must have been the case during the Early Atlantic desiccation.

During the first half of the Atlantic, the water level in the Hunze depression east of Emmen became considerably higher. In view of the tailing-off height of the Middle Atlantic stump layer in face $B$ at a little over $15.80 \mathrm{~m}+$ N.A.P. (influence of side valley?) and in face $\mathrm{D}$ at $15.3^{\circ} \mathrm{m}+$ N.A.P., we think it is fairly certain that the 
peat-growing surface was higher than $15.30 \mathrm{~m}+$ N.A.P. at c. 4500 BC. The spillway in the cover-sand ridge east of Nieuw Dordrecht must have been filled with peat in the first half of the Atlantic. In the same period, comparatively thick ombrogenous peat deposits were already developing south of this ridge (FLoRschüTz et al, 1935) due to which more and more water was retained. It is possible that this water retention was one of the factors which caused the Middle Atlantic desiccation, just as we have presumed with the Early Atlantic desiccation. As a result of the now much higher water level, the level of the spillway bottom had a direct influence on the degree of the desiccation, as we have assumed with the Early Atlantic desiccation.

\subsubsection{Other signs of desiccation in the non-ferruginous fen peat}

Here and there in the non-ferruginous fen peat, stump layers with a limited horizontal spread occur, indicating localized areas of desiccation, e.g. in face $\mathrm{C}$, above pits 54 and $76-81$, where Pinus stumps were found. In face $E$, above pit $I 7 I$ and above pit I 74 , wood levels are present at $13.10 \mathrm{~m}$ and at $13.30 \mathrm{~m}+$ N.A.P. respectively, just under the fen-wood peat. It is our opinion that these may also be regarded as signs of very localized desiccation.

The particularly high wood content of the fen-wood peat in face $\mathrm{J}$, between pits $292-332$, is probably connected with desiccations which, due to the locally very strong relief of the subsoil, must have led, more quickly than elsewhere, to a comparatively dry bog surface, very suitable for tree growth.

\subsection{THE FEN PEAT IN THE MARgINAL PARTS OF THE BOG}

In the marginal parts of the bog, the peat developed with a higher wood content than further inwards in the bog. This is true even for the fen peat, as is clearly demonstrated by peat-face A. In fact, after the Preboreal, it was not so much fen peat as wood peat which developed here, originally with Betula and Pinus, but from the beginning of the Atlantic, with Alnus too. See fig. 66, 3-Po, and fig. 64, I-Po, and 4.4.(p. 49), where the composition of the forest in the marginal parts of the bog has been further discussed.

Fluctuations in the water level to which the marginal parts of the bog are especially sensitive, and the enriching of the peat water with minerals from the Hondsrug, greatly affected the character of the types of peat formed here. In 3 -Po (fig. 66), spectra I I-38, from 
the fen-wood peat, aquatic plants such as Menyanthes, Triglochin, Typha, Sparganium and Potamogeton are present in very low percentages, if at all. The indistinct and also comparatively late transition to the Pinus forest with Scheuchzeria points to only a very weak reaction by the peat growth to the Middle Atlantic desiccation, which was described in the preceding section. The course of the two charcoal layers in face A, pits $24-29$, is an indication of gaps in the peat deposits.

The peat present in the side-valley of face $A$, pits $\mathrm{x}-9$, in which we made a distinction between fen-wood peat and pine wood peat, see I-Po, fig. 64, indicates a very localised development. Peat accumulation here started only belatedly-during the Atlantic.

\subsection{STRATIGRAPHY AND DEVELOPMENT OF THE NON-FERRUGINOUS FEN PEAT}

The first fen peat deposits in the area studied occurred in the Preboreal (fig. 73, 10-Po). They are limited to depressions in the Late-glacial depositions (e.g. face $\mathrm{C}$, pits 68-72), which indicates that at the time the rise in the water level was still only slight. The peat accumulation is slight, a maximum of $40 \mathrm{~cm}$ in the Preboreal; in Emmen io (face $\mathrm{C}$, pit 69; see fig. 73, Io-Po) it amounted to $2.5 \mathrm{~cm} / 100$ years, in comparison with $6.5 \mathrm{~cm} / 100$ years for the fen peat which was formed during the Boreal and the first half of the Atlantic (up to the Middle Atlantic stump layer, see 8.5.3.)in EMMEN 10 and its immediate surroundings. These measurements apply to peat in a desiccated condition.

The first peat is a sedge peat, with possibly Betula (fig. 73, ro-Po) and perhaps Pinus growth here and there on the higher places (fig. 66, 3-Po). In spite of the still slight rise in the water level, the peat must have been very moist in the lowest-lying places, in view of the presence of pollen of Menyanthes and the Sparganium type, see 10-Po, fig. 73. Towards the end of the Preboreal, the fen peat dried out at the lowest point too (EMMEN Io, face C, pit 69, see fig. 73 , ro-Po), due to which Pinus could establish itself, at least in some places, in the peat. The charcoal-rich layer in Io-Po, just at the transition between Preboreal and Boreal is an indication of intense desiccation of the peat. All the peat formed along the slope of the Hondsrug during the Preboreal very probably disappeared because of fire (see fig. 66, 3-Po and fig. 65, 2-Po).

After a break lasting for a few centuries perhaps, the peat growth re-established itself at the beginning of the Boreal; non-ferruginous 
peat, which has a relatively low wood content, developed again in the Hunze valley. Betula, perhaps together with Pinus (fig. 66, 3 -Po), is a frequently occurring tree along the edge of the bog. It is probable that a considerable part of the Hunze valley was overgrown by this non-ferruginous fen peat in a comparatively short time during the Boreal. The Boreal gyttjas developed east and south of this bog complex, see Ch. 7 and fig. 7 . Towards the end of the Boreal, the western branch of the gyttja deposit was overgrown by non-ferruginous fen peat, see fig. 7 . This peat growth was again interrupted c. $5300 \mathrm{BC}$ by a thorough desiccation; Pinus could establish itself on the peat surface again, and the peat surface was affected several times by fire, see 8.5.2.

It can be concluded from the position of the occasionally double "Early Atlantic desiccation layer" relative to the Late-glacial deposits that possibly significant parts of the Boreal fen peat were burned. The regular growth of the pine trees on the dried-out Early Atlantic peat surface already mentioned in 8.5.2. points to a break in the peat formation lasting for several centuries. A renewed supply of water caused the water level in the Hunze valley to rise again, due to which the peat growth started again c. $5000 \mathrm{BC}$. This provided Alnus with many suitable habitats in the peat (see fig. 66, 3 -Po and fig. ${ }_{3},{ }^{14} \mathrm{C}$-diagram), so that during the Atlantic the Hunze valley was covered with an alder fen-wood, in which sedges were frequently still present. Simultaneously, the extensive ferruginous seepage peat growth started to develop (see next chapter) to the east of these non-ferruginous fen peat complexes, see map with extent of the fen peat complexes, fig. 7. Originally, Alnus was a common tree in the seepage peat, too.

The westwards shift of the eastern border of this deposit after the Early Atlantic desiccation, which has already been mentioned in 8.3.2. (p. 72 ), was caused by seepage, due to which large quantities of water were released into the Hunze depression. The conclusion that a large supply of non-ferruginous ground water must have appeared again after this desiccation may be drawn from the considerable thickness of the non-ferruginous fen and fen-wood peat deposits which formed during the Atlantic up to c. $45^{\circ 0} \mathrm{BC}$ (Middle Atlantic relative drying-out). This amounted to an average of about $80 \mathrm{~cm}$ in a drained condition, see peat-faces B, C, D, E and $J$. This gives an extremely high peat accumulation of $c .16 \mathrm{~cm} / 100$ years. The Atlantic non-ferruginous fen peat has a considerably higher wood content than the Preboreal and the Boreal fen peat; partly because Alnus wood perishes fairly slowly under water, and 
partly because the enormous accumulation of organic material during the Atlantic will have had a strong preservative effect. Betula was not absent from this fast-growing peat; bands of white bark testify to its presence. It is probable that changes in the milieu, especially of a trophic nature, favoured the localized establishment of Betula. The large quantities of Menyanthes seeds which were exposed on breaking open lumps of non-ferruginous peat are indications of the presence of open water. During the Atlantic the proportion of Alnus in the peat-forming vegetation declined. Its place was largely taken over by Betula, see fig. 66, 3-Po, spectra 27-32 and 8.r. (p. 7o), 29-Po, 11-Po. I7A-Po. Highly humified Sphagnum peat was forming already here and there, including in face $\mathrm{C}$, pit 63 and face $\mathrm{E}$, pits $\mathrm{I}_{57}$ and $\mathrm{I} 7 \mathrm{I}$, see also fig. 79, I7A-Po and 8.I., 29-Po, II-Po, I3-Rh and I7A-Po. Open water could still occur in places almost up to the very top of the fen peat (see 8.I., I I-Po) This will not have been the case everywhere; e.g. 29-Po, spectrum I (see fig. 98) shows evidence of a less wet situation, in our opinion.

Concerning herb vegetation, the sometimes wholesale spread of Dryopteris and Rumex (29-Po, see fig. $9^{8}$ and I I-Po, see fig. 74) is, along with the occurrence of aquatic plants such as Nymphaea and Menyanthes, worthy of mention. At some places, Scheuchzeria palustris could establish itself in the non-ferruginous fen or fen-wood peat, e.g. in face $D$, pits $123-125$, face $E$, pits $I_{3}$ and $166-173$. This does not amount to thick Scheuchzeria deposits, however. This aspect of the peat formation will be further discussed in 11.39 . (p. 203). The milieu must, in any case, have been rather acid here, see also 8.I., p. 70, 29-Po, I3-Rh and I7A-Po. Widespread Scheuchzeria vegetation does occur in the contact zone between the non-ferruginous fen peat and the iron-rich seepage peat, see face $\mathrm{J}$, pits $334-336$. This phenomenon will be discussed in 9.15. (p. 104).

The localised establishment of Pinus in the non-ferruginous peat, as was observed in face $\mathrm{C}$, pits 54 and $74-8 \mathrm{r}$, undoubtedly points to an only slight desiccation of the bog surface.

During the fen peat formation, the marginal parts of the bog also became clearly more oligotrophic, see 4.4. (p. 49). The forest present here originally had a herbaceous layer with a great variety of species (spectra 13-27), but many herbs disappeared with the increase of Betula (spectra 28-32).

In the side valley of face $A$, the developing fen-wood had a completely different composition, see 8.2. It developed under considerably drier conditions. 
Halfway through the Atlantic c. $4500 \mathrm{BC}$, the non-ferruginous fen peat growth stopped; Pinus established itself in large numbers on the bog surface, accompanied in many places by Scheuchzeria palustris. The distribution of these two species on the bog surface indicates slight variations in the relief, reflecting the topography of the subsoil (see I0.3., p. II7). A relative drying-out must have caused this relief, see also 8.5.3. In spite of the shrinkage of the fen peat deposit, ground water could not reach the surface; the fen peat growth did not re-establish itself even at the lowest-lying places. There is, however, a sufficient accumulation of precipitation water for the moisture-loving Scheuchzeria to be able to establish itself.

The roughly speaking similar spread of most of the organic deposits which had formed up till now in the western half of the Hunze valley (see the distribution maps, figs. 5 and 7) points to the presence of a drainage pattern in this area, from the Lateglacial onwards, such as is drawn in fig. 6, which illustrates the drainage patterns in the Hunze depression. Fluctuations in the water supply to this drainage valley caused the peat growth to stagnate several times, e.g. c. $5300 \mathrm{BC}$ and $4500 \mathrm{BC}$. From the second half of the Allerød, when the Braunmoostorf growth stagnated (see 6.4., p. 57), up to almost the end of the Boreal, it is not possible to establish such a clear-cut drainage. See also the shape of the Boreal gyttja deposits, figs. 6 and 7. The increase in humidity (see 6.8., p. 64) noted towards the end of the Late-glacial in the Hunze valley is presumably the result more of localized stagnation of rain water, than of water from the southern part of the Hunze depression being transported. The Late Preboreal desiccation (see Io-Po, fig. 73), which was described in 8.5.I., and the small peat accumulation in the early Post-glacial (see the beginning of this section, p. 77) point to a comparatively low water level in the Hunze valley at this time. The drainage pattern given in fig. 6 will, in all probability, still have functioned during the ombrogenous peal growth, see ir.7. and II.8. (p. I 45 ff.).

With regard to the two periods of desiccation which can be dated in the Atlantic, it has been assumed that increasing water retention in the area south of the east-west orientated cover-sand ridge near Nieuw Dordrecht was an important factor in causing these desiccations, as a result of the peat growth starting up there. 


\section{CHAPTER 9.: SEEPAGE PEAT}

\section{I. INTRODUCTION}

The high iron content, the cause of the red colour of the ash (see 8.I. p. 7o), is only one of the many differences between this seepage peat and the stratigraphically related non-ferruginous fen peat which was discussed in the preceding chapter. Other differences are the occurrence of siderite and vivianite, the presence of drying cracks, of dopplerite formations, and the generally low wood content of the peat, of which (not identified) Hypnaceae are the most important sources. The discussion of the seepage peat is based mainly on data which were derived from:

- vertical peat-faces $F$ - I, the eastern part of face $J$, and faces $\mathrm{K}-\mathrm{Q}$,

- diagram 2I-Po (fig. 9o), which was dealt with in 7.2. (p. 65),

- profile EMmererfscheidenveen i, which is reproduced beside the ${ }^{14} \mathrm{C}$-diagram (fig. 63 ),

- the sections Emmen 24, 25, 26 and 27 (figs. 53, 54, 55 and $5^{6}$ respectively) from peat-face I; in this chapter, only the seepage peat part of the sections will be dealt with, see the following section. The ombrogenous peat part of these sections will be discussed in Chapter II.,

- the diagram SMeulveen, by Florschütz, published by VAN HeuvelN (1958), of a peat monolith, which originates in the vicinity of peat-face I, pits $277-278$,

- spectra 4-6 from diagram 29-Po (fig. 98), originating from peat-face J, pit 328 , which will be discussed in 10.7 , see p. 130,

- spectra $\mathrm{I}-4$ from diagram 30-Po (fig. 99), originating from face M, pit 407, which will be discussed in Io.8., see p. I3I,

- the seepage peat part of the diagrams $19 \mathrm{~B}-\mathrm{Rh} / \mathrm{Mo}$ (fig. 89 ) and of $3 \mathrm{I}-\mathrm{Po}$ and ${ }_{3} \mathrm{IRh} / \mathrm{Mo}$ (figs. I 00 and Ior). Section EMmen I9, from face $\mathrm{H}$, above pits $263-268$, and profile EMmeN $3^{\mathrm{I}}$, of face $\mathrm{O}$, pit 442, will be discussed in Chapter $\mathrm{I}$. The information from these diagrams, from $29-\mathrm{Po}, 30-\mathrm{Po}$ and from the diagram SMEulveEN which is necessary for the treatment of the seepage peat is given below.

\section{Smeulveen}

There is a peat deposit, on the Boreal gyttja deposit, about I.3o m thick and containing a siderite lens, which was described by $V_{A N}$ Heuveln as fen peat. This fen peat, rich in Hypnaceae, was formed 
after the beginning of the Atlantic. The fen peat growth ceased shortly before the Atlantic/Subboreal transition.

The Pinus curve has a clear maximum just at the base of the siderite lens. VAN HeUveLN assumed that this was caused by local pine growth. In our opinion, we are here concerned with the Middle Atlantic pine forest, which forms the transition from the nonferruginous fen-wood peat to the ombrogenous peat, see $8.5 \cdot 3$. (p) 75), and Io.Io. and ro.I. (p. I $32 \mathrm{ff}$.). The start of the siderite formation here can therefore be dated at c. $4500 \mathrm{BC}$ or shortly afterwards.

29-Po (fig. 98, spectra 4-6).

Calluna and Empetrum had already become fairly widespread (spectrum 5) in the pine forest here (middle stump level, see also I0.7., p. I 30) which can be dated at about the Atlantic/Subboreal transition. This is an indication of a comparatively acid milieu. The Sphagnum minimum in spectrum 5 can possibly be ascribed to a desiccation which is - in view of the dating of the middle stump level in this diagram (at the Atl/SB transition) - very probably the desiccation of $\mathrm{c} .3100 \mathrm{BC}$ which will be discussed in this chapter.

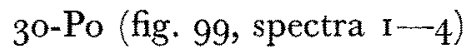

The percentages of Rumex and Melampyrum are indications of the existence of these plants here in the peat. Dryopteris and Gramineae reach striking maxima, Betula also increases strongly. This means that the milieu of the peat growth clearly altered before the sudden end of the supply of seepage water which can be dated at c. 3100 BC (see 9.5 .2 , p. 9o). From the absence of, or the relatively low percentages of Calluna, the Andromeda-Vaccinium type, Erica, Empetrum and Sphagnum, we can perhaps conclude that, in spite of the changes, the milieu was not particularly acid.

$$
\text { I9B-Rh/Mo (fig. 89, spectra I and 2) }
$$

Aulacomnium palustre occurs regularly in this seepage peat, probably more frequently than Sphagna, of which only a very few identifiable remains were found. The presence of Amphitrema flavum might be an indication of a comparatively acid milieu.

$3^{\text {I-Po AND }}$ 3 I-Rh/Mo (fig. Ioo, spectrum I and fig. roI, spectrum I)

Rumex would have been present here. It is remarkable that 
Aulacomnium palustre is absent here; its place was possibly taken by Drepanocladus and Polytrichum. Amphitrema flavum is present, although in slight quantities, which is perhaps a weak indication (just as with $19 \mathrm{~B}-\mathrm{Rh} / \mathrm{Mo}$, see above) that the milieu was relatively acid here towards the end of the seepage peat growth.

9.2. Emmen 24, Emmen 25, Emmen 26, Emmen 27, (figs. 53, 54, 55, and 56 ), from peat-face I, between pits $279-282$.

These sections were drawn using a grid with $0.5 \times 0.5 \mathrm{~m}$ squares. The basal Boreal gyttja and the seepage peat lying on it were not further specified in the drawings; see peat-face drawing I. As far as the secpage peat part of these sections is concerned attention was particularly directed towards the siderite lenses, the drying cracks and the dopplerite layer.

Two monoliths from EMmen 24 were sampled at r.6 HS (= horizontal scale; VS = vertical scale) and at $3.0 \mathrm{HS}$, viz. $24 \mathrm{~A}$ and ${ }_{24} \mathrm{~B}$ resp., which were examined for their rhizopod and moss content. The diagrams $24 \mathrm{~A}-\mathrm{Rh} / \mathrm{Mo}$ and ${ }_{24} \mathrm{~B}-\mathrm{Rh} / \mathrm{Mo}$ are reproduced in fig. 94: Pollen analysis was made only of $24 \mathrm{~A}: 24 \mathrm{~A}-\mathrm{Po}$ (fig. 93).

A monolith at $0.3 \mathrm{HS}$ from Emmen 25 was sampled for rhizopod and moss analyses (25-Rh/Mo, fig. 95). Only spectrum I of $25^{-}$ $\mathrm{Rh} / \mathrm{Mo}$ is discussed in this section.

EMmen 24 (fig. 53), from peat-face I, between pits 279-280.

In the large siderite lens between $0.5-4.2 \mathrm{HS}$ and $13.30-13.80$ VS ( $=$ N.A.P.), there is a vertical crack, filled with dopplerite, at I. 5 HS. This runs from the level of the dopplerite layer which forms the transition between the seepage peat and the ombrogenous peat (seepage peat dopplerite layer). The but slightly elastic nature of the siderite-rich seepage peat must undoubtedly have been a contributing cause of the forming of the drying cracks, which points to a thorough desiccation of the seepage peat. Wood occurs in places right at the top of the seepage peat; such as e.g. the Alnus stump between $0.2-0.4 \mathrm{HS}$, which reaches into the ombrogenous peat.

EMmen 25 (fig. 54), from peat-face I, pit 280, 15 m east of EMMEN 24.

The absence of siderite in the peat on both sides of drying cracks 
(see also sections Emmen 26 and 27 , below) is a generally-occurring phenomenon. This will be further discussed in 9.6. (p. go).

Above the right-hand side part of the siderite lens is a layer of Hypnaceae peat, about $10 \mathrm{~cm}$ thick, upon which lies very highly decomposed amorphous peat containing wood (Alnus or Betula). This amorphous peat lies loosely on the Hypnaceae peat. In all probability it is redeposited peat, just like the peat lumps found in the drying cracks. This points to the occurrence of erosion after the thorough desiccation which must have caused the drying cracks. We think that the funnel-shaped mouth of the crack (similar to the cracks of EMmen 26 and 27) was shaped by the eroding action of the water. The lumpy peat in the drying cracks is Hypnaceae peat. This dates the erosion at even earlier than the ombrogenous peat growth here. It appears from spectrum I of $25-\mathrm{Rh} / \mathrm{Mo}$ that, towards the end of the seepage peat formation, Sphagnum and Aulacomnium palustre, as well as Hypnaceae, were constituents of the peat-forming vegetation. The wood remains at the top of the seepage peat at I.2-I.5 HS and 2.4-2.6 HS (Betula) come from trees which would have grown here in the bog. The seepage peat dopplerite layer overlies the wood remains.

EmMen 26 (fig. 55), from peat-face I, between pits $280-28 \mathrm{I}$, about $10 \mathrm{~m}$ east of EMMEN 25.

In contrast with the situation in the other sections of this group, there is here no question of a siderite lens with a drying crack running through it. For the rest, the similarity to the crack of EMMEN 25 is so striking that we may assume that here, too, an eroding water flow must have existed after the seepage peat dried out. After the peat digging, this crack could be followed over a length of more than I $5 \mathrm{~m}$ in the horizontal plane. It turned out to be approximately rectilinear, to run in a SW-NE direction, and at the top to be completely filled with redeposited peat. It was in contact with a number of cracks which ran in a slightly different direction, a few of which display similar erosion phenomena. We think that this type of crack is clearly characterised by the name "erosion drying crack".

Emmen 27 (fig. 56 ), from peat-face I, between pits $28 \mathrm{I}-282$, about $35 \mathrm{~m}$ east of EMMEN 26.

The wide mouth of the drying crack, $14.00-14.30 \mathrm{VS}, 1.5-2.0$ $\mathrm{HS}$, and the fact that it is filled with lumps of redeposited peat are again indications of the occurrence of erosion (cf. EMmeN 25 and 
26), due to which the top-most part of this crack acquired a gulley-like shape. This section lies in that part of face I where the upper side of the seepage peat (the seepage peat dopplerite layer) is domed, and this, fairly certainly, did not develop exclusively in the preceding roo years, see 9.13. (p. 102).

The crack could be followed over a distance of more than $20 \mathrm{~m}$ in a SW-NE direction. A polygonal structure of cracks was very clearly visible in the horizontal plane in the immediate neighbourhood of this section.

\subsection{Stratigraphical aspects and dating of the SeEpage peat}

Peat which leaves a red ash after burning occurs in faces $F, G, H$, I, K, L, M, N, O, P and the eastern part of face J. It was also found sporadically in the non-ferruginous fen peat area, e.g. in face $\mathrm{C}$, above pits $65-69$, see 9.16 ., p. I05.

We have carried out no investigation of the iron content; relatively large differences undoubtedly exist. Instead of the purely descriptive, although entirely correct name "ferruginous fen peat", we will use the genetic name "seepage peat" here. In our opinion, this indicates much more clearly the essential difference between the peat which was discussed in the preceding chapter, and the peat which will be dealt with here. The area in which this peat was found by us, or in which, according to information from the local population, it had been present, has been drawn in fig. 7. It soon became clear that we were here dealing with an unbroken area of this peat. The form in which we have drawn the area will be further discussed in 9.II. (p. 98). The lowest-lying occurrence is somewhat below I3.00 m+N.A.P. in faces F, G and J, where it lies on the Early Atlantic desiccation layer, and in faces $\mathrm{H}$ and $\mathrm{I}$ where it lies on Boreal gyttja. In the remaining faces it lies on fluvial loam between $13.40 \mathrm{~m}+$ N.A.P. (in face $\mathrm{O}$ ) and $\mathrm{i} 5.10 \mathrm{~m}+$ N.A.P. (in face $\mathrm{M}$ ). In faces $F, G, H, I$ and $J$ it occurs up to about $14.00 \mathrm{~m}+$ N.A.P., in faces $\mathrm{K}$ and $\mathrm{L}$ up to almost $\mathrm{I} 5.00 \mathrm{~m}+\mathrm{N}$.A.P., in faces $\mathrm{M}$ and $\mathrm{N}$ up to $15.45 \mathrm{~m}+$ N.A.P. and in faces $O$ and $P$ to over $15.00 \mathrm{~m}+$ N.A.P. The relief of the present seepage peat surface roughly follows the topography of the subsoil. At two places, in the faces I and M, the surface is, moreover, noticeably domed, see 9.13., p. 102.

Special characteristics of the seepage peat are: siderite lenses (especially in faces $\mathrm{H}, \mathrm{I}, \mathrm{M}, \mathrm{N}, \mathrm{O}$ and $\mathrm{P}$ ), siderite and vivianite lenses (especially in face I), drying cracks (particularly in faces 
F, G, H, I, M, N, O and P), drying cracks with erosion phenomena (face I) and dopplerite. All these phenomena will be further discussed in the following sections. The black desiccation bands of the non-ferruginous fen peat are not present in the seepage peat.

In agreement with VAN HeUveln (1958) we assume that extensive seepage in the central parts of the peat basin made this ironrich peat forming possible, see the next section. The start of the seepage peat formation has been dated at the beginning of the Atlantic by 2I-Po (fig. 90), from the lowest seepage peat level in the area investigated. In the SmeulveEn diagram (VAN Heuveln, I958), the transition from gyttja to his "fen peat" can be dated at rather early in the Atlantic. The abundant occurrence of Alnus wood at the base of the seepage peat in peat-faces $\mathrm{K}-\mathrm{P}$ would also indicate an Atlantic beginning of the iron-rich peat formation. The end of the seepage peat growth is dated at c. 3 roo BC by the stump groups Munaut A and C, see 10.12. (p. I35). The pollen diagrams $3^{0-P o}$ (fig. 99) and 29-Po (fig. 98) also yield a late Atlantic date for the end of the seepage peat formation.

The botanical content of the seepage peat is fairly uniform throughout the whole of the area investigated, and also outside of it; it is predominantly a Hypnaceae-Carex peat with many Menyanthes remains (see also VAN Heuveln I958). The peat is orangebrown on first appearance; it oxidises fairly quickly (within 15 minutes) on exposure to the air, thereby acquiring a deep blueblack colour. The non-ferruginous fen peat stays much browner. Rumex and Melampyrum must have regularly found a suitable habitat in this peat, which, when fresh, resembles Braunmoostorf to some extent (30-Po, fig. 99 and $3 \mathrm{r}-\mathrm{Po}$, fig. I0o). Alongside Alnus and Betula, Quercus occurs at the base of this peat.

\subsection{Seepage}

The prerequisite for the occurrence of seepage is the presence of a good porous sand or gravel deposit in the subsoil, through which water from the higher-lying "infiltration area" can flow to the seepage area. If it flows through an iron-rich subsoil (moraine material), the water may become strongly ferruginous, especially if the distance to be covered is considerable.

Seepage occurs in many places throughout the whole of the Hunze depression, and causes ferruginous water to appear. As late as the I $g^{\text {th }}$ and 20 th centuries, iron-rich deposits were still being formed under the influence of seepage (VAN Bemmelen I895, 


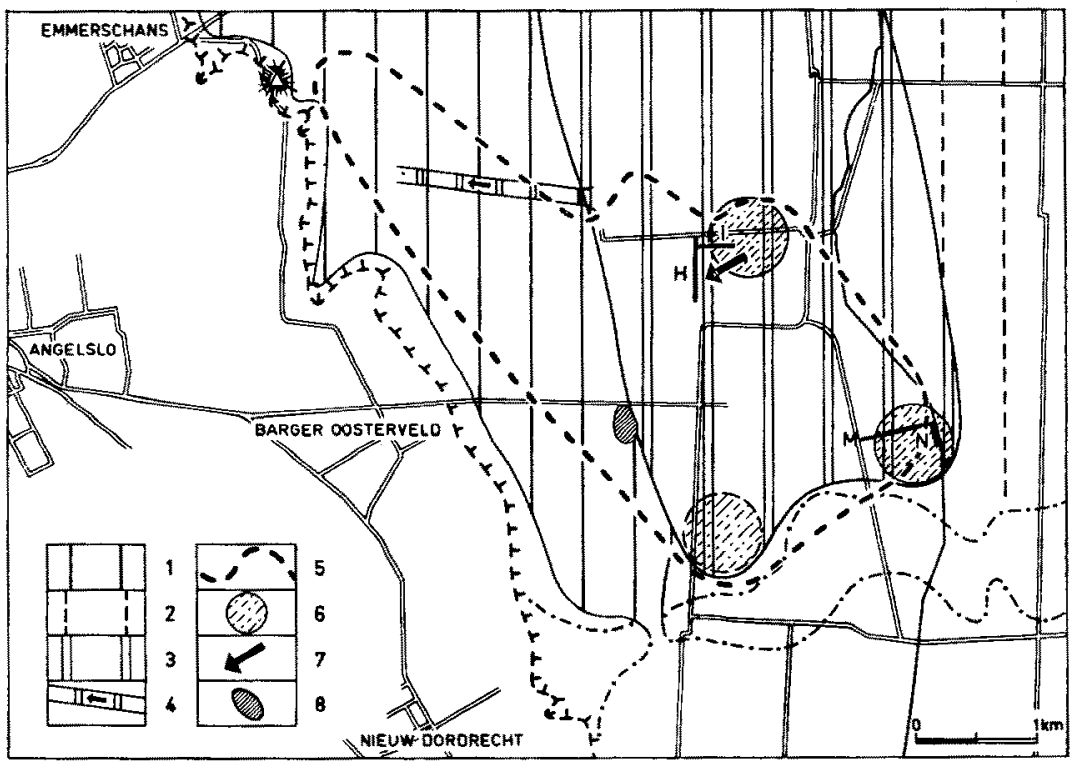

Fig. 8. Fen peat and seepage peat in the Hunze depression: $\mathrm{I}=$ non-ferruginous fen peat area since c. 5000 B.C.; $2=$ idem in the eastern part of the Hunze depression; $3=$ iron-rich seepage peat area c. 5000-3100 B.C.; $4=$ vein with iron-rich fen peat on the non-ferruginous fen peat with indication of the direction of the ferruginous water flow; $5=$ seepage area, according to VAN HeuvetN (1958); $6=$ seepage centres; $7=$ extent and direction of erosion from c. 3100 B.C. in the angle formed by faces $\mathrm{H}$ and $\mathrm{I} ; 8=$ the Scheuchzeria-peat contact zone, from $4500-4000$ to 2500 B.C.

Reinders I go2), not only in the Hunze depression, but in several valleys. We have noticed the presence of seepage many times during the field work. In a large number of pits in the Braunmoostorf area which were dug down into the sandy subsoil (see map fig. 5), ground water collected fairly quickly, sometimes to a height of half a metre above the sandy subsoil. Within a few days, a brownish film formed on this water as a result of the quantity of iron in the ground water.

Up to 1963 , a few peat diggers drew seepage water from peatblock $\mathrm{C}$ in pits 59 and 60 to make coffee. Due to its high iron content, boiling alone turned this water brown, so that the addition of ground coffee beans was not necessary - at least for the colour! Seepage was also found in several pits under the fluvial loam layer. Pit 420 (peat-face $N$ ) contained running sand, out of which much water arose. 
Probably a seepage flow at c. $14.00 \mathrm{~m}$ above N.A.P. is involved here (see also 9.12., p. 99). This is the highest level at which seepage was found. The level of the seepage will be determined to a significant extent by the water level in the infiltration area. This means that desiccation of the peat formed in seepage milieu can be caused both by changes in the seepage area, e.g. by a different drainage pattern, and by changes in the infiltration area, especially by a lowering of the water level.

The seepage area in the Hunze depression according to VAN Heuveln is given, in the map, fig. 8. There is good agreement between his results and ours concerning the occurrence of seepage.

VAN HEUveln thinks that, because of its boulder clay mantle, the Hondsrug cannot be considered as an infiltration area for seepage in the Hunze depression. In the "stream valley area" (fig. Io) lying between the villages of Sleen and Emmen, about $10 \mathrm{~km}$ west of our investigation area, where the boulder clay was eroded away, he can point to a period with a high water level which would correspond closely with the occurrence of iron-rich seepage in the Hunze depression. Partly for these reasons, he thinks that this stream valley area can be shown to be the infiltration area for the iron-rich seepage.

One might wonder if the Late-glacial Braunmoostorf developed under the influence of seepage, too. In the Late-glacial, however, the stream valley area could not have functioned as an infiltration area, since large supplies of water were not present here during this period (communication: VAN Heuveln), so that it is very unlikely that the Braunmoostorf can be regarded as a deposition in seepage milieu. Moreover, the Late-glacial Braunmoostorf is non-ferruginous. The fact that no iron-rich seepage occurred in the western part of the Hunze depression where non-ferruginous fen peat was formed from the Preboreal onwards, can be ascribed with reasonable certainty to the presence of Late-glacial deposits under this fen peat which are non-porous.

\subsection{Dating of the seEpage}

\subsection{The beginning of the seepage}

Van HeuvelN (1958), who has thoroughly investigated the origin of seepage peat, assumes that the Boreal gyttjas (see Chapter 7) were deposited in a milieu already affected by seepage. He explains the relatively non-ferruginous character of the gyttja compared 
with the peat as the result of the presence of a large quantity of elements in the gyttja which are far less combustible.

According to this author, a "Klarwassersee" - a lake with open water - would have developed due to seepage action during the Boreal, and this lake had no contact with the Boreal fen peat in the Hunze valley. It is true that peat accumulation in the period is still slight (see 8.7. p. 77), but the topography of the subsoil (see peat faces E, F, G, H and I and the contour map fig. 4) and the occurrence of Boreal gyttja on the Late-glacial deposits in face $\mathrm{J}$ (cf. Chapter 7.) exclude the possibility of the existence of such a seepage lake. The formation of Boreal gyttja was a relatively localized process which was limited to the system of shallow lakes east and south of the developing Boreal non-ferruginous fen peat deposit (see fig. 7), in an area which was flooded because of stagnation in the drainage. We are of the opinion that the seepage did not start earlier than the beginning of the Atlantic. This can be deduced both from the absence of Boreal ferruginous depositions and from the dating of the start of the ferruginous peat growth by diagrams $2 \mathrm{I}-\mathrm{Po}$ (fig. 9o) and Smeulveen (Van Heuveln 1958), see 9.1.. Non-ferruginous fen peat lies under the Early Atlantic desiccation layer, see 8.5.2., p. 73 , in faces $\mathrm{F}^{\mathrm{P}}$ and $\mathrm{G}$, whereas in the case of iron-rich seepage in the Boreal, ferruginous peat would certainly have been formed here. In these faces the Early Atlantic desiccation layer was overgrown by what is clearly ferruginous peat. A more exact dating for the beginning of the seepage can be obtained by assuming a relationship between the Early Atlantic desiccation layer and the occurrence of seepage. In this connection, the observation mentioned already, that this desiccation layer forms the lower limit of the ferruginous peat in faces $F$ and $G$, is of importance. Even in the Boreal, the soil of the Hunze depression in the area investigated was relatively moist (non-ferruginous fen peat formation) or even wet (Boreal gyttjas). The Early Atlantic desiccation (see 8.5., p. 73) was the result of a decrease in the water level, due to which the water pressure in the Hunze depression north of the cover-sand cross-ridge near the village of Nieuw Dordrecht must have fallen away. Because of this disturbance of the water balance which had prevailed so far, the seepage possibly started up.

Proceeding from this reasoning, the start of the seepage can be dated at shortly after $5300 \mathrm{BC}$ (the start of the Early Atlantic desiccation), but clearly before 5 ooo $\mathrm{BC}$, when the non-ferruginous fen peat growth had started up again. It is obviously extremely unlikely that the fen peat could form again in the Hunze valley, 
while, to the east of this, in the central basin of the bog, the bed was still dry.

\subsubsection{The end of the seepage}

The end of the forming of the seepage peat, which can be dated at c. $3100 \mathrm{BC}$ (cf. 9.3., p. 86), must have come very suddenly (see 9.14., p. 103). The large number of drying cracks (see 9.9., p. 96) and the sharp transition from seepage peat to ombrogenous peat, on which transition the seepage peat dopplerite layer is found (cf. 9.8., p. 94), point to an abrupt end to the water supply and to an equally sudden disappearance of the water present in the seepage peat area. In our opinion, this is an indication of a direct relationship between the end of the seepage and the coming to a stand-still of the seepage peat formation in the whole of the ferruginous peat area. We may therefore date the end of the seepage also at c. 3100 BC. In 9.8. a few more datings of the transition level from seepage peat to ombrogenous peat will be dealt with. These are the dates of dopplerite from section EMMEN I9, from face $\mathrm{H}$, above pit 263 , and from profile EMMEN 3I, from face O, above pit $44^{2}$.

\subsection{Siderite}

This peat mineral occurs in the area investigated mainly as lenses in the ferruginous peat. The lenses can be immediately recognised on the peat-faces by their red colour. They are present in large numbers in peat-faces $\mathrm{H}, \mathrm{I}, \mathrm{M}, \mathrm{N}, \mathrm{O}$, and $\mathrm{P}$, and in small numbers in faces $F, J, K$ and $L$. The distribution is thus limited to the central part of the bog. Since these lenses are not cut for peat sods, their form could be determined in many places not only in the vertical cross-section, but also in the horizontal plane. They are all roughly isodiametrical, from 0.5 to $10 \mathrm{~m}$ in cross-section, see also fig. 53, Emmen 24, fig. 54, Emmen 25, fig. 55, Emmen 26 and fig. 56, EMMEN 27. The thickness varies from $0.2-1.0 \mathrm{~m}$, usually amounting to $20-50 \mathrm{~cm}$. The lenses appear almost exclusively in the upper half of the iron-rich peat. The lower part of the lenses usually consists of a gradual transition from Hypnaceae peat to pure siderite; thin layers of Hypnaceae peat are often still visible in the lenses (EMMEN 24-27). A vertical drying crack runs through a large number of lenses, and in this, erosion has sometimes occurred (EMMEN 25-27). 
The siderite does not usually extend as far as the seepage peat surface and the cracks (see 9.2.). Mostly there is still $10-30 \mathrm{~cm}$ of iron-rich Hypnaceae peat above the lenses and on both sides of the cracks, see Emmen 24-27. Van Heuveln (1958) describes a number of siderite lenses with a drying crack, found in the immediate neighbourhood of face I, pits $277-278$. He calls the peat lying on top of these lenses, without exception, redeposited (allochtonous) peat. Our opinion is that this may well be incidentally true, e.g. in those cases where a drying crack has obvious traces of erosion, but that this interpretation is not valid for the black coloured peat above siderite lenses without drying cracks, or where certainly no erosion has occurred in the crack. The large majority of siderite lenses are of those two types.

The fine red colour of the siderite is a secondary phenomenon; during the peat digging, it comes to light as an off-white, strongly greasy, loam-like substance, called "witte klien" in the peat area. In about three weeks it changes to red due to air oxidation. By "siderite" is meant here both the oxidised and the unoxidised form.

VAN BEMmelen (1895) analysed both the siderite and the surrounding Hypnaceae peat. He found that unoxidised siderite is an amorphous material with a high water content which contains (when free of water) nearly go \% ferrous carbonate, a few percent calcium carbonate and 10 \% plant remains. More than half of the $3 \%$ mineral constituents of the surrounding peat proved to consist of iron oxide. The plant remains found in the siderite lenses cannot, in our experience, be distinguished from the surrounding Hypnaceae peat. In the oxidation, ferrous iron is oxidised to ferric. In contrast with the crystalline ferrous carbonate occurring in the mineral subsoil, and which is also called siderite, it is the amorphous compound which is found in the peat (REINDERS, I896, I902).

Extremely diverging suppositions concerning the origin have been put forward by various authors. VAN BEMMELEN (1895) believes it to be possible that micro-organisms e.g. iron bacteria, played a part in the deposition of the dissolved or colloidal iron in the Hypnaceae peat. VISSChER (I93I) thinks that the iron-rich water has been transported by the rivulet, the Runde. According to VISSCHER, the siderite lenses came into existence during a desiccation of the Hypnaceae peat (regarded by him as fen peat), during which accumulations of iron compounds precipitated in the fen peat in the lowest part of the peat area. He supposed that the peat with siderite lenses was situated in the lowest part of the Hunze depression. It appears from the contour map fig. 4 that this is not correct. 
From our observations, it appears that his suggested relationship between the ferruginous peat, especially the siderite lenses, and the bog rivulet, the Runde, does not exist. In II.I8. and II.I9.(p. ${ }_{1} 5^{8} \mathrm{fr}$.) we shall go further into the question of the development of this bog rivulet.

Van Heuveln (1958) assumes that the siderite was formed in water cushions under the peat surface by the gradual coagulation of colloidal iron carbonate compounds under anaerobic conditions, until an irreversible gel-condition was reached. According to VAN Heuveln, the development of these water cushions is closely connected with the type of peat-forming he supposes to have taken place here, the filling up by floating peat islets (Dutch: kraggen) as was described by VoN Bülow (1929). Water would have been retained under the floating peat islet, and would no longer have been able to flow away. The iron compound would have flocculated into the water cushions thus formed.

Such a genesis does not seem probable to us, since this, in view of the wholesale occurrence of siderite lenses at approximately the same level (see below, end of this section), should have been accompanied by enormous masses of water in the bog, a condition which must be considered an impossibility in this peat area, see contour map fig. 4. We have found no trace of peat growth by floating peat islets. VAN HEUveln also observed that a clear picture of floating peat growth is not present. Moreover, we are of the opinion that peat growth by floating islets is not a type of peat formation with which considerable peat accumulation occurs, as was the case with this ferruginous Hypnaceae peat.

Since siderite is present in the peat in an unoxidised form, its formation must have taken place under anacrobic conditions, i.e. not on or in, but under the peat-forming surface. It is possible that the iron was reduced by the reaction from the ferric to the ferrous form. Although we have not examined the peat in this respect, we consider it very likely that micro-organisms played an active part in forming of siderite.

The isodiametrical shape of the siderite lenses points to the absence of disturbances during the siderite formation. As was already reported at the beginning of this section, on p. 9o, thin Hypnaceae peat layers which did not turn red are still present in the lenses, and this makes it probable that siderite was deposited in the peat during its formation, although this process would not have taken place on the peat surface. It is possible that micro-organisms fixed the iron compounds from the seepage water as siderite between the Hypna- 
ceae vegetations. We consider the thickness of the non-red coloured peat above the siderite lens to be no indication of the depth under the peat surface at which the anaerobic process of the iron fixation is supposed to have taken place. The absence of siderite on both sides of the drying cracks which run through the lenses points to the possibility that the removal of iron from the parts of the lens concerned occurred e.g. by means of infiltrating acidic bog water from the ombrogenous peat.

A precise dating for the beginning of the siderite formation cannot be given since the underside of a lens cannot be pin-pointed exactly, see beginning of this section, p. 9o. Although the beginning of the siderite development in this seepage peat area undoubtedly cannot be dated to one particular point in time, it is still very probable, from stratigraphical considerations, that siderite formation on a large scale started up within a comparatively short period of time, possibly within a few centuries. In VAN Heuveln's profile drawing $(1958$, p. $4 \mathrm{I})$ the underside of the small siderite lens $(275 \mathrm{~cm}$ below the surface) and of the large lens $(245 \mathrm{~cm}$ below the surface) are situated at the level of a Pinus maximum in the pollen diagram $(280-240 \mathrm{~cm}$ below the surface) which we think can be ascribed to the Middle Atlantic expansion of Pinus over the non-ferruginous fen peat, see 9.I. (p. 8I) and 8.5.3. (p. 75). With some reservations, therefore, we may to date the beginning of the large-scale siderite formation at $4500-4000 \mathrm{BC}$.

The end of the siderite forming probably coincides with the end of the seepage peat forming, i.e. about 3 IOo BC. It appears from $30-\mathrm{Po}$ (fig. 99) and from $25-\mathrm{Rh} / \mathrm{Mo}$ (fig. 95) that there had already been a marked change in the milieu before this time. Perhaps the siderite production had already decreased before c. 3100 BC.

\subsection{Vivianite}

On oxidation by the air, a number of siderite lenses turns out to acquire not only a red colour, but to display a fine blue coloration as well. In these lenses, thin blue bands of vivianite alternate with considerably thicker red siderite layers. The phenomenon was clearly observed in the area investigated only in peat-face I.

VAN Bemmelen (1895) also analysed this material. According to this author, it is composed of c. $40 \%$ ferrous phosphate (= vivianite), $20 \%$ ferrous carbonate (= siderite) and $40 \%$ plant remains. During the field work we also observed the considerably 
higher proportion of plant remains in vivianite compared with siderite; vivianite is present mostly in very thin Hypnaceae peat layers in the siderite lenses which have not developed a red colour. It, more clearly than siderite, therefore, is deposited in a matrix of peat, probably by a process which is roughly parallel to the siderite deposition.

Vivianite, which, like siderite, comes to light as an off-white, loamy substance, changes to blue after a few days.

Since we found it exclusively in siderite lenses, the vivianite formation may be dated in the same period as the siderite formation.

\subsection{Dopplerite}

Quite different from the distribution of siderite and vivianite in the seepage peat is that of dopplerite, a humic substance which, when fresh and moist, is brownish-black and elastic ("ox blood"), and whose fractures are clearly shell-shaped. Dopplerite turns black on drying, and in this condition the material, having become very hard, disintegrates easily. In the area investigated, three forms may be distinguished, corresponding to the occurrence of dopplerite:

I. as a filling of the hollow stems of monocotylous plants, in roots, in and between wood remains, between leaf remains, etc. both in the mineral subsoil just below the peat and in the fen peat; in this latter case, particularly in the bottom layers. In general, this form appears only in small quantities. It is mentioned by several authors (Borgman i89o, Van Baren I927, Visscher, I931). We carried out no investigation of this form of dopplerite, which is found in many bogs.

2. as a filling of the drying cracks in the seepage peat already mentioned (9.2., Emmen 24, Emmen 25, Emmen 26, Emmen 27) and to be discussed later, which appear especially in faces $\mathrm{H}$ and $I$, to a lesser extent in faces $F, G, M$ and $N$, and in relatively small numbers in faces $\mathrm{F}, \mathrm{G}, \mathrm{K}$ and $\mathrm{L}$. This occurrence was also reported by the authors mentioned above, but only in the bog area east of Emmen.

3. as a thin, $0.5-4 \mathrm{~cm}$ thick layer, especially at the top of the peat between plant remains. It can only rarely be scraped in a relatively pure condition from the peat-faces. In contrast with the dopplerite in the drying cracks, this form dries out more laminated than crumbly. We have called this layer the "seepage peat dopplerite layer". Visscher (I93I) also knew this form of dopplerite, 
which is present in the area investigated in all the faces with ferruginous seepage peat between this peat and the highly humified Sphagnum peat.

A close similarity to this seepage peat dopplerite layer was shown by a thin dopplerite layer in the highly humified Sphagnum peat of faces $\mathrm{H}$ and $\mathrm{I}$, which also dries out leafy and which, because of its stratigraphical position, was called "Sphagnum peat dopplerite layer", see I1.I4. (p. 154). This layer is drawn in in sections Emmen 19, (fig. 48), EMmen 24 (fig. 53) and Emmen 25 (fig. 54). According to Van Baren (1927), Visscher (1931) and VAN Heuveln (1958), dopplerite is a humic colloid with a $\mathrm{C} / \mathrm{N}$ ratio between 30 and 50; the ash contains more than $30 \% \mathrm{Ca}$ (VAN BAREN). Micromorphologically, it consists of very small spheres, which are linked together by yellowish-brown humus (Van Heuveln).

Little concrete information is available concerning the origin of dopplerite and the mechanism of the dopplerite deposition. It is assumed that it is a precipitated humic colloid (VAN HEUveLN).

VAN Heuveln assumes that there is a relationship between the desiccation of the central part of the bog (to be discussed in 9.I4., p. I03) and the development of dopplerite in the drying cracks. After the desiccation, the colloidal humus may have been washed out, from the seepage peat into the drying cracks.

The dopplerite of the seepage peat dopplerite layer may have developed from the humic acids which were present in the highly humified Sphagnum peat. The contact layer between highly humified Sphagnum peat and seepage peat must have presented itself as a suitable precipitation level. In fact, the seepage peat dopplerite layer consists of the topmost layer of Hypnaceae peat, impregnated with dopplerite.

The circumstance that there is no dopplerite layer on the border between highly humified Sphagnum peat and non-ferruginous fen peat (faces B, C, D, E and J) can perhaps be ascribed, on the one hand, to the milieu in the pine stump layer here being unsuitable for precipitation, and on the other hand, to the possibility that the difference in milieu found to exist during the highly humified Sphagnum peat growth (see I I.7. and II.8., p. I45 ff.) also has a bearing on whether the humic acids are released or not.

Two ${ }^{14} \mathrm{C}$-measurements were done on the dopplerite from the transition from seepage peat to the ombrogenous peat which lies on top, a transition which can be dated at c. 3 roo BC. The seepage peat dopplerite from section EMmen I9, face $\mathrm{H}$, at $48 \mathrm{~m}$ HS (see 
fig. 48) was dated at $265^{\circ} \pm 9^{\circ} \mathrm{BC}$ or older $\left(\mathrm{GrN}-4^{802}\right)$. Because the dopplerite was soluble in alkali, it was pre-treated only with acid, so that only the minimum possible age was obtained.

Three levels from profile EMmen 3I, face O, pit $44^{2}$ (see diagram

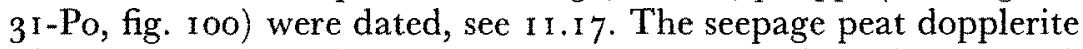
of the lowest level (transition ferruginous-non-ferruginous peat) was dated at $2290 \pm 60 \mathrm{BC}(\mathrm{GrN}-4804)$.

Since, in the one case, only the minimum possible age was obtained (EMmen 19), and in the other, the date proved to be so much more recent than was expected (contamination?) (EMmen $3 \mathrm{I})$, the ${ }^{14} \mathrm{C}$-datings can give us no insight into the origin of the material.

The development of the Sphagnum peat dopplerite layer is also linked with a desiccation, see 11.14., p. 154. This is an argument in favour of the assumption that dopplerite is humic colloids originating from higher levels which have precipitated at the transition between two types of peat.

\subsection{Drying Gracks}

These were found in large numbers throughout the whole of the ferruginous seepage peat deposits. Large concentrations are present particularly in the siderite-rich seepage peat and in faces $\mathrm{H}$ and $\mathrm{I}$.

The cracks are predominantly vertical, see fig. 9. They are Io-20 $\mathrm{cm}$ broad at the top, nearly closed at the bottom, and partly filled with dopplerite. The top-side extends to the highly humified Sphagnum peat (EMMEN 24, fig. 53) or the Menyanthes-Betula peat (faces $\mathrm{O}$ and $\mathrm{P}$, see profile EMmen 3 I, fig. 100). These cracks are not present in the highly humified Sphagnum peat. Most of the cracks come to an end in the mineral subsoil, some run right through the Late-glacial deposits (in faces F, G and J). In the horizontal plane, the cracks form the pattern of a polygonal ground. There can be no doubt that desiccation of the whole seepage peat deposit was the cause of this drying crack formation.

The phenomenon of the drying cracks was established by several authors. They all ascribe their origin to a thorough desiccation of the peat (VAN Giffen 1913 and I925, VAN Baren I927, Visscher I93 I, VAN HEUVELN 1958).

It follows from $V_{\text {AN }}$ HEUvELN's observations that the dopplerite filling must be regarded as a depositing of this peat mineral on the vertical cleavage face. Sometimes lumps of peat are present at the 

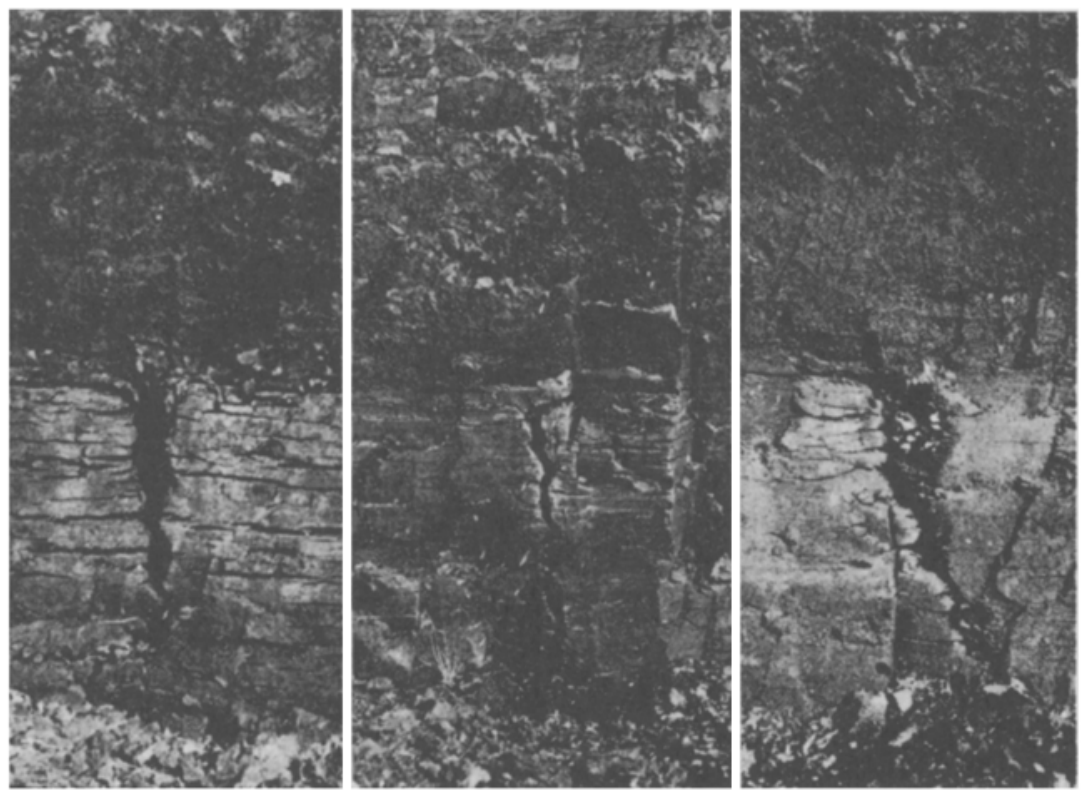

Fig. 9. 3 drying cracks in the seepage peat (face H). Photograph by C.F.D.

top of the dopplerite filling, the origin of which is not always obvious, see e.g. EMmen 24, fig. 53. It turns out that air-hollows occur at the top, even in the cracks which came to light during the peat-digging. It is not clear whether these are of primary origin, having been produced during the formation of the crack, or whether they are the result of the artificial drainage during the previous century. In any case, they form an extensive network of air-canals, through which - at least in recent times - ventilation took place in the peat. The sinking of the lowermost layer of highly humified Sphagnum peat into the crack, see fig. 53, EMMEN 24, has possibly developed only after the recent drainage.

\section{IO. DRYING GRAGKS SHOWING EROSION}

In 9.2. (p. 83), three drying cracks were described, the funnelshaped mouths of which (see fig. 54,55 and 56 ) point to the occurrence of erosion shortly after the development of the cracks. We found this type of drying crack only in peat-face $I$, between pits $277-283$. The drying cracks with erosion phenomena described 
by Van Heuveln ( 1958 ) and already mentioned in 9.6. (p. 9o) come from this area. The direction of the five cracks we observed with obviously funnel-shaped mouths and a filling of redeposited peat was approximately SW-NE (a coincidence?), although the cracks were not strictly parallel. The drying crack given in section EMmen 27 (fig. 56) comes from that part of face I, where, as has already been reported in 9.2., the top-side of the seepage peat is domed, a shape which did not develop exclusively in the last century, see also 9.13. (p. 102).

From this relief, which was already present at the time of erosion, a south-westerly direction of the eroding water flow can fairly certainly be concluded.

The erosion drying cracks are not present in face $\mathrm{H}$. This means that erosion must have affected the bog surface only over a short distance. The very limited extent of this erosion, viz. within the rectangle with the faces $\mathrm{H}$ and $\mathrm{I}$ as short sides (see the position of the peat-faces drawn in fig. 2) and the but superficial degree to which the seepage peat has been affected are indications of a strictly localized phenomenon. It is probable that the eroding water disappeared through the numerous drying cracks present in the subsoil here. The position of these erosion phenomena is given in fig. 8.

We were not able to coniirm the large layers of redeposited peat noted by Van Heuveln (1958) in connection with these drying cracks, in particular the large horizontal spread above the cracked siderite lenses (see also 9.6., p. 9o).

\section{II. THE BoUndaries OF THE SEEPAgE PEAT}

By "seepage peat" we have up till now understood ferruginous to iron-rich Hypnaceae peat which contains siderite lenses, drying cracks and dopplerite in many places. The occurrence of seepage peat could easily be established by these and a number of other accompanying characteristics, such as the red ash of the peat cutters' fires, the blue-black colour of the peat when oxidised by the air, the absence of many wood remains and the quality of the peat sods.

It appears that the seepage peat occurs in one single area of about $15 \mathrm{~km}^{2}$, which we have called the central basin of the bog, see the maps fig. Io and fig. 7. The southern extension runs almost to the cover-sand ridge which is overgrown by non-ferruginous ombrogenous Sphagnum peat. The seepage peat tapers out 200-300 
$m$ south of peat-faces $M$ and $N$, between $15.00-15.20 \mathrm{~m}+$ N.A.P., against the foot of this cover-sand ridge. We have been able to determine that the eastern limit lies between peat-faces $P$ and $Q$. Face $O$ contains ferruginous Hypnaceae peat over its entire length. The western limit has been placed in face $\mathrm{J}$, between pits $335-336$; here, between the seepage peat and the non-ferruginous peat, a Scheuchzeria peat deposit was formed which will be discussed in 9.15. (p. 104). Somewhat further north, the limit is exactly between faces $E$ and $F$. The northern limit lies about $5 \mathrm{~km}$ north of the area investigated, near the village of Nieuw Wecrdinge, see fig. Io. This northern limit could not be so precisely determined, because the Hypnaceae peat became gradually less ferruginous towards the north. For the determination of the shape of the ferruginous peat area given in fig. Io, much use was made of observations of peat-faces which will not be discussed here, and of information from the local population, as was already reported in 9.3. (p. 85). In our opinion, the lack of contact with the mineral margin of the bog, see fig. Io, clearly indicates that the ferruginous water was not transported over the surface, see also 9.4. (p. 86). The data reported by Visscher (I93I) and VAN HeuvelN (I958) concerning the occurence of iron-rich peat and siderite lenses are in good agreement with our observations.

\subsection{Seepage centres}

The mineral subsoil (fluvial sand and loam) of the ferruginous Hypnaceae peat deposits slopes down about $6 \mathrm{~m}$ over a distance of a good $8 \mathrm{~km}$ in a northerly direction; from about $15 \mathrm{~m}+$ N.A.P. (near peat-faces $M$ and $N$ ) to about $9 \mathrm{~m}+\mathrm{N}$.A.P. near the village of Nieuw Weerdinge, see also fig. Io. We may assume that the places where the ferruginous seepage water has appeared are situated in the area with ferruginous Hypnaceae peat deposits described in the preceding section. In view of the decline of the subsoil, the southern part of the ferruginous peat area particularly must be considered as a possible centre of the seepage. It is highly improbable that a seepage centre could have existed in those parts of the Hunze depression where the loam layer and the impervious Braunmoostorf deposit have been present since the Allerød (see fig. 4), or in those places where the fluvial loam deposit, which causes strong water stagnation, has sedimented. Neither can the SW-NE cover-sand ridge (fig. 6) lying just south of the seepage peat area 
be considered in this connection, since it is overgrown with highly humified Sphagnum peat, and ferruginous deposits are not present along its slope, see preceding section.

The subsoil suitable for the occurrence of seepage, viz. sand, can be found in the area investigated in the approximately $\mathrm{I} \mathrm{km}$ wide N-S zone between the Braunmoostorf and loess deposits on the western side and the fluvial loam layer on the eastern side, see fig. 5. Particularly in the immediate neighbourhood of faces $\mathrm{H}$ and I, situated in this zone, see fig. 2, we think we can support the argument for the presence of a seepage centre. The ferruginous peat occurs here, as also in faces $F, G$ and $J$, at a comparatively low level (12.6o-12.90 $\mathrm{m}+$ N.A.P.). The lowest point with ferruginous peat measured in the other peat-faces is in face $O$, pits 425,433 and $44^{1}$, at $13.4^{\circ} \mathrm{m}+$ N.A.P. A large number of strikingly large siderite lenses are present in face $I$ and the northern part of face $H$. It appears both from VIsscheR's (1931) observations and from our own investigation that the rather rare vivianite occurs almost exclusively in face I and its immediate surroundings. It may be assumed that most siderite or vivianite was formed especially in those places where the seepage water is richest in iron and phosphate compounds. The reason for the phosphate compounds forming vivianite in a much smaller area is perhaps to be found in a much smaller supply of phosphates. The mineral subsoil itself (fluvial sand) is particularly non-ferruginous, see also Ch. 5. In our opinion, the very high iron content of the seepage peat in the northern part of face $\mathrm{H}$ and in face $\mathrm{I}$, and the presence of vivianite in face I lead one to suspect the presence of a seepage centre in the immediate neighbourhood of these peat-faces.

In the eastern part of face $\mathrm{M}$, but especially in face $\mathrm{N}$, the seepage peat is particularly rich in siderite; face $N$ can actually be regarded as one large siderite lens. Instead of fluvial loam, pit 420 of face N contains running sand in which, during the investigation, strong seepage still occurred. Up till recent times, there was still a seepage flow here, at $14 \mathrm{~m}$ above N.A.P. It is here, too, that the seepage peat reaches its maximum height, $15.45 \mathrm{~m}$ above N.A.P., which is a good $30 \mathrm{~cm}$ higher than the tailing-off height against the foot of the cover-sand ridge at the south side of the seepage peat area, see also the next section. Moreover, if we leave the situation in the marginal parts (faces A and B) out of consideration, this is the highest point at which soligenous or topogenous peat occurs in the area investigated. This clearly points to an upward pressure of ground water, i.e. to a seepage centre with, as a result, larger peat 
accumulation here. The presence of a seepage centre in the neighbourhood of face $\mathrm{N}$ conflicts with the supposition given at the beginning of this section (p. 99) that no seepage centres are to be expected in the area with fiuvial loam. It is probable that the fluvial loam here was so thin that it was not proof against the upward pressure of the ground water, or perhaps the fluvial loam deposit was absent from a few places in this region; we did not observe the latter. The extra peat accumulation in the eastern part of face $\mathrm{M}$ and in face $\mathrm{N}$ is visible in the extreme eastern part of face $M$ (pits $4 \mathrm{I} I-4 \mathrm{I}$ ) as the doming of the seepage peat surface which was already mentioned in 9.3., p. 85. The eastern part of face I (pits $28 \mathrm{I}-284$ ) has a perfectly comparable doming of the seepage peat surface. We regard this as an additional argument for our assumption that a seepage centre existed near face I. It appears from 9.I4., p. I03, that there is a highly porous soil present here.

It can be concluded from the relief of the subsoil (fig. 4, contour map) and from the shape of the ferruginous Hypnaceae peat region (fig. 8), that, apart from near face I and face N, seepage water must also have arisen elsewhere. A place which must be considered particularly is the extreme southern point of the seepage peat region, where, just as is the case near face $\mathrm{N}$, the mineral subsoil lies at c. I $4 \mathrm{~m}+$ N.A.P. Since the peat has long since disappeared from here, there was no possibility for us to test for the presence of a seepage centre at that point. This southern point is situated in the N-S zone already mentioned (p. Ioo), between the Braunmoostorf and loess deposit on the western side and the fluvial loam deposit on the eastern side, see fig. 5 .

Although we were unable to collect sufficient information to prove the existence of seepage centres, we still consider it very likely that the iron-rich seepage water came to the surface at a small number of places of limited extent in the central bog area. These places are indicated as seepage centres in fig. 8. The ironrich water would have flowed from these centres especially in a northerly to north-westerly direction, see the extension of the seepage peat in fig. 10, unimpeded by a sand ridge barrier such as that which is present south of the seepage peat region, see also fig. 4, contour map.

Vivianite is not present in the siderite lenses of faces $M$ and $N$; this points to differences in the mineral composition of the seepage water. It is possible that the seepage water was transported via different courses during the Atlantic period. 


\subsection{The PEAT-Forming SURface}

Up to the northern limit of its distribution area near the village of Nieuw Weerdinge (approximately $5 \mathrm{~km}$. north of the area investigated), the seepage peat surface broadly follows the relief of the subsoil, see fig. 4 (contour map) and fig. Io (the spread of the seepage peat). Near Nieuw Weerdinge, where the mineral subsoil lies between 9 and $10 \mathrm{~m}+$ N.A.P., the average thickness of the seepage peat deposit amounts to nearly $80 \mathrm{~cm}$. This is roughly the same as in the southern part of the seepage peat area which lies more than $4 \mathrm{~m}$ higher (faces $\mathrm{K}, \mathrm{L}, \mathrm{M}, \mathrm{N}, \mathrm{O}$ and $\mathrm{P}$ ). The seepage centres discussed in the preceding section must have been present on the Hypnaceae peat surface as extra elevations which do not correspond with out-croppings of the mineral subsoil.

In faces $\mathrm{K}$ and $\mathrm{L}$ and the western $200 \mathrm{~m}$ of face $\mathrm{M}$, only a thin seepage peat deposit is present, in which, moreover, only a few siderite lenses occur. The average thickness of the deposit is about $40 \mathrm{~cm}$ here. In faces, F, G, J, O and $\mathrm{P}$ the deposit is, on average, a good $80 \mathrm{~cm}$ thick. The limited thickness of the seepage peat in faces, $\mathrm{K}, \mathrm{L}$ and the western $200 \mathrm{~m}$ of face $\mathrm{M}$ can perhaps be ascribed to the circumstance that this part of the seepage peat deposit lies exactly between the drainage courses of the two southern seepage centres which run in an approximately northerly direction (see the drainage pattern of the seepage peat area in fig. 6). This means that lateral spreading of the seepage water would have taken place to only a very limited extent (see also the overflow in face C, 9.16 , p. I06) and this would, to a significant extent, have determined the width of the seepage peat region, see fig. 8. The thick - and siderite-rich - seepage peat deposit of faces $\mathrm{O}$ and $\mathrm{P}$ might be explained by the fact that the drainage of the seepage water which came to the surface near face $\mathrm{N}$ was directed almost due north. The approximately NNW out-flow of seepage water from the southern point of the seepage peat region (see also the preceding section, p. 99), might explain the considerable seepage peat accumulation of faces $F, G$ and $J$. The almost complete absence of siderite in the comparatively thin seepage peat deposits of faces $\mathrm{K}, \mathrm{L}$ and the western $200 \mathrm{~m}$ of face $\mathrm{M}$ can possibly be ascribed to a relatively high dilution with precipitation water. We found it unnecessary to introduce a separate name for this mixed soligenousombrogenous peat.

There is no layered structuring, extending over a considerable distance in the iron-rich to ferruginous Hypnaceae-Carex peat, such 
as frequently occurs in the non-ferruginous fen-peat (charcoal layers, wood-rich layers). This might be an indication of a constant supply of seepage water, due to which desiccations did not occur. It is also possible that the Hypnaceae and Carex vegetations tolerated desiccations to a relatively large extent.

Before the desiccation of c. $3100 \mathrm{BC}$, the subsoil relief was, in general, reflected in the seepage peat surface; in addition, it is very likely that the places of the seepage centres we have suggested and the north to north-west directed seepage water drainage courses formed extra elevations on this bog surface.

\section{I4. The Desiccation of C. 3IOO BC}

No clear erosion phenomena are present in the whole complex of the seepage peat deposits. A drainage of the topsoil of the seepage peat deposit would, in view of the topography of the subsoil of the Hunze depression, have been bound to cause extensive erosion, especially in the northern part (near Nieuw Weerdinge, see fig. Io). The only erosion phenomenon we observed is the superficial damage to a few SW-NE drying cracks in face I (see 9. Io.). This erosion, however, dates from after the desiccation of c. $3100 \mathrm{BC}$. Moreover, the direction of erosion was very probably SW, since at least one of the erosion drying cracks (EMMEN 27) is in that part of face I where the seepage peat surface is clearly domed. This doming, in fact, makes a north or northeast directed water flow over the dried seepage peat surface impossible, see also fig. 8 .

In faces $F$ and $G$ a number of drying cracks penetrate to about $12 \mathrm{~m}+$ N.A.P. in the mineral subsoil. This points to a very deepseated desiccation of the seepage peat deposit, due to which the water level must have fallen to below I $2 \mathrm{~m}+$ N.A.P. On the grounds of the observations mentioned above, we think that it maybe accepted that a drainage through the subsoil to below i $2 \mathrm{~m}+$ N.A.P. occurred, and that it may be dated at c. $3100 \mathrm{BC}$ (see 9.5.2., p. 90). The cause of the drainage is probably drainage of the infiltration area, due to which iron-rich seepage water would have flowed from the central basin of the bog back in the direction of the infiltration area. VAn Heuveln (verbal communication) is able to date extensive erosion in the stream valley area between the villages of Sleen and Emmen (see fig. Io) - the area regarded as the infiltration area see also 9.4. and 9.16. - at the end of the Atlantic. The nature of this erosion points to a single, solitary emptying of a large water 
basin, which had no outlet until the time of that drainage. The base of this erosion is below $12 \mathrm{~m}+$ N.A.P.

Large concentrations of drying cracks were found, especially in faces $\mathrm{H}$ and $\mathrm{I}$, between $\mathrm{I} 3$ and $\mathrm{I} 4 \mathrm{~m}$ above N.A.P. This indicates a considerably more thorough desiccation of the peat near these peat-faces in comparison with the remainder of the seepage peat area.

The drainage of the seepage peat area could have gone largely, if not completely, via the subsoil near faces $\mathrm{H}$ and $\mathrm{I}$. The most intense desiccation of the seepage peat deposit observed was here. Moreover, the sandy subsoil in this part of the area investigated is particularly porous, see 9.12. (p. 99), see also 9.10. (p. 97).

It might be possible that the seepage peat growth near face $\mathrm{N}$, where we have also suggested a seepage centre, was able to continue for a time after the drainage of $3100 \mathrm{BC}$. Till recently there was another seepage centre present here, see 9.12, . which possibly had its water supplied by a seepage channel other than the one of the centre near face $\mathrm{I}$. In view of the ${ }^{14} \mathrm{C}$-date of pine stump group Munaut A (c. 3100-2950 BC) from the Late Atlantic pine forest found c. $100 \mathrm{~m}$ from face $\mathrm{N}$, we may conclude that forming of seepage peat near this centre too must have ended c. 3 Ioo BC (see I0.12., p. I35).

Nowhere at the top of the seepage peat did we find a weathered layer. The Hypnaceae peat probably still retained the water which was present to some extent, and the drained seepage peat was rather quickly overgrown by the ombrogenous peat. The Pinus wood layers here and there are a clear indication of the latter (see 10.12.).

\section{I5. The scheuchzeria peat gontact zone}

Between the seepage peat and the highly humified Sphagnum peat in face J, pits $33^{0}-33^{6}$, there is a zone rich in Scheuchzeria remains (fig. 8), which must have developed in the transition area between the ferruginous seepage water and the acid raised bog water; see also I 1.39., p. 203. The particular topography of the subsoil must undoubtedly have contributed to the formation of this peat deposit, which is exceptional for this peat area.

The beginning of the establishment of Scheuchzeria palustris on this massive scale can be dated, on stratigraphical grounds, between 4500 and $4000 \mathrm{BC}$, simultaneous with the Middle Atlantic pine forest, see I0.Io. and IO.II., p. I $32 \mathrm{ff}$. The transition to the highly 
humified Sphagnum peat proceeds via a thin pine stump layer. The outer tree rings $50-60$ of a stump from this layer were dated at $2410 \pm 55 \mathrm{BC}$ ( $\mathrm{GrN} 480 \mathrm{I})$. This dating is confirmed by 29 -Po (fig. 98), which shows that the topmost phase of pine growth which, stratigraphically, can be directly correlated with the stump dated, belongs to the Subboreal.

After the sudden end of the seepage, c. 310o BC, Scheuchzeria palustris peat could continue growing in this comparatively narrow zone between the iron-rich and the non-ferruginous peat area till c. $2500 \mathrm{BC}$.

\section{9.i6. Stratigraphy and deVelopment of the seepage peat}

At the beginning of the Atlantic, fen-wood developed with particularly Alnus (21-Po, fig. 90), but with Betula (see e.g. VAN Heuveln, 1958) and Quercus too, in the region of peat-faces $\mathrm{H}$ and I, on the Boreal gyttja. We found a number of trunks of fallen oak trees along peat-face $\mathrm{H}$, especially above the low sand plateaux between the east-west gulleys. This points to flooding of the fen-wood as a result of rises in the ground water. We consider the occurrence of seepage to be the cause of these rises in ground water level. It is possible that the seepage became active here when the water pressure had fallen away in the drainage gulley (the Hunze valley) during the Early Atlantic dessication (c. 5300 BC), see 8.5.2., p. 73; and 9.5.I., p. 122. The peat forming in the seepage milieu is a Hypnaceae-Carex peat, which has a notably high iron content. In the first half of the Atlantic, large parts of the section of the Hunze depression which was covered with fluvial loam (see fig. 4) and part of the non-ferruginous fen peat (see fig. 7) were overgrown by the seepage peat in a relatively short time.

The forest which existed here originally, in which particularly Alnus was frequently present, disappeared. The remains are visible as a rather thin wood-peat layer at the base of the ferruginous seepage peat in many peat faces.

The seepage water which, according to our suppositions, emerged from the subsoil in three places in the area studied - the seepage centres, see fig. 8 - was already significantly ferruginous so that the first siderite lenses developed (face $H$, pits 268-269). Yet, extensive siderite formation did not materialise in the first half of the Atlantic, which possibly points to an unsuitable milieu for this in the bog area. The seepage was so abundant that the eastern part 
of the Boreal non-ferruginous fen peat and the Early Atlantic desiccation layer were also overgrown by the ferruginous Hypnaceae-Carex peat (faces $F$ and $G$ ). We found ferruginous peat in a single area of c. $15 \mathrm{~km}^{2}$ (see fig. Io) as well as at several places in the non-ferruginous fen and fen-wood deposits. One of those places is immediately above the Early Atlantic desiccation layer above pits $16 \mathrm{I}-167$ in peat-face $\mathrm{E}$. A deposit of this kind is also present at a somewhat higher level in face $\mathrm{E}$, above pits $\mathrm{I} 74-\mathrm{I} 76$ and I 79- $18 \mathrm{r}$. Ferruginous peat occurs in face $\mathrm{B}$ above pits 38 and $49-50$, just under the Middle Atlantic pine layer, the beginning of which, c. $4500 \mathrm{BC}$, is regarded as a terminus ante quem, see 10.10., p. 132. From this it can be concluded that even from the Early Atlantic the ferruginous seepage water must several times have sought an outlet in the non-ferruginous fen peat area.

This is not in agreement with the absence of significant lateral seepage water flows mentioned in 9.13. (p. 102). We are not completely clear about the relationship between these two phenomena - the drainage of the seepage water in a north to north-westerly direction, and the occurrence of ferruginous peat in the nonferruginous fen peat. Lateral flow was perhaps occasionally possible, e.g. after shrinkage of part of the non-ferruginous fen peat deposit as a result of a localised desiccation. The origin of the "overflow" in face C, above pits 65-69, which will be discussed on p. 108 , does indicate this possibility.

These floodings are possibly the result of comparatively large variations in the seepage water supply to the central part of the bog during the first half of the Atlantic.

The seepage peat, however, contains no clear desiccation phenomena in the form of wood-rich or charcoal-containing layers such as those present in the non-ferruginous fen peat, see also $9.13 .$. This predominantly tree-less Hypnaceae-Carex peat was possibly not as susceptible to desiccation as the non-ferruginous fen peat. However, the frequent occurrence of Menyanthes remains, both seeds and leaf remains, is an indication of generally extremely moist conditions in the seepage peat area.

Obvious changes in the peat area occurred c. $4500 \mathrm{BC}$, which can, at least partly, be ascribed to changes in the bog hydrology. It has already been reported in 8.5.3. (p. 75) that, after a slight drying out, Pinus and Scheuchzeria palustris were able to establish themselves on the non-ferruginous fen peat surface, as a prelude to ombrogenous peat growth. The extensive establishment of Scheuchzeria and Sphagna points to a clear decline in the effect of the (non-ferrugin- 
ous) ground water on the peat growth (see also II.39., p. 203). At this time the siderite lenses began to develop in the ferruginous seepage peat. It can be calculated from FlorschüTz's diagram (Van Heuveln 1958, p. 43) that the peat accumulation in the seepage peat during the second half of the Atlantic was approximately as large as that in the first half. From this we may conclude that a sudden decrease in the seepage water supply cannot have occurred. Neither can the siderite forming be ascribed simply to a sudden increase in seepage. A marked increase would certainly have led to an enlargement of the seepage area, as well as, possibly, to siderite formation. Such an increase has not taken place in the area studied. The capacity of the "overflow" in face C, above pits $65-69$, see p. 108 , must be considered insufficient to have been able to drain away vast quantities of seepage water. The (at least apparently) approximately equal iron content of the peat in both this overflow and the seepage peat that formed in the seepage peat area in the first half of the Atlantic leads to the assumption that the iron content of the seepage water c. 4500 BC had, at most, changed only slightly. The ombrogenous peat growth which was starting up about this time west and south of the seepage peat area perhaps had some influence on the milieu of the peat growth in the seepage peat area.

Between the area with peat forming in an acid milieu and the seepage peat area, a narrow zone developed in which conditions led to an enormous increase of Scheuchzeria palustris, see face J, pits $33^{0}-33^{6}$ and fig. 8. The occurrence of Scheuchzeria in this contact zone can probably be ascribed sooner to mineralising of acid bog water than to a possible iron tolerance. This will be further dealt with in I 1.39. (p. 203). The relatively slight east-west width of about $100 \mathrm{~m}$, together with its not inconsiderable thickness, $70 \mathrm{~cm}$ in a shrunken condition, indicates the absence of intensive lateral water flow in this contact zone, which developed c. $45^{00} \mathrm{BC}$ or shortly afterwards, see 9.15.. The absence of a significant lateral water flow in the seepage peat area, as could be established on the basis of other phenomena, has already been mentioned in 9.13.

The conversion of iron compounds to siderite and of phosphorus compounds to vivianite, the latter only in the neighbourhood of face I, probably took place below the bog surface (see 9.6.), possibly as a result of the activity of micro-organisms. It can be concluded from the isodiametrical shape of the siderite lenses that siderite deposition continued for $1000-1500$ years (between c. $4500-3100$ $\mathrm{BC}$ ) in an apparently undisturbed milieu, see 9.6. The mainly 
north to north-west orientated water transport (see fig. 6) from the relatively small seepage centres (see fig. 8) will therefore not have had the characteristics of real streams.

The domes in the peat surface, found in face $I$, pits $28 \mathrm{I}-290$, and face $M$, pits $414-415$, are, as we said in 9.13. , the result of extra peat accumulation here, caused by an upward pressure of the ground water. In our opinion, the large number of siderite lenses in the neighbourhood of these domes, which were possibly more than $0.5 \mathrm{~m}$ high, may be correlated in both cases with the presence of a seepage centre. The siderite lenses found outside the seepage centres are almost all situated above depressions in the mineral subsoil. The lenses are not present above the elevations of the mineral subsoil in face $M$, pits $393-395,400-402$ and $407-408$, in face $O$, pits $43^{6}-440$ and $443-445$ and in face $P$, pits $455-46 \mathrm{r}$, in the ferruginous peat. They occur frequently on both sides of these elevations of the subsoil, which are, in fact, cross-sections of approximately N-S orientated sand ridges. As is obvious, the ironrich seepage water must have been drained off northwards, especially through the gullies lying between these ridges, due to which the siderite formation in general remained limited to the seepage peat existing here.

The "overflow" in face $\mathrm{C}$, above pits $65-69$, is a deposit of ferruginous, occasionally red-coloured (siderite) peat that is clearly situated on top of the non-ferruginous fen-wood peat. From observations on a few $\mathrm{N}$-S peat-faces situated east of face $\mathrm{G}$, and from information gathered on the spot, it appears that we are here concerned with the lens-shaped cross-section of a vein of iron-rich peat, the course of which could be relatively accurately established, see fig. 8. The vein could be traced in an easterly direction as far as the seepage peat area just north of the eastern end of face E. In an easterly direction it points precisely to the seepage centre we have suggested near face $I$. The vein is not present in face $B$. The ferruginous water flow would undoubtedly have been westwards; the vein must have served as an overflow for the seepage peat area, probably for the seepage centre near face I in particular. Since the vein lies on and not in the non-ferruginous fen-wood peat, and stratigraphically at the level of the Middle Atlantic pine forest, the start of this overflow can be dated at c. $4500 \mathrm{BC}$ or very shortly afterwards (see also Io.Io., p. I32). Since the upper side of the "lens" protrudes into the highly humified Sphagnum peat, the end of this ferruginous peat growth perhaps coincides with that of the seepage peat area, c. $3 \mathrm{I}$ oo $\mathrm{BC}$. 
The vein lies in face $\mathrm{C}$, just above the lowest point of the mineral subsoil in the area investigated (face $\mathrm{C}$, pit $69,11.20 \mathrm{~m}+$ N.A.P.). The vein in the N-S peat-faces lying at c. $200 \mathrm{~m}$ and $400 \mathrm{~m}$ respectively east of face $\mathrm{G}$ is also situated above depressions in the subsoil, which together form an approximately E-W gulley. It would seem likely, in our opinion, that, during the slight drying-out of the nonferruginous fen and fen-wood peat dated at c. 4500 BC (see 8.5.3., p. 75), the peat surface acquired a relief of such a nature that an overflow course for the seepage peat area could easily be created here.

It appears from 3o-Po (fig. 99) that Betula (again) increases in the topmost layers of ferruginous seepage peat. 29-Po (fig. 98) provides a similar picture. In several places the seepage peat at the top has a comparatively high wood content, e.g. face $\mathrm{H}$, pits 259-266 (Alnus and Betula), face $\mathrm{K}$, pits $378-3^{8} 4$ (Alnus and Betula), face M, pits $400-402$ (Betula); this picture is not present in faces $\mathrm{O}$ and $\mathrm{P}$ ( $3 \mathrm{I}-\mathrm{Po}$, fig. 100$)$. The milieu suitable for tree growth is comparatively localised, and in general is limited to seepage peat without siderite lenses.

Even in the seepage peat spectra of 25 - Rh/Mo (fig. 95) and $3 \mathrm{I}-\mathrm{Rh} / \mathrm{Mo}$ (fig. IoI) rhizopods (such as Amphitrema flavum) and Sphagnum leaves (S. rubellum) appear in considerable numbers. Just as with the establishment of Alnus and Betula, this can very probably be ascribed to a decreased influence of the iron-rich seepage water on the local peat growth. This can undoubtedly be very largely accounted for by the circumstance that the counter-pressure in the seepage peat area became larger as the level of peat growth rose here. The proportion of rain water in the peat water increases relatively due to this.

It is not possible to deduce the maximum height of seepage from the information available at present. In view of the situation near peat-face $\mathrm{N}$ - seepage peat up to $15.45 \mathrm{~m}+$ N.A.P. in a shrunken condition - it is not inconceivable that the highest level of seepage was between $15.50-1600 \mathrm{~m}+$ N.A.P. Since siderite lenses occur here right to the very top of the seepage peat, it may be assumed that the seepage was iron-rich right up to the end.

In the second half of the Atlantic, the seepage peat surface must have appeared as follows for a considerable time: extensive swards with predominantly Hypnaceae and Carex communities alternated with smaller, strip-shaped areas where alder and birch trees also appeared. These groups of trees were present especially above sand ridges and other elevations in the mineral subsoil. These elevations 
must have been recognisable by the relief of the bog surface which forms a more or less pronounced reflection of the subsoil relief, as well as by the groups of trees. The seepage centres were present as extra elevations on this uneven surface which slopes downwards both from east to west and also from south to north. Drainage of the seepage water went through a number of north to north-west orientated gulleys, where the peat accumulation is clearly larger than above the sand ridges and in the gulleys situated outside the seepage drainage pattern. This caused a certain levelling of the subsoil relief. The larger peat accumulation in the drainage gulleys was perhaps partly caused, as is the case with the seepage centres, by the depositing of siderite which is mainly limited to these places.

Significant water stagnation occurred in many places in the seepage area, due to which numerous pools developed; Menyanthes trifoliata found suitable habitats in these. Sphagnum cushions were present at several places on the bog surface; possibly especially at those places where the ferruginous seepage water could no longer penetrate into the bog surface, or, if it could, only in a condition strongly diluted with precipitation water. Extensive Sphagnum peat growth, however, did not materialise. As has already been observed on p. ${ }_{10} 7$, extensive Scheuchzeria vegetations (see also 9.15.) had existed since $4500 \mathrm{BC}$ on the edge of the seepage peat area and on the complex with highly humified Sphagnum peat which had developed west of it, see fig. 8 .

The desiccation of c.3 I0o BC which brought the ferruginous peat growth to an end was very intense. In most places the ombrogenous peat deposits lie directly on the seepage peat, without a transitional layer. From this can be deduced that the desiccation must have developed in a very short time. That there can be no question of surface drainage in a northerly direction in the form of a "Moorausbrauch" (bog burst) has already been argued in 9. I4.. The raised bog complex developing in the west, which will be discussed in Ch. Ir., must have made drainage in a westerly direction impossible. In view of the subsoil relief (see fig. 4, contour map), drainage in a southerly or easterly direction can also be excluded.

We have come to the conclusion (see 9.14) that the desiccation was brought about by the sudden disappearance of the seepage water supply along underground courses. We think that the seepage centre near face I and its immediate surroundings, one of the few places suitable for such a water drainage, can be taken as the centre of this drainage. The cause of the drainage was possibly the empty- 
ing of the lake in the stream valley area between the villages of Sleen and Emmen (fig. Io) as a result of erosion caused by the overflowing of the lake (VAN HeUveln, 1958). This lake had no outlet and is regarded as an area where infiltration took place.

With this overflow, the great volume of water would have had such an eroding action that parts of the mineral banks were swept away, due to which deep erosion gullies were made and the lake was drained. The drop in water level was possibly more than $4 \mathrm{~m}$, since the water level in the seepage peat area presumably fell from c. $16 \mathrm{~m}+$ N.A.P. (assumed highest seepage level, see p. Iog) to below $12 \mathrm{~m}+$ N.A.P. (lowest level at which desiccation phenomena - cracks in faces F and G - were observed). VAN HeUveln thinks that the rivulets of the Oosterstroom, the Holslootdiep and the Drostendiep can be taken as these erosion gulleys (verbal communication), see fig. Io. This figure shows, within the limits of the supposed area of infiltration (between Sleen and Emmen), in outline, the minimum area which the lake must have covered at its maximum waterlevel (cf. the $16 \mathrm{~m}$ and $17 \mathrm{~m}$ above N.A.P. contour lines of the mineral subsoil). One might imagine that a very long seepage course - in our case c. Io $\mathrm{km}$ - has a strong delaying action on processes which develop as a result of changes in pressure. The sudden nature of the desiccation might therefore be regarded as an argument against the subterranean drainage of the peat water. In this connection, however, it should be observed that, even in a short time, the seepage was able to increase greatly at the beginning of the Atlantic. (see 9.5.r.).

The highly humified Sphagnum peat complex on the western side of the central basin has scarcely reacted to this thorough desiccation, see II.7. (p. 145), and II.I5. (p. 156). The dried-up bog surface of dead Hypnaceae and Carex communities and perhaps dead Betula and Alnus too, with numerous drying cracks here and there, would not have been able to retain rain water for long. Within a short time the greater part of the precipitation would have been drained away via the drying cracks to the lowest part of the seepage peat area. The erosion described in 9.10. near faces $\mathrm{H}$ and I must have developed in this way. This slight erosion had no great influence on the further development of the peat. In spite of this drainage of the rain-water the bog surface became sufficiently moist to make Sphagnum growth possible, see I I.I., p. I38.

It is possible that after some time the drying cracks closed up again, or that the dopplerite deposits in the cracks (see 9.8.) provided sufficient blocking of the perforated peat layers. The seepage 


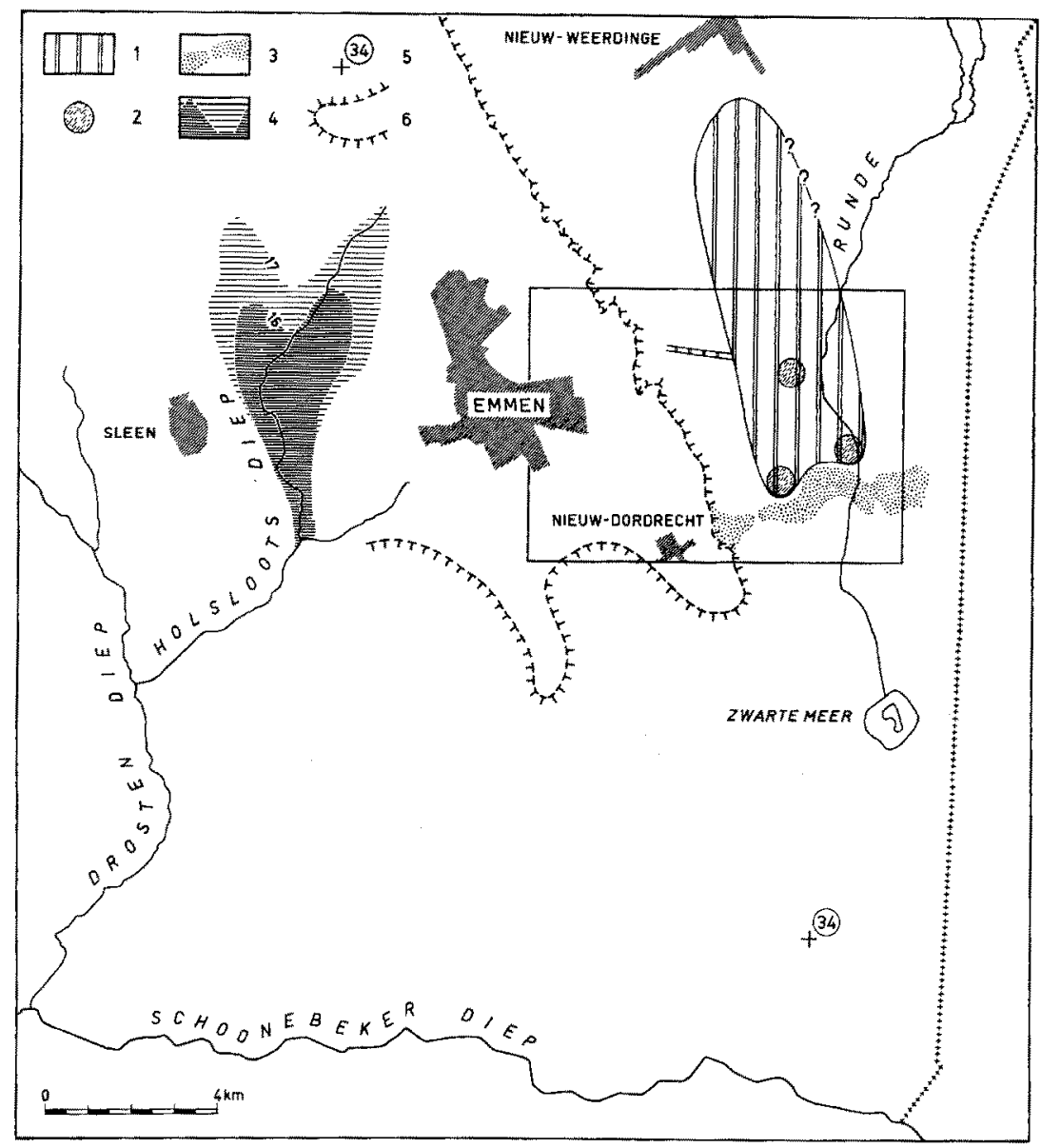

Fig. 10. Spread of the iron-rich seepage peat in the Hunze depression and the probable infiltration area. $I$ = seepage peat area (with the vein of iron-rich fen peat); $2=$ seepage centres; $3=$ east-west orientated cover-sand ridge; $4=$ the possible infiltration centres, indicated by the 16 and $17 \mathrm{~m}$ contours of the mineral subsoil between the villages of Sleen and Emmen; $5=$ position of grid section EMMEN $34 ; 6=$ margin of the bog.

had no further influence on the post-Atlantic (ombrogenous) peat growth.

The seepage peat dopplerite layer which is normally present on the sharp transition between the seepage peat and the peat lying on top of it, is absent between pits $432-434$ of peat-face $\mathrm{O}$, see 9.8 . 
The presence of a thick, very heavy fluvial loam deposit under the seepage peat and the absence of drying cracks here possibly caused some localised delay in the desiccation of c. 3100 BC. No desiccation level would have developed here, then, upon which dopplerite could later precipitats.

\subsection{The Influence OF THE DIfFerent SYSTEMS OF PEAT GROWTH ON EACH OTHER}

During almost the whole of the Atlantic, between c. $5300-3100$ $B C$, two clearly different systems of peat growth existed in the Hunze depression east of Emmen: (I) the iron-rich seepage peat described in this chapter, and (2) a non-ferruginous system in which fen and fen-wood peat (see CH. 8.) were originally formed (to c. $4500 \mathrm{BC}$ ) and which changed into highly humified Sphagnum peat via a pinestump layer (see CH. Io.). It will be obvious that the two systems continuously had a direct influence upon each other as far as the water level is concerned. We consider the presence of the coversand cross-ridge near the village of Nieuw Dordrecht in the Hunze depression to be of primary significance for keeping the two sorts of ground water (non-ferruginous drainage water and seepage water) apart. In spite of the fact that they were in contact over a distance of about $6 \mathrm{~km}$ on the western side of the seepage peat area, scarcely any mixing occurred here. In fact, only the contact zone in face J, see 9. I 5., can be regarded as the result of mixing. Iron-rich seepage water did flow several times to comparatively deep in the non-ferruginous area. The clearest example of this is the overflow in face C, pits $65-69$, which was described on p. 108 . The opposite also possibly occurred. It will be clear that this cannot be confirmed.

\section{CHAPTER IO.: PINUS STUMP LAYERS}

\section{IO.I. INTRODUCTION}

Stumps of Pinus sylvestris L. occur on several levels in this peat area, usually in layers, see e.g. 8.5.2., 8.5.3. (p. 73 ff.) and Ir.39. (p. 203). Near the margin of the bog Pinus formed a comparatively thick deposit of wood peat (peat-faces A, B and D). In this chapter, the investigation both of stumps (p. I I5) and of different 
stump layers (p. 128) will be under discussion. The discussion is based mainly on information which was obtained from:

- peat-faces $A-Q$,

- spectra I 4 and 15 from the diagram I0-Po (fig. 73), which was dealt with in 4.2 . (p. 47 ),

- spectra $31-5^{0}$ from the diagram 3 -Po (fig. 66), which was discussed in $4 \cdot 4$. (p. 49),

- the Atlantic part of the ${ }^{14} \mathrm{C}$-diagram and of the profile $\mathrm{EM}$ MERERFSCHEIDENVEEN I (fig. $6_{3}$ ), which was discussed in 4.3 . (p. 48 ),

- spectra 5-ro from the diagram 1-Po (fig. 64), which was discussed in 8.2., (p. 7I),

- spectra 7-ro from i I-Po (fig. 74),6-8 from I I-Rh (fig. 75) and $5-9$ from $13-\mathrm{Rh}$ (fig. 75); EMmen I (face $\mathrm{C}$, between pits 68 and 69 ) and Emmen 13 (face $\mathrm{C}$, pit 64) are discussed in I I.3. and $\mathrm{I}$ I.4. (p. I4I),

- spectra 5-I I from I 7A-Po (fig. 79), 5-7 from I $7 \mathrm{~A}-\mathrm{Po} / \mathrm{bog}$ plants (fig. $8_{3}$ ) and 7 from I7A-Rh/Mo (fig. 84), from section EMMEN I 7, from peat-face E, between pits I 7 and 172 , which will be discussed in 11.26 . (p. I $74 \mathrm{ff}$.),

- spectrum I from 33B-Rh (fig. I02); the position of section EMmEN 33, which will be discussed in 11.5 . (p. 143), is indicated in fig. 2,

- section Emmen 19 (fig. 48), in particular $19 \mathrm{C}$ (fig. 49) and spectra 2-4 from I9B-Rh/Mo (fig. 89); EMMEN I9 from peatface $H$, above pits $263-268$, will be discussed in I I. 4 I. (p. 209 ff.),

- sections EMMEN 24 (fig. 53) and EMMEN 25 (fig. 54) and spectra 3 from 24 A-Po (fig. 93), I-4 from $24 \mathrm{~A}-\mathrm{Rh} / \mathrm{Mo}$ (fig. 94), I-4 from $24 \mathrm{~B}-\mathrm{Rh} / \mathrm{Mo}$ (fig. 94) and $2-6$ from $25-\mathrm{Rh} / \mathrm{Mo}$ (fig. 95); the seepage peat part of EMMEN 24 and EMmen 25, from peatface $I$, above pits $279-280$ was discussed in 9.2 . (p. 83 ); the ombrogenous peat of these sections is discussed in 11.42 . and I 1.43. (p. 2 I $3 \mathrm{ff}$.),

- section EMMEN 14 originating from peat-block $\mathrm{C}$, which will be discussed in I0.3. (p. I I 7 ff.); see also figs. $7^{6}$ and 77 ,

- section EMmen 4, from peat-block B, which will be discussed in I0.4. (p. I2 I and fig. 68),

- diagram 29-Po (fig. 98), originating from peat-block $\mathrm{J}$, pit 328 , to be discussed in 10.7 . (p. 130); the lowest part of 29-Po was already under discussion in $9.1 .($ p. 81 ),

- diagram 30-Po (fig. 99), originating from peat-face $M$, pit 


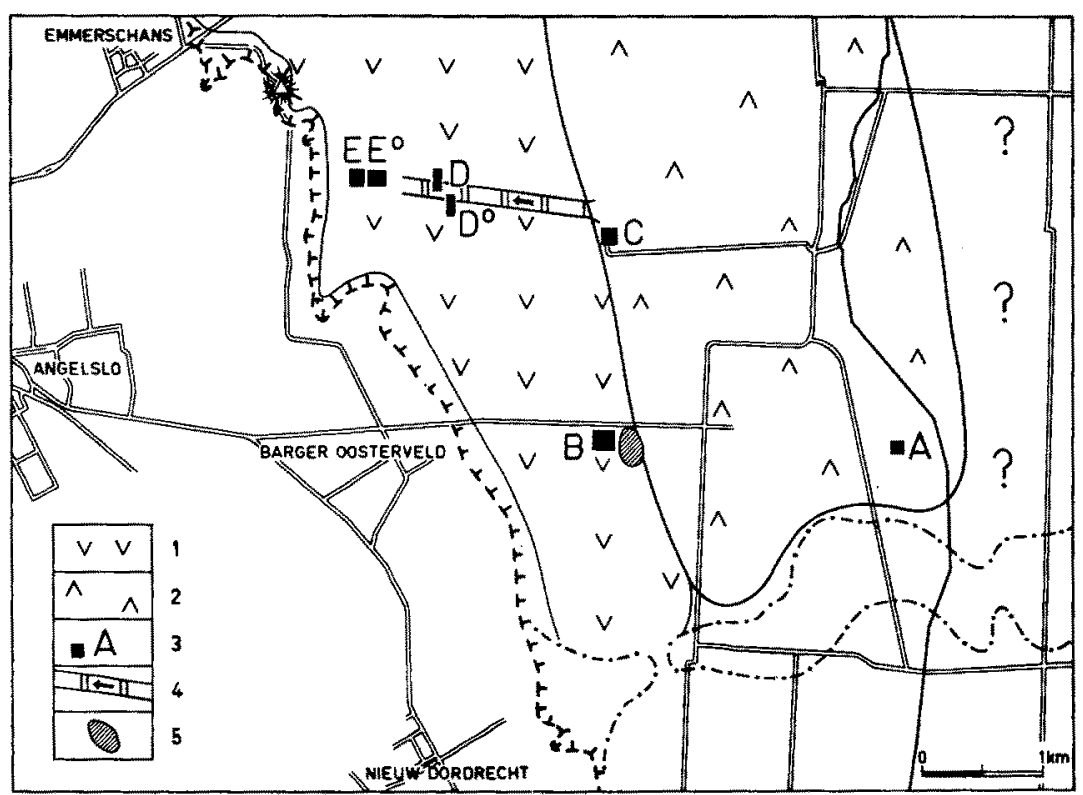

Fig. Ir. Areas with Pinus forests on the transition to ombrogenous peat: $1=$ middle Atlantic Pinús forest, $4500-4000$ B.C.; $2=$ area of the late-Atlantic Pinus forest, $3100-295^{\circ}$ B.C.; 3 = sampling spots for the dendrochronological investigation; $4=$ vein with iron-rich (fen) peat in the middle Atlantic Pinus forest; $5=$ Scheuchzeria peat contact zone, from $4500-4000$ to 2500 B.C.

407 (p. I 31 ), to be discussed in 10.8.; the lowest part of $30-\mathrm{Po}$ was already discussed in $9 . \mathrm{I}$. (p. $8 \mathrm{I}$ ),

- the tree ring investigation of pine stumps from our investigation area carried out by Dr. A. V. Munaut, Laboratoire de Dendrochronologie, Heverlee/Louvain (Belgium) (Munaut and CAsPARIE, I97I); the results of this investigation will be further discussed in 10.5 . (p. I $22 \mathrm{ff}$ ), see also figs. I I and 105-109.

\section{IO.2. INVESTIGATION OF STUMPS}

The frequently encountered cone-shaped tops of stumps indicate a smothering of trees by the upward growth of the peat. The cone shape is not generally present in large stumps. This is undoubtedly linked with a smaller accumulation of peat due to which the pine trees were able to grow longer, but the rotting process could penetrate deeper into the wood after the trees had died off. 
The outermost annual rings of much larger stumps are missing because of this, and only a very short part of the trunk remains.

Nearly all the stumps have plank-shaped roots; only rarely is anything resembling a vertical pen root present. In many cases more or less obvious multi-level roots occur, see fig. I 2. In the clearest cases the roots of the lowest level are approximately horizontally directed, and those of the higher levels diagonally upwards. The root ends often point upwards slightly more. These characteristics are usually less clearly present in the case of the large stumps.

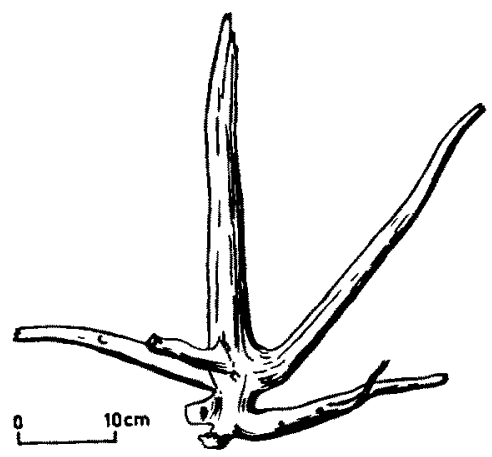

Fig. 12. Pine stump from the group of stumps, Munaut $A$ (see fig. I1), with multilevel roots. The lower level has approximately horizontal plank-shaped roots; the higher levels usually have upward sloping roots.

The growth was considerably more regular with these large stumps, see I0.5. (p. 122). Together, the plank-shaped roots formed a kind of supporting platform, which was often of considerable dimensions, especially in large stumps. The plank form developed, as appears from a large number of root cross-sections, by wood-formation taking place especially on the top side of the roots. This is undoubtedly connected with poor aeration of the peat soil. Many stumps have a so-called sickle shape. This is a curving of the lowest part of the trunk, which developed due to geotropical corrections during the growth of the trees on very soft soil. This remarkable shape is limited mainly to stumps of c. 5- $15 \mathrm{~cm}$ diameter. We consider the absence of the sickle shape in larger stumps to be a question of habitat; Pinus could grow to a considerable size, see io.3., only on the somewhat drier, firmer places. Only rarely did the fallen trees which are found here and there appear to possess fine, straight trunks. Instances of deformation were mostly present as double tops, bumps, twists, horizontal sections of trunks, etc. (German: Krüppelföhre). The trees had nearly always developed a great 
number of branches, usually even at a very low level. It is not known if the trees which had become very large also had such characteristics. Those stood in such firm soil that toppling would probably seldom have occurred. With badly growing trees, the effect of the wind and possibly also of the sun on the wood formation is clearly observable (see 10.4., p. I21).

10.3. Emmen I4 (figs. $7^{6}$ and 77 ), peat-block C, above pits $52-9^{8}$.

\subsection{Introduction}

Stumps of widely varying dimensions occur in the pine-stump layer which covers the non-ferruginous fen-wood peat (Middle Atlantic Pinus forest, peat-faces A, B, C, D, E and J, see also 8.5.3., p. 75). The large stumps, i.e. those with a diameter of more than $20 \mathrm{~cm}$, are mainly found in groups in the peat. Tremendously large stumps are often present near the edge of the bog. According to peat-cutters, the appearance of large stumps is mostly linked with elevations of the sandy subsoil (without there being any question of roots extending into the subsoil). In this section we investigated if there is indeed a relationship between stump-thicknesses and the relief of the mineral subsoil. Pinus and Scheuchzeria palustris L. regularly occur together in layers, see also 11.39., p. 203. In this section, therefore, attention was also paid to the presence of Scheuchzeria in the peat in which the stumps investigated were found.

\subsubsection{Investigation}

The diameter of the trunk just above the roots was measured of all the stumps which came to light during the peat digging season in 1962 of a $4 \mathrm{~m}$ broad peat-block from peat-face $\mathrm{C}$. The result of these measurements has been set out in fig. 76 in diagram form: the stem thickness in centimetres along the $x$-axis, and the numbers along the $y$-axis. The total number of stumps measured amounted to 3777 . The stump thickness varied from $2-65 \mathrm{~cm}$. The measurements were made in 56 sections of $20 \mathrm{~m}$ length along the II $20 \mathrm{~m}$ long peat-face. From the position in the field in which the stump was found after the peat-digging, the original position of the tree in the peat can be approximately deduced, for peat cutters throw any stumps they find in the peat away, in a direction at right angles to the peat-face. It will therefore be clear that the original level at which the tree grew cannot be determined; the stumps which came from the highly humified Sphagnum peat of face C, above pits 52-54, 
were also measured in this way, since they could not be distinguished with any certainty from those from the Middle Atlantic pine forest. This will be gone into further in 10.3 .3 .

From the information collected, the composition of the forest per section with a length of $20 \mathrm{~m}$ and a width of $4 \mathrm{~m}$ (= the width of the peat block which was dug out) and the average stump thickness per section were calculated. The average stump thickness for all the 3777 stumps was $10 \mathrm{~cm}$. The results of the calculations are produced in fig. 77 . The $5^{6}$ sections with a length of $20 \mathrm{~m}$ (total i I 20 $\mathrm{m}=$ the length of face $\mathrm{C}$ ) were set out at the top and bottom of the figure. The composition of the forest per section is given in the block diagram I. Above the O-line are the symbols for stump thicknesses which are more than $10 \mathrm{~cm}$. Below the O-line are the stump thicknesses of $\mathrm{I}-5$ and $6-\mathrm{IO} \mathrm{cm}$.

The average thickness per section is set out in curve II; the horizontal dotted line indicates the average diameter of the total, viz. I $\mathrm{cm}$. The horizontal scale of I and II was chosen in such a way that the place of each section corresponds with its position with respect to the mineral subsoil of peat-block $\mathrm{C}$, which was given in IV.

The occurrence of Scheuchzeria in the Middle Atlantic stump layer was given in III, on the horizontal line. Above this line the occurrence of Pinus and Scheuchzeria in the highly humified Sphagnum peat was indicated, and under this line the occurrence of pine stumps in the non-ferruginous fen-wood peat, as found when peat-face $\mathrm{C}$ was drawn in. It appears from III that the results of the sections $\mathrm{I}-8$, I 2 and $43-45$, in particular, have been influenced by the presence of stumps from layers other than the pine stump layer at the transition from non-ferruginous fen-wood peat to highly humified Sphagnum peat.

The Scheuchzeria deposit of the sections $31-35$ lies above the vein with iron-rich peat (the "overflow", see 9.16., p. I05) of face C (pits $65-69$ ). The stumps present in this deposit do not therefore all belong to the Middle Atlantic pine forest (from c. 4500-4000 $\mathrm{BC}$, see I0.ro., p. 132 , and 8.5 .3$, p. 75), since this overflow of the seepage peat area was possibly overgrown only after $3100 \mathrm{BC}$, see 9.16., p. r05. This phenomenon too may have had an adverse effect on the results.

I0.3.3. Conclusions

a. Stump thicknesses and age

It appears from fig. $7^{6}$ that the majority of the stumps has a 
thickness of less than $20 \mathrm{~cm}$. The obvious under-representation of stumps with a diameter of less than $5 \mathrm{~cm}$ has two reasons. Firstly, very small stumps could still be worked into peat sods; secondly, it is very difficult to differentiate between small stumps and roots.

The distribution of the stumps in 3 thickness groups is given in table VI. In brackets we show the approximate range of ages per thickness group, as this appeared from a number of tree-ring counts. With thick stumps, however, it appeared that it was a question not only of a longer life, but of the tree-rings often being thicker, which points to differences in the bog milieu during the pine forest phase.

Table VI

EMMEN 14, stump thicknesses

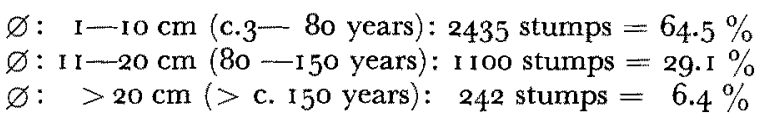

It follows from the graph of fig. 76 that the percentage of stumps with a diameter of less than $10 \mathrm{~cm}$ must have been considerably larger than is indicated by table VI. Only a few percent of the trees reached a thickmess of $20 \mathrm{~cm}$ or more, which corresponds with an age of more than 150 years. Almost two-thirds of the trees we measured did not even reach the age of eighty. Of these two-thirds, nearly $60 \%$ have a trunk diameter of $\mathrm{I}-5 \mathrm{~cm}$, showing that the trees had not even reached the age of fifty. If we had been able to include all the very small pine stumps of peat-block $\mathrm{C}$ in this investigation it would have become clear that the percentage of trees which had died within fifty years of germination is not $50 \%$, but must be considerably higher.

b. The forest density

It appears from the graph of fig. 76 that a regular rejuvenation of the forest occurred. The majority of the trees did not even reach the age of eighty (see above), whereas the period of the Middle Atlantic pine forest covered at least $25^{\circ}$ years, see stump group Munaut D, in fig. Io9, see Io.ro., p. 132. A calculation of the space occupied per tree, therefore, is meaningless. What is clear is that the density of the forest, in spite of the large numbers of stumps. found, could not have been high.

c. The pine forest

The very thick stumps $(\varnothing>20 \mathrm{~cm})$ are not uniformly distributed throughout the peat-face. They are found particularly in sections 
2-3, I I-I 9 and 38-49 (fig. 77, block diagram I). The occurrence of these stumps is, in general, accompanied by minimum numbers (e.g. section I6 with I 7 stumps, compared with section 30 with 108 stumps); particularly of very small stumps. In sections 2 and 3 , large numbers of small stumps are also present (section 3, total number of stumps: I81), along with very thick stumps. These two sections are part of the section with many small stumps, consisting of sections $\mathbf{I}-9$. A very high proportion of these stumps must have originated, as can also be deduced from fig. 77, III, from the PinusScheuchzeria layer in the highly humified Sphagnum peat. We found only small stumps (up to c. $7 \mathrm{~cm}$ diameter) in this layer. A similar, if less clear-cut, situation exists in section 12. All these predominantly small stumps undoubtedly have influenced the average stump thickness which is given in fig. 77 , II.

Most of the sections with an average stump thickness of more than $10 \mathrm{~cm}$ are situated together in two groups: sections I I-2 I and 3848 (curve II). These two maxima correspond with two elevations in the sandy subsoil (fig. 77, IV). These elevations are emphasised in the figure by the horizontal dotted line drawn in IV. It is to be noted that the level of this line has no significance whatsoever except to emphasise the elevations of the subsoil.

As has already been stated above, the sandy elevations of sections $\mathrm{I}-7$ does not accompany an increase in the average stump thickness; the presence of the many small stumps in the highly humified Sphagnum peat is noticeable here (fig. 77, I and III). The occurrence of Scheuchzeria palustris at the transition between the non-ferruginous fen-wood peat and the highly humified Sphagnum peat (fig. 77, III) is restricted to places just above depressions in the sandy subsoil. Where Scheuchzeria occurs, the average Pinus stump thickness is less than $10 \mathrm{~cm}$.

The phenomena can be explained by assuming the existence of a wet-dry mosaic on the surface of the fen-wood peat at the time of the establishment of Pinus and Scheuchzeria (c. 450o BC, see Io. Io., p. 132. and fig. Iog, stump group Munaut D). Pinus could attain a good development in the drier places; in the wetter places Scheuchzeria could also establish itself; these places might then have been so moist that the growth of Pinus was serious hampered. The drier places correspond with elevations in the sand, the wetter places with depressions in the mineral subsoil. This points to a relief in the fenwood peat surface at c. $45^{\circ} \mathrm{BC}$ in which was reflected the subsoil relief. Such a fen-wood peat surface can only be explained by shrinkage of the peat deposits as the result of a drying out. 
After this probably slight drying-out (precipitation) water would have collected in the lower parts, and in this Scheuchzeria was able to develop well, see I I.39., p. 203. The higher places remained drier for a comparatively long time, and due to this Pinus found a good habitat here.

The relationship, already known to the peat-diggers, between the stump thickness of Pinus and the relief of the mineral subsoil does indeed appear to exist, as fig. 77 demonstrates clearly. A slight drying-out of the fen-wood peat deposit can be regarded as the cause of this phenomenon.

\section{I0.4. EMmen 4 (fig. 68), peat-block B, above pits $3^{\mathrm{I}}-35$}

For 105 stumps from the thick Pinus-Scheuchzeria deposits of peatface B, lying on top of the highly humified Sphagnum peat, it was established on which side of the trunk wood-forming had mainly occurred. The purpose of this was to check if it was possible to prove that external factors had influenced the forming of the wood. After the cone-shaped, rotten top had been sawn off, the direction of the shortest distance between the heart of the tree and the approximately circular circumference of the trunk (i.e. the side with least wood formation) was determined with a compass. The heart of the 5-io $\mathrm{cm}$ thick stumps (up to about 6o years old) could be clearly determined in all cases. The results are produced in fig. 68, EMmEN 4. The measurements were sub-divided into Io groups. The column on the extreme left indicated what the situation was with the trunks which were found in a horizontal position. The adjacent column gives the number of times that the heart was in the centre (no orientation). Next, the information about trunks with eccentricallypositioned hearts is produced, sub-divided into 8 groups, 8 points of the compass, from N, via NE, round to NW. Under the diagram, by means of schematic trunk cross-sections, the position of the heart in the trunk has been indicated by a black dot. The stump layer was not dated. On stratigraphical grounds it can be assumed that the layer must have been formed between c. $2000-1500 \mathrm{BC}$.

The heart is in the centre in 27 trunks. With the horizontal trunks we are dealing with trees which had already toppled during their lifetime. The toppling would mostly have been a very gradual process in the course of which the well-known sickle-shaped trunk developed. It appeared that the underside of these fallen trunks had the most wood formation. With sickle-shaped stumps (not 
reported as such in the graph) it could be established that the outer side of the sickle was the side with the most wood-formation. Both with these and with the fallen trunks, this was probably a manifestation of the same phenomenon, viz. movement of the centre of gravity in one direction, due to which gradual toppling took place. This movement of the centre of gravity was possibly the result of irregular branch formation.

With the stumps with an eccentrically positioned heart, an obvious orientation of the side with most wood forming appeared. The smallest increase in the thickness of the trunks is situated mainly on the south-west side. It is natural to ascribe this to the effect of sun and wind (external influences). It is possible that the influence of the wind was more important than that of insolation, since the side with least wood forming lay more to the west and north-west side than to the south. Perhaps irregular branch formation was also a factor here, in the sense that the western side of the trees had fewer or smaller branches, due to which less wood forming took place on this side.

\section{I0.5. DENDROCHRONOLOGY}

\subsection{Introduction}

It can be shown from 10.3. (Emmen I4) that Pinus established itself probably more or less simultaneously on large parts of the non-ferruginous fen and fen-wood bog surface.

The purpose of MunAuT's dendrochronological investigation was, on the one hand, to try to confirm the conclusion drawn from EMMEN 14, and, on the other, to obtain an insight into the type of forest, the duration of the Pinus forest, and the possible spreadingout of the forest over the seepage peat. With regard to this last point, it may be remarked that the dendrochronological investigation was carried out before there was any clear idea of the seepage peat formation. We refer to Munaut i 966 and 1969 for the method of the dendrochronological investigation. After the peat-digging in May, I963, at five different places in the area investigated, a total of $25^{6}$ pine stumps was collected, divided into Io groups, see fig. I I and table VII.

Partly as a result of the bad state of preservation of many of the stumps, but especially because of the irregular growth of the trees (see e.g. the preceding section), many of MúnAuT's curves could not be synchronised with one or more other curves. Munaut, however, did manage to synchronise a few curves per stump group 
TABLE VII

Groups of sampled stumps from the Emmen area

\begin{tabular}{|c|c|c|c|}
\hline Site & Characteristics of the site & group of stumps & $\begin{array}{l}\text { number } \\
\text { of stumps }\end{array}$ \\
\hline $\mathrm{A}$ & $\begin{array}{l}\text { in the central basin of the bog; on the fer- } \\
\text { ruginous seepage peat; near face } M \text {, pits } \\
405-410 .\end{array}$ & $\begin{array}{l}\text { Munaut A } \\
\text { Munaut } A^{0} \\
\text { Munaut } A^{00}\end{array}$ & $\begin{array}{r}19 \\
1 \\
2\end{array}$ \\
\hline B & $\begin{array}{l}\text { near the eastern boundary of the non-fer- } \\
\text { ruginous fen-wood peat area on which Pinus } \\
\text { formed an unbroken forest; near face J, pits } \\
322-333 \text {. }\end{array}$ & $\begin{array}{l}\text { Munaut B } \\
\text { Munaut } \mathbf{B}^{0}\end{array}$ & $\begin{array}{l}59 \\
12\end{array}$ \\
\hline C. & $\begin{array}{l}\text { on the eastern border of the non-ferruginous } \\
\text { fen-wood peat area and the western border } \\
\text { of the seepage, peat area; between faces } E \\
\text { and } F \text {. }\end{array}$ & Munaut $\mathrm{C}$ & 80 \\
\hline $\mathrm{D}$ & $\begin{array}{l}\text { in the middle of the non-ferruginous peat } \\
\text { area, about } 800 \mathrm{~m} \text { from the western margin } \\
\text { of the bog; near face } \mathrm{C} \text {, pits } 56-60 \text { and } \\
7^{2}-89 \text {. }\end{array}$ & $\begin{array}{l}\text { Munaut D } \\
\text { Munaut } \mathbf{D}^{0}\end{array}$ & $\begin{array}{l}32 \\
18\end{array}$ \\
\hline $\mathrm{E}$ & $\begin{array}{l}\text { near the western edge of the non-ferrugin- } \\
\text { ous fen-wood peat area, } 400-600 \mathrm{~m} \text { from } \\
\text { the western margin of the bog; near face } \mathrm{B} \text {, } \\
\text { pits } 3^{0-}-35 \text { and } 3^{8-}-44 .\end{array}$ & $\begin{array}{l}\text { Munaut } \mathrm{E} \\
\text { Munaut } \mathbf{E}^{0}\end{array}$ & $\begin{array}{l}16 \\
17\end{array}$ \\
\hline & & Total & 256 \\
\hline
\end{tabular}

with each other, with the exception of groups $\mathrm{A}^{0}, \mathrm{~A}^{00}$ and $\mathrm{B}^{0}$. Moreover, it turned out that groups $\mathrm{D}, \mathrm{E}$ and $\mathrm{E}^{0}$ could be synchronised with each other. He was able to set up 5 groups, each with a floating chronology: Munaut A, Munaut B, Munaut C, Munaut $\mathrm{D}^{0}$ and Munaut D E $\mathrm{E}^{0}$. By radiocarbon dating of one or more samples per floating chronology, 3 pine forest phases could be deduced which all appeared to date from the Atlantic period, viz. an Early Atlantic, a Middle Atlantic and a Late Atlantic forest phase. In figs. 105-I09, the results of the dendrochronological investigation with the ${ }^{14} \mathrm{C}$-dates are given. All the ${ }^{14} \mathrm{C}$-dates for these pine stumps are reported in table VIII.

In figs. 105-109, the chronological relationships between the groups of the synchronised trees are shown as horizontal black bands $\left(\mathrm{D}^{0}{ }_{2}, \mathrm{D}^{0} \mathrm{I}, \mathrm{E}_{3}\right.$ etc.) (black: synchronised part of the trees). The curve of the average thickness of the tree-rings is also shown for each group (see also Munaut 1969). In the floating chronology (placed under the group curve) we have taken as the first year of 
each chronology the first tree-ring of the oldest tree, although this ist not the usual practice in denchronology. Using the ${ }^{14} \mathrm{C}$-dates, it was possible to date the different pine forest phases approximately, see the dates in italics on the left and right-hand sides under the floating chronologies in figs. 105-rog. Three trees $\left(\mathrm{C}_{9}, \mathrm{C}_{2}\right.$ and $\left.\mathrm{C}_{4}\right)$ in group Munaut $\mathrm{C}$ (fig. 107) have been indicated as shaded columns. The correlation of these three trees with the remainder of MunauT $\mathrm{C}$ was dubious.

\section{I0.5.2. Munaut $A$ (figs. II and 105)}

The trees were relatively fast growing (tree-ring thickness averages more than $\mathrm{I} \mathrm{mm}$ ). In general they were not old (maximum 83 years: $\mathrm{A}_{4}$ ). Growth was very irregular, particularly between the years 50-I12. This points to strong fluctuations in the milieu, probably in the water content of the peat in particular, in which the trees were rooted. In the stumps of this group in particular, fine multi-level roots occurred, see fig. 12.

The stump group is too small to yield information about rejuvenation of the forest. In the pine stump layer from which group Munaut A originated (face $M$, between pits 405 and 410 ), only one stump level was present, see also 3o-Po, fig. 99. The establishment of Pinus on the desiccated seepage peat was probably, therefore, possible during a relatively short period of time. It can be deduced from fig. I05 that this was presumably only a few decades (between I-40 of the floating chronology). The process by which the pine forest was overgrown was also one lasting a few decades (between 70-112 of the floating chronology). It can be deduced from the often more than $60 \mathrm{~cm}$ long parts of the trunks which were preserved that this overgrowing was a comparatively rapid process. This establishment of pine trees on seepage peat can be roughly dated between 3100 and $295^{\circ} \mathrm{BC}$. This date holds in all probability also for all the other establishments of pine trees on the surface of the desiccated seepage peat. Although no unbroken forest existed, we have still regarded this forest phase as one forest, the Late Atlantic pine forest, see also 10.I2., p. 135.

\section{I0.5.3. Munaut $B$ (figs. II and 106)}

The average tree-ring thickness is, especially in the years $I-80$, clearly more than I mm, which points to a relatively rapid growth. The lifetime of the trees is here somewhat longer than in Munaut A (maximum rog years: $B_{2}$ ). The establishment of the trees extends over a period of $c$. 60 years, the period of decline over about 75 
years. Both values are clearly higher than was found in Munaut A. From this can be concluded, be it with due reservation, that the (here non-ferruginuos fen-) peat surface remained suitable for pine growth longer than was the case in the situation of Munaut A (seepage peat surface).

Two noticeable minima are present in the curve, viz. in the years 48 and 6 I of the floating chronology. It is clear, particularly from the first, that these must have been caused by a deterioration in the growth conditions in the preceding twenty years. This would have been mainly a question of increasing water content of the bog sur-

TABLE VIII

${ }^{11} \mathrm{C}$-dates of the Munaut stumps

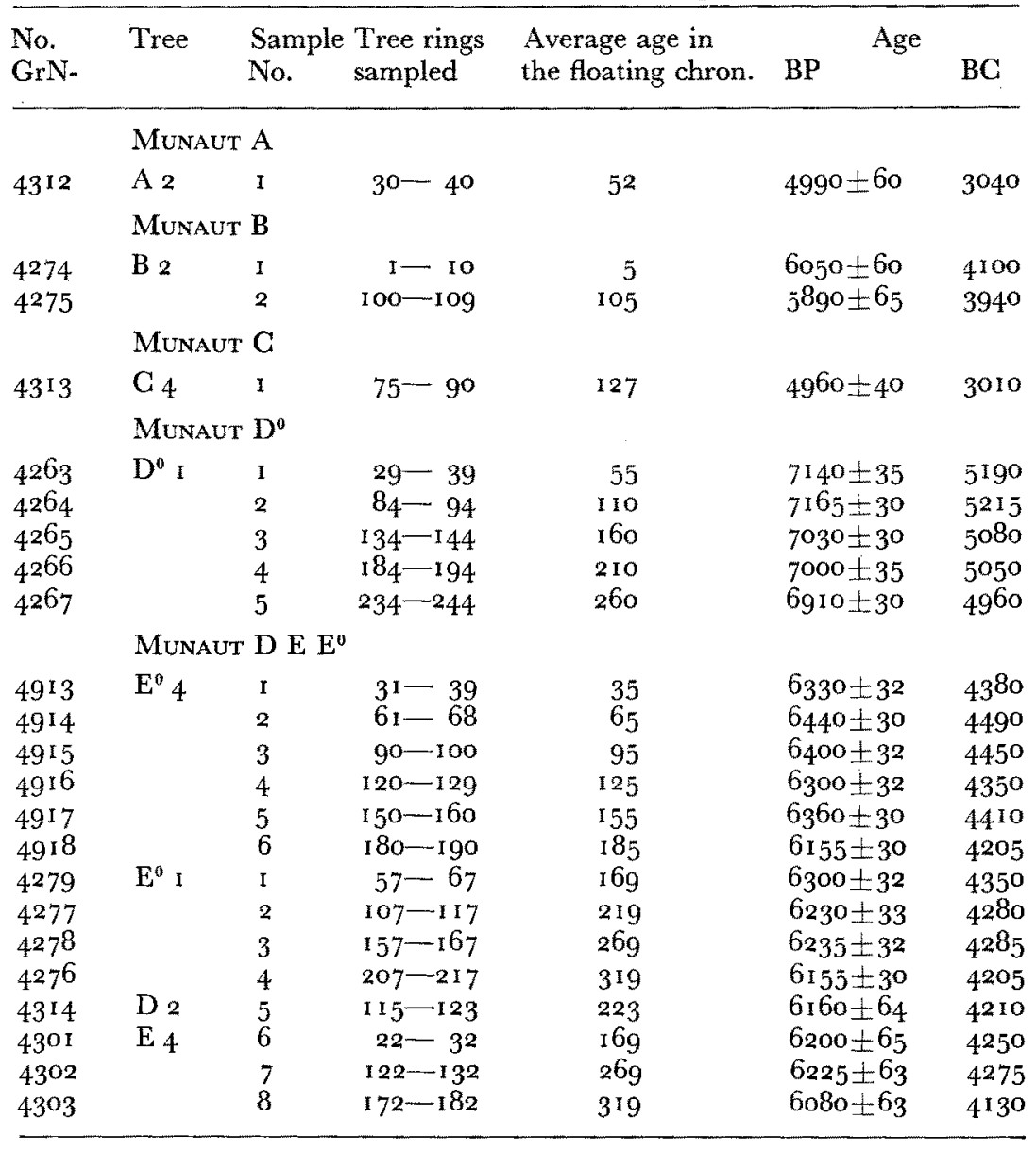


face. Growth was relatively regular between the years of $64-128$. This Pinus establishment can be roughly dated between $4 \mathrm{I} 00-385^{\circ}$ BC. This is somewhat younger than stump group Munaut D E $\mathbf{E}^{0}$. We are, however, of the opinion, especially on stratigraphical grounds, that we are here concerned with one and the same pine forest, the Middle Atlantic pine forest, see also Munaut DE E ${ }^{0}$, p. I27. In 29-Po (fig. 98, see also p. I30), three stump levels are present in the profile EMMEN 29, face J, pit 328, sampled here. It is clear that the stumps investigated by Munaut came from the lowest level.

\subsubsection{Munaut $C$ (figs. II and 107).}

The average tree-ring thickness is here more than $\mathrm{I} \mathrm{mm}$, too. As is also the case in Munaut A, the synchronised trees of this group did not grow very old (maximum age: 105 years: C9). Half of the total of twelve trees measured in this group reached an age of between 100 and 150 years. This group shows a rather close similarity with Munaut A. Here, too, the bog surface was suitable for presumably a comparatively short time for the establishment of Pinus, viz. between the years $\mathrm{I}-30$ of the floating chronology. The period during which most of the trees died, between the years $98-116$, is strikingly short. In all probability, this indicates a very rapid deterioration of the growth circumstances. The stumps of this group had, as did those of Munaut A too, a particularly long trunk. One might think that we are here dealing with two groups of stumps, and that the trees indicated by black bands derive from a layer different from that of the trees $\mathrm{C}_{9}, \mathrm{C}_{2}$ and $\mathrm{C}_{4}$, see fig. 107 .

From the long part of the trunk which was preserved, the clear multi-level root system and the irregular growth (see also the average curve of fig. 107), it can, however, be concluded that the trees $\mathrm{C}_{7}, \mathrm{C}_{1}, \mathrm{C}_{5}$ and $\mathrm{C}_{3}$ probably do not originate from an older (i.e. Middle Atlantic) layer. Nowhere in the ombrogenous peat did we find stumps which were older than about 60 years. We are therefore fairly certain that the stumps which were not ${ }^{14} \mathrm{C}$-dated belonged to the same forest phase as the dated group. This Pinus establishment must therefore be synchronous with Munaut A (c. 3100-2950 BC). It belongs to the Late Atlantic pine forest.

\section{I0.5.5. Munaut $D^{0}$ (figs. I I and I08)}

In this group the average tree-ring thickness is less than $\mathrm{Imm}$. Two of the three synchronised trees reached a great age: $\mathrm{D}^{0}{ }_{1}$ was 309 years old and $\mathrm{D}_{2}{ }_{2}$ at least 294 . The growth in the years $124-210$ 
of the floating chronology was remarkably regular. In this section - with an average tree-ring thickness of more than $\mathrm{I} \mathrm{mm}$ ! characteristic years are missing ( $\mathrm{M}$ and $\mathrm{m}$ ). These features might point to the absence from the milieu during that period of important changes which would have been unfavourable for Pinus growth. In view of the narrow spread of the birth years of the three synchronised trees, the bog surface must have become suitable for Pinus establishment within possibly a relatively short time.

The forest period lasted at least $33^{\circ}$ years. In the first Ioo- 120 years, rather large fluctuations perhaps occurred in the water content of the bog. It is not possible to deduce from the available information to what extent rejuvenation of the forest occurred nor whether new forest developed after an establishment lasting for a comparatively short period of time (the years $\mathrm{I}-\mathrm{-c} .30$ of the floating chronology). It is not clear from the course of the average thickness curve after $24^{\circ}$ years on the floating chronology that the trees died as a result of a shortage of oxygen in the soil due to the high water level. It can be deduced from the datings that an Early Atlantic pine forest is involved here.

\subsubsection{Munaut $D E E^{0}$ (figs. I I and 109)}

The average tree-ring thickness in this large group is clearly more than I mm. The birth years of the synchronised trees reveals a remarkable spread of more than 200 years, which indicates that the (non-ferruginous fen and fen-wood peat) surface gradually became suitable or remained suitable for a long time for the establishment of Pinus. The birth years of seven of the ten synchronised trees, however, $\left(\mathrm{D}_{2}, \mathrm{E}^{0}{ }_{1}, \mathrm{E}_{3}, \mathrm{E}_{5}{ }_{5}, \mathrm{D}_{1}, \mathrm{E}_{4}\right.$ and $\left.\mathrm{D}_{3}\right)$ fall within the relatively short period from year 104 to year 159 of the floating chronology. It is possible that the bog surface at that time was particularly suitable for the establishment of Pinus. The rather large spread in the dates of dying (from year $23 \mathrm{I}-450$ of the floating chronology) points to a natural cause of death (old age: often more than 200 years) rather than to the bog surface having become unsuitable for Pinus growth by a more or less sudden process.

Regular forest rejuvenation took place in this forest, which covered the entire non-ferruginous fen and fen-wood peat surface east of Emmen (cf. I0.3., EMmeN 14, p. I I7) as can be deduced, with due reservation, from, on the one hand, the dendrochronological investigation, and on the other hand, (as had already become clear to us) from the field investigation. 
In the period between the years $150-270$ of the floating chronology, the average curve shows a very regular growth of the trees, which leads to the assumption that the milieu changed very little or not at all in that time, see also p. 126, Munaur $D^{0}$. It is, however, also possible that we are here concerned with an only apparently quiet period, due to the absence of the first c. 30 years of many trees. It is precisely this first period in the life of trees that is often characterised by very irregular growth.

In spite of the rather long period of time during which establishment of Pinus was possible, we still think it possible to speak of a synchronous pine forest, since a fairly large surface is involved here.

The overgrowing of the forest by highly humified Sphagnum peat would have progressed slowly, especially in the marginal area: the process of decay penetrated deeply into many of the stumps. This is particularly true for group $\mathrm{E}$.

The forest period can be roughly dated from $4500-4000 \mathrm{BC}$ : the Middle Atlantic pine forest.

\section{IO.6. INVESTIGATION OF STUMP LAYERS}

The peat of stump layers often has a crumbly structure, as a result of, among other things, animal activity and the presence of many bark fragments, needles and cones. Where Pinus and Scheuchzeria occur together a strongly laminated deposit has generally formed. The occurrence of Scheuchzeria by themselves and together with Pinus, will be further discussed in 1 r.39., see p. 203. Most of the stump layers contain rather a lot of charcoal particles, not only from the trees, but also from the soil vegetation, which, especially in the drier places, had a high Vaccinium content. Sometimes considerable Polytrichum vegetations also occurred, see face C, pit 94 . The lower side of a wood peat layer can generally be more clearly distinguished than the upper side. This upper side nearly always displays a gradual transition from crumbly wood peat containing many fragments, needles, branch remains etc., to a much more compact peat in which these tree remains are not present. Before dealing with the Early, Middle and Late Atlantic Pinus forest and the Pinus establishments in the ombrogenous peat, we shall first give, below, the information necessary for this discussion. Diagrams 29-Po and 30-Po, which concern the Middle Atlantic and the Late Atlantic Pinus forest respectively, will be discussed in the two sections following. 
10.6.I. Concerning the Middle Atlantic Pinus forest

I I-Po (fig. 74, spectra 7-Io) and I I-Rh (fig. 75, spectra 6-8)

The establishment of Pinus on the fen-wood peat surface (spectrum 7) can scarcely be seen from the Pinus curve. It is possible that Betula established itself in the Pinus forest in which Empetrum and Melampyrum also occurred. A correct date for the stump layer here is not possible, see I I.3., I I-Po (p. I4I). The rhizopod content of the wood peat is slight.

13-Rh (fig. 75, spectra 5-9)

Pinus possibly established itself here in highly humified Sphagnum peat (see also 8.I., I3-Rh, p. 70). During the pine growth it probably became temporarily moister here, as can be deduced from the increase in Amphitrema flavum.

${ }_{7}$ A-Po (fig. 79, spectra 5-II), I7A-Po/bog plants (fig. 83, spectra 5-7). I7A-Rh/Mo (fig. 84, spectrum 7)

The establishment of Pinus is visible in the diagram (17A-Po), although the percentages remain below $20 \%$. Sphagnum and Calluna regularly occurred here already ( $7 \mathrm{~A}-\mathrm{Po} / \mathrm{bog}$ plants, see also in 8. I., p. $70,17 \mathrm{~A}-\mathrm{Po}$ and $17 \mathrm{~A}-\mathrm{Po} / \mathrm{bog}$ plants). The milieu in this oligotrophic, rather acidic peat was not yet suitable for Amphitremas ( $7 \mathrm{~A}-\mathrm{Rh} / \mathrm{Mo}$ ).

$33^{\mathrm{B}-\mathrm{Rh}}$ (fig. I02, spectrum I)

The presence (even in low values) of Amphitrema flavum, Arcella spec. and Assulina muscorum, among others, is an indication that Pinus grew in a comparatively acidic milieu here.

10.6.2. Concerning Pinus establishments in ombrogenous peat

I 9 B-Rh/Mo (fig. 89, spectra 2-4)

In view of the almost complete absence of rhizopods, the ombrogenous peat probably formed in not too moist a milieu. The specimens of Amphitrema wrightianum in spectra 3 and 4 must have arrived here due to in-wash, see II.4I. (p. 209). Spectrum 4, from the Sphagnum peat dopplerite layer, in which Pinus stumps appear here and there, is not different from those just above and just below as far as rhizopod and moss content is concerned.

24A-Po (fig. 93, spectrum 3), 24A-Rh/Mo (fig. 94, spectra I-4) and ${ }_{24} \mathrm{~B}-\mathrm{Rh} / \mathrm{Mo}$ (fig. 94 , spectra $\mathrm{I}-4$ )

Here, too, the rhizopod content of the ombrogenous peat below 
the level of the Sphagnum peat dopplerite layer is particularly low. Calluna, Erica and Empetrum were presumably important components of the not very wet peat forming vegetations.

25-Rh/Mo (fig. 95, spectra I-6)

Here it was clearly moister than was the case in EMMEN 24 during the first ombrogenous peat formation. No recognisable leaf remains of mosses were found just below the Sphagnum peat dopplerite layer (spectrum 5), possibly as a result of strong decomposition of the peat at this level.

$$
\text { 10.7. 29-Po (fig. 98), face J, pit } 328
$$

EMMEN 29 was sampled in the immediate neighbourhood of stump group Munaut B (fig. I I). The profile was analysed by Miss I. W. J. van Otterloo.

A clear Ulmus decline is visible from the diagram (spectra 5-6). The lowermost wood level, therefore, can be correlated with a reasonable degree of certainty with the Middle Atlantic Pinus forest, Munaut B, which can be dated at c. $4^{100}-3850$ BC, see 10.5.3., p. I24, and fig. 106. It will undoubtedly be possible to correlate the middle wood level with the Late Atlantic Pinus forest, see 10.5.2. and 10.5.4., p. 124 and 126. A stump sampled from the topmost wood level between pits 335 and 336 was ${ }^{14} \mathrm{C}$-dated. The (outermost) tree-rings $50-60$ could be dated at $24.10 \pm 55 \mathrm{BC}$ ( $\mathrm{GrN}$ 480 I, see table VIII). This wood level, dated at c. $2500 \mathrm{BC}$ or very shortly afterwards, can possibly be correlated with the desiccation of the highly humified Sphagnum peat in face $\mathrm{H}$, on which level the Sphagnum peat dopplerite layer developed (see II.I4., p. I54). This will be further discussed in 10.13. Scheuchzeria played an important part (spectrum 4) in the overgrowing of the Middle Atlantic Pinus forest. In the Late Atlantic Pinus forest, Calluna and Empetrum occurred frequently here, while. Sphagnum declined sharply (spectrum 5). These phenomena point towards a possible desiccation of the bog, but this is not borne out by the course of a number of other curves, including those of Scheuchzeria, Rumex, Gramineae and Cyperaceae.

The topmost stump level, for which the dating also indicates the end of the Scheuchzeria peat contact zone (see 9, I5. p. I04, see also I I. 39., p. 203) contains stumps with preserved trunk pieces up to $60 \mathrm{~cm}$ in length. This points to a rapid process of overgrowing of the Pinus forest which can be dated between $2500-2400$ BC. 
10.8. 30-Po (fig. 99), face M, pit $4^{07}$

This profile, also analysed by Miss I. W. J. van Otterloo, was sampled in the immediate neighbourhood of stump group Munaut A (fig. II). Because of this, the stump layer can be roughly dated at $3100-295^{\circ} \mathrm{BC}$, see fig. 107 and 10.5., Munaut A (Late Atlantic Pinus forest).

The clear elm decline, spectra $2-7$, places the stump layer approximately at the Atl/SB transition. This is in complete agreement with the ${ }^{14} \mathrm{C}$-date for the stump group, see above.

The transition from seepage peat to wood peat (spectra $4 / 5$ ) is accompanied by clear changes in the pollen picture, indicating a great reversal in the vegetation.

The stump layer contained many Betula-wood remains as well as Pinus. It is remarkable that the course of the Pinus curve does not show Pinus growth here, whereas the course of the Betula curve is in complete agreement with the stratigraphical observations (spectra 4-8). The more or less sudden disappearance of Rumex, Melampyrum and Dryopteris (spectra 5-6) is undoubtedly connected with the falling-off of the seepage, see also I I.I4., p. 154 .

The increase of Calluna, Empetrum and Sphagnum after the overgrowth of the Pinus forest (spectra 8--9) is completely analogous with the stratigraphical development.

\section{io.9. The EARly atlantic PINUS forest}

The only wood remains of this forest are the MUNaUt $\mathrm{D}^{0}$ stumps, found near face C, see I0.5.5., Munaut $\mathrm{D}^{0}$ and figs. I I and I 08 , and dating from c. $5300-4900$ BC. The long lifetime of a few trees (total forest period more than 330 years, see fig. I08) points to a prolonged break in the fen peat growth. In 8.5.2. (p. 73 ff.) we explained that the Early Atlantic desiccation layer can be regarded as the fossil forest base of this Early Atlantic Pinus forest. The probable extent of this forest was given in fig. 7. The fact that stumps are largely absent (only found near face C) might be ascribed to the very prolonged desiccation due to which conservation of wood was rare.

It is not known what trees accompanied the spread of Pinus; Betula was probably an important component of the forest (see fig. $63,{ }^{14} \mathrm{C}$-dated diagram). The fact that this was overgrown by an Alnus fen-wood peat, such as is visible in almost all the peat-faces with the Early Atlantic desiccation layer (the non-ferruginous fen- 
wood peat) indicates a rise in the bog water table after the desiccation of the fen peat in the Hunze valley, which can be dated at about $5300 \mathrm{BC}$ (see also 8.5.2., p. 73 ff.). The extreme eastern part (faces F, G and the eastern part of face J) was overgrown by ironrich seepage peat, see 9.5.I., p. 88. The supply of seepage water and the renewed supply of non-ferruginous ground water probably developed c. 5000 BC or shortly before that.

\section{IO. IO. THE MIDDLE ATLANTIG PINUS FOREST}

This constitutes the transition from the non-ferruginous fen-wood peat (in faces $\mathrm{A}-\mathbf{E}$ and face $\mathrm{J}$ ) to ombrogenous peat. VIsscher (193I) had already described this transition, which he called the "middle stump horizon". It occurs in the whole of the non-ferruginous fen-wood peat area, see figs. 7 and II. A presumably slight drying-out was the cause for the establishment of Pinus, see I0.3., EMmen 14, p. I 7 ff. and 8.5.3., p. 75, where this stump layer was already discussed.

Besides Pinus, Betula and, (to a much smaller extent) Alnus also grew in the forest. Alongside Scheuchzeria palustris and Polytrichum (face C, pit 94), other species, including Empetrum, Calluna, Vaccinium and possibly Melampyrum, are present in this forest, see 10.7., p. I 30 and fig. 98, 29-Po. The Pinus forest was roughly dated from $4500-$ 4000 BC (stump group Munaut D E E0, fig. I09). The forest period lasted for more than 330 years. From the average synchronisation curve of Munaut D E E $\mathrm{E}^{0}$ we may, with due reservation, conclude (see 10.5.6., p. 127) that a steady growth of the forest took place, especially between the years $120-240$ of the floating chronology. The total synchronised period of 339 years displays a few phases of slower growth (slightly falling curve). These are between the years $40-80$, I06-I I 9 , I $35-$ I 65 and between $195-265$. This last period of slower growth appears especially in MUNAUT D. The alterations in the rate of growth are probably connected with changes in the bog hydrology. Here and there, several wood levels are present, e.g. face $\mathrm{B}$, pits $3^{0}-34,45-4^{8}$, and face $\mathrm{D}$, pits I03I16. There is a very strong probability that these higher levels represent Pinus growth from later than c. $4000 \mathrm{BC}$. The tremendously thick stump layer on the western margin of the bog (face A, and, to a certain extent, face $D$ also) represents a considerably longer forest period there (see fig. 66, 3-Po and fig. 64, I-Po) than further inwards in the bog. This may be ascribed to the eutrophic- 
ating influence of the Hondsrug, as well as to the occurrence of repeated desiccations of the marginal zone of the bog.

Stump group Munaut B (fig. Io6) dates from a few centuries later than the group Munaut D E E $\mathrm{E}^{0}$. It is possible that Pinus arrived somewhat later on the eastern border of the non-ferruginous fen peat area. In view of the large surface over which Pinus distributed itself, we still think it correct to speak of one Pinus forest.

In several places traces of fire were found on the stumps; a few times also on the underside of fallen trunks. The forest must have re-established itself after a fire, at least on some places, since these fallen, charred trunks are occasionally overgrown by pines.

\section{IO.I I. Stratigraphy and Development of the Middle atlantic} PINUS FOREST

After a probably not too deep-seated desiccation of the non-ferruginous fen and fen-wood peat deposits, dated at c. 4500 BC (see I0.5.6., Munaut D E E ${ }^{0}$, p. 127), conditions became favourable for the establishment of Pinus; both hydrological and trophic factors must have been involved (see 10.3., EMmen 14, p. 1 I 7). It spread within a short time from the marginal area of the bog, where possibly Pinus had been able to grow from the Preboreal (10-Po, see fig. 73), over the non-ferruginous fen and fen-wood peat surface which possessed a slight relief. It is possible that the tree reached the eastern edge of this region a few centuries later (face J, stump group Munaut B, see I0.5.3., p. I 24). On the border between this Pinus-forest-on-fen-peat and the central part of the bog, where the iron-rich seepage peat growth continued, a relatively narrow mixture area developed of two sorts of bog water, in which extensive Scheuchzeria vegetations started to develop: the Scheuchzeria peat contact zone of face J, see 9.15. (p. 104) and II.39. (p. 203). It appears that, just on the western side of this zone, Pinus was able to establish itself several times during a very long period between c. $4100-2500$ $\mathrm{BC}$, see $10.7 ., 29-\mathrm{Po}$, p. 130 and fig. 98. In the lowest-lying places of the non-ferruginous fen peat surface, which has a relief in which is reflected the topography of the mineral subsoil, extensive Scheuchzeria vegetations, as well as Pinus growth, was able to materialise, see 10.3., EMmen I 4, p. I I 7. In contrast with these low-lying places, the pine trees could reach a considerable age on the higher, somewhat better drained places (stump group Munaut D, see 10.5.6., p. 127). Where the trees did die off fairly quickly as a result of too 
high a soil moisture content, a renewed growth of pines very probably took place repeatedly (10.3., EMmen I 4 , p. I I 7 ). This indicates that the milieu which was suitable for Pinus establishment probably the somewhat acidic peat soil becoming slightly more eutrophic (see I I.39, p. 203) - remained unchanged for a long time. The renewed growth of Pinus which probably occurred several times, especially in the lowest lying places, possibly points to a temporary improvement in the growth conditions, e.g. by a drop in the undoubtedly high water level in this Pinus forest. When the healthy trees had grown to considerable dimensions, after c. Ioo years, a clear mosaic had developed in this forest. Groups of pines packed rather closely together, just above elevations of the mineral subsoil, were situated between parts of the forest with considerably smaller pines, which were rooted in Scheuchzeria vegetations. The vein of iron-rich peat, the "overflow" of the seepage peat area (see 9.I6., p. 105), ringed by Scheuchzeria vegetations, bisects this forest (see also fig. 8). A peculiar phenomenon is that this Pinus establishment is but scarcely visible, in the diagrams, see e.g. I $-\mathrm{Po}$, spectra $7-10$, (fig. 74) I 7A-Po, spectra 5-I I (fig. 79), 29-Po, spectra I-5, (fig. 98), whereas the late Preboreal Pinus establishment, as can be deduced from 10-Po (see fig. 73, and 4.2., го-Po, p. 47), is visible as a very high Pinus maximum in the diagram. It appears from the information available (see, among others, ro.1., p. I I4 ff.) that the soil in which the pines were rooted was already generally somewhat acidic. Ericaceae and Sphagnum were already present in many places. On this forest soil a large development of Sphagnum could soon take place, preceding the growth of the highly humified Sphagnum peat.

The Pinus forest was smothered by the increasing thickness of the peat. The most weakly growing trees, which had their roots in the very wet Scheuchzeria vegetations, would have died first; but ultimately, towards c. $4000 \mathrm{BC}$, all that remained of the once nearly unbroken forest were some scattered fragments. These consisted predominantly of rather old, perhaps even mainly very old trees which were rooted at a somewhat higher level in the forest soil. In the peat-faces, these forest fragments are revealed as an extra wood level at the top of the stump layer, e.g. face B, pits $43-48$.

On the western margin of the bog, near the Hondsrug, the Pinus forest was not overgrown by ombrogenous peat. Pinus, together with Scheuchzeria, was able to continue growing here for a long time yet, as a result of eutrophication of the peat, (face A, see fig. 64, I-Po and fig. $66,3-\mathrm{Po})$. 
The desiccated seepage peat (see 9.14., p. 103) above sand elevations in the subsoil proved to be suitable for Pinus establishment, so that a forest consisting of groups of trees separated by fairly large treeless areas of bog surface could develop in the seepage peat area indicated in fig. 8, see also fig. 11. This forest which consisted of scattered groups of trees was found in face $\mathrm{H}$, pits 235-240; face $\mathrm{K}$, pit 356 ; face L, pits $386-388$; face $M$, pits $400-402$ and $405-4$ I I (stump group Munaut A, see fig. I05, and 30-Po, see fig. 99); face $\mathrm{N}$, pits $415-424$. It is also present in face J, see 10.7., 29-Po (p. I 30 ). Isolated stumps were occasionally found. The forest period can be roughly dated from c. 3 100-2950 BC (stump groups MUnAU'T A and Munaut C), see 10.5.2. (p. 1 24), 10.5.4. (p. 1 26), and figs. 105 and 107. Visscher (193I) made no distinction between this Late Atlantic Pinus forest and the Middle Atlantic Pinus forest, both of which he described as the middle stump horizon. The stumps do not appear above siderite lenses in the peat. It appears from $30-\mathrm{Po}$ (face M, pit 407, see also fig. 99) that the trees could grow on seepage peat with a relatively low iron content, where Betula had already been able to grow. They were often rooted in Scheuchzeria vegetations; the growth conditions must have been unusually unfavourable, see also 10.3. (p. II 7). The stumps are generally wellpreserved, and long, often sickle-shaped trunk pieces more than half a metre in length remain. The layer has a maximum thickness of $25 \mathrm{~cm}$. The stumps protrude far into the ombrogenous peat.

From the relatively short lifetime of the trees (mostly only a few decades), the establishment in Scheuchzeria vegetation, the good state of preservation of the stumps which occur on one level only, and the poor growth of the trees, we can conclude that the bog surface was suitable for Pinus establishment for only a short time. Both within and outside the forest, highly humified Sphagnum peat would have quickly developed, due to which the forest would not have had the chance to become centuries old, as did the two Pinus forests already discussed.

The very great difficulties experienced by Munaut in synchronizing the stumps of groups Munaut A and Munaut $\mathrm{C}$, are indications of great local differences in the milieu, mainly caused by a high bog water level, with probably many fluctuations. These fluctuations can be clearly seen in the average synchronisation curve of group Munaut A, see fig. 105. It might be concluded from diagrams $30-$ Po (see ro.8., p. I $3^{\mathrm{I}}$ and fig. 99) and $3^{\mathrm{I}-\mathrm{Po}}$ and 
3I-Rh/Mo (see II.I 7., p. I57 and figs. Ioo and Ior) that, after the desiccation of c. 31 IOo BC (see 9.I4., p. I03), the seepage peat surface was not sufficiently acidic in many places for Pinus establishment, and that the high degree of moisture on this level, as appears from $3 \mathrm{I}-\mathrm{Po}$ and $3 \mathrm{I}-\mathrm{Rh} / \mathrm{Mo}$, originated only after the establishment of Pinus.

\section{i O. I3. Pinus establishments in the ombrogenous peat}

\section{I0. I3. I. In the highly humified Sphagnum peat}

The dried-out area in the central part of the bog (faces $\mathrm{H}$ and $\mathrm{I}$ ) which was probably bowl-shaped, and which is visible rather far down in the highly humified Sphagnum peat as the Sphagnum peat dopplerite layer, see Emmen $19,19 \mathrm{~A}, 19 \mathrm{~B}$ and $19 \mathrm{C}$ (figs. 48 and 49), EMmen 24 (fig. 53) and Emmen 25 (fig. 54), was surrounded by pine trees which had an average age of less than 30 years. This desiccation will be further discussed in I I. I 4., p. I 54. The desiccation and the Pinus establishment induced by it, can be dated at c. 2500 $\mathrm{BC}$, see table I. This thorough desiccation, no parallel for which was found in the rest of the highly humified Sphagnum peat, was most probably created by a very localised drainage via the underlying drying crack systems.

C. 2500 BC or very shortly afterwards, Pinus established itself in the Scheuchzeria peat contact zone of face J, pits 330-336, (see 9. I5., p. 104), preceding the highly humified Sphagnum peat growth, see I0.7., 29-Po, p. I30 and table I. It is possible that Pinus growth was induced here by a relative drying-out. The facts that Pinus established itself only once, and that it was quickly overgrown by highly humified Sphagnum peat (within a few decades), are indications that the milieu was suitable for Pinus for only a short time.

The time difference between this phenomenon and the desiccation of c. $2500 \mathrm{BC}$ in faces $\mathrm{H}$ and $\mathrm{I}$ (see above) which can, at most, have been very small, suggests a correlation between the two phenomena, in the sense that the desiccation of c. $2500 \mathrm{BC}$ in faces $\mathrm{H}$ and I was observable here as a slight drying-out, due to which the Scheuchzeria growth was disrupted, see also I I.39., p. 203.

In faces B, C, D, E and J, a few stump layers exist in the highly humified Sphagnum peat above parts of the sandy subsoil which has a comparatively varied relief. The length of the layers varies from c. Io $\mathrm{m}$ (face $\mathrm{B}$, pit $4^{2}$; face $\mathrm{J}$, between pits $293-33^{\circ}$ ) to more than roo $\mathrm{m}$ (face C, pits 52-54). Scheuchzeria can also occur in 
these layers, see also II.39., p. 203. The pines have plank-shaped roots, are usually less than 30 years old, and are usually well-preserved. Such stump layers are not present in the blue-black highly humified Sphagnum peat, see i r.8., p. I58. The occurrence of Pinus in the highly humified Sphagnum peat was undoubtedly linked with the existence of drier positions in the bog, e.g. due to local or slight desiccations. Several desiccations would, in all probability, have caused a slight shrinkage of the peat deposit, due to which the subsoil relief was reflected, more or less clearly, in the peat surface, see also i0.3., Emmen 14, p. I17. The pine would have been able to establish itself a few times in this highly humified Sphagnum peat on the highest, and therefore driest, places.

\section{I3.2. In the intermediate deposits}

The establishment of Pinus in this bog, i.e. between c. $2000-500$ $\mathbf{B C}$, is mainly limited to the narrow marginal parts (faces B and D), where no hummocks and hollows have developed, see Emmen 5 (fig. 38) and I I.50., p. 229. The trees here display the same characteristics as those in the rest of the ombrogenous peat: poor growth, short span, etc., see also 10.4., EMmen 4, p. 121. Pinus was found in very small numbers in face $J$, in a few places at the bottom of the intermediate deposit.

The majority of these Pinus stump layers can be dated between c. $2000-1500 \mathrm{BC}$, particularly where they are at the bottom of the intermediate deposit.

The limited distribution of Pinus cannot be accounted for only by the water content being too high. Many hummocks e.g. of Emmen 9 (fig. 38, see also I I.2 I., p. I64) and of Emmen I 7 (fig. 45, see also I I.29., p. I 84), must undoubtedly have been dry enough for Pinus growth. The absence of Pinus from these drier places can therefore be ascribed, in all probability, to the strongly oligotrophic milieu. At first, the hollows would be sufficiently mesotrophic (Scheuchzeria!) but far too wet for Pinus establishment. That the stump layer in the intermediate deposit appears particularly in the marginal area of the bog is an indication of a certain enrichment in the minerals of the bog surface as a condition for Pinus establishment, see also Io.ri., p. I33.

\section{I0.13.3. In the fresh Sphagnum peat}

Pinus was not able to establish itself in the extremely oligotrophic, fresh Sphagnum imbricatum-papillosum peat (see I I.52., p. 233 and I I. 55., p. 239). 
After the final, artificial, drainage of this raised bog (i.e. after the I6th century) Pinus was even then unable to spread in the peat, but Betula pubescens, Sorbus aucuparia and Salix spp. could develop extensively.

\section{GHAPTER IY: OMBROGENOUS PEAT}

\section{I.I. INTRODUCTION}

The ombrogenous peat formations in the area investigated can be sub-divided into four main subdivisions. The lowest layer of the ombrogenous peat, of which Sphagna are the predominant formers, consists of the highly humified Sphagnum peat, which lies immediately above the Middle Atlantic Pinus wood layer, the Late Atlantic Pinus wood layer, or the seepage peat; and the Menyanthes-Betula peat, which is of the same age as the highly humified Sphagnum peat. This lies on seepage peat. The intermediate peat deposits form the transition, in both a stratigraphical and a genetic sense, between the highly humified Sphagnum peat and the fresh Sphagnum peat.

The highly humified Sphagnum peat consists of a western brownblack, and an eastern blue-black complex. The Menyanthes-Betula peat is found on the eastern side of the blue-black complex. The bog rivulet, the Runde, is here, too.

The intermediate deposit is composed mainly of highly humified hummocks and poorly humified hollows. Four types of hummockhollow systems can be distinguished. The differentiating of the peatforming surface into different hummock-hollow mosaics is connected with the drainage patterns of the bog surface. A raised bog lake without outlet was present in the intermediate peat.

The fresh Sphagnum peat can be regarded as having developed from the peat of the hollows, in which the composition of this peat changed to a certain extent.

The ombrogenous peat that developed in the Hunze depression after the falling-off of the ground water and the seepage water supply, was considerably more extensive and often thicker than the fen and fen-wood peat and the seepage peat. Even in that part of the Hunze depression extending to Io $\mathrm{km}$ south of the investigation area where fen peat could form only occassionally, huge numbers of peat forming Sphagna established themselves, see fig. 6o, EMMEN 34 and fig. I.

The Sphagnum peat in many places was already too dricd out for us 
to be able to determine the degree of humification $\mathrm{H}$ according to Von Post's squeezing method. In its place we looked particularly at the colour of the peat and at plant remains which were identifiable or at least clearly visible when the peat lumps were broken open. Where possible, we checked this method with Von PosT's squeezing method. There was generally good agreement between the two methods. The humification of the fresh and poorly humified Sphagnum peat is $\mathrm{H}_{\mathrm{I}}-3$; for the highly humified peat it is $\mathrm{H}_{7}-9$. We did not find $\mathrm{H}$ 10. Peat with a degree of humification $\mathrm{H}_{4}-6$ is called moderately humified peat. In the monolith descriptions of rhizopod, moss and pollen analyses, a further differentiation in humification was made, see fig. 62 .

The ombrogenous peat has a low ash content and is non-ferruginous, even where it lies on the iron-rich seepage peat. Those parts of the mineral subsoil of the Hunze depression which are overgrown with Sphagnum peat, such as the southern part, the east-west orientated cover-sand ridge (see fig. 3) and the slope of the Hondsrug, have a peat podsol. Podsolisation also developed under the Pinus wood peat layer on the slope of the Hondsrug, see peat-faces A and D.

The genetic aspect of the different deposits is the principal item in the discussion of the ombrogenous formations. It turned out to be impossible to split up the information available from diagrams, sections, etc., to correspond consistently with the four main subdivisions to be dealt with (highly humified Sphagnum peat, Menyanthes-Betula peat, intermediate deposits, fresh Sphagnum peat), and to set it out for each main subdivision. The emphasis in the discussion is laid on the intermediate deposits. Most information is therefore in this main sub-division. For this reason, reference will be made several times to information placed in the main sub-division, "intermediate deposits", particularly in the discussion of the highly humified Sphagnum peat. The discussion of the fresh Sphagnum peat is based on information already given in the first and third main sub-divisions. The stratigraphy and genesis of the whole of the ombrogenous peat will be summarized in one section.

\section{Highly humified Sphagnum peat}

\section{I.2. INTRODUCTION}

The information on which the discussion of the highly humified Sphagnum peat is based was mainly derived from: 
- peat-faces $A-Q$,

- those parts of the ${ }^{14} \mathrm{G}$-diagram and of the profile EMmererfSCHEIDENVEEN I (fig. 63) which refer to the ombrogenous peat, and which were discussed in 4.3.

- spectra $5^{\mathrm{I}-64}$ of the diagram 3-Po (fig. 66), which was discussed in 4.4., and table IV, Emmen 3, macroscopic remains (p. $5^{8}$ ),

- the topmost spectra of diagram I-Po (fig. 64), which was discussed in 8.2., p. $7 \mathrm{I}$,

- spectra 4-8 of the diagram 29-Po (fig. 98), which was discussed in 10.7 . (p. 1 30 ),

- spectra 8-I I of the diagram 30-Po (fig. 99), which was discussed in Io.8. (p. 13I),

- the highly humified Sphagnum peat part of the sections to be discussed in the third main sub-division: EMmen 5 (fig. 38, see p. 229), Емmen 8 (fig. 4r, see p. 168), and Emmen 9 (fig. $4^{2}$, see p. I64) from face B; EMmen I 7 (fig. 45, see p. I 74) and EMMEN I 8 (fig. 47 , see p. 182 ) from face $E$; EMmen $19,19 A, 19 B$ and $19 \mathrm{C}$ (figs. 48 and 49, see p. 209), EMmen 20 (fig. 50, see p. 187), EMmen 22 (fig. 5I, see p. 185) and Emmen 23 (fig. 52, see p. 186) from face H; Emmen 24 (fig. 53, see p. 2 I3), Emmen 25 (fig. 54, see p. 215), Emmen 26 (fig. 55, see p. 2I5), Emmen 27 (fig. 56, see p. 215), and Emmen 28 (fig. 57, see p. 216) from face I; EMmen 32 (fig. $5^{8}$, see p. 188 ) and EMmen 34 (fig. 6o, see p. 206), the position of which was indicated in figs. 2 and ro respectively. The seepage peat part of EMmen 24, EMmEN 25, EMmEN 26 and Emmen 27 has already been discussed in 9.2., (p. 83); diagrams from sections Emmen i7, Emmen i9, Emmen 24 and Emmen 25 have already been partly dealt with, see 8.1., p. 70; 9.I, and 9.2. p. 8I; the ombrogenous peat of these diagrams will come under discussion in the sections concerned.

- diagrams I I-Po (fig. 74) and II-Rh (fig. 75) of profile Emmen II, from peat-face $\mathrm{C}$, between pits 68-69, which will be discussed in II.3. and I I.4. The fen peat part of I I-Po has already been dealt with in 8.r., p. $7^{0}$.

- diagram I3-Rh (fig. 75), of peat-face C, pit 64, which will be discussed in II.4. and the fen peat part of which has already been discussed in 8.1., p. 70 .

- section Emmen 33 (fig. 59); the position of this section is indicated in fig. 2.

- profile Emmen 3i (see I i.17.) from the Menyanthes-Betula peat of face $\mathrm{O}$, pit $44^{2}$; spectrum I of the diagrams $3 \mathrm{I}$-Po (fig. 10o) 
and $3 \mathrm{I}-\mathrm{Rh} / \mathrm{Mo}$ (fig. Ior), from the seepage peat, has already been discussed in 9.r., p. 8I.

\section{i i.3. Emmen i i, face G, between pits 68-69}

From this profile, II-Po (fig. 74) and II-Rh (fig. 75) were made. The pollen diagram was analysed by Drs. P. BuLT. Two radio-carbon dates are available from the transition from highly humified to fresh Sphagnum peat, via a layer of "Vorlaufstorf" (poorly humified Sphagnum-cuspidatum peat) at I4.93 m + N.A.P.; the classic "Grenzhorizont" in WebER's (1906) sense extends to about $3 \mathrm{~m}$. The topmost $3 \mathrm{~mm}$ of highly humified Sphagnum peat were dated at $18 \mathrm{I} 5 \pm 4 \mathrm{O} \mathrm{BC}\left(\mathrm{GrN}_{4} \mathrm{I} 46\right)$, the lowermost $3 \mathrm{~mm}$ of the fresh Sphagnum cuspidatum-Scheuchzeria peat, immediately above the dated highly humified Sphagnum peat, were dated at I80o \pm 50 $\mathrm{BC}$ ( $\left.\mathrm{GrN} 4^{\mathrm{I}} 48\right)$. The dates are given in I I-Po and are also reported in table I.

In this case the transition VII/VIII might be placed, at the beginning of a clear decline of Ulmus, just above the level at which Fagus appears in the pollen diagram, between spectra 4 and 5 . The zone transition VIII/IX might be placed at the beginning of the large increase of Fagus, where Corylus decreases from 23-I $4.5 \%$, between spectra 35 and 38 . Proceding from these zonings and datings, the peat accumulation from $3000 \mathrm{BC}$ (at $13.55 \mathrm{~m}+$ N.A.P.) to $\mathrm{I} 800 \mathrm{BC}$ (at $14.39 \mathrm{~m}+$ N.A.P.) would amount to $7 \mathrm{~cm} / \mathrm{Ioo}$ years $(84 \mathrm{~cm}$ in $\mathrm{r} 200$ years). Between $\mathrm{r} 800 \mathrm{BC}$ and $800 \mathrm{BC}$ (at $\mathrm{r} 4.63$ $\mathrm{m}+$ N.A.P.) only $24 \mathrm{~cm}$ of peat (also in a shrunken condition) was formed, which amounts to a peat accumulation of $2.4 \mathrm{~cm} / \mathrm{roo}$ years. This would mean that, in the first half of the Subboreal, during which mainly highly humified Sphagnum peat was formed, the accumulation of organic material here would have been three times as rapid as in the second half of the Subboreal, when predominantly fresh Sphagnum peat was formed. It is also possible, however, that the zone transitions have not been correctly placed, or that there was a gap in the peat growth. We did not observe this latter possibility.

Originally, Empetrum, which was already present in the Pinus forest, Melampyrum, Potamogaton and Scheuchzeria found suitable habitats (II-Po, spectrum Io) in the highly humified Sphagnum peat that overgrew the Pinus forest. We can deduce from I I-Rh, spectrum 9, with an Amphitrema flavum maximum, that it must have been 
very moist here. Scheuchzeria is visible at this level on the peat-face. It should also be observed in this connection that profile EMmen I I was sampled above a depression in the mineral subsoil, see ro.3., EMMen I4, p. II 7 .

Amphitrema flavum reaches a higher value again in the somewhat less humified peat layer between I 4.01 and 14 .Io $m+N$.A.P. and this is an indication of a somewhat moister milieu. This phenomenon is present in $\mathrm{I} 3-\mathrm{Rh}$ too, see the next section. The origin of this peat layer, which is visible in face $\mathrm{C}$ above pits $62-65$ and 69 , will be further discussed in I I.12., see p. I53. The curve of Plantago lanceolata begins just above the level of the layer, see II-Po, spectra 19-44. The layer, therefore, can probably be dated at about $2500 \mathrm{BC}$, see also 4.3. , p. 48 and fig. $63,{ }^{14} \mathrm{C}$-diagram. The transition from highly humified to fresh Sphagnum peat, which can be dated at about $\mathrm{I} 800 \mathrm{BC}$, shows up clearly in the rhizopod diagram (spectra 27-28). The moisture content increased even during the growth of the highly humified Sphagnum peat (spectra 2627: Amphitrema wrigthianum also already present!). This increase in the moisture content can be roughly dated at about $2000 \mathrm{BC}$, see especially I I.26., p. I74, where this development will be further dealt with. The transition from highly humified to fresh Sphagnum peat, c. I80o BC, will probably have proceeded here without interruption. We are dealing here with a base of fresh hollow-peat, see also II.2I., p. 164. The share of Calluna in the peat-forming vegetation probably declined rapidly (I I-Po, spectra 25-29). The Sphagnum values too are no longer as high as at some levels in the highly humified Sphagnum peat. Some clear peaks are visible in the curves of the Amphitremas. The three thin Sphagnum cuspidatum layers (spectra 34,37 and 40) correspond fairly well with the somewhat higher values for the Amphitremas. These three cuspidatum layers and the layer at $14.95 \mathrm{~m}+$ N.A.P. can be dated roughly in the first centuries of the Subatlantic.

\section{1.4. Emmen I3, face C, pit 64 (fig. 75)}

Diagram I $3-\mathrm{Rh}$ was made of this profile, sampled just to the south of the vein of iron-rich peat in face C (the "overflow", see 9.16., p. I05).

In the highly humified Sphagnum peat of this profile, a somewhat less humified layer is present (13.86-14.03 $\mathrm{m}+$ N.A.P.), too, and in it, Amphitrema flavum reaches somewhat higher values (spectra 
13-15), see also fig. 75, and the previous section. This will be further discussed in II.I2.

The great expansion of the Amphitremas took place here only when the forming of fresh Sphagnum peat had already started (spectra 2527). This is connected with the conditions on the bog surface here at the time; the monolith was not sampled through the lowest part of a hollow, see also I I.21., p. i64. The strong decline of the Amphitrema content in the fresh peat towards the top (especially spectra $32-3^{8}$ ) indicates that the peat became less suitable for these rhizopods.

I I.5. Emmen 33 (fig. 59), the trackway XXI (Bou), c. I500 m south of the eastern point of face J, see fig. 2

In March - April 1964 , we excavated a $75 \mathrm{~m}$ long section of this wooden trackway, which is made of trunks, about $3 \mathrm{~m}$ in length, laid cross-wise. Fig. 59 illustrates the relief of the trackway surface, as that was found during the excavation, and was established by measuring the heights of the ends of all the trunks. The vertical scale is exaggerated here by a factor of 5 . The relief of the northern side of this $\mathrm{E}-\mathrm{W}$ road is given at the top of the figure. The relief of the southern side is placed in the highly schematic section (in the lower part of the figure). After removing the trunks, though also during the excavation, it appeared that a clear distinction could be made between a fairly firm peat with many remains of Calluna vulgaris and Eriophorum vaginatum and a very soft Scheuchzeria-Sphagnum cuspidatum peat.

Differences in the degree of humification, varying from $\mathrm{H} 6-8$, and connected with this, could not be precisely established. We are here dealing with a bog surface that was already, at the time of the building of the wooden trackway, divided into fairly dry hummocks and very moist to wet hollows, see especially i I.34., concerning hummock and hollow mosaics. The $4 \mathrm{~m}$ broad bog surface at the level of the road is given in fig. 59 between the two cross-sections of the wooden trackway, and here a distinction is made between the firmer Calluna and Eriophorum-rich hummock peat (horizontal stripes close together) and the softer Sphagnum cuspidatum and Scheuchzeria-rich hollow-peat (horizontal stripes further apart). Two ${ }^{14} \mathrm{C}-$ datings of the trackway are available: $213^{\circ} \pm 55 \mathrm{BC}(\mathrm{GrN}$ 1087) and $215^{\circ} \pm 55 \mathrm{BC}$ ( $\mathrm{GrN} 29^{86}$ ), see also table I. At $3^{8}$ and $40 \mathrm{~m}$ respectively, a profile was sampled through a hummock and through 
a hollow as far down as the Pinus stump layer; 33A-Rh (fig. I02) and $33 \mathrm{~B}-\mathrm{Rh}$ (fig. 102) were made of this.

The bog surface of c. $2150 \mathrm{BC}$ proved to have a fine hummock and hollow mosaic, with oval hummocks, $3-6 \mathrm{~m}$ long and $2-4 \mathrm{~m}$ broad, north-south orientated, separated by irregularly shaped hollows. See I I.35., where this hummock and hollow mosiac will be further discussed. It appears that a close correspondence exists between the undulating road surface and the hummocks and hollows mosiac. The drainage of the last century has undoubtedly contributed largely to causing the development of the relief which is now found. The fact that such a type of relief can be caused by shrinkage is mainly a consequence of the nature of the peat: the softer hollow-peat offers less resistance to the pressure upon the surface than the firm hummock-peat. It is probable that the surface already had some relief at the time of the building of the trackway, as is usually the case with hummock and hollow surfaces.

With a number of hummocks (e.g. from 10-15 m, from $\mathrm{I}_{7}-23$ $\mathrm{m}$, the two hummocks between $25-35 \mathrm{~m}$, from $6 \mathrm{r}-64 \mathrm{~m}$ and from $70-75 \mathrm{~m}$ ), it could be clearly established from the peat-faces of the excavation ditch that the hummock-forming apparently continued uninterrupted after the building of the track. Some of these hummocks could befollowed to more than i $m$ above the trackwaysurface. In the two rhizopod diagrams $33 \mathrm{~A}-\mathrm{Rh}$ and $33_{\mathrm{B}-\mathrm{Rh}}$ (fig. I02), it is particularly striking that this highly humified peat has such a high Amphitrema flavum content. This pronounced flavum type is an indication that the highly humified peat formation probably took place in an extremely wet milieu. Secondly, it is remarkable that there is here no essential difference in rhizopod content between the hollow-peat and the hummock-peat.

\section{i i.6. Highly humified Sphagnum PEAT}

This peat, also often called "older Sphagnum peat", and known to the local population as "blue peat" or "black peat", is present in all the peat-faces, and in most of the pits, with the exception of face A. The degree of humification is mainly $\mathrm{H} 8$; it varies from $\mathrm{H} 7-9$. Fairly large variations exist in the composition of the highly humified Sphagnum peat, which is often regarded as a homogenous peat deposit, and these variations indicate not inconsiderable differences in the peat-forming milieu. Not very conspicuous, although very important, is a slight colour difference: the highly humified Sphag- 
num peat of the faces $\mathrm{B}, \mathrm{C}, \mathrm{D}, \mathrm{E}$ and $\mathrm{J}$ has a somewhat browner tint than on faces F, G, H, I, K, L, M and N, where the peat assumes more of a blue-black colour on drying out. In faces $\mathrm{O}, \mathrm{P}$ and $\mathrm{Q}$, very little highly humified Sphagnum peat is present, and this again assumes a somewhat brownish tint.

The colour difference is accompanied by a number of other differences, for instance in the occurrence of Pinus and Scheuchzeria, in the distribution of Eriophorum vaginatum, and in the average thickness of the peat. We have therefore sub-divided the highly humified Sphagnum peat into two complexes: the brown-black complex in which the peat-forming milieu was presumably fairly acidic; and a blue-black complex, where peat forming would have taken place in a more reducing milieu.

Sphagnum cf. rubellum is the predominant peat-producing moss in both complexes. Sphagnum rubellum L. is a pronounced hummockforming moss (BEYERINCK I934, MüLleR 1965) which, even at present, is one of the most important hummock builders in Northwest Germany. Sphagnum molluscum Bruch was comparatively rarely found. Several times the samples contained Sphagnum leaves which we were not able to identify further. Anthophyta which found a suitable habitat in the peat include several Ericaceae such as Calluna vulgaris (L.) Hull, Erica tetralix L., Oxycoccus palustris Pers., Andromeda polifolia L., and Vaccinium spp. L., further, Empetrum nigrum L., Melampyrum L., Rumex acetosella L., Rhynchospora alba (L.), Vahl., and Eriophorum vaginatum L. The mosses Polytrichum cf. strictum Banks., Leucobryum glaucum Schp., Aulacomnium palustre Schwaeg., and Drepanocladus sp. (C.M.). Roth. were also found. In section II.9., II.10. and II.I I., a number of these bog plants will be further discussed. Highly humified Sphagnum peat formation occurred in some places even before the establishment of the Middle Atlantic Pinus forest, e.g. in face $\mathrm{C}$, pit $6_{3}$ and face $\mathrm{E}$, pit ${ }_{17 \mathrm{I}}$. In view of its very slight extent, this phenomenon has not been discussed.

1 i.7. Stratigraphical aspects and dating of the brown-black GOMPLEX

The brown-black Sphagnum peat is present in faces B, G, D, E and $\mathrm{J}$. Its presence is restricted to the western part of the Hunze depression, to the same area where the non-ferruginous fen and fen-wood peat was formed, see fig. I 3 and fig. 7. Its presence in the extreme east of the investigation area is not absolutely certain. In all proba- 


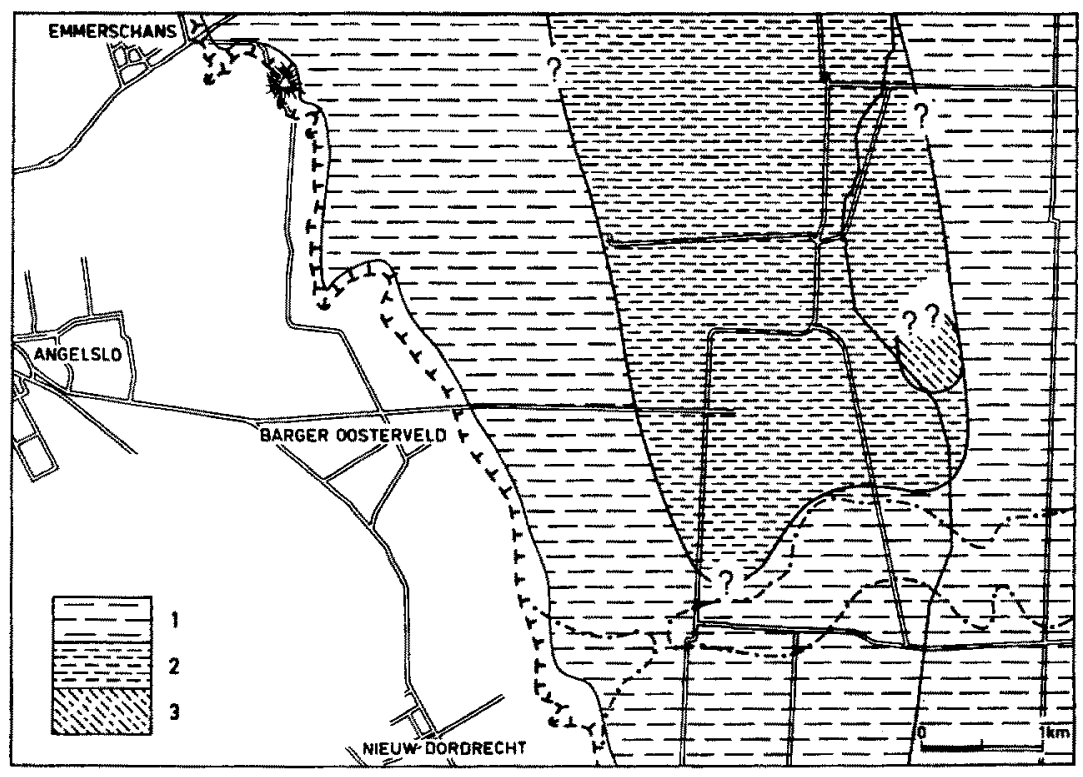

Fig. 13. The ombrogenous peat deposits between c. 3000 and 2000 B.C. I = brown-black highly humified Sphagnum peat (from about 4000-2000 B.C.); 2 = blue-black highly humified Sphagnum peat (from 3100-c. I500 B.C.); $3=$ Menyanthes-Betula peat (from $3100-2000$ B.C.).

bility, the highly humified Sphagnum peat lying to the east of the course of the stream, the Runde, (see fig. I) belongs to another raised bog complex, a fragment of which we found in face $Q$.

The thickness of this peat deposit varies from $30-120 \mathrm{~cm}$, the average thickness is about $80 \mathrm{~cm}$. The brown-black highly humified Sphagnum peat lies on the Middle Atlantic stump layer, see Io.ro., p. I32, so that the beginning of this peat forming can be dated at shortly after $4500 \mathrm{BC}$ to $\mathrm{c} .4000 \mathrm{BC}$. We took as the end of the growth of this type of highly humified Sphagnum peat, the point at which the first fresh (Sphagnum cuspidatum) peat developed in the highly humified hollows. This can be dated at about 2000 BC, see I I.20., p. I62. The rate of accumulation of this deposit can be taken as $3.5 \mathrm{~cm} /$ Ioo years. In the marginal area the highly humified Sphagnum peat formation continued for a considerably longer time (EMMEN 5 , fig. $3^{8)}$ see I 1.50., p. 229 , as a result of special local conditions: desiccations and eutrophication.

There is often a clear layering in the peat, examples of which include the layer-shaped nature of the establishments of Pinus and 
Scheuchzeria, see II.39., p. 203. Eriophorum vaginatum appears fairly regularly in the whole of the brown-black deposit. Eriophorum layers are present in several places, particularly at the top (EMmen 8, see fig. $4^{1}$ and Emmen I 7 , see fig. 45; see I I. I I., p. 152.). Stem remains of Calluna vulgaris are found frequently on the peat-faces. The conclusion that the moisture content in the brown-black Sphagnum peat must have varied widely, can be drawn, we believe, from, among other things, the presence of the moist phase in face C (see I I.I2., p. I53) and from the appearance of "liver peat" (see I I.I3., P. I54) alongside Calluna-rich peat in face E (see I I.10., p. $15 \mathrm{I}$ ).

The smaller peat accumulation in comparison with the blue-black complex $(3.5 \mathrm{~cm} / 1$ oo years as against $7 \mathrm{~cm} / 100$ years, see I I.8.) was probably caused by oxidation proceeding further in the more acidic milieu. This was possibly the result of somewhat greater aeration; for the brown-black complex was situated in the drainage area of the southern part of the Hunze depression, see also fig. 6 . It is not impossible that a northwards directed water transport occurred here in the bog during the growth of the highly humified peat, such as took place here before in the peat deposits present (see fig. 6), thus causing the extra aerration. EMmEN 33, originating near the spillway of the east-west orientated cover-sand ridge in the Hunze depression (see figs. 2 and 3 ), provides an indication for such a water movement (I I.5., p. I43). The very wet milieu, in which the highly humified Sphagnum peat formed here, could very easily have been caused by a concentration of the drainage of the southern part of the Hunze depression in the spillway.

I I.8 Stratigraphical ASPECTS AND DATING OF THE BLUE-BLACK COMPLEX

The Sphagnum peat area underwent a great expansion c. 3 roo BC, when Sphagna became established on a large scale on the desiccated seepage peat surface (see 9.I4., p. I03). The peat which formed here, found by us in faces F, G, H, I, K, L, M and N, varies in thickness from $40-180 \mathrm{~cm}$. The average thickness is more than $\mathrm{I} \mathrm{m}$. The transition to the intermediate deposit can be dated at c. I500 BC or somewhat later, see I I.34.3., p. I 9 r. The rate of accumulation of this peat amounts to about $7 \mathrm{~cm} /$ roo years (more than I $\mathrm{m}$ of peat in c. I60o years). In our opinion, the fact that this is approximately twice as much as in the brown-black complex cannot be a coinci- 
dence, see the preceding section. Scarcely any layering appears in the deposit. It contains some clearly visible centres with a high proportion of Eriophorum vaginatum, e.g. face $\mathrm{H}$, pits $224-232$ and face $\mathrm{K}$, pits $373-383$, see II.II., p. I 52 . In most of the faces the upper half of this deposit is clearly richer in Eriophorum than the lower half. This is very striking in face $M$ particularly. This blue-black peat contains somewhat less Calluna than the brown-black peat. As was reported already, Pinus and Scheuchzeria layers are not present. Also because of the occurrence of dopplerite at this level (see Ir.I4.), the desiccation layer of c. $2500 \mathrm{BC}$ has a completely different character from the desiccation layers present in the brown-black peat.

In those places where the underlying seepage peat deposit is comparatively thin, e.g. in face $\mathrm{K}$, and the western half of face $\mathrm{M}$, a conspicuously thick deposit of highly humified Sphagnum peat is present. Above the domes of the seepage peat surface in faces I, pits $28 \mathrm{I}-288$, and M, pits $409-4 \mathrm{I} 5$, the blue-black deposit is obviously thinner. Most peat accumulation will very probably have occurred at the moistest places, in depressions of the desiccated seepage peat surface.

On the Menyanthes-Betula peat in faces $\mathrm{O}$ and $\mathrm{P}$, there is a comparatively thin deposit of highly humified Sphagnum peat that connects up towards the east with an again conspicuously thick deposit in face $\mathrm{O}$ above pits $445-447$ and in face $\mathrm{P}$, above pits $472-474$, see also I I.I 8., p. I 58 .

It might be thought that the iron compounds from the seepage peat on which the blue-black deposit lies played a part in the development of the more reducing milieu of the highly humified Sphagnum peat formation in the central basin of the bog. The ash from this Sphagnum peat is, however, non-ferruginous, so that the influence of these iron compounds on the Sphagnum peat growth must be considered to be out of the question. It appears from fig. I 3 that the blue-black deposit was formed, as it were, in the lee of the east-west orientated cover-sand ridge. It is possible that this sand ridge, just as with the seepage peat formation, prevented the flow of water from the southern part of the Hunze depression, due to which water flowed less freely here in the growing peat, so that there was practically no oxidation in the peat-forming surface. It is, however, remarkable that the blue-black peat lies on a subsoil, the seepage peat, which is, at least apparently, very porous. We must assume, however, that the numerous drying cracks caused no aëration and drainage of any consequence, which could have favoured oxidation of the peat. 
Although the picture we have outlined of the development of the more reducing milicu is largely hypothetical, we do think we may safely assume that a relationship exists between the blue-black nature of this deposit and its position in the Hunze depression, viz. in the lee of the sand ridge. The fact that the growth of the highly humified Sphagnum peat continued here for approximately 500 years more is an indication that originally this peat was in all probability not yet acidic enough for the establishment of the fresh and poorly humified peat formers, see I I.34.3. and I 1.34.4. (p. 191), I I.37. and I I.38. (p. 20 I ff.).

\section{1.9. The OCCURRENCE OF EMPETRUM NIGRUM L.}

A generally very conspicuous Empetrum maximum is present in a large number of pollen diagrams of this peat area: 3-Po fig. (66), spectra 35-44; I I-Po (fig. 74), spectra 5-22; I 7A-Po/bog plants (fig. 79), spectra I I-15; I 7 B-Po/bog plants (fig. 83), spectra $3-9$; 24-Po (fig. 93), spectrum 3; 28-Po (fig. 96), spectrum I I; 29-Po (fig. 98), spectra $4-8$; 30-Po (fig. 99), spectra 7-10; 34A-Po (fig. I03), spectrum I. This maximum can be dated at the beginning of the Subboreal, roughly between $3000-2500 \mathrm{BC}$. It does not appear in the Subboreal part of 3 I-Po (fig. IOo), which, considering the peat found in profile Emmen $3{ }^{1}$ (Meyanthes-Betula peat), is not surprising. An Empetrum maximum is present in spectra 7-10 in I-Po (fig. 64), i.e. somewhat later in the Subboreal. This very general occurrence of Empetrum pollen in the diagrams is an indication of the existence of extensive Empetrum nigrum vegetations during the foration of both complexes of highly humified Sphagnum peat at the beginning of the Subboreal.

At the present time the plant is regularly in evidence around (raised) bog pools in north-west German raised bogs (MüLLER, 1965) As far as its appearance on the bogs is concerned, we know the plant particularly from the raised bog Esterweger Dose, (Germany), on the bank of some pools, and from the "Meerstalblok", $6 \mathrm{~km}$ south of the area studied, where it is also present on the margin of the now dried-up raised bog pools. Empetrum nigrum is obviously connected here with a strong wet-dry gradient in the now somewhat acidic bog surface. Although the present climate is not the same as that in the early Subboreal, it may still be supposed that the ecological requirements of Empetrum in the early Subboreal were not essentially different from the present ones. We may therefore assume that its 
early Subboreal expansion can be linked with a fairly high moisture level, or at least an increase in the moisture level in the highly humified peat. I I-Rh (fig. 75) gives a clear indication of this, where maxima for Amphitrema flavum are present (spectra 8-i I resp. and I5I8) at the level of the Empetrum maxima in I I-Po (fig. 74), spectra 7 and I6). It is not certain that Empetrum is here on the wet side of the strong wet-dry gradient, because the correspondence between increases in Empetrum and wet or moist phases in the highly humified Sphagnum peat is less clear in the diagrams of EMmEN I 7 (figs. 83, 48 and 87). The fact that the spread of Empetrum is not restricted to one highly humified Sphagnum peat complex points, in all probability, to an increase in the moisture content in the bog, which was caused climatically and which will perhaps have been optimal for Empetrum growth c. $2500 \mathrm{BC}$. Along with this, the correct degree of acidity and good trophic circumstances would have been important factors.

The disappearance of the extensive Empetrum vegetations, 2500 $\mathrm{BC}$, must have taken place within a comparatively short time. This can be caused by changes in the degree of acidity or the trophic conditions as well as by a desiccation. We regard it as not impossible that the drainage of c. $2500 \mathrm{BC}$ in the central basin of the bog (cf. I 1.I4), in spite of its localized extent, still had a somewhat desiccating effect even on the highly humified Sphagnum peat far removed from the drainage centre, due to which the bog became rather too dry for Empetrum nigrum.

Formation of Empetrum peat recognizable on the peat-faces did not take place, with perhaps the exception of the moist phase in peat-face $\mathrm{C}$. In this connection, however, local conditions had a great influence on the development of this somewhat less humified layer, see I I.I2.

Although the hummock and hollow-peat must have been moist enough in many places, no large-scale establishment of Empetrum took place in the intermediate deposits. This means that the occurrence of Empetrum nigrum in the peat would not have been dependent only on a certain degree of moisture gradient. Probably the peat of the intermediate deposit was too acidic and too oligotrophic to enable extensive Empetrum nigrum vegetations to develop. Considering the distribution of Empetrum nigrum, increase in the mineral content of the bog surface would have had no positive effect on its establishment. Eutrophication was undoubtedly of importance, since it is particularly in the vicinity of raised bog lakes that Empetrum can develop on a large scale. 
Calluna turns out to be present as an important peat-forming component in the highly humified Sphagnum peat of face B, above pits $49-5 \mathrm{I}$, as also in face $\mathrm{E}$, above pits $\mathrm{I} 5 \mathrm{O}-\mathrm{I} 6 \mathrm{I}$, where it forms the western boundary of the "liver peat", cf. r I.13. Peat diggers know this peat, the sods of which are sharp to the touch because of the heather shoots, as "sharp peat". Calluna vulgaris can, however, be regarded as one of the common plants in the peat, since it is only very rarely absent in ombrogenous peat.

In the area studied, there were rather more heather remains visible on the peat-faces in the brown-black peat than in the blue-black peat, where a large Calluna colony developed only here and there at the top, see Emmen 20 (fig. 5o) and 23 (fig. $5^{2}$ ). An increase of the Calluna vegetation on the bog often points to desiccation and stagnation in growth (see I 1.26., section EMMEN I 7). The establishment of Calluna as a result of the recent drainage of raised bogs is a clear example of that. Overbeck (1952: quoting Hayen 1966, p. 289) could deduce the times of bog desiccations from the synchronous increase of Calluna pollen in his diagrams. The distribution of the Calluna peat which we found - in faces B and E - cannot be reasonably considered as the result of dry periods. Moreover, in the case of EMMEN I7 which we investigated thoroughly, the curves of Calluna and Sphagnum do not alternate in the way Overbeck found (cf. I7 A-Po/bog plants; i 7 B-Po/bog plants; i $7 \mathrm{C}-\mathrm{Po} /$ bog plants, fig. 83). We assume that the Calluna peat in face $\mathrm{E}$, just above a slope in the subsoil, formed here as a drier edge of the probably very moist liver peat, cf. I I. I3. In face B, there is absolutely no evidence that might explain the presence of the Calluna peat.

The occasional, strong Calluna spread appearing at the top of the blue-black peat, cf. EMMEN 23, can possibly be ascribed to the bog becoming more acidic, due to which fresh peat formers could also become established later; this is further discussed on p. 20 I ff.

Concerning the large-scale occurrence of Calluna in the highly humified Sphagnum peat in the area studied, the most important point is that this cannot primarily be linked with dry times or periods, but that the local milieu was to a large extent decisive. $A$ dry bog surface would certainly have been favourable to the establishment of Calluna, of course.

In the intermediate deposit, Calluna vulgaris is present particularly in hummocks and in the more humified, darker bands in 
hollows. This is undoubtedly connected with the drier peat which formed here, see the third main subdivision, p. I62 ff.

A remarkable phenomenon is that usually little Calluna seed was found, sometimes even less than that of Erica tetralix, even in peat with numerous woody Calluna remains. It is possible that Erica also occurs frequently in such peat, but that the larger measurement of the Calluna stems were decisive in determining the type of the peat.

\section{I.I I. THE OGGURRENGE OF ERIOPHORUM VAGINATUM L.}

One of the best-known peat components is hare's tail, of which the very tough leaf-sheath remains, called "flake" or "curl" by the peat diggers, are recognisable as tussocks or knots on the peatface. In the area studied, Eriophorum vaginatum is present both in the more and in the less humified peat; on the average, however, more in the former. Especially in the blue-black peat, it occurs more in the upper half than in the lower half. Its presence was recorded in many section drawings, e.g. EMmeN 23, fig. 52.

In face $\mathrm{H}$ a conspicuous concentration of Eriophorum vaginatum remains was observed in the topmost half of the highly humified Sphagnum peat above pits 220-221 and 224-233. The same phenomenon is present in face $\mathrm{K}$ above pits $373-383$. The topmost half of the highly himified peat of face $\mathrm{M}$ may also regarded as Eriophorum peat. Concentrations of Eriophorum knots are situated in faces $\mathrm{O}$ and $\mathrm{P}$, above pits $446-448$ and $472-474$ respectively. In this case, a correlation with the special peat-forming milieu (MenyanthesBetula peat) is obvious. Eriophorum vaginatum is completely absent from the fen and fen-wood peat; in all probability this milieu was not acidic enough. Its large extent in the blue-black peat leads to the supposition that it does not favour strongly acidic milieus.

The appearance of Eriophorum vaginatum can often be linked with desiccations or drier deposits of ombrogenous peat. Sphagnum spores usually occur in Eriophorum peat only in small numbers; rhizopods are mostly absent or show a sharp decline, see e.g. I $7 \mathrm{~A}-\mathrm{Rh} / \mathrm{Mo}$ (fig. 84) between spectra 22-75. Eriophorum can sometimes form extensive vegetations, which create an impression of desiccation levels (cf. Emmen 8, fig. 4I, and Emmen 23, fig. 52), although less clearly than the Calluna peat layers. It is, together with Calluna, a typical hummock coloniser in the hummock and hollow system. Although Eriophorum vaginatum undoubtedly has a "dry" aspect in its distribution, its occurrence may not be linked with desiccated 
peat without further qualification. It is more probable that places with a strongly fluctuating water level in comparatively highly humified, not extremely acidic peat are preferred. The appearance of Eriophorum in faces $\mathrm{O}$ and $\mathrm{P}$ can perhaps be explained in this way. The Eriophorum vegetations at the top of the highly humified peat of Emmen I 7 (fig. 45) also point to this. Eriophorum developed extensively just before the increase in moisture became visible stratigraphically - the Sphagnum cupsidatum hollow in the lower right of the section.

The Eriophorum-rich peat in face $\mathrm{H}$, pits 224-233, formed above a depression in the mineral subsoil which is also clearly reflected in the seepage peat surface. This indicates a certain degree of extra moisture in the peat rather than dry conditions.

\section{1.12. The Moist phase in Face $\mathrm{C}$}

In the highly humified Sphagnum peat of face C, there is a somewhat less humified layer at about $\mathrm{I} 4 \mathrm{~m}+$ N.A.P. above pits $63-65$, in which remarkably few Calluna remains are present. As appears from the rhizopod content, see 13 -Rh (fig. 75), spectra $13-16$, this layer possibly formed in moister conditions. The phenomenon is also present at about $14 \mathrm{~m}+$ N.A.P. in the highly humified Sphagnum peat between pits 68-70 of face C, see I I-Rh (fig. 75), spectra $\mathrm{I} 7$ and $\mathrm{I} 8$. Roughly speaking, the layer coincides with the end of the Empetrum vegetations in the peat, which can be dated at c. $2500 \mathrm{BC}$, see II.9.

The occurrence of these layers on either side of the "overflow" with ferruginous peat (see 9.16.) leads to the supposition of a correlation between these layers and the ferruginous vein. The phenomenon could be explained by assuming a desiccation of the peat surface to be dated at c. $2500 \mathrm{BC}$. Just as with the relative dryingout of c. 4500 BC (see I0.10., p. I32), the subsoil relief might again be reflected in the bog surface, with this restriction, that the considerably less shrunken iron-rich peat in the vein (which was not yet present c. $4500 \mathrm{BC}$ ) extended into the depression as a low ridge, overgrown with a thin layer of highly humified Sphagnum peat. Thus, two gulley-shaped depression swould have developed on either side of this ridge, and in them water could collect, with the result that a fairly moist, less humified Sphagnum peat could develop. It is possible that the desiccation which preceded this moist phase was the result of the drainage of the central basin of the bog which can be dated at c. $2500 \mathrm{BC}$. 


\section{II.I3. The liver PEAt IN faGe E}

In the highly humified Sphagnum peat of face E, there are to be found numerous layers, often tailing out into each other, of somewhat more yellowy-brown, liver-coloured peat, which is remarkably deficient in Calluna remains. Some peat diggers call this type of peat "liver-like". Visscher (193I) also reports the name, liver peat. He describes liver peat as a non-shrinking type of peat, which is worthless as a fuel. The highly humified peat present in face $\mathrm{E}$ is, however, suitable for the making of peat sods, so that there is a possibility that the same name is being used here for two different types of peat.

In our case, we thought that a certain similarity could be observed between these Calluna-deficient, liver-coloured peat layers of face $\mathrm{E}$ and the peat of the moist phase of face $\mathrm{C}$, see the preceding section. It appears from $17 \mathrm{~B}-\mathrm{Rh}$ (fig. 86), spectra $10-15$ and ${ }_{17} \mathrm{C}$ $-\mathrm{Rh} / \mathrm{Mo}$ (fig. 85), spectra $\mathrm{I}-3$, that very moist deposits are, in fact, present in the highly humified peat of face $\mathrm{E}$.

The stratigraphy of the highly humified peat of face $\mathrm{E}$ was not, as far as we could determine, clearly systematic. There is not present here any such regularity as occurs in a hummock and hollow pattern of the intermediate deposits, a regularity which can also be seen in the horizontal plane (cf. EMmen 32, 33 and 6, figs. 58, 59 and 39). It is possible that we are dealing here with a deposit of humified peat of limited dimensions which was formed in moist to wet conditions. Considerably drier Calluna-rich peat (pits $150-16$ I), see I I.10., is said to adjoin this peat on the west side. The position of this deposit of Calluna peat, just above a slope in the subsoil, points to the conclusion that the greater degree of moisture in this liver peat formation can be ascribed largely to a saucer or gulley-shaped bog surface and not to an increases in moisture caused by climate.

\section{II.I4. The SPhagnum PEAT DOPPLERITE LAYER IN FACES H AND I}

The thin dopplerite layer in the highly humified Sphagnum peat of faces $\mathrm{H}$ and $\mathrm{I}$ undoubtedly developed at the transition of two types of peat. There was, however, scarcely any differentiation to be observed on the peat-faces between the peat below and above the layer. Neither could large differences between the lower and upper parts of the peat be determined by pollen, rhizopod and moss analyses, cf. $19 \mathrm{~B}-\mathrm{Po}$ (fig. 88); $24 \mathrm{~A}-\mathrm{Po}$ (fig. 93); $\mathrm{IgB}-\mathrm{Rh} / \mathrm{Mo}$ (fig. 89); $24 \mathrm{~A}-\mathrm{Rh} / \mathrm{Mo}$ (fig. 94 ); $24 \mathrm{~B}-\mathrm{Rh} / \mathrm{Mo}$ (fig. 94); $25-\mathrm{Rh} / \mathrm{Mo}$ 
(fig. 95). That there nevertheless must have been an interruption in the peat forming can be deduced from the observed lack of cohesion between the lower and upper parts of the peat and from the occurrence of Pinus at the level of this layer, cf. EMmen I9, 24 and 25 (figs. 48,53 and 54). Originally we supposed that we were here dealing with a bog pool in the highly humified peat; a bowlshaped depression, filled with water, which would have been filled up with highly humified peat. The incorrectness of this supposition is evident from ${ }_{24} \mathrm{~B}-\mathrm{Rh} / \mathrm{Mo}$ (fig.94) and from $25-\mathrm{Rh} / \mathrm{Mo}$ (fig. 95); without any doubt the Sphagnum peat dopplerite layer developed at the level of a desiccation.

The most remarkable characteristics of this desiccation layer are its bowl shape and its position in the peat, almost at the lowest level of the blue-black peat. A weathered layer containing e.g. Pinus, such as happened in the brown-black faces particularly (cf. 10.13.r., p. I36), was not formed. The mineral subsoil is very porous here; if the larger number of drying cracks present in the seepage peat were open, they would have made the downward drainage of bog water quite possible. The desiccation found here perhaps developed due to a drainage of a then not very thick deposit of highly humified Sphagnum peat via the drying cracks and the mineral subsoil. This can be dated at c. 2500 BC. The centre of the drainage was, in all probability, situated at the position of the northern part of face $\mathrm{H}$ and the western part of face I, under our Sphagnum peat dopplerite layer.

The Sphagnum vegetations must have died off here as a result of this drainage. Because the drainage took place at a low level in the Sphagnum peat deposit, the bowl which was formed by the shrinking would very probably have rapidly become so moist again that peat formation could quickly resume. At some places, however, Pinus could establish itself first, especially on the higher-lying parts of the bowl-shaped depression.

It is possible to imagine that the effect of this drainage, a slight drying-out, penetrated at suitable places, into the brown-black Sphagnum peat deposit which was relatively sensitive to desiccation. See e.g. the moist phase in face $\mathrm{C}$ (see preceding section), which was probably caused by a relative drying-out, and the Scheuchzeria peat contact zone of face J (see 9.15., p. I04), which was presumably overgrown by Sphagnum peat after a slight desiccation. Against this, however, it can be argued that the brown-black deposit, at least apparently, shows no, or hardly any reaction to the undoubtedly much stronger drainage of c. $3100 \mathrm{BC}$ (9.14., p. 103). 


\section{I. I5. Other DESICGATION PHENOMENA}

Pinus stump layers can in general be regarded as desiccation levels. This has already been extensively discussed in the preceding chapter. Spreads of Calluna vegetations can very probably also be ascribed to drier situations in the bog. This is at least partially true for the increase in Eriophorum vaginatum, too. In contrast with the non-ferruginous fen and fen-wood peat, there are no formations present in the highly humified Sphagnum peat which indicate a prolonged interruption of the peat growth due to desiccation. Undoubtedly, this is principally connected with the differences in hydrology of the two types of peat. The increasing humidity and precipitation were possibly also factors in this.

Even more thin charcoal layers are found in the highly humified Sphagnum peat than in the fen peat. These are usually very small, sometimes less than one square metre and less than one millimetre thick. In many cases these layers, which appear on breaking open the lumps of peat, can be recognised as charred remains of Calluna vulgaris. Other charred Ericaceae, and sometimes charred Sphagnum, could also be recognised occasionally. With perhaps a few exceptions, these charcoal layers are the charred remains of the desiccated vegetation above the peat-forming surface. Particularly in dry summers the dead parts of e.g. Calluna vulgaris can easily be destroyed by the flames. These fires would only rarely have been so fierce that part of the bog surface was also destroyed. No desiccation phenomena were found in the transition to the intermediate deposit. It even appears that the moisture level began to increase during the formation of the highly humified peat.

\section{I.r6. HumMOCKS AND HoLlows}

The generally uniform humification, and especially the strong humification, make observation of the texture of the highly humified peat difficult. The absence of the particularly conspicuous hummock and hollow pattern does not mean that no hummocks and hollows existed. Their occurrence in the highly humified Sphagnum peat formation is evident in Emmen 33 (fig. 59). The strong similarity in shape, dimensions and pattern with the hummocks and hollows from the intermediate deposit (see II.35., p. $197 \mathrm{ff}$.) can be regarded as evidence that we are not dealing with an exception in EMmEN 33 caused by uncommon, e.g. very wet, 
conditions. Moreover, it is scarcely conceivable that the extensive Sphagnum rubellum peat growth proceeded without hummocks and hollows. The hollows were probably less moist than in the intermediate deposit, due to which less differentiation could occur into hummock and hollow peat.

Especially in those places in the blue-black peat where Eriophorum vaginatum could develop extensively, the bog surface very probably did not have hummocks and hollows of the types we distinguished, which will be discussed in the third main subdivision. Moreover, Sphagnum swards must have been present here and there, as they can also be found on bog surfaces of more recent date. Our impression is that these occurred more in the blue-black peat than in the brown -black peat, since the former complex has a somewhat more uniform stratigraphy.

\section{Menyanthes-Betula peat}

The discussion of this deposit is based especially on information which was derived from the preceding main subdivision (p. I 39 ff.), peat-faces $\mathrm{O}$ and $\mathrm{P}$, and from profile EMmen $3^{\mathrm{I}}$.

\section{I.17. Emmen 31, face O, pit 442}

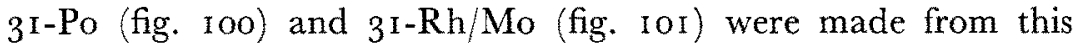
profile, sampled about $500 \mathrm{~m}$ east of the former river, the Runde. The profile was ${ }^{14} \mathrm{C}$-dated at 3 levels:

I. the upper side of the Menyanthes-Betula peat: $1920 \pm 60 \mathrm{BC}$ $\left(\mathrm{GrN}_{4} 626\right.$ ),

2. the thin Scheuchzeria layer containing wood remains at $15.06 \mathrm{~m}$ + N.A.P.: $235^{\circ} \pm 55 \mathrm{BC}\left(\mathrm{GrN}_{4803}\right)$,

3. the seepage peat dopplerite layer: $229^{\circ} \pm 60 \mathrm{BC}\left(\mathrm{GrN}_{480}\right)$. The dates are given in $3 \mathrm{I}-\mathrm{Po}$, see also table I.

Fagus is absent from the lowermost spectra of $3 \mathrm{I}-\mathrm{Po}$; Plantago lanceolata appears in spectrum 4 and Carpinus is absent from whole diagram. Although the Ulmus curve provides absolutely no indication in this direction, it is not impossible that the transition Atlantic/ Subboreal can be placed between spectra $\mathrm{I}$ and 4 . The ${ }^{14} \mathrm{C}$-date for the peat immediately above spectrum I $(2290 \mathrm{BC})$ is undoubtedly too young. It is possible that contamination occurred during 
the sampling. Evidence for placing the transition Atl/SB between spectra I and 4, i.e. at the level of the seepage peat dopplerite layer, includes the existence of this dopplerite layer itself, the siderite lenses in the seepage peat occurring almost as far as the dopplerite layer, and the dopplerite-filled drying cracks which stretch from the upper side of the seepage peat to within the fluviatile subsoil (see also 9.9., p. 96). The greater age $\left(235^{\circ} \mathrm{BC}\right)$ of the sample from $60 \mathrm{~cm}$ higher also indicates an incorrect dating of the seepage peat dopplerite level. There can actually be no doubt that the desiccation of the seepage peat here involves the same phenomenon as the desiccation in profile EMmen 30 (face M, pit 407), dated at $\mathbf{c}$. 3 roo BC, see 10.8., p. I3I.

It looks as if the development after the desiccation of about 3100 $\mathrm{BC}$ originally followed the trend of ombrogenous peat growth; Scheuchzeria vegetations became established on the peat surface, as in many places elsewhere in the seepage peat area, in which Amphitrema flavum could flourish $(3 \mathrm{I}-\mathrm{Rh} / \mathrm{Mo}$, spectrum 2$)$. Then a reversal took place quite rapidly to a milieu in which - according to macroscopic remains - Betula and Menyanthes found a suitable habitat. Recognisable Sphagnum remains are not present in the majority of the samples of the Menyanthes-Betula peat (3I-Rh/Mo, spectra 5 and $8-16$ ). Rhizopods found no suitable habitat in this milieu. Polytrichum sp. was found at a few levels, see $3 \mathrm{I}-\mathrm{Rh} / \mathrm{Mo}$, spectrum 7 , among others. The change-over to highly humified Sphagnum peat, shortly after $2000 \mathrm{BC}$, is clearly visible in the diagrams (spectra I6-18). We could not identify one of the Sphagna established here. It is possible that the reversal was the result of increasing acidity of the bog water, see the sections EMmen 9 (II.2I.) and EMMEN I7 (I I.26.) of the next main subdivision.

1 1. 18. STRATIGRAPHICAL ASPEGTS OF THE MENYANTHES-BETULA PEAT

This non-ferruginous peat has a very localised spread; we found it only in faces $O$ and $P$. It is possible that VIsscher (193I) observed it in his profile 79 , c. $500 \mathrm{~m}$ north-west of face $\mathrm{O}$. The extent of the deposit is only very imperfectly known. Only the eastern limit is known with certainty. One certain fact about the southern limit is that this peat does not occur south of the east-west orientated cover-sand ridge (fig. 3). Neither is it present in faces $\mathrm{M}$ and $\mathrm{N}$; the western limit probably does not extend much further than the 
western end of faces $\mathrm{O}$ and $\mathrm{P}$. The spread in a northerly direction is completely unknown. In fig. 13 we have given the possible distribution of the Menyanthes-Betula peat.

The most noticeable aspect of this deposit is its stratigraphical position: on the seepage peat. It is surrounded by highly humified Sphagnum peat. A clear dopplerite layer separates the seepage peat from the Menyanthes-Betula peat. Only in pit 433 of face $\mathrm{O}$ is this sharp transition absent, see also 9.16. The lowest point of the deposit was found in face O, pit 426 at i $4.30 \mathrm{~m}+$ N.A.P.; the highest point measured is in face $P$, pit $47 \mathrm{I}$ at $16.20 \mathrm{~m}+$ N.A.P. This is somewhat higher than the highest point of the east-west orientated cover-sand ridge; it may be assumed that this would have been considerably more before the artificial drainage of the raised bog. The deposit is somewhat thicker in face $\mathrm{P}$ than in face $\mathrm{O}, 200 \mathrm{~m}$ further north. This is perhaps an indication that the MenyanthesBetula deposit tails off in a northerly direction.

The formation of this peat must have started up shortly after the desiccation of C. 3 I0o BG, see I I.I7., EMmEN 31. The end was dated at $1920 \mathrm{BC}$.

The average thickness of the deposit is about $75 \mathrm{~cm}$. The rate of accumulation amounts to $7.5 \mathrm{~cm} / 100$ years; that of the blueblack highly humified Sphagnum peat, of which this deposit forms the eastern border, is, roughly speaking, $7 \mathrm{~cm} /$ I oo years, see p. 147 . There can therefore have been no noticeable difference in height between the two deposits during the formation of the MenyanthesBetula peat. The peat growth continued for more than Iooo years without great changes in the total area, see peat-faces $O$ and $P$. This is an indication of relatively undisturbed conditions. Betula was the most frequently occurring tree in this fen-wood. The undergrowth included Rumex, Dryopteris, (3 I-Po, fig. I0o), Polytrichum and Aulacomnium palustre (3I-Rh/Mo, fig. IoI). The numerous seeds and the frequent occurrence of leaf remains of Menyanthes trifoliata in this peat are indications of a high moisture level in this oligotrophic carr. Rhizopods did not find a suitable habitat here; they are almost entirely absent from this peat. The wood-rich level of spectrum 10 (fig. Ioo, $3 \mathrm{I}-\mathrm{Po}$ ), dated at $235^{\circ} \mathrm{BC}$, is very probably a desiccation level, on which Scheuchzeria palustris established itself when it became moister and possibly also more acidic here. Perhaps a connection exists between this desiccation and that of c. 2500 BC, which was discussed in I 1. I 4. (Sphagnum peat dopplerite layer).

The bog rivulet, the Runde, flowed in the neighbourhood of the 
Menyanthes-Betula peat right up to the time of the artificial drainage of the south-east Drenthe raised bog area. We assume that the Runde originated from this peat which formed between two different highly humified Sphagnum bog complexes. Because of the absence of suitable peat-faces we were not able to test this further.

\section{1.19. THE ORIGIN OF THE RUNDE}

Up to some time during the igth century, the drainage of the southern part of the Bourtanger Moor in the Hunze depression took place via the rivulet, the Runde, which probably had its source in the "Zwarte Meer" (Black Lake), 3-4 km south of the south-eastern point of the investigation area (see fig. I 7). The position of the "Zwarte Meer" and the course of the Runde do not correspond with a valley-like scour of the mineral subsoil; it is therefore certain that both phenomena originated only after the beginning of the peat forming (Visscher, I93I). The course of the Runde is drawn on the distribution maps according to data of topographical map i8C, Klazienaveen (I : 25000, I959 edition). This course only approximates to the former actual bed of the rivulet in the bog.

Roughly speaking, the Runde flows over a low, approximately $\mathrm{N}-\mathrm{S}$ sand ridge in the Hunze depression; this does not clearly emerge in the contour map, fig. 4. The presence of this ridge does, however, appear from the contours of the sandy subsoil of faces $\mathrm{K}$, $\mathrm{L}, \mathrm{M}, \mathrm{N}, \mathrm{O}$ and $\mathrm{P}$. VIssaHer dates the origin during the seepage peat forming, i.e. in the Atlantic (see 9.5.1., p. 88). There are, however, no breaks in the seepage peat dopplerite layer or other characteristics present in the seepage peat in faces $\mathrm{K}, \mathrm{L}, \mathrm{M}, \mathrm{N}, \mathrm{O}$ and $P$ which would indicate a very strong flow of water during the seepage peat forming, as Visscher assumed. Moreover, the type of peat outlined in 9.16., p. 105, would probably not have developed in such a milieu. Also, the Runde flows over the east-west orientated cover-sand ridge, which was not overgrown by soligenous peat. According to VISSCHER, not a single trace of a river bed is present in this ridge, so that the southern part of the river can only have originated after the sand ridge had been overgrown with peat (between c. $2500-2000 \mathrm{BC}$, see 1 1.38.). It is our opinion that it can be taken as certain that the Runde dates from after the desiccation of c. 3 roo BC and due to this it can be regarded as a raised bog river s.s., existing in the contact zone between two bog complexes. 
This could explain its presence just above the highest part of the Hunze depression. The western bog complex is present in, among others, peat faces F, G, H, I, J, K, L, M and N; a fragment of the eastern complex was found by us in face $Q$. Both began to develop c. 3 roo BC on the desiccated seepage peat surface.

The milieu in the contact zone must have been unsuitable for Sphagnum growth, possibly due to accumulation of dissolved minerals, and because of this, a carr could develop. We consider this explanation for the origin of the Menyanthes-Betula peat deposit to be quite probable. Originally, little or no drainage will have occurred in a northerly direction, since relatively little water was available as yet in the developing Sphagnum peat. A directed flow of water in this contact zone can only have become a reality with an increasing water content in the surrounding peat. When and how this arose cannot be deduced from the composition of the MenyanthesBetula peat deposits. It is possible that the movement of the water in a northerly direction remained diffuse till c. $2000 \mathrm{BC}$, i.e. without the formation of clear gulleys. The water was not very acidic, since the highly humified Sphagnum peat was formed in a somewhat reducing milieu, see I r.8. Scheuchzeria palustris could survive for only a few periods, lásting for relatively short times, see Ir.39., p. 203. The water was oligotrophic, since only peat with much Betula and Menyanthes developed, see I I.I 7., 3 I-Po.

The end of the Menyanthes-Betula peat forming will not have signified the end of the drainage, i.e. the Runde. How water transport took place after c. $2000 \mathrm{BC}$ cannot be deduced from the field information at our disposal. Presumably, a shift of the drainage course occurred: there are no remains of gulleys present in the highly humified Sphagnum peat which covered the Menyanthes-Betula peat, whereas the water content and probably also the water surplus would have increased in this peat area, about 2000 BC; see I I.34.4., p. I93 and I I.49., p. 227, in which the Runde as a drainage rivulet will be further discussed. To the north of the investigation area, the Runde proceeds in a northerly direction as Ruiten $\mathrm{A}$, and then as Westerwoldse A, the mouth of which is in the Dollard, see fig. I. The bed of the still existing part of this river is in the mineral subsoil. 


\section{Intermediate deposits}

\section{I.20. INTRODUCTION}

The information on which the discussion of the intermediate deposits is based is principally derived from:

- peat-faces $B-Q$,

- the ombrogenous peat parts of the ${ }^{14} \mathrm{C}$-diagram and of the profle EMMERERFSCHEIDENVEEN I (fig. 63), which were discussed in 4.2 . (p. 47 ),

- profile Emmen I I, from peat-face $\mathrm{C}$, between pits 68 and 69 , which was discussed in I I.3. (p. I4I), see figs. 74 and 75,

- profile Emmen I3, from peat-face $\mathrm{C}$, pit 64, which was discussed in 11.4 . (p. 1 42), see fig. 75 ,

--- section EMmEN 33 (fig. 59), which was discussed in I 1.5 . (p. I43), see also fig. 102; the position of this section is indicated in fig. 2,

- profile EMMEN $3^{\mathrm{I}}$, from peat-face O, pit $44^{2}$, which was discussed in 11.17 . (p. 157), see also figs. Ioo and Ior,

- the ombrogenous peat parts of sections EMMEN 24 (fig. 53), Emmen 25 (fig. 54), Emmen 26 (fig. 55) and EMmeN 27 (fig. 56) from peat-face I, between pits $279-282$, see II.42.-II.45. (p. $2 \mathrm{I} 3 \mathrm{ff}$.); the seepage peat part of these sections has already been discussed in $8.1 .$, p. 70 ,

- section EMmen 5 (fig. $3^{8}$ ) from peat-face B, pit 33 ; see 1 I. 50 , p. 229 ,

- section Emmen 6 (fig. 39), from peat-face B, between pits $44-5^{\text {I }}$; see I I. $23 .$, p. I 70 ,

- section Emmen 7 (fig. 40), from peat-face B, above pits 48-49; see I I.24., p. I 72 ,

- section EMmen 8 (fig. 4I), from peat-face B, above pit $5^{\circ}$; see I 1.22, p. 168 ,

- section EMmen 9 (fig. 42), from peat-face B, above pits $5^{\mathrm{O}-5^{1}}$; see 11.21 , p. I 64 ,

- section Emmen 12 (fig. 44), from peat-face $\mathrm{C}$, above pit 68; see I I 25, , p. I 72 ,

- the profiles EMmen 15 from peat-face D, near pit 68; see I I.28., p. 184 ,

- the rhizopod analyses Emmen i6, from peat-face E, above pits I $65-166$; see I I.29., p. I84, and table IX,

- section EMMEN I 7 (fig. 45), from peat-face E, above pits $17 \mathrm{I}$ 172; see 11.26., p. 174. This section was already discussed in CAsparie ig69, 
- section Emmen i 8 (fig. 47), from peat-face E, above pit I 78 ; see I I.27., p. I 82 ,

- section Eммел 19 (figs. 48 and 49), from peat-face $\mathrm{H}$, above pits 263-268; see I I.4I., p. 209. The seepage peat and the dopplerite layers of this section have already been discussed in 9. I. p. $8 \mathrm{I}$ and 10.6 .2 . p. 129 ,

- section Emmen 20 (fig. 50), from peat-face $\mathrm{H}$, above pit 235; see II.32. p. I 87 ,

- section Emmen 22 (fig. 5 I), from peat-face $\mathrm{H}$, above pit 224; see I I.3o., p. i 85 ,

- section Emmen 23 (fig. 52), from peat-face $\mathrm{H}$, above pit 223; see II.3I., p. I 86 ,

- section EMMEN 28 (fig. 57), from peat-face I, above pits 288 289 ; see I I.46., p. 216 ,

- section EMMEN 32 (fig. 58 ), originating c. IO00 $\mathrm{m}$ south of peatface $M$, (see fig. 2); see I I. 33., p. I 88,

- section EMmeN 34 (fig. 6o) originating about $10 \mathrm{~km}$ south of the area investigated (see fig. Io), see I I.40., p. 206.

In a vertical line, there is, towards the top of the intermediate deposits, an increase in fresh Sphagnum peat at the expense of highly humified peat. In a horizontal line, a clear alternation can be observed in most places between highly humified Sphagnum rubellum hummocks, often containing many remains of Eriophorum vaginatum and Calluna vulgaris, and fresh hollows, the basis of which is fresh Sphagnum cuspidatum peat. The already mentioned division (I I.I., p. I38) of the hummocks and hollows into four types was made on the basis of shape and dimensions, the dates and the vegetational development (which can be deduced from the analyses). The information given in the following sections has been arranged in four groups according to the four types, each group being named according to the most extensively investigated section. Both the morphology and the genetics of the four types will be discussed in sections I I.34. I I.38. (p. r 89 ff.). They are schematically represented in fig. 6r. The distribution of the four types was determined by surveying and reproduced in fig. 16.

The line which connects the fresh hollow bases, i.e. the lowest level at which fresh (Sphagnum cuspidatum) peat appears, was taken as the under-side of the intermediate deposits, see also i r.7., p. I 45 . The intermediate deposits ended when the more humified hummocks were overgrown by fresh peat. Neither the one level nor the other can always be exactly determined on the peat-face, since the obser- 
vation points (the pits of the peat-faces) were not always chosen at the position of a hollow base or a hummock top. This means that, in actual fact, the peat of the intermediate deposits sometimes begins at a lower level and extends to a higher level than is indicated in the peat-face drawings.

Exceptions to the mosaic of hummocks and hollows visible on the peat-faces are present in the marginal parts, see sections 1 1.50. and I I.5I., p. 23I ff., and in faces $H$ and $I$ in the central part of the bog. The bog lake, EMmen 19, developed here (i I.47., p. 218). A close relationship seems to exist between the growth mechanisms of the different hummock and hollow systems and the drainage pattern in the intermediate deposits. The raised bog lake, Emmen r 9, occupies a crucial position in this drainage system. Information necessary for the discussion of the drainage system is given in sections Ir.4o. - I I.46., p. $206 \mathrm{ff}$. The drainage system and the relationship of the different hummock and hollow systems with this drainage will be discussed in sections I I.47.-- I I.49., p. 2 I8ff. Before proceeding to this, the distribution of Scheuchzeria palustris, both horizontally and vertically, in the area studied will be dealt with, II.39., p. 203. I I.52., p. 233 deals with the occurrence of Sphagnum papillosum and Sphagnum imbricatum in this peat area. In I I.53., p. 235, a discussion is given concerning the three wooden trackways found in the intermediate deposits, and, finally, in I I.54., p. 236 , the views of a number of authors on the transition from highly humified to fresh Sphagnum peat will be briefly discussed.

\section{Type Emmen 9}

I I.2 I. Emmen 9 (fig. 42), face B, between pits 50-5I

This section has been drawn in, using a grid with $0.1 \times 0.1 \mathrm{~m}$ squares. Diagrams $9 \mathrm{~A}-\mathrm{Po}, 9 \mathrm{~B}-\mathrm{Po}$ (fig. $7 \mathrm{I}$ ); $9 \mathrm{~A}-\mathrm{Rh} / \mathrm{Mo}$ and $9 \mathrm{~B}-$ $\mathrm{Rh} / \mathrm{Mo}_{\text {(fig. }}$ 72) were made from the two profiles sampled. By means of the two pollen diagrams, a short-distance correlation was established, by which six synchronous levels could be distinguished in the section, see fig. 43 .

\section{I.2 I. I. Correlations and datings}

In 9 A-Po, spectra 5,7 and 8 , Fagus increases from $0.8-2.5 \%$, Carpinus from 0.2 - $1.8 \%$, only to become somewhat lower again in spectrum I , Corylus drops from $23-$ c. $7 \%$. Fraxinus is present with low values, c. I $\%$, while the continuous Tilia curve ends. In $9 \mathrm{~B}-\mathrm{Po}$, spectra 6,8 and 9 , Fagus increases from $\mathrm{I} .3$ via $2.2-$ 
I. $6 \%$. Carpinus remains at c. $0.2 \%$, Corylus drops from c. $2 \mathrm{I}-\mathrm{I}-\mathrm{I} 6 \%$, while the continuous Tilia curve ends.

We can conclude from this that, in spite of the dissimilarity in the paths of a few curves, the two diagrams are synchronous, with the qualification that $9 \mathrm{~A}-\mathrm{Po}$ continues longer. The sections in $9 \mathrm{~A}-$ Po and $9 \mathrm{~B}-\mathrm{Po}$ which are thought to be strictly synchronous have been given as a rectangle between the lithology and the main diagram. It is clear that, in the right-hand half of the section $\left({ }_{9} \mathrm{~B}\right)$, a larger peat accumulation developed than in the left-hand half $(9 \mathrm{~A})$.

The conclusion from pollen analysis is supported by stratigraphical information. Running through both profiles, some more humified (darker). bands are present in the fresh (lighter) peat in the section, e.g. from $\mathrm{j}$, I via c, 35 to e, 50 and from 1,3 via $\mathrm{l} / \mathrm{m}, \mathrm{I} 3$ and $\mathrm{f}, 3^{8}$ to $\mathrm{g}, 5^{\circ}$. They are all somewhat closer together in $9 \mathrm{~A}$ than in $9 \mathrm{~B}$. In view of the very short distances over which correlations were made, we think it may be assumed that each darker band represents a synchronous level.

On the grounds of the above observations and considerations, six synchronous levels were distinguished in this section, below. They are shown in fig. 43. The levels were characterised as follows (see also 9A-Po and $9 \mathrm{~B}-\mathrm{Po}$, fig. $7 \mathrm{I}$ ):

$\alpha$ in gA:the basis of the fresh Sphagnum cuspidatum-Scheuchzeria layer; in $9 \mathrm{~B}$ : the right-hand tip of the same Scheuchzeria deposit, which is moderately humified here.

Can be dated between $2000-\mathrm{I} 500 \mathrm{BC}$, even before the beginning of the increase in Fagus to I \%.

$\beta$ in $9 \mathrm{~A}$ : the thin Calluna-rich layer of moderately humified peat, from which spectrum 5 comes;

in $9 \mathrm{~B}$ : the Calluna-rich layer of highly humified peat under a layer of considerably less humified peat.

Originated still in the Subboreal (Corylus more than $20 \%$, Fagus c. 1 \%), probably between goo--1200 BC.

$\gamma$ in $9 \mathrm{~A}$ : the double, moderately humified layer above $\beta$;

in $9 \mathrm{~B}$ : rather high up in a layer of moderately humified peat, which is covered by a thin layer of fresh to moderately humified peat, on which Eriophorum-rich peat lies.

This layer can probably be dated to the beginning of the Subatlantic, at c. $700 \mathrm{BC}$.

$\delta$ in $9 \mathrm{~A}$ : a moderately humified layer, a few centimetres under a cuspidatum layer; 
in $9 \mathrm{~B}:$ a comparatively thin, Calluna-rich layer of moderately humified peat, lying on and under fresh peat.

Can be dated to c. $600 \mathrm{BC}$, in the period of the first large increase in Fagus.

$\varepsilon$ in $9 \mathrm{~A}$ : the $\mathrm{c.} 4 \mathrm{~cm}$ thick cuspidatum layer;

in ${ }_{9} \mathrm{~B}$ : a relatively thick, moderately humified Calluna-rich layer. Can be dated to c. $500 \mathrm{BC}$, at the level of the first large Fagus maximum, which is not present in the diagrams as a result of the large sampling distance. Comparison with the many other diagrams from this area shows that this supposition must be correct.

$\zeta$ in $9 \mathrm{~A}$ : a very thin cuspidatum layer on a thin layer of moderately humified peat;

in $9 \mathrm{~B}$ : a thin, Calluna-rich, moderately humified layer at the top of the section. The wooden trackway XIV (Bou), which is dated to $170 \mathrm{BC}$ (see II.24.), lies on this layer.

There is satisfactory agreement between the pollen analytical data and the stratigraphical observations as far as the levels $\beta, \gamma$ and $\delta$ are concerned. The stratigraphical correlation of the remaining levels is much clearer, since the darker bands and, in the case of the lowest level, the transition in peat-type, can be followed without difficulty right through the section. The conclusion that the six synchronous levels which have been assumed suggest six fossil bog surfaces, to be dated between 2000 and $170 \mathrm{BC}$, is therefore wellgrounded. During this time, approximately twice as much organic material accumulated in the right-hand part of the section, profile $9 \mathrm{~B}$, as in the left-hand side of the sction, profile $9 \mathrm{~A}$.

The course of these 6 fossil bog surfaces, see fig. 43 , clearly illustrates this difference in the rate of accumulation.

\section{I.2 I.2. The bog development}

The Middle Atlantic Pinus forest (between $14.00-14.50 \mathrm{~m}+$ N.A.P.) was overgrown by a highly humified Sphagnum peat containing predominantly Sphagnum rubellum, in which Ericaceae were important constituents. A hummock formed just above the remarkably thick stump in the right-hand side of the section, while a hollow developed in the left-hand side (p/q, I-I $)$. The edge of the hollow consists of moderately humified peat containing Scheuchzeria ( $\mathrm{q}$, I9-33). The large number of Amphitremas, the profusion of Scheuchzeria palustris and of fresh Sphagnum cuspidatum peat indicate the pre- 
sence of open water in the hollow, during part of the year at least.

Sphagnum papillosum ( $9 \mathrm{~A}-\mathrm{Rh} / \mathrm{Mo}$, spectrum 3) established itself in the hollow, and continued growing during the time the hollow remained in existence. Originally this Sphagnum occurred in the hummock too, $(9 \mathrm{~B}-\mathrm{Rh} / \mathrm{Mo}$, spectrum 5$)$, but it played no part in the upward growth of the hummock. S. imbricatum, which originally did not occur in the hollow, developed well here (see also i i.52,, p. 233). Layers with more humified peat (the darker bands) alternate with a lighter coloured fresh peat in both the hollow and the hummock.

It is not clear from $9 \mathrm{~A}-\mathrm{Rh} / \mathrm{Mo}$ whether the darker bands were formed under drier conditions than the fresh papillosum peat in between them.

The values for Amphitrema wrightianum in the layers of moderately humified peat are only slightly lower than in fresh peat (spectra 5 , 7 and $8=$ levels $\beta, \gamma$ and $\delta$ opposite spectra 4 and 6 ). There is therefore no question of real desiccations, due to which Calluna-dominated hummock communities could spread over the hollows. Very probably, however, regularly occurring changes in the local bog hydrology contributed to the fact that the hollow at the left-hand side of the section has a layered filling.

The hummock was built up of peat which formed under considerably drier conditions, and in which hardly any rhizopods occur $(9 \mathrm{~B}-\mathrm{Rh} / \mathrm{Mo}$, spectra $3-9)$. Large fluctuations in the moisture content are not demonstrable in the hum mock. However, the spreading-outwards of the Calluna vegetations both in the hummock and over the edge of the hollow $(0,25-n, 29$ and $m, 29-1,36)$ point to variations in the water content of the bog surface during the upward growth of the hummock.

The smaller peat accumulation in the hollow can perhaps be partly ascribed to the occurrence of erosion; there is a small irregularity present in the peat-face at $1 / \mathrm{m}, 12-15$, possibly the remains of a bog stream. Perhaps a regularly occurring flow of water through the hollow prevented the establishment of rapidly accumulating Sphagna. After the flooding between 2000 and 1500 BC, Sphagnum cuspidatum re-established itself on a larger scale only once in the hollow (1, I-I3). This layer of c. 500 BC can very probably be related to the bog stream of $1 / \mathrm{m}$, I2-I 5 . After $1500-1200 \mathrm{BC}$ there is no longer any question of a hollow with stagnant open water, a pool, with the exception, then, of a period around $500 \mathrm{BC}$. In the plane of observation, the darker bands $\delta, \varepsilon$ and $\zeta$ have no contact with the hummock, the centre of which came to lie clearly outside 
the plane of observation during the upward growth. Comparison of the two rhizopod diagrams shows that, originally, between 2000 and $600 \mathrm{BC}$, large differences in water content existed on the surface. In $9 \mathrm{~A}-\mathrm{Rh} / \mathrm{Mo}$, spectra $3-\mathrm{Io}$, the Amphitremas especially appear in large numbers, while in $9 \mathrm{~B}-\mathrm{Rh} / \mathrm{Mo}$, spectra $2-\mathrm{Io}$, these rhizopods, which live in moist to wet Sphagna, are present at the most in small numbers.

This originally clear differentiation between less humified, humid peat and more highly humified, drier peat which is often more Calluna-rich, gives way after c. $600 \mathrm{BC}$ to a situation in which there is no longer a clearly discernible difference in water content, at least according to $9 \mathrm{~B}-\mathrm{Rh} / \mathrm{Mo}$, spectra $\mathrm{IO}-\mathrm{I} 3$. However, these topmost spectra come from the edge of the hollow from which Sphagnum papillosum is still absent, and not from the hummock.

The hummock would meanwhile have become considerably smaller and would very probably have had a rhizopod content which is directly comparable with that of $9 \mathrm{~B}-\mathrm{Rh} / \mathrm{Mo}$, spectra $3-8$. By c. $600 \mathrm{BC}$, the hummocks of this type were not yet completely overgrown by hollow peat, see II.25.

I 1.22. EMmen 8 (fig. 4I), face B, above pit 50, 20 m west of EMMEN 9 (see preceding section)

This section was drawn in by means of a grid with $0.1 \times 0.1 \mathrm{~m}$ squares.

\subsection{The bog development}

Sphagna established themselves in the comparatively moist Middle Atlantic Pinus forest (14.25-I $4.55 \mathrm{~m}+$ N.A.P.), and due to this the forest was slowly overgrown by highly humified Sphagnum peat. Originally Scheuchzeria continued growing to the level j, I-8; i, 8$16 ; \mathrm{h}, 16-22 ; \mathrm{i}, 22-50$. Scheuchzeria palustris is not present above this line; Ericaceae occur at the extreme left and right of the section, Betula became established on the bog surface (h, 33- 35 and i, 49 $50)$, possibly as the result of a desiccation. Eriophorum vaginatum spread out extensively at that time $(\mathrm{g}, \mathrm{1} 9-42)$. At the extreme left and right of the section respectively, two hummocks developed on this Eriophorum-Ericaceae-surface, separated by a hollow, in which both Scheuchzeria and Sphagnum cuspidatum occur. Perhaps the hummocks developed from the Ericaceae-centre at the left of the section $(\mathrm{g} / \mathrm{h} / \mathrm{i}, \mathrm{I}-9)$ and the Eriophorum-Ericaceae-centre at the right of the section $(\mathrm{g} / \mathrm{h} / \mathrm{i}, 44-5 \mathrm{o})$. The extensive Eriophorum vegetation be- 
tween the two hummock bases, $\mathrm{g}, 19-4 \mathrm{I}$, became so wet due to the increase in moisture content that Spagnum cuspidatum was able to displace Eriophorum vaginatum $(\mathrm{f} / \mathrm{g}, 20-38)$. The moderately to highly humified cuspidatum layer thus formed was overgrown by moderately humified peat in which Scheuchzeria palustris became established after some time (f, I9-44). This flooding caused the forming of a comparatively large pool in which Sphagnum cuspidatum vegetations could develop. The cuspidatum peat deposit from $\mathrm{f}, 9$ via e/f, $18-27$ to $f, 44$, which originated in this way, was overgrown by fresh peat which soon had to give way to Calluna-containing, moderately humified peat in the centre of the hollow, e, 23-29. A moderately humified, Calluna-rich hummock containing some Eriophorumvaginatum developed here, possibly the offshoot of a hummock outside the plane of the section.

The layered structure (fresh and moderately humified peat) of the hummocks present already at the left and right-hand sides of the section arouses the suspicion that these hummock nuclei also lie outside the plane of the section. A wet hollow developed between the left-hand hummock and the centrally situated new hummock, with a Calluna-containing, moderately humified base. The cuspidatum peat which formed in this hollow $(e, 10-d, 2 I)$ was overgrown by fresh hollow peat, undoubtedly Sphagnum papillosum (e, 5-a, 22), which, in turn, had to give way to the moderately humified Eriophorum vaginatum-containing vegetations spreading out from the lefthand hummock $(\mathrm{d} / \mathrm{e}, 5-\mathrm{e}, \mathrm{I} 8)$. Such a development is not present to the right of the centrally situated hummock. A hollow margin is very probably present between e, $30-40$, which would not have contained open water. The centrally-situated hummock could not maintain itself; due to the increasing moisture content of the bog surface, the hollow vegetations became more extensive; a large hollow developed again (d, 6-40), in which Sphagnum cuspinatum vegetations could become established (d, $18-27$ and e, $28-3 \mathrm{I})$. The conspicuous shape of this layer may have been formed by a secondary process as the result of a difference in shrinkage. The small flooding lasted a comparatively short time; hummock communities established themselves again in the middle of the large hollow, on the cuspidatum peat $(\mathrm{d}, 27-30)$. The rest of the hollow was filled up by fresh peat, which was then overgrown by moderately humified peat from the hummocks. This hummock peat spread out from the Calluna-rich centre, c, $4-8$, via the centrally situated hummock to the hummock on the right. The centre of this lastmentioned hummock shifted to the left (c, 40-44). 
The centrally situated hummock was ultimately overgrown by hollow peat at the level, c, 26-3I. The layer of moderately humified peat lying on top of it is interrupted at b/c, 25-26, which was probably caused by erosion. The lump of peat concerned lies loosely at an angle of $45^{\circ}$ in very loose fresh peat.

The bog streamlet, the cause of the erosion, was undoubtedly part of the drainage system in the hollows of this peat area.

The hummocks continue above the section, where they become increasingly less pronounced. Ultimately the hummocks, right under the present-day peat surface, were completely overgrown by fresh peat. Meanwhile, the hollow developed into a bog stream with peat with a very high water content. It is the same hole as that of EMmen 7, 24-29 m, see fig. 40 and I I.24.

\section{1.23. Emmen 6 (fig. 39), peat-block B, above pits 44-5I}

This horizontal plane in the intermediate deposits was created by digging off the upper metre of peat. The surface area $\left(\mathrm{I} 35 \times 4 \mathrm{~m}^{2}\right)$ slopes from $15.90 \mathrm{~m}$ above N.A.P. at the western extremity to $15.60 \mathrm{~m}$ above N.A.P. at the eastern extremity.

The darker bands and spots visible in the surface are centres of moderate or highly humified hummock peat.

The light-coloured peat lying between the darker bands and spots is fresh hollow peat. In the hummock peat, obvious gradations in heather and hare's tail content were present, while the degree of humification varied perceptibly too (from $\mathrm{H}_{5}-\mathrm{H} 8$ ). Clear cuspidatum peat concentrations as well as Sphagnum imbricatum-papillosum peat were present in the fresh hollow. Only the distinction between hummock peat (horizontal lines close together) and hollow peat (horizontal lines further apart) was made in the report. In fig. 39 the position of the hummocks in the I $m$ high peat-face which was dug out (hummock peat, vertical lines close together and hollow peat, vertical lines further apart) and also the position of sections EMmen 7,8 and 9 have been indicated (see also fig. 40,4I and 42 ). A number of hummocks stand out in the non-synchronous surface, e.g. between $\mathrm{I} 3-15 \mathrm{~m}, 30-35 \mathrm{~m}, 45-5^{\circ} \mathrm{m}, 5^{8}-67 \mathrm{~m}$ and I I 5 - I 20 $\mathrm{m}$. Smaller pockets of hummock peat lie among these hummocks. The frequently oval-shaped bands are horizontal sections of moderately humified layers which lie between the hummocks in the hollows (see figs. $4^{\mathrm{I}}$ and 42 ). These moderately humified layers can perhaps be regarded as slight desiccation levels of very localised 


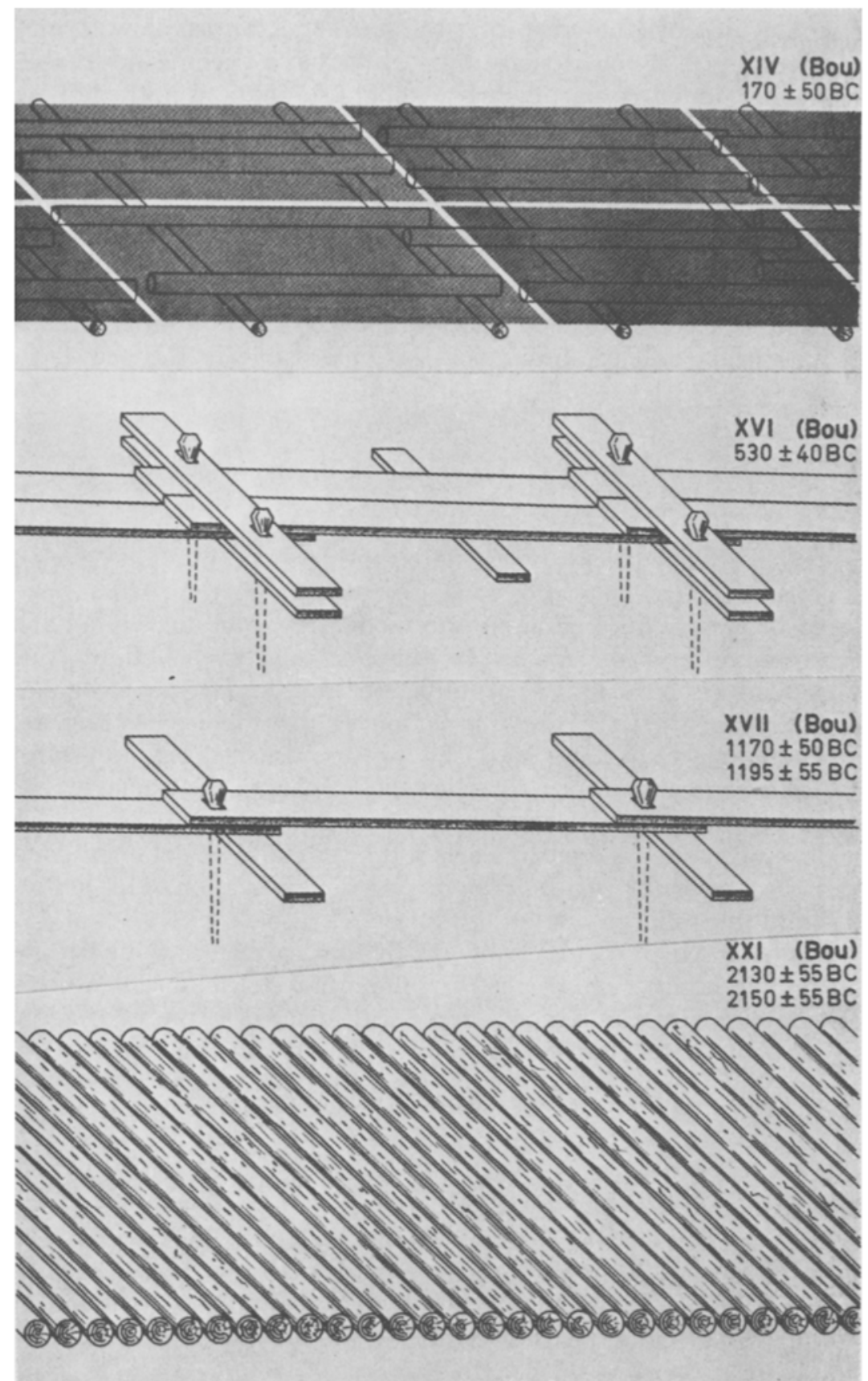

Fig. 14. Construction of the wooden trackways we found in the area studied. The numbering (after HAYEN, see foot-note, p. 26) as well as the date of each trackway is given. Only an outline of the hurdle track dating from r 70 B.C. has been given. For this path see also fig. I5. For the situation of the tracks, see fig. I 8. 
extent, which originated during the hummock and hollow formation, see II.2I. Such desiccations would have become noticeable in the marginal area particularly, as slight stagnations in the hollow peat growth, due to which hummock vegetations could take over the hollow surface.

The hummocks probably have a round to oval base of $\mathrm{c} .3$ by $5 \mathrm{~m}$, see also I I.5., p. I43. The long axis, if observable, is more or less NNW-SSE, roughly parallel to the Hondsrug, the western edge of the bog.

There is a satisfactory correlation between the hummocks found in the surface and the hummock sections visible in the peat-face.

I I.24. Emmen 7 (fig. 40), peat block B, above pits $48-49$

Part of the wooden trackway XIV (Bou), made from hurdles (see fig. ${ }_{5}$ ). The trackway was dated to $170 \pm 5^{\circ} \mathrm{BC}\left(\mathrm{GrN}_{4} \mathrm{I} 47\right)$.

During the excavation of 1963 , the peat under the road surface could be clearly differentiated into moderately humified hummock peat containing some Eriophorum vaginatum, and fresh hollow peat. This is shown in the lower part of fig. $4^{0}$, in a similar way to fig. 39 , EMmen 6, see also the preceding section. In the upper part of fig. 4 , in a similar way to EMmen 33, (fig. 59, see also I I.5., p. I43) with five-fold vertical enlargement, the relief of part of the trackway has been shown, along with the foundation found in a deep pool. This pool, which contained particularly soft peat, could be not negotiated without supporting planks, even during the excavation. This hollow is found in profile in Emmen 8, fig. 4I, see also i I.23.

The exposed peat surface of 170 BC has a relief in which hummocks and hollows can be clearly differentiated. Measurements and orientations of the hummocks agree with those of EMmEN 6 (fig. 39, see also the preceding section) and of EMmen 33 (fig. 59, see also I I.5.). The trackway was overgrown with fresh peat.

I1.25. Emmen I2 (fig. 44), peat-face C, above pit 68

Cross-section of the wooden trackway XIV (Bou) which was mentioned already in the previous section. In the drawing of the profile, differentiation was made only between moderately to highly humified hummock peat (vertical lines close together) and fresh hollow peat (vertical lines further apart). 


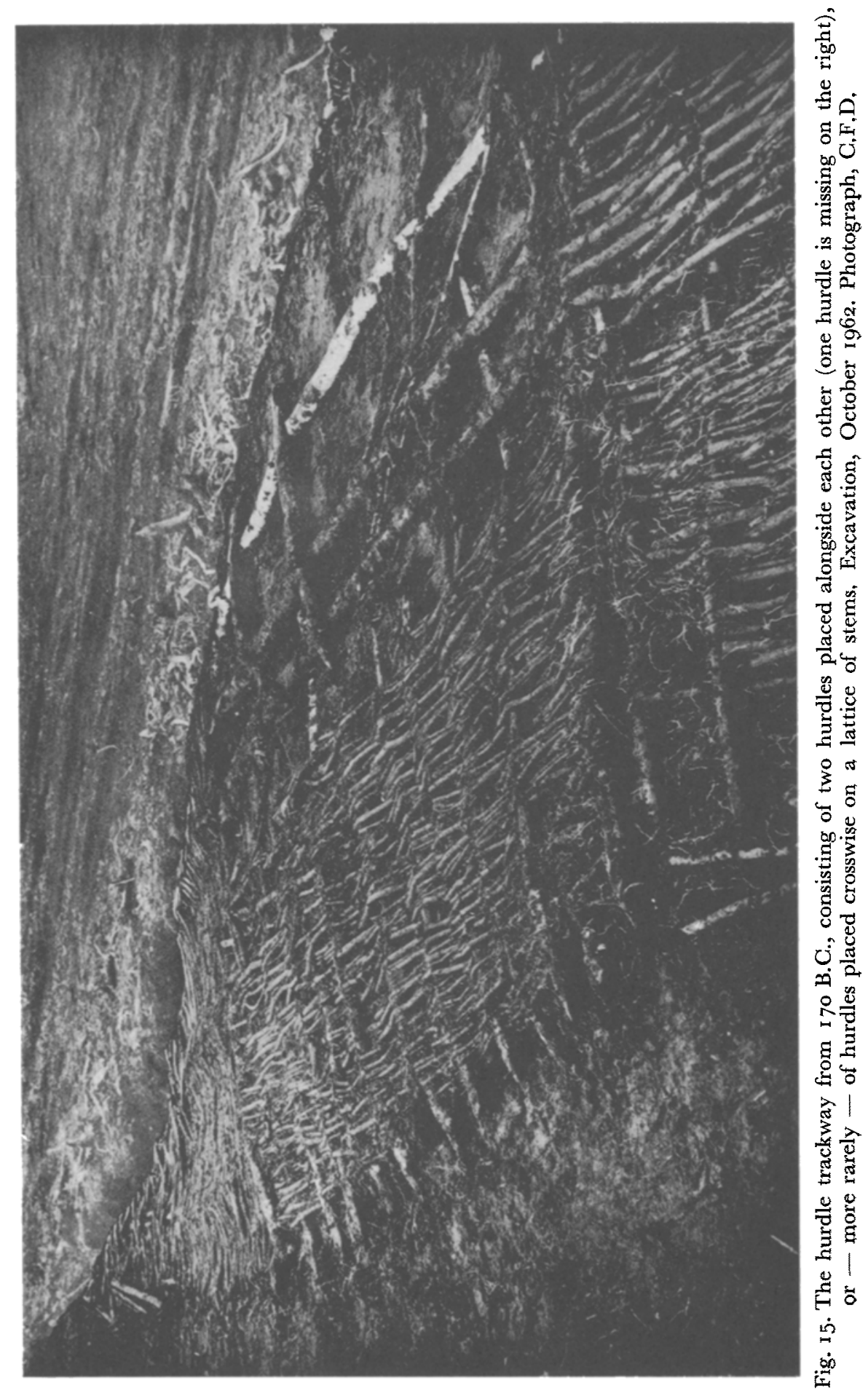


The wooden trackway was overgrown by fresh Sphagnum imbricatum-papillosum peat on the hummock as well as in the hollow, a characteristic which is also shown at several places by the wooden trackway XV (Bou), dated to $53^{\circ} \pm 4^{\circ} \mathrm{BC}\left(\mathrm{GrN}_{4} 622\right)$, see I I.28. The extra weight on the bog surface possibly caused some shrinkage, due to which it could become so moist here that a hollow milieu developed, also above the hummocks. The greater degree of weathering of the peat between the hurdles was perhaps caused by its being walked upon.

The trackway which had neither subsided nor shifted did not need to be anchored (as was necessary with wooden paths XV (Bou), see II.28., and XIV (Bou), see Ir.29., see also fig. 14); the bog surface could therefore not have been very wet at the time of the building of the wooden trackway, around $\mathrm{I}$ 70 BC.

\section{Type Emmen i7}

I I.26. Emmen I7 (fig. 45) face E, between pits I 71 and $I_{72}$

This section was drawn using a grid with $0.1 \times 0.1 \mathrm{~m}$ squares. Pollen diagrams $17 \mathrm{~A}-\mathrm{Po}$ (fig. 79), $17 \mathrm{~B}-\mathrm{Po}$ (fig. 80) and $17 \mathrm{C}-\mathrm{Po}$ (fig. 8I) were made from the three profiles sampled ( $17 \mathrm{~A}, \mathrm{I}_{7} \mathrm{~B}$ and ${ }_{7} \mathrm{C}$ ). Separate pollen diagrams, $17 \mathrm{~A}$-Po/bog plants, i $7 \mathrm{~B}-\mathrm{Po} / \mathrm{bog}$ plants and $17 \mathrm{C}-\mathrm{Po} /$ bog plants (see fig. 83), were made from the plants which grew in the pf... ?nd which occur in not inconsiderable percentages in the three pollen diagrams - Sphagnum, Empetrum, Calluna, Cyperaceae. Rhizopod muss diagrams, figs. 84 and 85 , were also made from profiles $I_{7} \mathrm{~A}$ and $\mathrm{I} 7 \mathrm{C}$. The rhizopod diagram, ${ }_{7} \mathrm{~B}-\mathrm{Rh}$ (fig. 86) and the macroscopic remains diagram ${ }_{17} \mathrm{~B}$-macr. (fig. 87) were made from profile $17 \mathrm{~B}$. In the lower half of the profile $17 \mathrm{~B}$, the samples for the latter were taken between two samples taken for rhizopod analysis.

The usual numbering has not been applied to these intermediate samples; they are numbered as follows: $2 / 3$ (= between 2 and 3 ), $5 / 6(=$ between 5 and 6$)$, etc. For this section see also Casparie I 969 .

\section{I.26.1. Correlations}

Short-distance correlation was used in the description of the bog development. For this purpose, the 3 pollen diagrams were subdivided into a number of zones, each characterised by the particular 
course of the curves. Only the curves of those plants - mostly trees - which do not grow on the bog were used for this sub-division. It may therefore be assumed that the corresponding zones in the pollen diagrams are synchronous. These three, drawn especially for the correlation pollen diagrams, are shown as $\mathrm{I} 7 \mathrm{~A}-\mathrm{Po} / \mathrm{corr}$, ${ }_{17} \mathrm{~B}$-Po/corr, and ${ }_{17} \mathrm{C}-\mathrm{Po} /$ corr in fig. 82.

The sub-divided zones are:

Zone $a$

first appearance of Fagus, Corylus lower than $20 \%$, Pinus maximum of more than $10 \%$, then decreasing to c. $6 \%$,

I 7 A: spectra $\mathrm{I}-\mathrm{II}$,

I 7 B: spectra $\mathrm{I}-5$,

$17 \mathrm{C}$ : not present.

Zone $\beta$

first appearance of Plantago lanceolata, Corylus maximum (c. $20 \%$ ), slight increase in Ulmus, increasing tendency in Fraxinus,

17 A: spectra $13-17$,

I 7 B: spectra 7 -I I,

$17 \mathrm{C}$ : not present.

Zone $\gamma$

Pinus decreases to c. $2 \%$, Corylus maximum (more than $20 \%$ ), first appearance of Carpinus, falling Ulmus curve,

I7 A: spectra I 7-24,

I $7 \mathrm{~B}:$ spectra I I-I 7 ,

I $7 \mathrm{C}$ : spectra $\mathrm{I}-4$.

Zone $\delta$

continuous Fagus curve with values below I \%, Fraxinus has higher values than Ulmus, at the bottom of the zone a decline in Corylus, after which Corylus increases again (not clear in I $7 \mathrm{~A}$ ), the tendency for Ulmus is to decrease, low Plantago lanceolata values, low Quercus maximum (not in ${ }_{17} \mathrm{C}$ ),

I 7 A: spectra $34-44$,

I 7 B: spectra $19-23$,

I $7 \mathrm{C}$ : spectra 8 - I3 or 17 .

\section{Zone $\varepsilon$}

beginning of the continuous Carpinus curve, Fagus attains values of an average of I \%, Fraxinus and Ulmus have approximately equal values of c. I \%, Plantago lanceolata maximum, 
I $7 \mathrm{~A}:$ spectra $54-64$,

I 7 B: spectra $26-40$,

I 7 C: spectra I 7 (or I9) -2 I.

Zone $\zeta$

beginning of the first large Fagus increase, beginning of the sharp Corylus decrease, Carpinus lower than I \%,

I $7 \mathrm{~A}$ : spectra $74-80$,

I 7 B: spectra $43-46$,

I $7 \mathrm{C}$ : spectrum 22.

Zone $\eta$

increase of Fagus to the first large maximum, Corylus falls to c. 10 \%, I 7 A: spectra $85-95$,

I 7 : spectra $49-66$,

r $7 \mathrm{C}$ : spectra $23-36$.

Zone $\vartheta$

sharp decrease in Fagus, Corylus is approximately ıo \%, Plantago lanceolata maximum,

I 7 A: spectra $95-$ I I 4 ,

I 7 B: spectra $66-8 \mathrm{I}$,

I $7 \mathrm{C}$ : spectra $36-38$.

Zone $\iota$

renewed increase in Fagus, rise in Carpinus,

I $7 \mathrm{~A}$ : not present,

I 7 B: spectra $86-96$,

I $7 \mathrm{C}$ : not present.

In general a satisfactory correlation is possible between the corresponding zones of the 3 diagrams. Only in $\mathrm{I} 7 \mathrm{C}-\mathrm{Po} / \mathrm{corr}$, the transition from zone $\delta$ to zone $\varepsilon$ could not be precisely determined. It is probable that this is caused by some what too large a sample distance.

A number of synchronous lines, each indicating a fossil bog surface, were drawn in the section on the basis of this zonation, to which only a strictly localised significance can be attached. These are indicated as $17-1,17-2,17-3,17-4,17-5,17-6,17-7$, I $7-8$ and $\mathrm{I} 7-9$ in fig. 46 . The approximate date which can be ascribed to each surface has been noted alongside. VAN ZeIST's $1955^{\mathrm{b}}{ }^{14} \mathrm{C}$ dates and two dates from the section were used for this: the bottom level of the moderately humified Sphagnum peat on the left next to profile $\mathrm{I} 7 \mathrm{~A}$, in $\mathrm{j}$, $10-\mathrm{I}$, at $15.07 \mathrm{~m}+$ N.A.P.: 
$\mathrm{I} 890 \pm 60 \mathrm{BC}\left(\mathrm{GrN}_{4644)}\right)$ and the topmost level of the unbroken highly humified to moderately humified (Sphagnum) peat deposit on the left next to profile $\mathrm{I} 7 \mathrm{~A}$ in $\mathrm{b}, 10-\mathrm{I}$, at $15.8 \mathrm{I} \mathrm{m}+$ N.A.P.: $54^{\circ} \pm 60 \mathrm{BC}(\mathrm{GrN} 4623)$. Both dates are given in ${ }_{7} 7 \mathrm{~A}-\mathrm{Po}$ (fig. 79) and $17 \mathrm{~A}-\mathrm{Po} /$ corr (fig. 82).

\section{1.26.2. Synchronous lines}

The pollen analytical correlation was followed as much as possible in drawing the synchronous lines, without, however, violating the stratigraphical observations.

I $7-1$

The first synchronous line was drawn fairly high up in zone $\gamma$. It runs exactly on the transition between highly and moderately humified peat, except between $\mathrm{j}, 37-43$. The line was dated to I $890 \mathrm{BC}$.

I 7-2

This line runs somewhat below the zone border $\delta / \varepsilon$ in profiles ${ }_{17} \mathrm{~A}$ and ${ }_{17} \mathrm{C}$, at the level where there is a noticeable change in the peat types. It was drawn just a little above this border in profile $\mathrm{i} 7 \mathrm{~B}$, at the line of contact between two types of moderately humified peat which differ only very little. The reliability of line $17-2$ in the right-hand part of the section is not very high, because the border $\delta / \varepsilon$ was not very clear in $\mathrm{I}_{7} \mathrm{C}$. The line can be dated to $\mathrm{c}$. $\mathrm{I}_{5}{ }^{\circ} \mathrm{O} \mathrm{BC}$. I $7-3$

This line runs right through the transition $\varepsilon / \zeta$. This level, which can be dated to c. $1200 \mathrm{BC}$, corresponded with a highly humified, charcoal layer in the section. The reliability is therefore fairly high.

\section{I $7-4$}

This line connects points which lie in the lower part of zone $\eta$. It runs over the highly humified peat of $\mathrm{I} 7 \mathrm{~A}$ and over the Sphagnum cuspidatum layer of $\mathrm{I} 7 \mathrm{~B}$. The line was placed somewhat higher in ${ }_{17} \mathrm{C}$ as the level cannot be given precisely because of the relatively large sample distance, and as it is probable, for stratigraphical reasons, that the transition from highly to moderately humified peat in profiles I $7 \mathrm{~A}$ and $I 7 \mathrm{C}$ can be regarded as sychronous. The line can be dated to $\mathrm{c} .700 \mathrm{BC}$, in the beginning of the Subatlantic period.

$17-5$

The line which was drawn at the level of the thin, but comparatively large cuspidatum layer of $c$, I $~ v i a ~ d / e, 27$ to $d, 3^{6}$ connects 
points at the top of zone $\eta$, and can be placed in $17 \mathrm{C}$ at the transition from moderately humified to fresh peat. The line can be dated to c. $600 \mathrm{BC}$, just before the first Fagus maximum.

I $7-6$

This line runs at the transition from moderately humified to fresh peat in the left-hand part of the section, rather far down in zone $\vartheta$. The line was placed at this height in profiles $17 \mathrm{~B}$ and $17 \mathrm{C}$ too, although here it lies completely in the fresh peat. The level was dated to $54^{\circ} \mathrm{BC}$.

I 7 -7

This line was placed approximately in the middle of zone $\vartheta$, just above the Fagus maximum. The line runs for its entire length through fresh peat, and can be dated to c. $400 \mathrm{BC}$.

I $7-8$

This line was placed right at the top of zone $\vartheta$ and can be dated to c. $300 \mathrm{BC}$. At the top left of the section, it runs through fresh peat, at the centre top of the section, through the base of the moderately humified peat, and at the right-hand side of the section outside the part of the peat-face which has been drawn.

\section{I $7-9$}

For the sake of completeness, the grid section already given in fig. 45 has been reproduced here again. The peat right at the top in the middle of the section may be dated from c. Ioo BC to c. IOO AD.

\section{I.26.3. The bog development}

Even in the highly humified Sphagnum peat, a differentiation takes place into drier, Eriophorum-rich communities $(j, \mathrm{I}-37)$ and wetter places $(j, 37-43)$, illustrated by a clear difference in rhizopod content: in I $7 \mathrm{~A}-\mathrm{Rh} / \mathrm{Mo}$, spectra 8-25 but little Amphitremas; in $17 \mathrm{~B}-\mathrm{Rh}$, spectra $2-18$ predominantly lacking in rhizopods, only in spectra $\mathrm{I} I$ and ${ }_{1} 4$ a clear Amphitrema flavum maximum; in ${ }_{17} \mathrm{C}$ $\mathrm{Rh} / \mathrm{Mo}$, a clear increase in Amphitrema flavum to very high values (spectra $\mathrm{I}-7$ ). Therefore, the bog surface given in $\mathrm{I} 7-\mathrm{I}$, which was dated at $1890 \mathrm{BC}$, will very probably have consisted of a highly humified Eriophorum hummock $(\mathrm{j}, \mathrm{I}-37)$ and a highly humified, probably moist hollow $(j, 37-i, 50)$, in which Eriophorum vaginatum could maintain itself here and there (i, 44-45 and 48-50). Such a hummock and hollow surface would not have shown much relief. Sphagnum cuspidatum ( $17 \mathrm{C}-\mathrm{Rh} / \mathrm{Mo}$, spectra 6-8) established it- 
self in the hollow, while $S$. imbricatum had already established itself on the highly humified hummock ( $17 \mathrm{~A}-\mathrm{Rh} / \mathrm{Mo}$, spectrum $3^{\circ}$ and I 7 B-macr., spectrum $17 / 18$ ), and could not continue growing. The large, highly humified hummock was overgrown by moderately humified rubellum peat, a minor constituent of which was Eriophorum (i, I-36). The centre of the flat-topped hummock forming at that time was comparatively dry (I $7 \mathrm{~A}-\mathrm{Rh} / \mathrm{Mo}$, spectra $29-4 \mathrm{I})$ : Amphitrema flavum does not appear to any great extent and $A$. wrightianum is present in only two spectra. The edge of the hummock was originally rather moist ( $7 \mathrm{~B}-\mathrm{Rh}$, spectra I $9-22$ ), as evidenced by the large numbers of Amphitrema flavum.

The almost complete absence of $A$. wrightianum in this moist edge of the hummock is striking. Although the milieu was moist enough, it was possibly still unsuitable for this rhizopod. The highly humified cuspidatum peat formation changes over to less humified cuspidatum growth in the hollow. Amphitrema wrightianum flourished in this milieu (I $7 \mathrm{G}-\mathrm{Rh} / \mathrm{Mo}$, spectra Io and I I). S. imbricatum and $S$. papillosum occur in the hollow peat (spectra 5-I I), but neither Sphagnum type could continue growing in the hollow. It is noticeable that the hollow shows signs of constantly decreasing moistness (spectra $12-$ I 7). Besides S. cuspidatum, S. rubellum occurs frequently. The situation after the growth of the moderately humified rubellum hummock and the filling up of the cuspidatum hollow was given in $17-2$. On the evidence of the rhizopod content, the centre of the hummock became considerably moister, Amphitrema flavum occurs in fairly large numbers and $A$. wrightianum increases strongly ( $7 \mathrm{~A}-\mathrm{Rh} / \mathrm{Mo}$, spectra $42-48$ ). Just the opposite is observable at the edge of the hummock; a sharp decline in Amphitrema flavum is observable in $17 \mathrm{~B}-$ $\mathrm{Rh}$ from spectrum 22 on, while Hyalos, henia papilio disappears. As appears from the short-distance correlation, the conspicuous $A$. wrightianum increase from spectrum 28 on does not belong to the hummock and hollow system illustrated in $17-2$, but to that of $17-3$. The distribution of drier and wetter parts of the bog surface c. I $500 \mathrm{BC}$ cannot be deduced from the rhizopod diagrams.

A clear change in the peat growth occurred about $1500 \mathrm{BC}$; a hummock with highly humified peat established itself in the hollow, and the moderately humified rubellum hummock was overgrown by a highly humified hummock, while a hollow formed above the edge of the hummock. Rhizopods occur in the highly humified peat of both hummocks only in small numbers ( $7 \mathrm{~A}-\mathrm{Rh} / \mathrm{Mo}$, spectra $48-$ 53, I7 C-Rh/Mo, spectra $18-25$ ). Calluna is an important constituent of the hummock communities, although that hardly appears 
from the pollen diagrams ( $17 \mathrm{~A}-\mathrm{Po} / \mathrm{bog}$ plants, spectra $54-80$, ${ }_{17} \mathrm{C}-\mathrm{Po} /$ bog plants, spectra $\left.19-2 \mathrm{I}\right)$. The highly humified hummock base, $\mathrm{g} / \mathrm{h}, 9-20$, is probably synchronous with the highly humified hummock base $h, 3^{8}-48$. A dubious factor in this correlation is the not very clear zone transition $\delta / \varepsilon$ in ${ }_{17} \mathrm{C}$-Po/corr. It is, however, clear that the cuspidatum layer $\mathrm{g}, 26-\mathrm{h}, 36$ cannot be regarded as an extension of the cuspidatum layer in the lower right-hand part of the section, but that it originated as the filling of a hollow between the two highly humified hummocks, in the middle of zone $\varepsilon$. The base of this hollow would then be the moderately humified peat, $\mathrm{h} 25$ 35 , lying under it.

It appears from ${ }_{17} \mathrm{~B}-\mathrm{Rh}$, spectra $27-3 \mathrm{r}$, that Amphitrema wrightianum underwent its first large increase in this moderately humified peat.

With the growth of the two highly humified hummocks after I $500 \mathrm{BC}$, the hollow situated between them remained.

Originally, moderately humified rubellum peat was formed, and afterwards a cuspidatum layer developed, which was overgrown $\mathrm{c}$. I 200 BC by a layer of peat with a high Calluna content ( $\mathrm{I} 7-3$ ). The layer is recognizable in the 3 rhizopod diagrams, viz., the disappearance of the rhizopods ( $17 \mathrm{~A}-\mathrm{Rh} / \mathrm{Mo}$, spectra $65-68$ ), a pronounced decline in the rhizopod content ( $17 \mathrm{~B}-\mathrm{Rh}$, spectra 35 40) and a slight decrease of the already low rhizopod values ( $77 \mathrm{C}$ $\mathrm{Rh} / \mathrm{Mo}$, spectra $2 \mathrm{I}$ and 22). Moreover, the spectra of this level contain few, if any, Sphagnum remains. The outward spread of the hummock communities over the cuspidatum hollow, as is shown in I $7-3$, points to a desiccation of the bog surface which must have been overgrown by Calluna during this time. Probably little remained of a differentiation into hummock and hollow peat. This desiccation was fairly certainly of short duration; peat growth resumed, both hummocks developed further, and water collected again in the hollow, where the establishment of S. cuspidatum became possible again. Another very thin desiccation layer is present in this cuspidatum layer; it was not drawn in the section, but is shown in ${ }_{1} 7 \mathrm{~B}-\mathrm{Rh}$, spectra 47 and 48 . It is probable that this desiccation in $17 \mathrm{~A}-\mathrm{Rh} / \mathrm{Mo}$ is present in spectrum 75. S. papillosum and occasionally S. imbricatum occur in this hollow ( 7 B-macr. spectra $42-49$ ).

The situation as it must have been c. $700 \mathrm{BC}$ is given in $17-4$ : there is a wet cuspidatum hollow between two clear, highly humified hummocks. Relatively large changes would have taken place here within a comparatively short time. It follows from $I_{7}-5$, dated to c. $600 \mathrm{BC}$, that both hummocks were overgrown by moderately 
humified peat and that the hollow shifted to the left somewhat, where it developed with fresh papillosum peat. During this process the Amphitremas increased in number, so that it is probable that the bog surface became wetter ( $17 \mathrm{~A}-\mathrm{Rh} / \mathrm{Mo}$, spectra $83-90 ; \mathrm{i} 7 \mathrm{~B}-\mathrm{Rh}$, spectra 50-59, I7 $\mathrm{C}-\mathrm{Rh} / \mathrm{Mo}$, spectra 25-35). Due to flooding, open water would again have collected on this bog surface, and because of this water, a thin cuspidatum layer could form, which, about $600 \mathrm{BC}$, covered the surface here to a considerable extent ( $17-5)$.

The flooding which produced the cuspidatum layer on the bog surface of $17-5$ induced a fresh imbricatum-papillosum peat growth, which covered the hummock and hollow system with a presumably very moist peat layer, in which only a very small nucleus of the left-hand hummock could maintain itself $(c, 6-10)$. This, according to the dating of the top of this hummock $(540 \pm 60 \mathrm{BC})$, had already been overgrown a few decades later. The situation as it had then developed is given in $17-6$. The final overgrowth of this hummock was probably preceded by another slight desiccation. A clear decline in the Amphitremas is discernible in $17 \mathrm{~A}-\mathrm{Rh} / \mathrm{Mo}$, spectra 100-I04, from the upper part of the hummock, and also in ${ }_{1} 7 \mathrm{~B}-\mathrm{Rh}$, spectra $62-64$. Because of the large sample distance in ${ }_{17} \mathrm{C}$, the level (here) is not demonstrable in ${ }_{17} \mathrm{C}-\mathrm{Rh} / \mathrm{Mo}$.

The only thing that still reminds us of the overgrown hummocks is the occurrence of Eriophorum nests, just above the hummocks (b/c, $2 ; b, 9 ; b, I 3$ and $b, 44 ; a / b, 46 ; c, 46 ; b, 49$ and $a, 49)$ in the otherwise fresh bog surface that existed here c. $4^{00} \mathrm{BC}$ ( $\left.17-7\right)$. The occurrence of $S$. imbricatum above the hummock on the right (i $7 \mathrm{C}-$ $\mathrm{Rh} / \mathrm{Mo}$, spectra 35-37), whereas S.papillosum is present exclusively above the hollow (17B-macr, spectra 63 and 70 ) and is the main constituent above the hummock on the left ( $17 \mathrm{~A}-\mathrm{Rh} / \mathrm{Mo}$, spectra I05-I IO), is a possible indication of a not observable stratigraphical differentiation in the bog surface of c. $400 \mathrm{BC}$, see also I 1.52., p. 233. Change in this situation came about because of the establishment of Calluna-rich communities, just above the hollow (c, 26-28), which probably grew within a very short time to a deposit of moderately humified peat in the central upper part of the section. This situation, shown in $17-8$, which can be dated at c. $300 \mathrm{BC}$, lasted for a comparatively long time. A slight decline in Amphitrema flavum is present in $17 \mathrm{~A}-\mathrm{Rh} / \mathrm{Mo}$, spectra 112 and II3, which presumably started even in spectrum rog. This decline corresponds with a very thin layer of moderately humified peat, which, during the drawing 
of the section, could be correlated, although with some difficulty, with the base of the moderately humified peat on $b, 20$.

In $17 \mathrm{~B}-\mathrm{Rh}$, the transition from fresh to moderately humified peat coincides with a strong decline in the Amphitremas (spectra $7 \mathrm{I}-75$ ), which afterwards increase again (spectra $76-80$ ), although without reaching extremely high values; only to decrease further very suddenly after this. Phryganella hemisphaerica is present from spectrum 67 , an indication of less favourable conditions for peat formation.

A hummock of moderately humified peat probably originated here c. $300 \mathrm{BC}$. possibly caused by an irregularity in the growth of fresh peat. $S$. papillosum was displaced from this hummock by $S$. imbricatum ( 17 B-macr., spectra $74-97$ ).

The thin layer of moderately humified peat that actually forms the bog surface of $17-8$ was overgrown by fresh peat both on the left (from a, I to b, 20) and on the right (from b, 34 to a, 39); this peat is rich in Amphitremas (I $7 \mathrm{~A}-\mathrm{Rh} / \mathrm{Mo}$, spectra I I 4 -I I 7 ).

It is possible that a short-lived, fairly thorough desiccation occurred first, inducing the moderately humified bog surface of $17-8$, after which the increase in moisture level caused the balance to swing only partially to fresh peat again. The moderately humified vegetation, once established, could maintain itself nearby for a protracted period, although over a smaller area $(\mathbf{I} 7 \mathrm{~B}-\mathrm{Rh}$, spectra 78-96). Renewed desiccation will occasionally have favoured the spread of Calluna (from a, $16-20$ via b, 27 to a, 29). It is the Amphitremas especially that illustrate such a desiccation most clearly ( 7 B-Rh, spectra 86-88).

I I.27. EMmen I8 (fig. 47), face E, above pit I 78

This section was drawn by means of a grid with $0 . \mathrm{I} \times$ o. I $\mathrm{m}$ squares.

\section{1.27.x. The bog development}

Cuspidatum peat spread extensively over the highly humified Eriophorum and Calluna-rich Sphagnum peat (g, I-3; f, 4-7; g, 8I I f , I $2-37 ; \mathrm{g}, 38-42$ ) - probably a large, flat-topped hummock; The spread possibly started from the cuspidatum layer $\mathrm{g}, 42-50$, which can be regarded as a hollow next to the flat-topped hummock. Nothing but the centre, $f, I_{5}-20$, of this large hummock still re- 
mained, and it, undoubtedly as a result of a desiccation, could extend again, after a comparatively short time, to a hummock in the left-hand part of the section, with $f, 5-20$ as a base, and to a flat extension of highly humified peat over the greater part of the hollow growth (from e/f; 20 to e, 35). A highly humified, Calluna-rich vegetation developed in the middle of the hollow, (e/f, $3^{8-46}$ ), possibly the extension of a hummock outside the plane of the section. A sharp increase in the moisture level caused the hummock area to shrink again (e,5-19) while cuspidatum peat $(e, 20-50)$ formed once more in the hollow. In the centre of the hollow this changed over fairly quickly to fresh imbricatum-papillosum peat (e, 3I-50). It is possible that Sphagnum cuspidatum still grew in part of the hollow (d/e, 20-28). The fresh imbricatum-papillosum peat in the large hollow was overgrown by moderately humified, Calluna-rich peat, the extension of a hummock outside the plane of the section. A considerable change in the bog surface had by now taken place here. The large hollow split into a smaller hollow, in which cuspidatum peat was formed (c, I9 to d, 30), and a hummock lying more to the right, outside the plane of the section. The presence of this hummock is clearly discernible by the development of a new hollow, in the upper middle part of the section. The left-hand limit of the section is formed by a hummock, in which the highly humified peat changes fairly quickly into fresh peat.

In the left-hand part of the new hollow, thin layers of fresh imbricatum-papillosum peat alternate with cuspidatum peat $(\mathrm{a} / \mathrm{b} / \mathrm{c}, \mathrm{I} 6$ 22), which points to fluctuations of the hummock/hollow areas respectively; probably as a result of changes in the moisture content of the peat. Eventually the cuspidatum peat was overgrown by imbricatum-papillosum peat. On the extreme left of the section $(\mathrm{a} / \mathrm{b}, \mathrm{I}-\mathrm{-})$, moderately humified hummock communities again developed in a hollow, the larger part of which lies outside the section, to the left. As a result of the activities of the peat diggers, we can no longer check the direction this development took.

It is possible that the large, flat-topped hummock in the lower part of the section $\left(\mathrm{g}, \mathrm{I}-4^{2}\right)$ is of the same type as the flat-topped rubellum hummock in the lower part of the section of EMMEN I 7 , which was able to last from c. $2000-\mathrm{I} 500 \mathrm{BC}$. The strongly pronounced hummock in the left-hand half of the section (with base $\mathrm{f}, 5-20$ ) would then have belonged to that hummock and hollow system which existed in EMmeN I 7 between c. I 500 and 500 BC; the moderately humified peat of $\mathrm{c} / \mathrm{d}, 3 \mathrm{I}-5^{\circ}$ must, in that case, be regarded as the margin of the neighbouring hummock. Evidence 
for this includes the shape and the filling of the centrally situated hollow, between $\mathrm{a} / \mathrm{b} / \mathrm{c}, \mathrm{I} 6-35$.

\author{
I I.28. EMmen 15, peat-block D, above pit i48, \\ the wooden path XV (Bou)
}

During the excavation of June-July, i $96_{3}$, two profiles were sampled, from a hummock and a hollow, respectively, in the immediate neighbourhood of this wooden path; $15 \mathrm{~A}-\mathrm{Rh} / \mathrm{Mo}$ (from the hummock) and ${ }_{5} \mathrm{~B}-\mathrm{Rh} / \mathrm{Mo}$ (from the hollow, see fig. 78 ) were made from these profiles. The path was dated pollen analytically (VAN ZersT 1955 a, pp. $48-49$, fig. I6) and was also radiocarbon dated (GrN 4622: $53^{\circ} \pm 40 \mathrm{BC}$ ).

The path lies at the top of a hummock and hollow system, of the type that was described in I 1.26., Emmen 17. This system was here very rich in Scheuchzeria palustris (see also I I.39., p. 203). It appears from both the stratigraphy of $15 \mathrm{~B}-\mathrm{Rh} / \mathrm{Mo}$ and the diagram that the hollow must have been particularly wet. The increase in Amphitrema wrightianum in the diagram leads to the supposition that the water content of the hollow increased. No great changes in the rhizopod content are observable at the level of the wooden path. The building of this path had undoubtedly little effect on the peat growth.

The rhizopod content of the hummock (I $5 \mathrm{~A}-\mathrm{Rh} / \mathrm{Mo}$ ) is considerably smaller. Amphitrema wrightianum does occur already, in contrast with EmMen i 6 (see the following section), but only in small numbers.

The Scheuchzeria-cuspidatum layer which covers the wooden path here can be regarded as an extension of the very wet hollow peat over the hummock. In agreement with this is the strong increase of Sphagnum cuspidatum in the diagrams from the level of the wooden path on, both in the hollow and on the hummock, especially at the expense of the Sphagna of the Cymbifolia group. Both diagrams indicate a clear increase in the water content of this peat area, even before the building of the wooden pathway.

I I.29. Emmen I6, peat-face E, between pits $165-166$, the pathway XVII (Bou)

During the excavation of March, $196 \mathrm{I}$, two peat samples, one from a hummock, the other from a hollow, were taken for rhizopod 
analysis from immediately below the surface of this plank path. The results are shown in the table below. The path was dated to I $17^{\circ} \pm 5^{\circ} \mathrm{BC}\left(\mathrm{GrN}_{4}{ }^{1} 49\right)$ and I $95 \pm 55 \mathrm{BC}\left(\mathrm{GrN}_{4342}\right)$. The path is situated in the hummock and hollow system described in i I.26., EMMEN I7.

Table IX

EMmeN 16 , rhizopod content

\begin{tabular}{lrr}
\hline & hummock & hollow \\
\hline Amphitrema flavum & 24 & 118 \\
Amphitrema wrightianum & - & $3^{8}$ \\
Arcella spec. & 5 & 9 \\
Assulina muscorum & 14 & I4 \\
Assulina seminulum & 3 & 5 \\
Hyalosphenia papilio & - & 4 \\
Heleopera sphagni & - & 2 \\
Nebela collaris & - & 1 \\
Phryganella hemisphaerica & I & - \\
Bullinula indica & I & - \\
\hline
\end{tabular}

There is a clear difference in the rhizopod content of the two spectra. The hollow spectrum is a pronounced wrightianum type; the absence of Amphitrema wrightianum and the lower value ot $A$. flavum in the hummock spectrum points to a considerably less wet peat type in the hummock. These results correspond with those of EMMEN I 7, to the extent that Amphitrema wrightianum already occurs frequently in the hollow in the topmost hummock and hollow system (c. $1500-500 \mathrm{BC}$ ), but is almost completely absent from the hummocks. However, there is a desiccation present in Emmen 1 7, which can be clearly dated to $\mathrm{I} 200 \mathrm{BC}$, and which is absent here.

\section{TyPe EMmen 22/23}

I I.30 EMmen 22 (fig. 5I), face H, above pit 224

This section was drawn in by means of a grid with $0.1 \times 0.1 \mathrm{~m}$ squares. 22-Po (fig. 9I) and 22-Rh/Mo (fig. 92) were made from the profile sampled.

I I.30. I. The bog development

In the highly humified Sphagnum peat some differentiation had 
already taken place into Calluna peat layers (lower, right-hand part of the section) and some highly humified Sphagnum cuspidatum layers, from which, however, no hummock and hollow pattern can be deduced. A slight expansion of the Calluna peat layers at the top of the highly humified Sphagnum peat preceded the formation of the large fresh cuspidatum layer, the base of which is on e/f, I-26. On stratigraphical grounds, the cuspidatum deposit can be considered as a growth of the raised bog lake EMmEN I9, which will be discussed in I I.4I. (p. 209) and I I.47. (p. 218). Renewed growth of the cuspidatum deposit took place, and the layer extends far beyond the section, both to the right and to the left, over the highly humified peat, with $\mathrm{d}, \mathrm{I}-25 ; \mathrm{d} / \mathrm{e}, 26-50$ and in EMmen 23 (fig. 52) d, $1-9$ as a base, (see also the following section). The total length of this uninterrupted cuspidatum deposit is c. $20 \mathrm{~m}$.

The occurrence of fresh Sphagnum cuspidatum is accompanied by an enormous increase in the Amphitremas (22-Rh/Mo, spectra 6-8). S. papillosum appears in the cuspidatum growth. S. imbricatum appears for the first time in the fresh peat which overgrew the cuspidatum layer. The growth of the cuspidatum layers belong to the time of the first large Fagus increase (22-Po, spectra $5-7)$. Its beginning can be clearly fixed as still belonging to the Subboreal (spectrum 5): Fagus $0.6 \%$, Corylus $23 \%$, Carpinus is still absent. Its end can very probably be dated approximately simultaneous with the first large Fagus maximum of c. $500 \mathrm{BC}$. This could be placed in 22-Po, just above spectrum 7 , that still comes from the cuspidatum peat.

\section{I.31. EMmen 23 (fig. 52), face H, above pit 223}

This section, which is situated a good $6 \mathrm{~m}$ to the south of Emmen 22 (fig. $5 \mathrm{I}$ ), was drawn in by means of a grid with 0 . I $\times$ o. I $\mathrm{m}$ squares. 23-Po (fig. 9I) and 23-Rh/Mo (fig. 92) were made from a profile which was sampled through the hummock which forms the southern limit of the fresh Sphagnum cuspidatum layer (see the preceding section) found in EMmen 22 (fig. $5 \mathrm{I}$ ).

\section{I1.3I.I. The bog development}

From level g, $1-25$ in the highly humified Sphagnum peat, an extensive Eriophorum vegetation developed, which was, however, in the long run overgrown by Calluna-rich peat $(\mathrm{e}, \mathrm{I}-7 ; \mathrm{e} / \mathrm{f}, 2 \mathrm{I}-5 \mathrm{0})$. A predominantly moderately humified, very flat-topped hummock with a highly humified centre developed on the Calluna-rich, highly 
humified bog surface, from d, 7 to e, 39. Scarcely any rhizopods developed in the hummock (23-Rh/Mo, 3-5). Hyalosphenia subflava occurs most frequently, which indicates a growth of ombrogenous peat under "unfavourable" conditions, e.g. as a result of strong eutrophication. The occurrence of Aulacomnium palustris is also a possible pointer in this direction (spectra 3 and 5 ), as is the absence of recognisable moss remains in spectrum 4 from the $\mathrm{Cal}$ luna-rich hummock centre. Rumex acetosa-type commonly occurred in the hummock peat (32-Po, spectra 4 and 6) which may be regarded as exceptional in the Sphagnum peat.

Perhaps it is necessary to consider the hummock as a more or less permanent island that was frequently visited by birds. This might explain the Rumex growth. The low Sphagnum value in 23-Po, spectrum 4 , and the absence of recognisable Sphagnum remains in spectrum 4 of $23-\mathrm{Rh} / \mathrm{Mo}$ are indications that the peat growth in the hummock must have virtually come to a standstill. Then the hummock would have grown further upwards again, which is probably connected with a rise in the water-level in the large hollow of EMmen 22 (fig. 5I). Calluna-Rumex communities with Aulacomnium cushions must have been present on the hummock.

Fluctuations in the water content of the peat resulted in the alternations of fresh and moderately humified peat layers $(\mathrm{b} / \mathrm{c} / \mathrm{d}, \mathrm{I} 2-2 \mathrm{I}$ and $\mathrm{b} / \mathrm{c} / \mathrm{d}, 42-50)$. During the upward growth of the hummock, its area became continuously smaller, while the original centre split into two smaller nuclei. Profile 23 was taken from the nucleus on the left; the nucleus on the right was able to continue growing for a longer time $(a / b, 39-4 \mathrm{r})$ during the forming of the fresh peat, of which $S$. imbricatum was an important constituent.

The start of the growth of fresh imbricatum peat, which took the place of the cuspidatum or rubellum peat formation, was probably correctly dated by $23-$ Po, spectrum 6 . The high Fagus value, the still low Carpinus value and the small Corylus percentage of less than $5 \%$ indicate that this transition in peat-forming can be dated at c. $500 \mathrm{BC}$.

I I.32. Emmen 20 (fig. 50), peat-face $H$, above pit 235

This section was drawn by means of a grid with $0 . \mathrm{I} \times 0 . \mathrm{I} \mathrm{m}$ squares.

I 1.32. . The bog development

A thin layer of moderately to highly humified Sphagnum cuspi- 
datum peat $\left(\mathrm{e} / \mathrm{f}, \mathrm{I}-\mathrm{f}, \mathrm{3}^{2}\right)$ lies on top of the $\mathrm{c}$. $\mathrm{r} .20 \mathrm{~m}$ thick deposit of highly humified Sphagnum peat which contains much Calluna. This layer is bordered on the right-hand side by a flat-topped, highly humified hummock $\left(f, 33-\mathrm{g} / \mathrm{f}, 5^{\circ}\right)$ of which Calluna is an important component. Eriophorum vaginatum continued growing in the hollow $(e / f, 5-9)$. It is possible that the large, moderately humified hummock at the left in the section grew upwards from this Eriophorum nest simultaneously with the large, moderately humified hummock at the right in the section $(\mathrm{c} / \mathrm{d} / \mathrm{e}, \mathrm{I}-\mathrm{I} 8, \mathrm{~d} / \mathrm{e} / \mathrm{f}, 25-50$, respectively).

The upward growth of the two moderately humified hummocks probably proceeded quite smoothly; the hollow in between, originally $\mathrm{c} / \mathrm{d}, \mathrm{I} 4-25$ then $\mathrm{b} / \mathrm{c}, 19-25$ ) changed in form only slightly.

An extensive expansion of imbricatum-papillosum peat from a centre outside the section caused a considerable decrease in the size of the hummocks. What remains of each hummock was only a small nucleus of moderately humified peat which could maintain the same rate of upward growth as the fresh peat (left: $a / b, I-2$; right: $\mathrm{b} / \mathrm{c}, 25-29)$. Ultimately almost the entire hummock and hollow system was overgrown by the fresh peat (right at the top of the section).

\section{Type EMmen 32}

\section{I1.33. Емmen 32 (fig. 58)}

Section from an east-west peat-face (which was not drawn as a whole), about $1 \mathrm{~km}$ south of peat-face $\mathrm{M}$, see fig.2. When drawing the section, special attention was paid to the hummock and hollow mosaic. For this reason we have distinguished only between moderate to highly humified hummock peat (narrow vertical stripes close together), fresh hollow peat (broad vertical stripes further apart) and fresh Sphagnum cuspidatum peat (white).

Thin layers of more humified peat occur in both the fresh hollow peat and in the moderately humified hummock peat. These were not drawn in since they apparently have no influence on the hummock and hollow pattern. The mineral subsoil (fluvial loam) is at c. $15.30 \mathrm{~m}$ above N.A.P. Here there is no fen peat under the more than I m thick highly humified Sphagnum peat deposit.

\section{II.33.I. The bog development}

An extensive hummock and hollow system developed on the highly humified Sphagnum peat (shown as moderately humified in fig. 58). The hummocks are rather flat-topped; the hollows were 
probably shallow. The abrupt transition in the degree of humification in the hollows is remarkable; moreover, it appears that in many places the cuspidatum layer lies almost completely loosely on top of the highly humified Sphagnum peat. Eriophorum nests are present here and there as small elevations in the hollow bases. The entire set-up strongly suggests that transport of water occurred in the hollows, causing the disappearance of hollow material. The process did not go far enough to cause the formation of erosion structures, such as those found in Emmen 34 (ir.40.) and Emmen I9 (II.4I.).

The Eriophorum nests may have maintained their position because of their greater firmness. The growth of the fresh cuspidatum peat could only start developing after the water transport came to an end. The fresh peat that grew in the hollows after the cuspidatum peat must have been mainly papillosum peat, see also I I.52., p. 233 . The hummocks, too, probably grew upwards during this process, scarcely altered in position and shape, and this might indicate an undisturbed milieu, unaffected by erosion. Cross-sections of such hummocks are present from $5-10 \mathrm{~m}, \mathrm{I} 5-\mathrm{I} 9 \mathrm{~m}, 29-32 \mathrm{~m}, 39-43$ $\mathrm{m}$ and $52-5^{8} \mathrm{~m}$.

Moderately humified hummocks tailing out into the fresh hollow peat ("fingers" of hummock communities) are visible at several places, e.g. between $30.5-32 \mathrm{~m}, 48.5^{-4}-49 \mathrm{~m}, 5 \mathrm{I}-52.5 \mathrm{~m}$ and between $57-60 \mathrm{~m}$. These could be extensions of the hummocks over the hollows caused by desiccations. Another possibility is that erosion determined the presence of these "fingers", in which case they were able to offer more resistance to erosion than most of the peat surrounding them. Observations in the neighbourhood of EMmEN 32 do not exclude this possibility, at least for part of these phenomena.

Eventually this intermediate peat was also overgrown by fresh imbricatum-papillosum peat. Significant movements of water did not occur here during this process.

We have no dates for this hummock and hollow system. However, it is probable on stratigraphical grounds that the system can be placed in the latter part of the Subboreal and the beginning of the Subatlantic, up to the first centuries AD.

\section{I.34. General characteristics AND Datings of THE hummock AND HOLLOW SYSTEMS}

\section{1.34. I. The occurrence of the different types}

It appears from the picture outlined in fig. 6 that the type EMMEN 


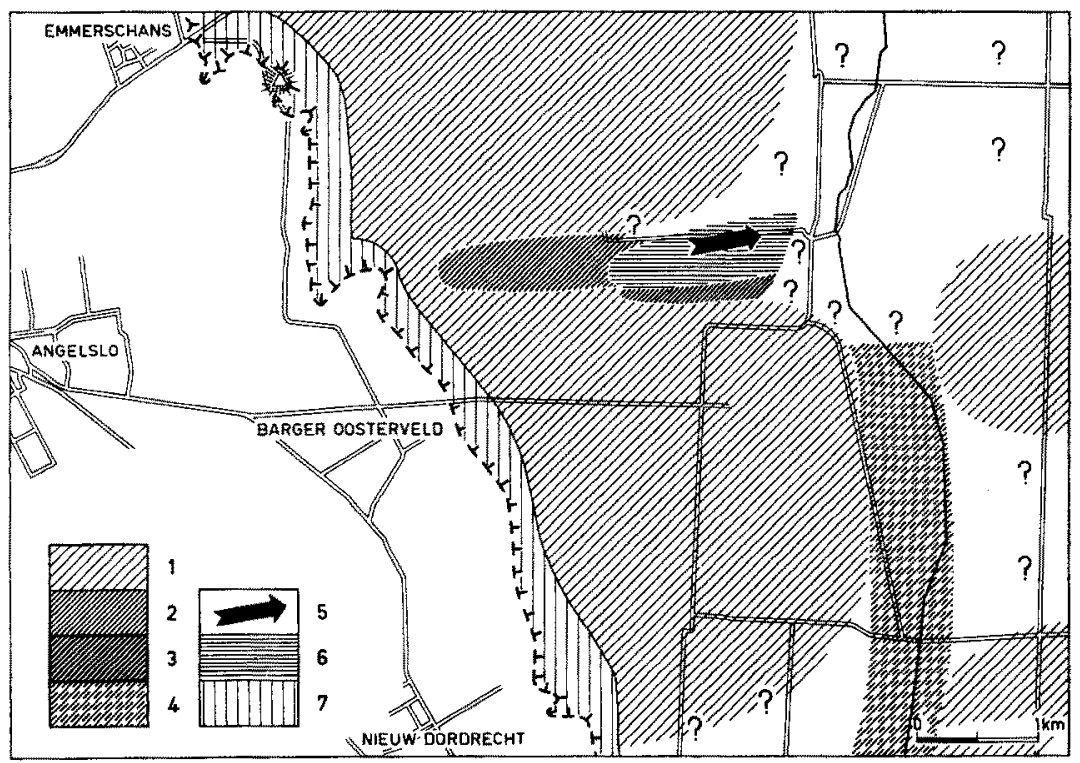

Fig. I6. The intermediate peat deposits between about $1000-500$ B.C. I = hummocks and hollows of the EMMEN 9 type (from c. $2000-200$ B.C.); $2=$ hummocks and hollows of the EMMEN I 7 type (from c. $1900-54$ o B.C.) $; 3=$ hummocks and hollows of the EMMEN 22/23 type (from c. 1200-500 B.C.); $4=$ hummocks and hollows of the EMmEN 32 type (probably from c. I 200-500 B.C.) 5 - width and direction of the erosion channel of the raised bog lake EMmEN 19 which can be tentatively dated c. 500 B.C.; $6=$ the raised bog lake EMMEN I9 (from c. I500-500 B.C.) ; $7=$ the intermediate deposits in the marginal part of the bog, without hummocks and hollows (from 3000/2000B.C. to perhaps the beginning of the Christian era).

9 in particular is present frequently in the investigation area; even more than the total of the other three types. Type EMmen 17 is present in a comparatively narrow strip on the western side of the raised bog lake, EMMEN 19, which will be discussed in I I.4I., p. 209. Type EMMEN 22/23 was found only in the immediate neighbourhood of this raised bog lake. Type EMmEN 32 occurs in a strip in the neighbourhood of the former bog rivulet, the Runde. The genetic connection between the types and the raised bog lake will be discussed in sections II.47-II.49., p. 218-229.

\section{1.34.2. Morphological characteristics}

The hummocks are round to slightly oval centres of highly or at least more humified peat with many remains of Eriophorum vaginatum and Calluna vulgaris (see II.10. and II.II., p. I5 I ff.). The 
measurements vary from $3-8 \mathrm{~m}$. However, it can no longer be determined how far above the hollow surface they projected during their growth. This was not necessarily the same for the different types. As far as a particular orientation could be determined with any degree of probability (e.g. EMmEN 6, fig. 39, and EMMEN 33, fig. 59), this is NNW-SSE to N-S. The hummocks of type EmmEN 22/23 and of EMMEN 32 were very probably round.

Roughly speaking, the proportion of moderately humified peat in the highly humified hummock gradually increased during its upward growth. Expansions of hummock communities over the hollow, such as happened several times in EMMEN 9 (see I I.2 I., p. I64), had no permanent, essential influence on the shape of the hummock. The hollows constitute the surface of the bog between the hummocks; they are therefore irregular in shape. The measurements vary quite widely within each group. In type EMmEN 9, hollow widths of 0.5 to c. $8 \mathrm{~m}$ were found. In type EMmen 22/23, the distance between two hummocks is from c. 2 to sometimes more than $20 \mathrm{~m}$, see I I.31., p. I 86 . But the different types can be characterised by certain average dimensions. Highly diagrammatic crosssections of the various types are given in fig. $6 \mathrm{r}$.

It appears that the fresh peat base of all the hollows consists of a cuspidatum layer; this varies in thickness from 5 to sometimes nearly $30 \mathrm{~cm}$. This cuspidatum peat, of which Scheuchzeria palustris is sometimes an important component (see fig. 42, Emmen 9) has a conspicuous, laminated structure.

Only in type EMMEN I 7 do fairly thick cuspidatum layers still regularly occur at a somewhat higher level, viz. in the younger hummock and hollow system (see I 1.26, p. 174). This is also the only type in which a hummock and hollow pattern changes during the upward growth of the peat surface.

\section{I r.34.3. Datings}

We have taken as the beginning of the intermediate peat growth, that moment at which the first fresh Sphagnum cuspidatum peat developed in the hollows, see also I I.20., p I62, and I I.7., p. I45. It will be clear that the transition to fresh peat in a hummock may have taken place considerably later. VAN ZEIST, 1955a, has already established this by pollen analysis (I955a, pp. 49-62). He dated a number of fresh cuspidatum layers from the investigation area (EMMERERFSCHEIDENVEENA, B, Cand D) which lie at the base of the fresh peat. A clear difference in the beginning of the fresh peat forming can be seen from his diagram fig. 24. The cuspidatum layer is absent 
from VAN ZeIsT's profiles $F$ and G. The transition to the fresh peat is considerably later here, cf. VAN Z.EIST I 955a, fig. 24. These latter two profiles were undoubtedly sampled through a hummock, while $\mathrm{A}, \mathrm{B}, \mathrm{C}$ and $\mathrm{D}$ originate from hollows. In addition, it is not clear if we are concerned here with hollows of different ages, or, if samples were always taken from the lowest point of the hollow.

VISSCHER, I93I, was familiar with the mosaic of highly humified hummocks and fresh hollows visible on the peat-faces. He interpreted the wavy line of contact between the more humified and the less humified Sphagnum peat as a "wellenartige Grenzhorizont" (= undulating Grenzhorizont). It is obvious that a synchronous line is not involved here, and this is also evident from the course of the darker bands in EMmen 9 (fig. 42), see also I I.21., p. 164 .

The start of the intermediate peat forming in EMmen 9 can be dated to shortly after $2000 \mathrm{BC}$. The date of c. I $800 \mathrm{BC}$ for EMMEN I I is in agreement with this, see II.3., p. I4I. In EMmEN 17 the intermediate peat began to form after I90o BC, see II.26., p. I74. The wooden trackway found in EMmEN 33 (see I I.5., p. I43 and fig. 59) and dated at $215^{\circ} \mathrm{BC}$ lies in highly humified peat. During the excavation in 1964, fresh Scheuchzeria-Sphagnum cuspidatum peat was found in the hollows only slightly above the level of the wooden trackway. This indicates that the intermediate peat forming started here at c. $2000 \mathrm{BC}$ or shortly afterwards.

The sections mentioned above are all from the area of brownblack highly humified Sphagnum peat (see also 11.7., p. I45 and fig. 13). Observations in this area show that the above dates are not exceptional, but that the intermediate peat began to develop c. $2000 \mathrm{BC}$ in a very large part of the brown-black area, with the deposition of fresh cuspidatum peat in hollows.

The hummock and hollow system of EMmen 22/23 in the blueblack Sphagnum peat area started to develop considerably later, see I I.30., p. I85. Dating this at c. I200 BC or somewhat later would appear to be reasonable. The beginning of the fresh cuspidatum peat formation in the raised bog lake, EMMEN 19, about $400 \mathrm{~m}$ north of sections $22 / 23$, is a few centuries earlier; this may be deduced from the stratigraphical observations on peat-face H, see II.4I., p. 209 and I I.47., p. 218 . Intermediate peat probably originated here even between I 300 and I 500 BC in the form of an extensive ScheuchzeriaSphagnum cuspidatum deposit.

C. $2000 \mathrm{BC}$ the Menyanthes-Betula peat in face $\mathrm{O}$ was overgrown by highly humified Sphagnum peat, see I I. I 7., p. I57. The intermediate deposit which consists here of hummocks and hollows of type EMMEN 
32 (see I I.33., p. I 88) clearly developed here several centuries after this overgrowing, possibly between 1500 and $1000 \mathrm{BC}$. The transition to the intermediate hummock and hollow formation took place in the region of the brown-black Sphagnum peat, where hummocks and hollows of type Emmen 9 and Emmen 17 were developing, i.e. from c. $2000 \mathrm{BC}$ on. However, in those parts of the blue-black area where hummocks and hollows of the types EMMEN 22/23 and EMMEN 32 originated,and also in the area of the raised bog lake, Emmen I9, the transition only occurred from c. $1500 \mathrm{BC}$. Where hummocks and hollows of type EMmen 9 developed on blue-black highly humified Sphagnum peat, i.e. mainly in the south-western part of the blueblack area (e.g. face $\mathrm{K}$ ), the transition could be dated - judging from stratigraphical observations - at c. I500 BC or somewhat later. This, however, is not at all certain.

The end of the hummock and hollow formation of the intermediate deposits in the region of EMmen 22/23 (see fig. I6) can be dated at c. 500 BC, see II.30., p. 185 and II.31., p. I 86 . Round about the same time, the differentiation between highly humified hummocks and less humified hollows almost or completely disappeared in the region of EMmeN 17 (fig. I6), see I I.26., p. 172. This is several centuries later for the region of EMmen 9: shortly after 200 BC, see sections II.21., p. I64, I I.24., p. I 72 and II.25., p. 172 .

A date similar to that of Emmen 22/23 can be considered for the end of the hummock and hollow forming of EMMEN 32: c. $500 \mathrm{BC}$, see also Ir.47.I., p. 218.

\section{I. 34.4 The peat-forming milieu}

The transition from highly humified Sphagnum peat to the intermediate deposit developed via a fresh cuspidatum layer in the four types we differentiated. This points to similar changes in the milieu, viz. to an increase in moisture content.

This transition manifests itself very clearly in all the rhizopod diagrams by a tremendous increase of Amphitrema flavum and the first appearance of Amphitrema wrightianum which quickly reaches large numbers. This is also the level at which Sphagnum papillosum and $S$. imbricatum are present in the moss diagrams for the first time (see also I r.52., p. 233), and S. cuspidatum massively increases in numbers for the first time.

Without any doubt, these changes indicate a considerable increase in the water content of the bog surface. These changes are completely or almost completely absent from the hummocks; there- 
fore, the increase in the water content remained limited to the hollows. The fresh/highly humified (hollow/hummock) mosaic on the bog surface is therefore, in fact, a wet/dry pattern.

The result of the development of the fresh peat in the hollows is a clear divergence in the physiognomy of the bog surface in the area investigated: while the highly humified peat forming $\left(\mathrm{H}_{7}-8\right)$ could continue growing more in the central basin of the bog in part of the blue-black region (area of types EMmEN 22/23, EMmen 32 and the raised bog lake, EMmEN I9, also i1.48., p. 233), a hummock and hollow system, with great variations in the humification of the peat forming ( $\left.\mathrm{H}_{2}-8\right)$, developed on the brown-black bog surface and the south-western corner of the blue-black bog surface. This situation continued from c. $2000 \mathrm{BC}$ to $\mathrm{I} 500 \mathrm{BC}$ or even later.

The increase in the moisture level in the hollows might have been caused by changes in the relief as the result of a desiccation, similar to the development of a wet/dry mosaic due to forming of the relief after the desiccation of c. 4500 BC, upon which Scheuchzeria palustris and Pinus could establish themselves (the Middle Atlantic Pinus forest, see 10.10., p. I 32).

Stagnant water in the hollows which were well-drained up to the suggested desiccation would have formed a suitable milieu for Sphagnum cuspidatum. As a result of the very high moisture level in the hollows (no longer any drainage), a high degree of humification in the peat-forming from these vegetations did not develop. We consider that this type of peat-formation at the level of the transition to fresh hollow peat is not very likely, particularly because an increase in the moisture content of the topmost layers of the highly humified Sphagnum peat can be deduced at several places from the rhizopod-moss diagrams of sections EMmen 9 (1 I.21., p. i64), EMmen i I (i i.3., p. I4I) and Emmen i 7 (I I.26., p. 174). Moreover, the forming of the fresh cuspidatum peat did not even begin simultaneously within each hummock and hollow type, while the variation (in time) between the different types possibly amounts to 1000 years (from c. $2000 \mathrm{BC}$ in Emmen I 7 to after c. 1200 BC in Emmen 22). In our opinion there is much more reason to ascribe the increase in the moisture-level of the bog surface to an increase in the precipitation. The nonsimultaneous reaction of the peat-forming vegetations to the change in climate could have been caused by localised milieu differentiation (brown-black or blue-black highly humified Sphagnum peat, surface relief, drainage pattern).

As the water supply to the peat increased (increasing precipita- 
tion), the hollows particularly would have first become wetter. This did not necessarily result in the hummocks becoming wetter; the rhizopod investigation clearly shows that considerably "drier" peat growth (in the hummocks) can continue for a very long time alongside a pronounced wet peat growth. We presume that the not very moist hollows of the highly humified brown-black Sphagnum rubellum peat gradually became moister due to increased precipitation. This would have caused a stagnation of the rubellum peat forming here, since Sphagnum rubellum shuns a wet habitat. The rubellum peat forming continued in the hummocks due to which the relief could increase somewhat. Eventually, so much water would have collected in the hollows that pools would have formed, particularly in the lowest-lying places, where only slight drainage, or none at all, was possible. As the moisture increased, the pool area would have become larger. Sphagnum cuspidatum would have found a particularly good habitat in these water accumulations, especially because the water would have been highly acidic and extremely oligotrophic. The role of S. rubellum in the hollows could therefore be taken over by $S$. cuspidatum which gave rise to the development of fresh peat. The development of pools was possibly also furthered by the fact that $S$. rebellum cannot retain very much water.

It will be clear that the transition in the hollows from highly humified rubellum peat to fresh cuspidatum peat did not necessarily occur simultaneously over the whole brown-black Sphagnum peat area. The date of c. $2000 \mathrm{BC}$ given by us for the lower limit of the intermediate deposit holds, strictly speaking, only for the lowest, wettest spots, and must therefore be regarded as a terminus post quem. The dates for this limit in EMmen I I (II.3., p. I4I) and EMMEN I 7 (I I.26., p. I 74) are indications of this. VAN ZeIsT's dates (r955a, fig. 24) also show a considerable staggering for the start of the fresh cuspidatum peat forming. This in itself, however, does not necessarily indicate a later increase in the moisture level of the hollow from which the profile concerned came. It is possible that the sample was not always taken through the centre of the hollow, in which case, instead of the hollow base, a relatively early stage of the hollow peat overgrowth of the hummock was dated.

The lower limit of the intermediate deposit (types EMmEn 9 and EMMEN 17 ) is, as has already been reported at the beginning of this section, the immigration-level of Sphagnum papillosum and $S$. imbricatum (see also I1.52., p. 233 where this phenomenon will be extensively discussed). Their presence points to a comparatively high humidity, and this can be seen as support for our con- 
tention that the precipitation must have increased c. $2000 \mathrm{BC}$. The increase in the water content of the peat could, however, also have been caused by a decrease in the average temperature, especially during the growing season of the peat mosses, due to which the evaporation greatly decreased. Theoretically, such a change in climate could lead to the same results regarding the formation of peat. We consider it quite possible that the evaporation may have decreased c. $2000 \mathrm{BC}$, but in addition a larger supply of water must have materialized. We cannot, in fact, imagine that the development of the large raised bog lake, EMMEN 19, which will be discussed in Ir.4I., p. 209, and Ir.47., p. 218 , would have been due exclusively to decreased evaporation from the bog surface. Sphagnum papillosum and S. imbricatum could not have established themselves in the pools which contained open water; therefore, their immigration into the investigation area can possibly be somewhat more accurately dated at the beginning of the increase in the moisture content in the bog, still before the period with pools. EMmen I 7 especially points to this, see II.26., p. I 74. It is possible that these most important components of the fresh peat established themselves in very many places on the highly humified peat, without being able to maintain their growth over so extended an area. In this respect, the presence of $S$. imbricatum in the blue-black peat, cf. $22-\mathrm{Rh} / \mathrm{Mo}$, spectrum 2 (fig. 92) is significant.

In a large part of this blue-black peat the forming of fresh cuspidatum peat only began many centuries later, as already reported on p. 193 (types Emmen 22/23, Emmen 32 and the raised bog lake, EMmen I 9 ; see their extent in fig. 16). Because of the significantly larger quantities of cuspidatum peat, this later transition is stratigraphically more clearly observable than the transition which can be dated at c. 2000 BC or shortly afterwards (e.g. EMmen 9, fig. 42 and EMmen 17, fig. 45). This indicates fairly large supplies of open water on the blue-black bog surface or a much more rapid (but later) increase in the moisture level in this area, in comparison with the brown-black complex.

The later change might be ascribed to the more reducing character of the blue-black peat (see ir.8., p. I47), due to which it was not acidic enough for the establishment of Sphagnum cuspidatum when the peat became moister c. $2000 \mathrm{BC}$. It can be seen from $22-\mathrm{Rh} / \mathrm{Mo}$ (fig. 92), among others, that the highly humified blue-black peat became moister; the highly humified Sphagnum peat (spectra I-4) contains both Amphitrema flavum and A. wrightianum. The occurrence of Sphagnum imbricatum already reported in spectrum 2 (which can 
be dated at c. 2000 BC with some degree of probability) is also an indication of a fair amount of moisture.

Another possible explanation for the absence of fresh cuspidatum peat in this part of the investigation area in the period from c. 2000$1500 \mathrm{BC}$ is perhaps to be found in the development of a doming in the blue-black complex, as a result of the large accumulation of blue-black peat (see 1 I.8., p. 147) which was unfavourable for the retention of water, and which had undergone sufficient alteration only after c. $1500 \mathrm{BC}$.

The transition to the intermediate deposit clearly displays the characteristics of a flooding in faces F, G, H and I. We think that this indicates that not only direct precipitation will have acted as a supply of water here, but that part of the water on the bog surface in which the thick and extensive cuspidatum deposits of type EMmEN 22/23 and of the raised bog lake, EMMEN 19, formed, must have originated in neighbouring bog complexes. The mechanism of the flooding will be further discussed in I I.47.- I I.49., p. 2 I $8 \mathrm{ff}$. We can, however, here remark that this flooding, which can be dated between c. $1500-500$ BC (see p. 212), does not correspond with similar phenomena in the hollows of type EMmen 9, in which, notably after c. $15000 \mathrm{BC}$, no further cuspidatum forming of any significance took place.

\section{I.35. HUMMOCKS AND HOLLOWS OF TYPE EMMEN 9}

The type was found in sections emmen $6,7,8,9, \mathrm{I} 1, \mathrm{I} 2$ and $\mathrm{I} 3$. EMmen 33 can also be included in this type as far as the shape and dimensions of the hummocks and hollows are concerned, see also II.16., p. I56. For the distribution, see fig. 16. The hummocks show very gradual transitions to the less humified hollow peat, and due to this they are sometimes difficult to distinguish on the peatfaces. They continue almost without exception in the intermediate deposit from below to above.

Little or no shifting of the hummocks occurred during the upward growth, and, as a result, the pattern of the hummocks is regular, see also fig. 6r. The hummocks are generally slightly oval in shape. The measurements at the foot of the deposit are roughly $3-6 \mathrm{~m}$, the long axis is N-S or NNW-SSE. There is apparently no arrangement in rows. The distance between the hummocks, i.e. the width of the holes, generally varies from $3-8 \mathrm{~m}$. The very regular pattern, the generally regular arrangement and the gradual transitions in humification point to an uninterrupted growth of these hum- 
mocks and hollows, cf. I 1.21., EMMEN 9, p. 164. Eriophorum vaginatum and Calluna vulgaris were able to spread out several times in the hummocks; darker bands and cuspidatum layers are present in the hollows. These phenomena indicate fluctuations in the water content of the bog, which were presumably caused both by the climate and by changes in the drainage pattern. The often slight thickness of these growths in the hollows arouses the suspicion that the climatic factor would be especially a question of very dry or very wet summers. For the rest, the water content of the bog would have had a decelerating effect on the development of desiccation phenomena.

The darker bands which occur frequently, particularly in the marginal area, can usually be followed only from the one hummock to its neighbour. Desiccations of large parts of the bog surface would therefore not generally have occurred. Although the hummocks would scarcely have been of any significance by c. $200 \mathrm{BC}$, it might be concluded from EMmen 7 (fig. 40) in comparison with EMmen 33 (fig. 59) that they hardly decreased in size. However, this effect was due to a vary large extent to the extensive shrinkage of the cuspidatum peat, which generally formed only in the centre of the hollow; and by extensions of hummock communities over the edges of the hollows. Due to this the edges of the hollows give the impression of belonging to the hummocks, see also Emmen 9, fig. 42.

The gro-vth of cuspidatum peat in the hollows was mainly limited to the lowcimost layers of the filling of the hollows, see fig. $4 \mathrm{I}, \mathrm{EM}-$ MEN 8, fig. 42, Emmen 9 and profile EMmen in in I I-Po, fig. 74 . This level displays a strong similarity to WEBER's "Grenzhorizont". The further filling of the hollows is predominantly papillosum peat.

The period of open water in the hollows (cuspidatum peat forming) can be roughly dated between c. 2000 and $1500 \mathrm{BC}$, see also Ir.2 I., p. I64, the synchronous level $\alpha$.

The drainage of the raised bog lake, EMmen ig, (see 11.47.r., p. 218), dated at c. $500 \mathrm{BG}$, has caused no distinguishable desiccation of the peat in type EMMEN 9 . Round about this time or somewhat later, the milieu changed to such an extent that the differentiation between hummocks and hollows (originally a wet/dry pattern) largely disappeared.

The difference in height existing at present between the synchronous points in EMmEN 9 (see figs. 42 and 43 ) would have originated mainly as a secondary phenomenon. Still, the hummock and hollow system would originally have had some relief, which - depending on the water content of the hollow peat and the rate at which the hummocks grew upwards - would have been variable. 


\section{1.36 . HUMMOCKS AND HOLLOWS OF TYPE EMMEN I 7}

This type was found in sections $I_{5}, 16,17$, and 18 . Its presence appears to be limited to a comparatively narrow area west of the raised bog lake, EMMEN I9, see fig. I6. This type of intermediate deposit has a complicated stratigraphy with sharp transitions in humification, many cuspidatum layers and centres of highly humified Calluna-rich peat, on both fresh cuspidatum peat and moderately humified rubellum peat containing little Calluna. It displays a very fine, but extremely complicated rhythm, differing widely from that of type Emmen 9, cf. fig. 6r.

EMmen I 7 seems to consist of two hummock and hollow complexes. The lower one can be dated from c. $2000 \mathrm{BC}$ to $1500 \mathrm{BC}$, the upper one continued from C. 1500 to $500 \mathrm{BC}$. As far as this system is concerned, we can recognize a relationship with the raised bog lake, EMmen I9, a relationship which is also indicated by the distribution of type EMMEN 17. The stratigraphy and vegetational development of this type was extensively discussed in I 1.26., p. I 74 . Here, too, a wet/dry pattern in the higly humified Sphagnum peat c. $2000 \mathrm{BC}$ preceded the formation of more humified hummocks and fresh cuspidatum peat.

The shape of the hummocks is not known with certainty; they are probably roughly circular, with a diameter of 4-8 $\mathrm{m}$. The width of the hollows varies from $2-6 \mathrm{~m}$. These large, flat-topped hummocks were probably not formed in such dry conditions as those of e.g. type EMmen 9 .

Several very thin layers of less highly humified rubellum peat are present in the cuspidatum layers. It is possible that the wet/dry pattern present here was less sharply differentiated than in type EMMEN 9, which was discussed in the previous section. The transition to the uppermost system, which is especially conspicuous because of its strongly pronounced hummocks and short hollows, very probably did not proceed via a desiccation. It is a radical change in the wet/ dry pattern; in this way a dry hummock was able to form within a hollow in, among other places, Emmen 17. In the uppermost system, wide wet/dry variations exist within very short distances. While scarcely any more cuspidatum peat formed in the hollows of type EMmen 9 after c. $1500 \mathrm{BG}$, see preceding section, cuspidatum deposits of a considerable thickness still developed in this type, $\mathrm{cf}$. Emmen 17 and 18 (figs. 45 and 47 ). This indicates the presence of open water, or at least a high water content between c. I $500-700$ $\mathrm{BC}$, cf. I I.26., p., I 74, which is not present in the hollows of type 
Emmen 9. We think that a relationship exists between the absence of open water from the hollows of type EMmen 9 after c. $1500 \mathrm{BC}$, the high moisture level in type EMmEN I 7 since c. I $500 \mathrm{BC}$ and the roughly synchronous flooding of the highly humified, blue-black peat at the position of faces $\mathrm{F}, \mathrm{G}, \mathrm{H}$ and $\mathrm{I}$, which resulted in the development of the raised bog lake, EMmen ig. In sections I1.47.II.49. (p. 218-229), this relationship is the crucial point in the discussion of the bog hydrology in the intermediate deposits.

The hummocks of the uppermost system are approximately round, have a diameter of $\mathrm{I}-2 \mathrm{~m}$, and are noticeable because of their highly humified, Calluna and Eriophorum-rich nuclei. As already said, Sphagnum cuspidatum is an important component in the short hollows.

Two desiccation levels are present in EMmen I7, which can be dated at c. $1200 \mathrm{BC}$ and at c. $800 \mathrm{BC}$, and the first of which especially can be described as deep-seated. We consider it unjustifiable to correlate these desiccations with those which appear to be present in EMmen 9, level $\beta$ and level $\gamma$ respectively (see figs. $4^{2}$ and 43). The desiccations found here must have been very superficial, cf. I I.2 I., p. I64, while the centres of these desiccations could just as well have been found in the marginal area.

Both wooden trackways XVII (Bou), dated at i I 7o BG (EMMEN I6, see I1.29., p. 184) and XV (Bou), dated at 530 BC (EMmen I5, see I I.28., p. I84) are situated for the greater part in the uppermost hummock and hollow system of EMmen 17 . Both the rhizopod analysis and the construction of the trackways lead to the conclusion that the peat was very moist here. It is remarkable, however, that the trackway in Emmen 16 dated at I 170 BC goes through a pool, while in EMMEN I 7, a synchronous desiccation was found. A considerable transport of water undoubtedly occurred in the hollows of the uppermost system of type Emmen 17. No extensive erosion developed with this. On the one hand, the differences in level on the bog surface would have been very slight, so that the water flowed superficially; on the other hand, cuspidatum vegetations, and further west Scheuchzeria vegetations would have been present in the hollows (Emmen I5, see fig. 78) in such abundance that formation of real bog streamlets (German: Rüllen) could not have taken place. The sharp transition to the fresh peat c. $5^{\circ 0} \mathrm{BC}$ can undoubtedly be connected with the drainage of the raised bog lake, Emmen 19, (Ir.41.1., p. 210) which, however, did not lead to a desiccation of the peat. See also $\mathrm{M}$ I.47.4 and II.47.5., p. 220 . 
This type was found only in face $\mathrm{H}$, from which sections Emmen 20 (fig. 50), Emmen 22 (fig. 5I) and Emmen 23 (fig. 52) come, and in face $F$. We can conclude from its distribution that this type is closely connected with the raised bog lake, EMmen 19 .

The few hummocks found in face $\mathrm{H}$ appear to be generally composed of moderately humified peat with a nucleus of highly humified peat, which does not have a particularly high Calluna content. The shape of the hummock is not exactly known. $6 \mathrm{~m}$ was the biggest size we found; the centre of the hummock in EMMEN 23 was not found. The topside is remarkably flat, the transition to the fresh imbricatum peat is very clear; the gradual overgrowth by hollow peat can only be clearly seen on the edge of the hummock.

The hollows with cuspidatum filling are many times larger than the hummocks; measurements of more than $20 \mathrm{~m}$ are no exception. There is no trace here of a wet/dry pattern on the highly humified bog surface such as was the cause of the other types, see also fig. 6 I.

The beginning of the fresh cuspidatum peat forming in EMMEN 22 can be fixed roughly at $1200 \mathrm{BC}$ or somewhat later. Although the cuspidatum deposit in face $\mathrm{H}$ is interrupted in several places by hummocks (e.g. EMmen 20, see fig. 50), it is, however, fairly certain that one large cuspidatum growth is involved here, with the raised bog lake, EMmen 19, as the centre.

The fresh layer in the cuspidatum peat of EMmen 22 would have formed during a decrease in the water level in this raised bog lake. This thin layer could be traced in almost the whole of the cuspidatum deposit of face $\mathrm{H}$. Although the layer can perhaps be dated to c. 800 BC, cf. 22-Po (fig. 9I), we do not consider it justified to correlate the drop of the water level with the desiccation in section EMmEN I 7, which can also be dated to c. $800 \mathrm{BC}$, see the previous section. Apart from this decrease, other fluctuations in the water level occurred which led to the development of alternating layers of more and less humified peat, e.g. in EMMEN 23.

Here, too, the peat growth did not come to a stand-still after the drainage of c. $500 \mathrm{BC}$, see I I.47.5., p. 221 . This did change to the extent that of the hummocks only a very small area with somewhat more humified peat remained; cf. EMMEN 20 and 23 , figs. $5^{\circ}$ and $5^{2}$. 
Only section EMmen $3^{2}$ (fig. 58) has been drawn in of this type. In the investigation area it occurs both in the eastern part of the blue-black highly humified peat, and on the highly humified peat south of the east-west orientated cover-sand ridge in the Hunze depression, cf. fig. I6. Clear humification transitions can be seen in this type. The hummocks are predominantly round, the diameter is roughly $5 \mathrm{~m}$, the hollows are often $5-7 \mathrm{~m}$ broad, see also fig. $6 \mathrm{r}$.

A rather thick cuspidatum deposit is present in the hollows. Often this lies loosely on the highly humified peat, tailing out into the hummock peat. Eriophorum nests are present on the floor of the hollow in many places. It is very probable that erosion occurred in these hollows, see I I.33., p. I88. This, however, would have been completely different in nature from the erosion which will be discussed in Emmen I9, see I I.47.4., p. 220. Probably the topside of the highly humified peat in the hollows eroded away at places here, due to which the stronger components of the then existing bog surface, the Eriophorum nests, could offer sufficient resistance to the erosion and remain intact. It is obvious to look for a connection between this erosion and the Runde which flowed in the neighbourhood, see also I 1.49., p. 227.

The appearance of this type south of the blue-black Sphagnum peat deposit makes this connection particularly likely. The drainage would also have gone via these hollows, especially at times with a high water level. The tailing-off of the cuspidatum peat into the edges of the hummocks might indicate a shift of cuspidatum peat into these edges, which would be pressed upwards at times of a high water level. This would indicate that erosion took place several times. This hummock and hollow formation was not dated; a duration between c. ${ }^{5} 500-500 \mathrm{BC}$ is not improbable on stratigraphical grounds. The transition from the highly-humified to the fresh Sphagnum peat above the Menyanthes-Betula peat in faces $\mathrm{O}$ and $\mathrm{P}$ proceeds via a hummock and hollow system, which shows a great similarity with type Emmen 32. The quality of this part of peat-faces $\mathrm{O}$ and $\mathrm{P}$ was too poor to make detailed observations. The base of the intermediate deposit here can be clearly dated after ${ }^{5} 5^{\circ 0} \mathrm{BC}$. Corresponding hummocks and hollows are also present in the "Meerstalblok" (meerstal = wet place on bog surface, pond or lake), a bog remnant lying about $6 \mathrm{~km}$ south of the investigation area (see fig. ${ }^{17}$ ). 
I I.39. THE OCCURRENGE AND DISTRIBUTION OF SCHEUCHZERIA PALUSTRIS L.

Pollen and seed of Scheuchzeria palustris L. are generally found only occasionally in the peat; this situation is in marked contrast to rhizoms and leaf-sheath remains, which can be seen in large quantities on the peat-faces. In this section, a summary will be given of the types of peat in which, and the places where Scheuchzeria-remains appear in the investigation area. The palaeo-oecology of Scheuchzeria palustris will be further discussed on the basis of the information thus obtained.

Scheuchzeria does not occur in Boreal and older deposits. Its first appearance, just above the early Atlantic desiccation layer (see 8.5.2., p. 73) on face D (pits $122-126$ ), face $\mathrm{E}$ (pits $178-179$ ) and face $J$ (pits $33 \mathrm{I}-333$ ) can be dated in the first half of the Atlantic.

The types of peat mentioned below have already been dealt with in the preceding chapters, and as far as the ombrogenous peat is concerned, partly in the preceding part of this chapter; a few types of peat will be still further discussed later in this chapter.

non-ferruginous fen and fen-wood peat ( $p .70-80$ )

Relatively little in face $D$, pits $122-126$; face $E$, pits $178-179$; face J, pits 33I-333. Dating: first half of the Atlantic.

Scheuchzeria peat contact zone in face J (p. 104)

Abundant in face J, pits 330-336. Dating: from c. 4 roo BC (stump group Munaut B, fig. Io6 and p. 124) to c. 2500 BC (29-Po, 10.7., p. I 30 and fig. $9^{8}$ and table I, p. 28$)$.

middle-Atlantic Pinus forest (p. 75 and 132)

In many places frequent to abundant, see among others, ro.3., p. I 7 ; particularly above depressions in the subsoil and in the wood peat above the slope of the Hondsrug (face A; face B, pits $30-35$; face $\mathrm{D}$, pits $99-\mathrm{I} 20$ ). Dating: from c. $4500-4000 \mathrm{BC}$; above the slope of the Hondsrug to late in the Subboreal (fig. 66; 3 -Po).

seepage peat (p. 8I)

Not present.

seepage peat dopplerite layer (p. 94)

In many places, but not abundant, in all peat-faces with seepage peat. Dating: c. 3 10o BC (p. 85). 
late-Atlantic Pinus forest (p. I35)

In several places extensive vegetations in association with Pinus, e.g. face M, pits 405-410. Dating: from c. 3100-2950 BC (stump group Munaut A, fig. I05).

brown-black facies of the highly humified Sphagnum peat (p. 145)

Forming clear layers, especially in face $D$, sometimes in association with Pinus (pits $\mathrm{r}_{32}-\mathrm{I}_{3} 6$ and $\mathrm{I} 4 \mathrm{I}-\mathrm{r} 46$ ). Similar phenomena in face $\mathrm{J}$ (e.g. pits $3 \mathrm{I}_{3}-3 \mathrm{I} 5$ ), though on a somewhat smaller scale; and in face $\mathrm{C}$ (pits 52-54), see fig. 77, EMmen I4. Dating: possibly between c. $3000-2500 \mathrm{BC}$. Along and above the vein with ironrich fen peat in face C, pits 65-69. Dating: probably from c. 4500 $-3000 \mathrm{BC}$. At and under the level of the wooden trackway of EMmen 33 (see I I.5., p. 143 and fig. 59, see also fig. 102), i.e. near the spillway in the east-west orientated cover-sand ridge in the Hunze depression (p. I44 and I 56). Dating: probably from c. 3000 $\mathrm{BC}$ to after c. $2000 \mathrm{BC}$.

blue-black facies of the highly humified Sphagnum peat (p. 147)

Not present.

Menyanthes-Betula peat (p. ${ }_{157}$ )

Present in a few thin, comparatively pure layers, faces $\mathrm{O}$ and $\mathrm{P}$. Dating: between 3100-1920 BC (p. I57).

intermediate deposits (p. I62)

Occurring frequently with Sphagnum cuspidatum as the base of the fresh hollows of types EMmen 9 (p. 197) and EMmen I 7 (p. 199) in the western $\mathrm{I}-\mathrm{I} .5 \mathrm{~km}$ of the peat area. Dating: from c. $2000-\mathrm{I} 500$ BC (see p. 191). Present with Pinus in the intermediate deposits on the margin of the bog (face B, pits $30-44$ and fig. 38, EMmen 5; face D, pits $127-128$ ), but, in this case, also present in the highly humified peat. Dating: probably from as early as c. $3000 \mathrm{BC}$, but more extensive from c. $2000 \mathrm{BC}$. Occurring abundantly in a number of places (Emmen igB, Emmen igG, fig. 49) in the raised bog lake, EMmen I9 (fig. 48), but not present at other places in the neighbourhood, e.g. EMmen 22 (fig. 5 I) and EMmen 23 (fig. 52). Dating: from c. $1500-500 \mathrm{BC}$. Occasionally forming thin layers in the hollows of type EMmen 32 (p. 202). Dating: from c. 1500-500 BC.

fresh Sphagnum peat (p. 239)

Occurring rarely: present mostly in thin cuspidatum layers (EMmen 
9, fig. 42). Dating: c. $500 \mathrm{BC}$ and later; even earlier in the poorly or not humified hollow peat, however, probably from c. 1500 BC.

Roughly speaking, the occurrence of Scheuchzeria in clear layers is limited to a $\mathrm{I}-\mathrm{r} .5 \mathrm{~km}$ wide zone in the western part of the peat area. Above the slope of the Hondsrug in faces A, B and D, remains of Scheuchzeria even form thick deposits. TALLIS and BIRKs (I965), who extensively studied the past and present distribution of Scheuchzeria, found a big increase in this plant during the Atlantic. They ascribe this to the increasingly wet climate in this period. According to these authors, it would not have spread any further during the Subboreal, as a result of considerably drier climatic conditions. Our observations point clearly to another conclusion, viz. an increasing expansion from the first half of the Atlantic onwards.

TALLIS and Birks (I965) report that the occurrence of Scheuchzeria is closely connected with peat areas with a high water level, and not so closely with a certain ion-content of the water. Our observations, that Scheuchzeria is present in at least apparently very widely differing milieus in that investigation area, might also point in this direction. The question then remains why it is absent from or only sporadically present in a number of other milieus, such as the seepage peat, the blue-black highly humified Sphagnum peat, in many hollows and in the fresh Sphagnum peat.

Scheuchzeria palustris is present in the fresh Sphagnumcuspidatum peat, which was formed between c. 2000-1500 BC in the hollows of peatfaces B (e.g. Emmen 8, fig. 4I; EMmen 9, fig. 42), C (e.g. Emmen i I, fig. 74) and D (e.g. Emmen 15, fig. 78). Scheuchzeria is, however, completely absent from the strictly synchronous and apparently completely comparable fresh Sphagnum cuspidatum layers of peatfaces E (e.g. Emmen I 7, fig. 45; Emmen 18, fig. 47) and F. Since the water level would have been sufficiently high in all these hollows, the high level in the undoubtedly rather acidic bog water in both groups of hollows, which was considered necessary by TALL is and BIRKs, is not sufficient to explain satisfactorily the presence or absence of Scheuchzeria in a certain peat deposit.

We think we can conclude from our observations that Scheuchzeria occurs particularly in rather acidic, somewhat eutrophicated or mineralized, very moist to wet milieus. The fact that the bog water has to have a rather low $\mathrm{pH}$ can be deduced from the absence of extensive Scheuchzeria vegetations from the non-ferruginous fen peat. Since Scheuchzeria is not present in many undoubtedly acidic enough hollows with fresh Sphagnum cuspidatum peat (e.g. in faces E and F), 
a low $\mathrm{pH}$ in itself could not have been sufficient for Scheuchzeria establishment. The abundant occurrence of Scheuchzeria along the western margin of the bog can very probably be ascribed to the eutrophicating influence of the Hondsrug. The Scheuchzeria deposit which surrounds the ferruginous "overflow" in face C, pits 65-69 (see also 9.16., p. 108), and the Scheuchzeria deposit in the contact zone of face J, pits $333-336$, might have originated in a milieu in which mixing of acidic bog water with seepage water (with part of the iron already removed) was an important factor. Eutrophicating of the water of the raised bog lake, EMMEN I9 (face $\mathrm{H}$ ), as a result of both the action of the waves and the presence of birds might have made Scheuchzeria growth in this lake possible. Solution of minerals from the fen-wood peat or the seepage peat in the acidic bog water probably played a part in its establishment in the Middle Atlantic Pinus forest and the Late Atlantic Pinus forest.

The joint appearance of Scheuchzeria and Pinus might possibly be ascribed to a common preference for a somewhat mineralized or eutrophicated, more or less acidic bog soil. Pinus would prefer the somewhat drier and perhaps slightly less acidic places (see 10.3., p. II 7 EMMEN 14), but could have continued growing for a long time after the bog surface became wetter. The repeated occurrence of Pinus and Scheuchzeria together indicates that factors other than climatic ones also played an important part in the establishment of these plants in the bog - plants which are often regarded as climate indicators.

The relatively rare occurrence of Scheuchzeria in the fresh Sphagnum peat possibly points both to a drastic decline in the number of possibilities for their establishment, and to this sort of peat being unsuitable for Scheuchzeria growth. On the one hand, places with open water (pools and bog lakes) became scarce after the drainage of the bog surface c. 500 BC (see I I.47.5., p. 221, the raised bog lake, EMmen I9); on the other hand, this peat was probably too oligotrophic for Scheuchzeria. A similar situation also arose earlier, c. I 500 $\mathrm{BC}$, in the fresh hollows of e.g. Emmen 8 (fig. 4I), Emmen 9 (fig. 42), EMmen I I (fig. 74) and EMmEN I5 (fig. 78), during the development of the drainage of these hollows, see I I.48., p. 223.

\section{DRAINAGE AND EROSION PHENOMENA}

$$
\text { I I.40. EMmen } 34 \text { (fig. 6o) }
$$

Section from a north-south peat-face (which was not drawn as a 
whole), about ro $\mathrm{km}$ south of the investigation area (see fig. Io). This section was drawn in using a grid with $0.1 \times 0.1 \mathrm{~m}$ squares. The section was interpreted as the cross-section through an erosion gulley. Diagrams $34 \mathrm{~A}-\mathrm{Po}$ (fig. I03) and $34 \mathrm{~A}-\mathrm{Rh} / \mathrm{Mo}$ (fig. I04) were made of profile $34 \mathrm{~A}$, sampled through the gulley itself. Profile $34 \mathrm{~B}$ was sampled just beyond the gulley. $34 \mathrm{~B}-\mathrm{Po}$ (fig. 103) and $34 \mathrm{~B}-\mathrm{Rh} /$ Mo (fig. I04) were made from this.

Numerous gulleys of this type occur in this peat area $\rightarrow$ the most southerly part of Bourtanger Moor - and they all apparently come from the same level: a thick Sphagnum cuspidatum layer which, because of its relatively strong horizontal adhesion, was able to offer more resistance to an erosion which affected a large surface than the highly humified Sphagnum peat lying underneath. This highly humified Sphagnum peat was swept away at many places, causing the cuspidatum deposit, which was thus undermined, to subside. The large spread of the cuspidatum deposit (over several $\mathrm{km}^{2}$ ) and the occurrence of very many, possibly hundreds of erosion gulleys in this cuspidatum peat area indicate that formerly enormous masses of water collected on the bog surface, with extensive Sphagnum cuspidatum vegetations, and that this entire pond, or lake, system must have been drained within a very short time.

It appears from $34 \mathrm{~A}-\mathrm{Po}$, spectra $\mathrm{I}-3$, that the peat-growth began comparatively late in this area. The Scheuchzeria peat layer, which covers the sandy subsoil here, was formed as late as the Subboreal, when Fagus was already appearing in the pollen diagram. This is also indicated by the presence of a pollen grain of Cerealia and of Plantago lanceolata. The Scheuchzeria layer was overgrown by highly humified Sphagnum peat, in which Scheuchzeria was originally still only a minor component. Close to the place where $34 \mathrm{~A}$ was sampled, there is a crack in the highly humified Sphagnum peat from 0,40 to within the Scheuchzeria layer. It is possible that younger, allochthonous peat fragments were displaced through this crack to the foot of the highly humified Sphagnum peat. This is, however, not true for the Amphitrema content of the highly humified Sphagnum peat.

The comparatively high values - for highly humified Sphagnum peat - of Amphitrema flavum in spectra 2-4 are not accompanied by Amphitrema wrightianum, which is, however, already present in the younger and in the allochthonous peat ( $34 \mathrm{~A}-\mathrm{Rh} / \mathrm{Mo}$, spectra $7-\mathrm{I} 7$; $34 \mathrm{~B}-\mathrm{Rh} / \mathrm{Mo}$, spectrum 4 ). Spectra I-3 of $34 \mathrm{~B}-\mathrm{Rh} / \mathrm{Mo}$ do not contain rhizopods; it is possible that the topmost highly humified Sphagnum peat, containing much Eriophorum and Calluna, was formed 
under drier conditions than the lower layers $(\mathrm{h} / \mathrm{i} / \mathrm{j} / \mathrm{k}, \mathrm{I}-25$ and $\mathrm{e} / \mathrm{f} / \mathrm{g}, 83-99)$. The cuspidatum layer, which is still probably in its original position from $\mathrm{g} / \mathrm{h}, \mathrm{I}-20$ and from $\mathrm{d} / \mathrm{e}, 9 \mathrm{O}-99$, lies on this highly humified Sphagnum peat which was formed under drier conditions.

A gully was formed by erosion in the highly humified Sphagnum peat between 30 and 50 , into which the cuspidatum layer subsided from the left and from the right $(\mathrm{g} / \mathrm{h}, 25-\mathrm{j} / \mathrm{k}, 37$ and from $\mathrm{f}$, $85-\mathrm{n}, 5^{\mathrm{r}}$ ). The highly humified Sphagnum peat under this cuspidatum slope on the right was badly affected by erosion. The cuspidatum layers situated between 50 and 81 in the highly humified Sphagnum peat would most probably have been deposited there when the highly humified peat was lifted up during the erosion (see EMMEN 24, fig. 53 and I I.42., p. 213). The fresh Sphagnum peat that fills the erosion gully up from the base $\mathrm{n}, 4 \mathrm{O}-5^{\mathrm{I}}$, is a very loose papillosum peat, in which both Amphitremaflavum and A.wrightianum are present; strangely enough, Sphagnum cuspidatum is not present $(34 \mathrm{~A}-\mathrm{Rh} / \mathrm{Mo}$, spectra $7-9$ ). The erosion can be roughly dated by the cuspidatum layer of $3{ }_{4} \mathrm{~B}$ which must have been formed before the erosion. In spectra 4 and 7 , Fagus has values of c. $4 \%$ and $3 \%$ resp., Corylus drops from I $3-9$ $\%$ and Carpinus is c. $0.3 \%$. The spectra can be dated in the Subatlantic at about the time of the first large increase of Fagus, c. 500 BC. The rather large difference in pollen content between spectra 2 and 4 (Alnus, Carpinus, Fraxinus, Cyperaceae and Rumex) indicates the possibility of an interval between the highly humified Sphagnum peat and the cuspidatum layer. This, however, has nothing to do with the dating of the erosion.

In $34 \mathrm{~A}-\mathrm{Po}$, there is a clear difference between, on the one hand, spectra I-5, with a low Fagus value, while Carpinus is absent, and on the other, spectra 7 and 9, which date clearly from the Subatlantic. The fresh peat filling of the gulley, therefore, dates, as has already been deduced from $34 \mathrm{~A}-\mathrm{Rh} / \mathrm{Mo}$, from after the erosion. The deposit of moderately humified peat, from $\mathrm{k}, 30$ to $\mathrm{m} / \mathrm{n}, 40$, consisting of a number of thin layers, is probably material which was redeposited. The cuspidatum peat growth came to an end as a result of the erosion of c. 500 BC, and a growth of fresh Sphagnum peat developed. After only a fairly short time this fresh Sphagnum peat was overgrown by a moderately humified, Calluna-rich peat, e/f, I; d, 20;1, 50; d/e, 7o; c, 99 , that runs as a thin band through the section. It follows from

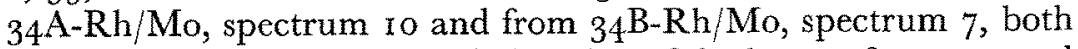
taken from this layer, that a desiccation of the bog surface occurred here. The Amphitrema content considerably decreased, possibly as a 
result of the disappearance of the imbricatum-papillosum peat in this layer.

After the desiccation, the fresh Sphagnum peat growth developed again; the cuspidatum layer of $h, 39$ to $j, 46$, and the fairly high Amphitrema content of the peat in the gulley $(34 \mathrm{~A}-\mathrm{Rh} / \mathrm{Mo}$, spectra I I - I 5) indicate a type of peat formed under very moist conditions. In $34 \mathrm{~B}-\mathrm{Rh} / \mathrm{Mo}$, spectra 8-10, Amphitrema flavum is present in much smaller numbers, while Amphitrema wrightianum is almost completely absent. The peat on the extreme right of the section was, therefore, very probably formed under considerably drier conditions, and this very probably points to the existence of relief in the bog surface during the formation of this fresh Sphagnum peat. The gulley now visible in the section (d, 20; e, 45-50; h, 55) is therefore not exclusively the result of shrinkage during the drainage of the preceding century. The cuspidatum layer $\mathrm{d}, 34 ; \mathrm{g}, 47 ; \mathrm{a}, 6 \mathrm{o}$; and the two smaller cuspidatum layers indicate a relatively long life-span for this gulley. We may not conclude from the present form of these cuspidatum layers that the gulley had this relief during the period of the filling-up. The thin, darker bands of moderately humified peat on the right of the gulley in the fresh peat indicate regularly recurring desiccations of the bog surface. The bog surface which would have been completely or almost completely levelled, will probably have acquired some relief again during such a slight desiccation.

On top of the topmost cuspidatum layer in the gulley, there is a deposit of moderately humified peat in which the rhizopods, Phryganella hemisphaerica and Hyalosphenia subflava reach comparatively high values (34A-Rh/Mo, spectrum I 7), whereas the Amphitremas disappear almost completely. This undated transition in the peatgrowth indicates what might be called a serious disturbance in the mechanism of the peat-growth. The regular occurrence of Picea in rather more than minimal percentages is remarkable in the two pollen diagrams. Picea was possibly present a relatively short distance away from this section.

I I.4I. Emmen I9 (fig. 48), peat-face H, between pits 263-267

This section was drawn in using a grid with $0.5 \times 0.5 \mathrm{~m}$ squares. The clear gulley cross-sections, Emmen I9A $(0-7.5 \mathrm{~m})$, EMmEN ${ }_{9} \mathrm{~B}$ ( $\mathrm{I}-\mathrm{I} 6.5 \mathrm{~m}$ ) and EMmen $\mathrm{I}_{9 \mathrm{C}}(\mathrm{I} 9.5-24.2 \mathrm{~m}$ ), of this section are given as slightly larger scale details in fig. 49. Thin, highly or poorly humified layers in the moderately humified peat are not further differentiated, and neither are the more humified layers in the fresh 
peat. A profile from Emmen $\mathrm{I}_{9} \mathrm{~B}$ was sampled, from which ${ }_{19} \mathrm{~B}-\mathrm{Po}$ (fig. 88) and $19 \mathrm{~B}-\mathrm{Rh} / \mathrm{Mo}$ (fig. 89) were made.

One of the Pinus stumps of the Sphagnum peat dopplerite layer (see I I.I4., p. I54) in EMmen I9C (fig. 49) was sampled at I4.80 VS (= vertical scale) and 21.0 HS (horizontal scale) and its outermost tree rings, 20-30, were dated to $2490 \pm 70 \mathrm{BC}\left(\mathrm{GrN}_{4} 625\right)$. A sample of dopplerite at $4^{8.0} \mathrm{~m}$ HS of the seepage peat dopplerite layer (see 9.8., p. 94) at the transition of seepage peat to ombrogenous peat was dated. Since dopplerite is soluble in alkali, only an acid pre-treatment was carried out, so that only the minimum age was obtained: $265^{\circ} \pm 90 \mathrm{BC}(\mathrm{GrN} 4802)$. The ${ }^{14} \mathrm{C}$-dates given here are also given in table I.

\section{I.4I.I. The bog development}

After the desiccation of c. 3I0o BC (see 9.I4., p. Io3), highly humified Sphagnum rubellum peat formed on the seepage peat. The contact level between the two types of peat, visible at c. I4.30 m + N.A.P. as a seepage peat dopplerite layer, runs remarkably horizontally. The drying cracks which developed because of the desiccation have not been drawn in. Our opinion is that the ${ }^{14} \mathrm{C}$-date of the dopperite is too young; see also 9.8., p. 94. Since the date gives only the minimum age, it is not certain that dopplerite is a coagulated humic colloid originating at a higher level. The Sphagnum peat grew upwards, possibly only very slowly, as very highly humified peat (at places, $\mathrm{H}$ 9). The few examples of Amphitrema wrightianum ( $\mathrm{I} \mathrm{B}-\mathrm{Rh} / \mathrm{Mo}$, spectra 3 and 4) probably reached this level in the peat by flooding due to the erosion which caused the development of the big gulleys, $19 \mathrm{~A},{ }_{19} \mathrm{~B}$ and ${ }_{19} \mathrm{C}$. This is presumably not the case with Trigonopyxis arcula, which would undoubtedly have found a habitat in this slowly growing, highly humified Sphagnum peat (c. 20 $\mathrm{cm}$ in 600 years).

The desiccation of the highly humified Sphagnum peat which can be dated at c. 2500 BC and which resulted in a saucer or gulleyshaped desiccation surface (the Sphagnum peat dopplerite layer, see also 9.8., p. 94), made the establishment of Pinus on the peat possible for a short time; see figs. 48 and 49 . The relatively small spread of the Sphagnum peat dopplerite layer (EMmen 19, fig. 48; EMmen 24, fig. 53 and EMMEN 25, fig. 54) indicates a localized desiccation, which can very probably be ascribed to a drainage via the drying crack network in the seepage peat, which is very extensive at this particular point. It is possible that this drainage followed the same 
course as the drainage of the seepage peat basin of $3100 \mathrm{BC}$, see 9.I4., p. I03.

The peat growth re-established itself again after this desiccation. Highly humified Sphagnum peat with, originally, Aulacomnium palustre ( $\mathrm{Ig} \mathrm{B}-\mathrm{Rh} / \mathrm{Mo}$, spectra 5 and 6 ) as an important component formed again, just as was the case in the topmost seepage peat (spectra I and 2) and in the highly humified Sphagnum peat which was formed before 2500 BC (spectra 3 and 4). Amphitrema flavum appears somewhat higher in the highly humified Sphagnum peat (spectra $6-8)$. Although flooding cannot be excluded, it is possible that we are here concerned with a somewhat moister or more acidic peat type. The disappearance of Aulacomnium palustre might also be a pointer in this direction. Since profile $19 B$ was sampled through an erosion gully, the subsequent development of the highly humified Sphagnum peat here could not be checked further.

Three centres of erosion where formation of gulleys clearly took place, $19 \mathrm{~A}, 19 \mathrm{~B}$ and $19 \mathrm{C}$, can be seen in the section which was drawn in. In view of the position of the Sphagnum cuspidatum layers and the atypical course of the curves in $19 \mathrm{~B}-\mathrm{Po}$, spectra 9-24 (fig. 88), gulley $\mathrm{I} g \mathrm{~B}$ (fig. 49) must have been filled completely with redeposited material. In the part of the erosion gulley system, which was not drawn in, north of EMmen 19 (above pits 267-276), a number of gulleys were cut right into the Sphagnum peat dopplerite layer. This is in agreement with what was observed in EMmEN 24, see following section.

Nearly all the cuspidatum peat in the extreme left of the section, $0-7 \mathrm{~m}$ HS ( $19 \mathrm{~A})$ has disappeared. The deepest erosion gullies are to the left (north) of the section drawn in. These had all caved in. It is therefore not unlikely that in section I 9 only the southern part of the total erosion profile was found.

Only one erosion level could be established, the upper side of the thick Sphagnum cuspidatum layer which had clearly been shifted in the gulleys (just as in EMmen 34, see the preceding section), so that we may assume that here, too, a flood of water causing erosion occurred only once.

After the drainage, the fresh Sphagnum peat growth, probably especially Sphagnum papillosum, would have developed again comparatively quickly. The drainage caused no desiccation of the peat; water must therefore have collected again very quickly in the eroded gulleys. 


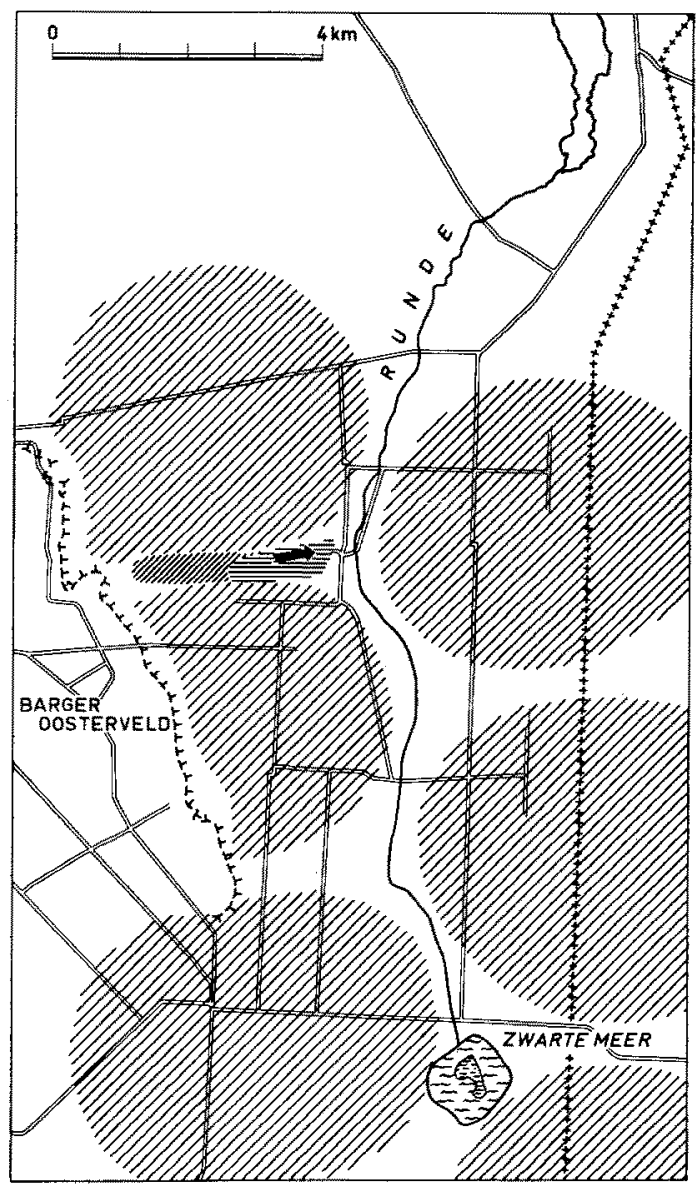

Fig. 17. Situation of the presumed domed bog complexes since c. I 500 B.C. The area with hummocks and hollows of the EMmeN 17 type and the raised bog lake EMmen 19 have been added here for the sake of clarity.

\section{1.41.2. Dating of the phenomena}

The transition from seepage peat to highly humified Sphagnum peat might be dated at c. 3 IOO BC, see 9.5.2., p. 90. The desiccation level at which the Sphagnum peat dopplerite layer formed could be reliably dated at c. $2500 \mathrm{BC}$ with the stump sampled in EMmeN I9C (see beginning of this section, p. 2 10).

Diagram I9B-Po cannot be used for a direct dating of the cuspidatum deposit. However, on stratigraphical grounds, the beginning of the cuspidatum growth can be dated as follows: 
The cuspidatum layer of Emmen 19 (fig. 48) is somewhat thicker than that of EMMEN 22 (fig. 5 I). Both belong to one large cuspidatum deposit, see I I.37., p. 201. The base of this layer is somewhat lower in Emmen 19 than in Emmen 22. The lowermost $4-8 \mathrm{~cm}$ of the deposit near EMMEN I9 tail off into face $\mathrm{H}$ in the highly humified Sphagnum peat, between sections Emmen 19 and Emmen 22. We may therefore conclude that the cuspidatum growth developed in EMMEN 19 some time, i.e. some centuries, earlier than in Emmen 22, where it can be dated to $\mathrm{C}$. I $200 \mathrm{BC}$ or somewhat later, see I I.37. We find a date of c. $1500 \mathrm{BC}$ quite acceptable.

The end of the cuspidatum peat growth in EMmen 22 is at the level of the first Fagus maximum (fig. 91, 22-Po), i.e. c. 500 BC. From I $9 \mathrm{~B}-\mathrm{Po}$ (fig. 88), spectrum 24, from one of the redeposited cuspidatum layers, can also be dated to $\mathrm{c}$. $500 \mathrm{BC}$ (Fagus more than $4 \%$ ). A similar date for the growth of fresh cuspidatum peat can be obtained from $24 \mathrm{~A}-\mathrm{Po}$ (fig. 93), spectrum 6 (see I I.42.) and 28B-Po (fig. 96), spectrum 7 (see 1 I.46., p. 216 ). There are no indications that this cuspidatum growth continued for a still longer time. The date of the erosion can therefore, in our opinion, be set at c. $5^{\circ 0}$ BC.

I I.42. EMmen 24 (fig. 53), peat-face I, between pits 279-280

This section was drawn in by means of a grid with $0.5 \times 0.5 \mathrm{~m}$ squares. The seepage peat part has already been discussed in 9.2. (p. 83).

It has already been stated in the preceding section that this method of drawing does not differentiate between thin, highly humified or fresh layers in the moderately humified peat and thin, more humified layers in the fresh peat. $24 \mathrm{~A}-\mathrm{Rh} / \mathrm{Mo}, 24 \mathrm{~B}-\mathrm{Rh} / \mathrm{Mo}$ (fig. 94) and 24A-Po (fig. 93) were made of this section.

In the highly humified Sphagnum peat which developed on the desiccated seepage peat surface (the seepage peat dopplerite layer), Ericaceae and Empetrum are important components (24A-Po, spectrum 3), in addition to Sphagna and Aulocomnium palustre (24A-Rh/ Mo, spectra $\mathrm{I}-3$ and $24 \mathrm{~B}-\mathrm{Rh} / \mathrm{Mo}$ ).

The Sphagnum peat dopplerite layer indicates the desiccation level which can be dated to c. $2500 \mathrm{BC}$ (see preceding section): from $14.00 \mathrm{VS}$ (= vertical scale) by o HS (= horizontal scale) to I 4.20 VS by 7.0 HS. Pinus established itself on the desiccated bog surface (between 0.8- I.6 HS). The fresh Sphagnum cuspidatum layer, lying at an angle in the section, which stretches between 1.5 and 1.7 
VS right to the Sphagnum peat dopplerite layer at $14.00 \mathrm{HS}$, has a layered structure which runs at an angle, parallel to the position of the layer. Spectrum 6 of 24 A-Po comes from this layer. It is distinguished by a relatively high value for Fagus $(4.3 \%)$ and low values for Ericaceae, while Empetrum is absent. Sphagnum has a very high value. In spectrum io (from the highly humified Sphagnum peat) Fagus has again declined; Calluna displays a maximum here, Fraxinus has sharply decreased and Tilia is again present, as in spectrum 3 . The fresh cuspidatum peat of spectrum 6 clearly dates from a more recent period, viz. from about the first Fagus maximum (c. 50o BG) than the highly humified Sphagnum peat (spectra 3 and ro) above and below it. We are here dealing with redeposited material.

The rhizopod-moss diagrams, too, point clearly to this. Spectra $5-9$ of $24 \mathrm{~A}-\mathrm{Rh} / \mathrm{Mo}$ (from the cuspidatum peat) have large quantities of Amphitrema flavum and A. wrightianum, Sphagnum papillosum, $S$. imbricatum (spectra 5 and 6 only) and $S$. cuspidatum. In contrast with spectra I-4, Aulacomnium palustre, which occurs especially in slowly-growing highly humified Sphagnum peat, is not present in the spectra from the cuspidatum peat. It is clear that the fresh peat of spectra $5-9$ was formed under very moist conditions. Similar changes above the level of the Sphagnum peat dopplerite layer are absent from ${ }_{24} \mathrm{~B}-\mathrm{Rh} / \mathrm{Mo}$ (fig. 94).

The redeposited peat, which dates from the Subatlantic, corresponds closely with respect to pollen, rhizopod and moss content with the cuspidatum layer of EMmEN 19 (see preceding section) and of EMmen 22 (I I.30., p. I85). It is very likely that this cuspidatum deposit would have here reached the position we found it in due to the erosion already mentioned in the preceding section. The Sphagnum peat dopplerite layer would have acted as a natural cleavage surface in this process. The eroding water would have lifted up large blocks of highly humified peat, with the result that this cuspidatum deposit was stuck tight between two such blocks when the whole of the peat deposit again subsided after having been brought into movement.

The irregular shape of the intermediate deposit in faces $\mathrm{H}$ and $\mathrm{I}$ (see also sections Emmen 25, fig. 54; Emmen 26, fig. 55; Emmen 27 , fig. 56 ; EMMEN 28, fig. 57) is undoubtedly the result of this erosion.

After this erosion came to a stand-still, fresh imbricatum-papillosum peat-forming started, in which no differentiation into hummocks and hollows occurred. 
I1.43. EMmen 25 (fig. 54), peat-face I, above pit 280

This section was drawn in a similar manner to section 24 (see preceding section), which lies $15 \mathrm{~m}$ west of this section. The seepage peat part has already been discussed in 9.2., p. 83. ${ }_{25} \mathrm{Rh} / \mathrm{Mo}$ (fig. 95) was made of this section.

After the desiccation of c. 31 oo BC (level of the seepage peat dopplerite layer), an originally very moist peat growth developed (spectrum 2, Sphagnum cuspidatum and Drepanocladus sp.). This diagram reveals several slight differences with ${ }_{24} \mathrm{~B}-\mathrm{Rh} / \mathrm{Mo}$ (fig. 94) which were discussed in the preceding section. Amphitrema flavum is present here in all the Sphagnum peat spectra, although in small numbers. It is possible that it was somewhat moister here between c. 3100 and 2500 BC (level of the Sphagnum peat dopplerite layer). Spectrum 5, from this dopplerite layer, is characterized by a minimal number of rhizopods and the complete absence of recognizable Sphagnum remains. Pinus was able to grow on the bog ( 14.25 VS and $0-0.2 \mathrm{HS}$ ) for a short time after the desiccation of $2500 \mathrm{BC}$; the trees were smothered by the upward growing peat within 30 years. In this section, too, the disturbance in the intermediate deposit as a result of the erosion, which we think can be dated at c. $5^{\circ 0} \mathrm{BC}$, is clearly visible. Hummocks and hollows did not form in the fresh Sphagnum imbricatum-papillosum peat.

I I.44. Emmen 26 (fig. 55), peat-face I, between pits 28o-28I

This section, about to m east of EMMEN 25, was drawn in a similar way to section Emmen 24 (I I.42.). For the seepage peat part, see p. 83 .

The Sphagnum peat dopplerite layer, which was found in EMmEN 24 (fig. 53) and Emmen 25 (fig. 54), is not present in the highly humified Sphagnum peat here. The erosion level at the top of the highly humified Sphagnum peat is characterized, in this section too, by a thick cuspidatum deposit, which, in all probability, was not found in its original position.

I I.45. Emmen 27 (fig. 56), peat-face I, between pits $28 \mathrm{I}$ and 282

This section, situated about $35 \mathrm{~m}$ east of EMmen 26, was drawn in a similar way to section EMMEN 24 (1 I.42.). The seepage peat part was discussed in 9.2., p. 83 . 
The Sphagnum peat dopplerite layer is missing here, too. The intermediate layer here was clearly deformed by the erosion mentioned already (II.41.2., p. 212) - from 14.65 to 15.25 VS over the entire length of the section.

I I.46. EMmen 28 (fig. 57), peat-face I, between pits 288 and 289

This section was drawn in by means of a grid with $0.1 \times 0.1 \mathrm{~m}$ squares. Parts $\mathrm{I}-5 \mathrm{O}$ HS and I0o- 1 ro HS were drawn in roughly, part 50-10o HS, in more detail. Two profiles were sampled from the section, 28A and 28B, of which diagrams $28 \mathrm{~A}-\mathrm{Rh} / \mathrm{Mo}$ (fig. 97), 28A-Po (fig. 96), 28B-Rh/Mo (fig. 97) and 28B-Po (fig. 96) were made.

In 28A-Po Fagus increases from 0.7 to $1.8 \%$; Carpinus is present in very low percentages (in spectra 4 and 6 only) and there is a clear tendency for Corylus to decrease. For these reasons the Subboreal/Subatlantic transition might be placed between spectra 4 and 6.

In view of its rhizopod content with Amphitrema flavum and $A$. wrightianum, among others, and the occurrence of Sphagnum papillosum (see also I1.52., p. 233), the Sphagnum cuspidatum layer, d/e, $8-\mathrm{i} / \mathrm{j}, 52$, is undoubtedly a deposit similar to the cuspidatum layer found in EMmeN I9 (II.4I.I., p. 2 Io); i.e. a deposit of the raised bog lake, ЕммеN 19, see following section. We are most probably dealing with a layer of redeposited peat here, a supposition which is also indicated by its position, at a pronounced angle.

The deposit of moderately humified peat which covers this cuspidatum layer has an unusually low rhizopod content (28A-Rh/Mo, spectrum 6). Amphitrema wrightianum is completely absent, only a few specimens of $A$. flavum occur, but Hyalosphenia subflava on the contrary, reaches a maximum. From this, and from the appearance of Sphagnum imbricatum in this peat, can be concluded that it is, in all probability, a displaced hummock of type EMmen 23 (see II.3I., p. I 86), which was deposited on the likewise displaced cuspidatum layer during the time of the erosion of the intermediate deposit by the drainage of the raised bog lake, EMmen 19, which has already been mentioned several times in the preceding section. For this reason we drew the curves in $28 \mathrm{~A}-\mathrm{Po}$ (fig. 96) with dotted lines.

The cuspidatum deposit can be dated towards the end of the Subboreal, the hummock peat dates from the early Subatlantic.

On the basis of the behaviour of the curves for Quercus, Alnus and Fagus in 28B-Po (fig. 96), a gap can be demonstrated between spec- 
tra 4 and 7. This gap does not coincide with the Subboreal/Subatlantic transition, but is clearly younger; see also $19 \mathrm{~B}-\mathrm{Po}$ (fig. 88), spectra 8 and 9. The first Fagus maximum is probably present in spectrum 7 of $28 \mathrm{~B}-\mathrm{Po}$; the erosion must have been very nearly simultaneous with this, see also II.4I.2., p. 2 I 2.

It is not impossible that the cuspidatum layer, from which spectrum 7 was taken, was formed only after the erosion. The cuspidatum layer of spectrum 4 is undoubtedly a formation of the raised bog lake EMMEN I 9 .

In this section we obviously cut through an erosion gulley. The left-hand slope shows up clearly (d, I to j, 45-55). The large Eriophorum tussock, bottom right in section $(\mathrm{g} / \mathrm{h} / \mathrm{i} / \mathrm{j}, \mathrm{IO} 4-\mathrm{I0} 7)$ was able to maintain its position during the erosion. The deposit of cuspidatum peat $\left(\mathrm{d} / \mathrm{e}, 8\right.$ to $\left.\mathrm{i} / \mathrm{j}, 5^{2}\right)$ and the moderately humified hummock (d, I I to $\mathrm{e} / \mathrm{f} / \mathrm{g} / \mathrm{h}, 5^{\circ}$ ) were deposited successively on the left-hand slope. Tufts of uprooted peat settled in the right-hand part of the section too, due to which the Eriophorum tussock was covered. Between these moderately humified tussocks $(\mathrm{e} / \mathrm{f} / \mathrm{g} / \mathrm{h} / \mathrm{i} / \mathrm{j}, 85-\mathrm{I}$ 10) and the cuspidatum layer which was deposited on the left-hand slope, there are cuspidatum layers on the highly humified Sphagnum peat, which were undoubtedly brought there by the erosion.

The rather wide gulley is filled to a large extent with redeposited peat. Fresh peat forming communities, of which Sphagnum imbricatum was an important component, established themselves, see $28 \mathrm{~B}-\mathrm{Rh} /$ Mo (fig. 97), spectra 8-12, in the remnant of the gulley which had originally remained open, with base e, $4^{8}$ via $h, 75$ to $f, 92$. The Amphitremas do not occur particularly frequently in this fresh peat. In view of its very loose structure, however, the peat was probably formed in a very moist milieu. Cuspidatum layers are almost completely absent; only at the left-hand side of the gully, d/e/f, $4^{8-65}$, has, mostly insignificant, cuspidatum peat growth taken place. The filling of the gulley (the imbricatum peat) was probably well-drained, so that no open water could collect here.

The many, somewhat darker, moderately humified layers which have a considerably more irregular form than could be drawn in, were perhaps caused by short-lived delays in the peat growth as a result of slight, but not widespread, desiccations (28B-Rh/Mo, spectrum 9). This, however, is not certain (28B- Rh/Mo, spectrum 11). The gulley and its immediate neighbourhood were eventually overgrown by fresh peat $(a / b / c, I-I I 0)$. 


\section{1.47. The RAISED BOG LAKE, EMmen I9}

\section{I.47.r. Stratigraphical observations and datings}

The transition to less humified peat (the intermediate deposit) is characterized, especially in faces $\mathrm{H}$ and $\mathrm{I}$, but also in faces $\mathrm{F}$ and $\mathrm{G}$, by a thick Sphagnum cuspidatum deposit in which Scheuchzeria also occurred plentifully. As we have already indicated several times in the preceding sections, this points to the presence of large masses of water on the bog surface, from c. $1500 \mathrm{BC}$ to c. $500 \mathrm{BC}$; for these datings, see II.4I.2., p. 2I2. The fresh imbricatum-papillosum peat overgrowth of this cuspidatum peat which was found on the peat-faces can be explained only be assuming that these large masses of water largely disappeared within a very short time, without the peat drying out. It could be clearly established in sections EMMEN I9 (11.41., p. 209) and EMmen 24, Emmen 25, Emmen 26, EMmen 27 and EMmen 28 (II.4.2., p. $213,-11.46 .$, p. 216 ) that the disappearance of the masses of water was accompanied by deep crosion. We interpreted the phenomena as a whole as the development of a raised bog lake, called EMMEN I 9 , which disappeared due to eroding drainage. Sphagnum cuspidatum vegetation will have been present in this lake.

\section{I.47.2. The extent of the raised bog lake}

We have been able to establish this approximately on the basis of the following observations and considerations (see also fig. I6):

On top of the highly humified Sphagnum peat over the whole of peat-face $\mathrm{H}$, there are extensive layers of cuspidatum peat, which contain Scheuchzeria in many places. In the southern part of the face, this cuspidatum deposit is interrupted at a number of places by low hummocks (see e.g. Emmen 20, fig. 50 and EMmen 23, fig. $5^{2}$ ). The southern limit of the lake is not present in face $\mathrm{H}$; it is, however, probable that this limit, in view of the occurrence of these flattopped hummocks, would not have been much further south than the southern point of face $H$, i.e. pit 220 . Peat-face $G$ is the intact remainder of a long peat-face which largely collapsed as a result of the peat slipping down the cuspidatum layers. The northern limit of the lake must have been here, approximately above pits 2 I 2-2 I 9 of face $\mathrm{G}$.

The northern half of peat-face $F$ (pits 194-2II) has no strikingly large quantities of cuspidatum in the intermediate deposit; this is in contrast with the southern part of face F. There was a clear hummock and hollow system present in peat-face $\mathrm{E}$ between $\mathrm{C}$. I 500 and 


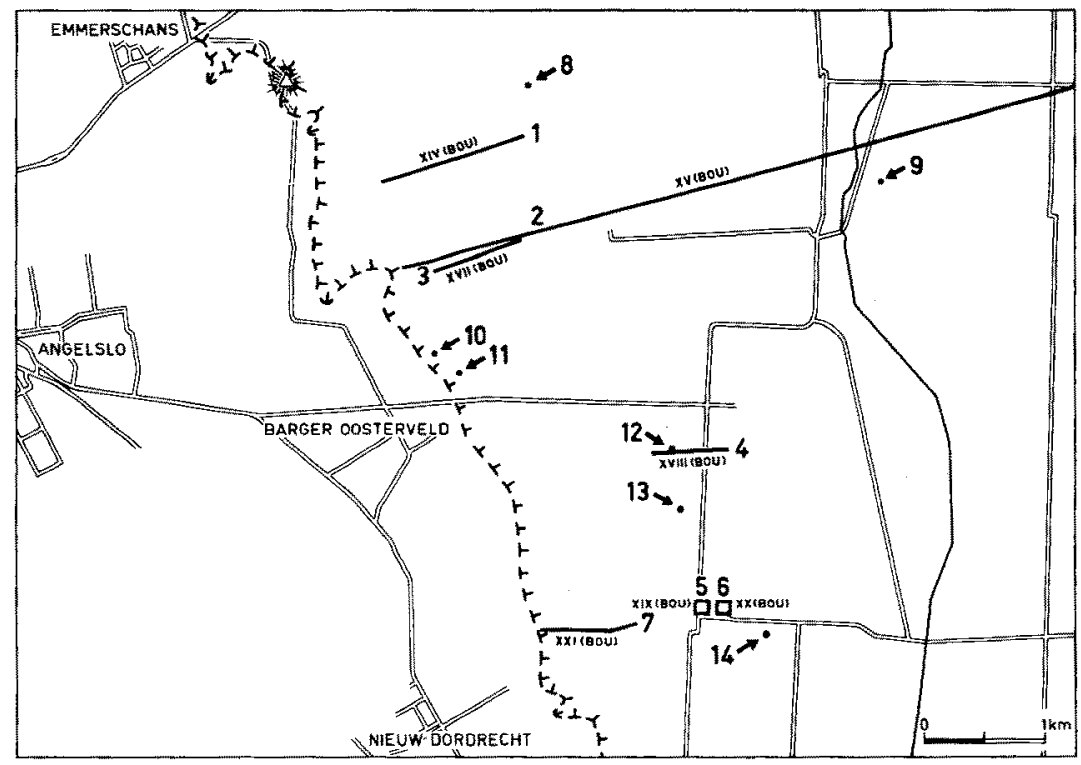

Fig. 18. Some bog finds from the area studied: $\mathrm{I}-7=$ wooden trackways $8=$ peat body; $9=$ bronze dagger; $10=$ small wooden sanctuary (129o B.C.) surrounded by a circle of stones; $11=$ bronze dagger; $12=$ disc wheel; $13=$ bronze dagger; $14=$ mesolithic hearths with microliths. Only the numbers

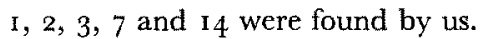

5 Oo BC (EMmen 17, see I I.26., p. I 74 and fig. 45); the lake, therefore, probably did not extend much further westwards than to face $F$.

The wooden track, XV (Bou), the northern wooden pathway dated at 530 BG (see also 11.28 , p. 184 ), which possibly ran to the eastern boundary of "Bourtanger Moor" (see also fig. I8), would have run alongside, and not through, the thick cuspidatum deposits, irrespective of whether it was built before or after the time of the drainage of the raised bog lake (see further on in this section, p. 222). About $300 \mathrm{~m}$ north of pit 276 , the foot-path intersects the line of continuation of peat-face $\mathrm{H}$, which more or less defines the northern extent of the bog lake here. From this information it is possible to define the western and northern boundaries of the raised bog lake at its greatest extent with some degree of certainty. The southern limit can be given somewhat less accurately, although it can probably be found in the region of the southern extremity of face $\mathrm{H}$. No trace of the eastern bank was found. This must be ascribed to the absence of peat-faces east of face I. In view of the quality of the 
intermediate deposit in this face, the eastern bank was, in any case, east of face I. For this reason we put question marks in fig. 16.

\section{II.47.3. The area of the bank of the lake}

In peat-face $\mathrm{H}$ there is no clearly developed bank of the lake present. Such formations are also absent from faces $F$ and $G$. The cuspidatum layers in face $\mathrm{H}$, however, were interrupted here and there, especially in the southern part of the face, by hummocks of type EMMEN 23, see above. The lake, therefore, very probably had an extensive marginal area, comprising numerous pools connected with each other, and large hollows (e.g. EMmen 22, see fig. $5 \mathrm{I}$ and I I.30., p. I 85) forming a gradual transition to the bog surface which was not under water. These phenomena indicate a continuous increase in the size of the lake as a result of a rising water level. The suggestion that the erosion which will be discussed later was caused by the lake overflowing is an obvious one.

\section{II.47.4. The erosion}

The clear erosion gulleys are situated in face $\mathrm{H}$ especially, above pits 263-267, where section EMMEN I9 (see figs. $4^{8}$ and 49) was drawn in. To the north of this section, face $\mathrm{H}$ had collapsed at several points, as a result of the peat deposits sliding over discordantly positioned cuspidatum layers in the gulleys, similar to those found in EMmen ig. The system of erosion gulleys of face $\mathrm{H}$ is, therefore, at least $100 \mathrm{~m}$ wide (above pits $263-276$ ).

The intermediate deposit of face I was affected by erosion throughout its entire length. The area affected by erosion in the raised bog lake was indicated in fig. I6. The direction is approximately eastwest. It is fairly certain that the eroding stream of water flowed in an easterly direction. If the water had disappeared in a westerly direction, then peat-faces $F$ and $G$ should have had clear erosion phenomena in their cuspidatum deposits. These were not observed. We think, therefore, that the lake was drained in an easterly direction, i.e. into the river Runde, flowing c. I km east of peat-face $\mathrm{H}$. This means that the eastern bank of the raised bog lake would have been worn away by erosion (see fig. 16).

As has already been reported (in, e.g. I I.41.2., p. 212), one erosion level is present, viz. at the transition from the thick, poorly humified cuspidatum deposits to the fresh imbricatum-papillosum peat. Fig. 49 clearly demonstrates the erosion in EMmen I9C took place as a single occurrence. In view of the predominantly very loose peatfilling in the eroded gulleys, including Emmen IgA, IgB and $19 \mathrm{C}$ 
(fig. 49), these gulleys must have acted as drainage gulleys for a long time.

\section{I.47.5. The development of the raised bog lake}

I. The origin

The origin of the lake is clearly connected with a very large flooding. We have already mentioned, in I I. $36 .$, p. 199, the occurrence of movements of water in the peat, which clearly developed c. I $500 \mathrm{BC}$ in the region of hummocks and hollows of type EMMEN I 7. The water would have come largely from the hollows of type Emmen 9 (see also I I.35., p. 197) which contained open water up to about $\mathrm{I} 500 \mathrm{BC}$. Within a relatively short time, the lake must have had a considerable size, since the base of the cuspidatum deposit in face $\mathrm{H}$ is strikingly level, with, of course, the exception of the eroded part. From section EMmen 22, among others (see I I.30., p. I85 and also II.4I.2., p. 212), we can conclude that the maximum extent indicated in fig. $\mathrm{r} 6$ - an estimated surface area of more than $0.5 \mathrm{~km}^{2}$ - was not attained at once. Besides the obvious spread observed in a southerly direction, the lake would, in all probability, have been able to spread out in other directions too. This would have proceeded via inundation of the surrounding hollows (such as in EMMEN 22, see II.30., p. I85), during which the highest hummocks remained above water level (EMmen 23, see i I.3 I., p. i 86).

This drainage system was able to continue for a long time; from c. I $500 \mathrm{BC}$ to c. $500 \mathrm{BC}$, in any case. It is possible that there was a short interruption, which might be dated to c. $800 \mathrm{BC}$, which resulted in a lower water level in the raised bog lake. See, e.g. the thin, fresh Sphagnum peat layer in the cuspidatum deposit of EMMEN 22 (fig. 5I) which can be dated to c. 800 BC (1 I.30., p. 185) and the desiccation layer in EMMEN I 7 of approximately the same age, which was not drawn in fig. 45 , but which was under discussion in I 1.26., p. I 74. Since, however, we do not know whether the lower water level of the lake was caused by a decreasing supply or by a sudden draining off of part of the water of the lake, we will go no further here than a statement of the phenomena.

We have already reported that the blue-black highly humified Sphagnum peat must have been formed in a less acidic milieu than the brown-black peat, see i 1.8, p. 147 . We are of the opinion that the development of the poorly humified cuspidatum peat formation in the hollows can be ascribed to a milieu which was sufficiently acidic here (I I.34.4., p. I9I). 
The very extensive fresh cuspidatum peat forming, which characterised the development of the raised bog lake, EMmEN 19, indicates that, within a short time, the blue-black peat became considerably more acidic on a very large scale. The conclusion that some eutrophication still took place can be drawn from the abundant occurrence of Scheuchzeria palustris, see I I.39., p. 203, and from the composition of the hummock peat of EMmen 23, see i I.3 I., p. I 86.

\section{The drainage}

Overflow of such a lake can take place if the upward growing of the peat which acts as a diffuse bank cannot cope with the rise in water level any longer. The overflowing water would have caused the lowest-lying part of the bank to be eroded ever more deeply, and, therefore, ever more quickly. A drainage which had originated in this manner might explain the depth of the erosion gulleys in the raised bog lake, EMmen 19, (down to the Sphagnum peat dopplerite layer, see fig. 53, EMmen 24). Another possibility is that one of the banks gave way as a result of too great a one-sided pressure, due to which the lake could empty at once. In either case, a lot of organic material must have been moved with the water (bog burst, German, "Moorausbruch"). The actual cause (overflowing or collapse of a bank) cannot be determined any longer from the information still present in the bog. The phenomenon can, however, be described as the single drainage of a raised bog lake which was previously predominantly without drainage. When this catastrophic drainage occurred, the water disappeared in an easterly direction, into the river $\mathrm{R}$ unde which flowed about $\mathrm{I} \mathrm{km}$ east of face $\mathrm{H}$, see also fig. I6. This will be further discussed in the following two sections.

\section{1.47.6. The raised bog lakes in Weisse Moor near Kirchwalsede (Germany)}

SaHNEEKLOTH $\left(1^{6}{ }^{6} \mathrm{~b}\right)$ describes a number of raised bog lakes in "Weisse Moor" near Kirchwalsede. In our case there is no question of the connection he suspected between these lakes and the fen and fen-wood peat lying underneath. Another very striking difference is the clear evidence of a bank that he found. Probably too little movement of the waves took place in our raised bog lake (perhaps as a result of the cuspidatum vegetations) to form a clear bank in the continually extending lake. To this must be added, however, that we have only one cross-section of the lake (face $\mathrm{H}$ ) in which only the southern diffuse bank - and it is not entirely complete - is present, while the influence of motion of the waves would be visible on the north-eastern bank especially, and not on the southern bank. It is 
certain, however, that the raised bog lakes described by ScHNEEкLOTH did not originate in the same way as the raised bog lake, EMmen 19.

\section{i 1 .48. Drainage Patterns and domed complexes}

\section{I.48.I. Rates of accumulation in hummock/hollow systems}

The moderately humified Sphagnum rubellum hummock of EмmeN I 7 ( I I.26., p. I 74, see also fig. 46) which was formed between I8go and $c .1500 \mathrm{BC}$, has an average thickness of $18 \mathrm{~cm}$. Consequently, the rate of accumulation of this moderately humified peat is $4.5 \mathrm{~cm} /$ Ioo years. For the roughly $5^{\circ} \mathrm{cm}$ thick highly humified hummock, which was formed between c. I 500 and 540 BC (I I.26., p. I 74, see also fig. 46 , the rate of accumulation amounts to a good $5 \mathrm{~cm} / 100$ years. The rate of accumulation for the total, roughly $70 \mathrm{~cm}$ thick hummock peat deposit of EMMEN 17, formed between 1890 and $540 \mathrm{BC}$ is $5 \mathrm{~cm} / 100$ years.

Although less accurate datings are known for the different hummock levels in EMmen 9 (I I.2 I., p. I64, see also figs. 42 and 43), the rate of accumulation can be determined in a satisfactory way here, too. The corresponding figure for the $110 \mathrm{~cm}$ thick hummock peat deposit which was formed between 2000-I $500 \mathrm{BC}$ (level $\alpha$ ) and c. $500 \mathrm{BC}($ level $\varepsilon)$ is a good $8 \mathrm{~cm} / 1$ oo years. The rate of accumulation between $2000-1500 \mathrm{BC}($ level $\alpha$ ) and $1200-900 \mathrm{BC}$ (level $\beta$ ), in which time an approximately $45 \mathrm{~cm}$ thick deposit was formed, is $6.5 \mathrm{~cm} / 100$ years. This period shows the closest correspondence with that period during which the flat-topped, moderately humified Sphagnum rubellum hummock of EMMEN I 7 mentioned above was formed.

The rate of accumulation of the hummock of EMmen 23 (I I.3I., p. 186 , see fig. $\left.5^{2}\right)-35 \mathrm{~cm}$ in approximately 700 years amounts to $5 \mathrm{~cm} / 100$ years.

Although all the calculations were not carried out with the same degree of accuracy, we think we are safe in saying that the hummock of EMmen 9 grew faster than the double hummock of EMMEN I7 and the hummock of EMmen 23. It is natural to suppose that this will also hold for types Emmen 9 and Emmen i 7 respectively. The faster upward growth of parts of the bog surface, viz. in the areas with hummocks and hollows of type EMMEN 9 (see fig. 16, the distribution of type EMMEN 9), would eventually have resulted in the development of a domed bog surface. 
We can deduce from the fact that drainage of the hollows of type Emmen 9 developed at c. 1500 BC (the end of the fresh Sphagnum cuspidatum formation, see I I.35., p. 197) that, even at this time, a certain degree of doming must have come about.

A complication arises with the development of the domes, in the sense that, at c. $2000 \mathrm{BC}$, the blue-black bog surface (accumulation of peat $\mathrm{c} .7 \mathrm{~cm} / 100$ years) would have been higher than the brownblack bog surface (c. $3.5 \mathrm{~cm} /$ roo years), see i i.7., p. I 45 . We consider it not impossible that this situation came to an end at roughly I $500 \mathrm{BC}$, which can be concluded from the flooding which caused the development of the raised bog lake, EMmEN I9 (see I I.4I.I., p. 210 ).

\section{I.48.2. The mechanism of the flooding}

The raised bog lake existed for a long time as a predominantly outlet-less lake, see preceding section. It was clearly elongated in shape with an approximately east-west long axis, see fig. 16 . This means that the lake was hemmed in (on the north, south and east sides) by a number of raised bog complexes with hummocks and hollows of type Emmen 9 (see fig. 16, see also I I.35., p. 197). On the western side of the lake, hummocks and hollows of type EMmen i 7 developed (see fig. 16, see also I I.36., p. 199), viz. the pronounced, short hummocks and small, cuspidatum-peat-containing hollows. This system developed c. I500 BC. At about the same time, the water already present in the hollows of type EMmEN 9, see I I.35., p. I97, where this was further described, began to flow off.

The following reconstruction of the mechanism of the formation of the raised bog lake can be deduced from the complete picture of the phenomena observed: at c. $2000 \mathrm{BC}$, the bog surface became so much moister that open water could collect in hollows, where formation of fresh cuspidatum peat (hummocks and hollows of type EMmeN 9, see I I.35., p. 197) could begin. The disappearance of the open water from the hollows of type EMmEN 9, which can be dated at c. $1500 \mathrm{BC}$, can be ascribed to the development of drainage in the raised bog complexes with hummocks and hollows of this type, due to the emergence of domed complexes with peripheral drainage (see beginning of this section). From the area of the hummocks and hollows of type EMmEN 17 and from the shape and position of the raised bog lake, EmMEN 19, between the hummock/hollow complexes of type Emmen 9 (see fig. 16), we can deduce that the water of the hollows of type EMmen 9 was drained via the hollows of type EMMEN I 7 to the raised bog lake, EMmen i 9 . 
The hummocks and hollows of type EMmen 17 and the raised bog lake, EMmen 19, can therefore be regarded as drainage zones (contact zones) of the raised bog complexes with hummocks and hollows of type EMmen 9, which, after c. I50o BC, were no longer able to retain the surplus of water in the hollows, undoubtedly because of the domed surface.

\section{I.48.3. The changed drainage pattern}

We have stated in $11.7 .$, p. I 45 , that we supposed that there was, in the brown-black highly humified Sphagnum peat, a movement of water in a northerly direction, viz. the drainage of the southern part of the Hunze depression via the spillway in the east-west orientated cover-sand ridge in the Hunze valley, see fig. 6 . Such a drainage pattern has also already been suggested for the Late-glacial Braunmoostorf formation and the post glacial non-ferruginous fen peat formations (6.8., p. 64). In so far as a drainage pattern developed in the blue-black highly humified Sphagnum peat, formed in the lee of the cover-sand ridge, see fig. 13 and $11.8 .$, p. 158 , it was of a completely different nature to that in the brown-black complex. It will be obvious that the fact that the subsoil slopes downwards in a northerly direction would have favoured a movement of water in that direction, also in the blue-black deposit.

It clearly appears from the preceding section and from what we have said in the present section, that the drainage of the bog was drastically changed in the intermediate deposit, and that, due to this the flooding which caused the formation of the raised bog lake, EMmen I9, became possible. This change can undoubtedly be partly ascribed to the development of the growth mechanism (with domed complexes) in this intermediate peat. On the other hand, the overgrowing of the east-west orientated cover-sand ridge with highly humified Sphagnum peat (which can be dated between c. 2500 and $2000 \mathrm{BC}$ ) would have been an important factor in the changes in the drainage pattern. Because the peat-forming surface grew to a higher level than this barrier, northerly-directed drainage then became possible over a considerably broader front. The overgrowing of the Menyanthes-Betula peat of faces $\mathrm{O}$ and $\mathrm{P}$ by highly humified Sphagnum peat (see I I. I 8., p. I 58 ) dated to c. 2000 BC, points to water movements in the blue-black area. It is possible that the water became somewhat more acidic after c. $2000 \mathrm{BC}$; the process of the overgrowing did, in fact, proceed simultaneously with the incresae of the (acidic) water content in the brown-black, highly humified Sphagnum peat area (hummock and hollow systems EMMEN 9 and EMMEN 
I7, see 11.35 . and I1.36., p. $197 \mathrm{ff}$.). The hummock and hollow system, Emmen 32 (see I I.38., p. 202), is also a clear indication of water movements in the blue-black area. From c. 1500 BC, the surplus of water would have been drained into this via a northwardsdirected water stream over the east-west orientated cover-sand ridge (see the distribution of type EMMEN 32, in fig. I6).

We think that it is very likely that this water transport (area of type EMmEN 32) originated in the contact zone of domed complexes. We can now determine the position and extent of a number of domed complexes with some degree of reliability.

\section{I.48.4. Position and description of domed complexes}

A domed complex exists both to the north and to the south of the area of Emmen i 7 and Emmen 19, see 1 i.47.2., p. 218 and fig. I6. The EMmen 32 area encloses the more southerly of these two complexes on the eastern side. On the western side, the two complexes were bordered by the marginal area, see II.5I., p. 23I. Proceeding from the assumption that we are dealing with concentric domed complexes, the diameter of the southern complex can be established at c. $3 \mathrm{~km}$. It was no longer possible to check the eastern border of the northern complex. We consider that it is not a coincidence that the bed of the Runde is situated within the area of Emmen 32 (see fig. I6), see the following section. We consider it a plausible suggestion that the bed of the Runde also indicates the eastern border of the raised bog complex north of the area EMMEN I 7 and EMmen 19 (see fig. I6), which would have had a diameter of c. $4 \mathrm{~km}$ in that case.

The raised bog complex east of the raised bog lake, Emmen i9, which partly caused stagnation of the drainage of the contact-zone EMMEN I 7 and EMmen I9 (see p. 224), was probably situated immediately east of the Runde. The Runde must, however, have been the eastern limit to which the raised bog lake extended, i.e. the bed of the Runde undoubtedly indicates the western edge of the eastern raised bog complex. In our opinion, the clearly curving course of the Runde is connected with the development of this river on a peat forming surface, that consisted to a large extent of domed complexes. It appears from fig. I 7 that from its source, the "Zwarte Meer", to where it leaves the bog and cuts into the mineral subsoil (just south of Roswinkel, see fig. I 7 ), the Runde curves for over $10 \mathrm{~km}$, a fact which points to the presence of presumably 6 domed complexes, each with a diameter of 3 to $4 \mathrm{~km}$. The development of the Runde will be further gone into in the following section. 


\section{1 48.5. The drainage pattern in the domed complexes}

The drainage of each complex separately did not lead to the development of streams within the complexes; several times, however, it did cause erosion, such as was observed in EMmEN 8 (I I.22., p. I68) and EMmen 9 (II. 2I., p. I64). Considering the enormous supplies of water in the bog, however, the extent of this erosion is negligible. In all probability, the drainage pattern (via the hollows) would have been sufficiently flexible to deal with the rather large variations in the water transport. From the thick Sphagnum cuspidatumand-Scheuchzeria layers in the hollow of EMmEN 7, we can conclude that, for a longer time, the water transport must have gone through predominantly the same hollows, see fig. 40 and I I.24., p. I 72. The absence of rivulets in the intermediate peat with hummocks and hollows of type EMmen 9, of which the domed centres mainly consist, can be ascribed fairly certainly to the strongly delaying influence of the hollow vegetation on the water transport.

On the other hand, the catastrophic drainage of the raised bog lake, Emmen i9, dated at c. 500 BC (I .47.5., p. 22 I) did clearly alter the hydrological conditions, but not so radically (e.g. thorough desiccation, establishment of plants which were not present in the intermediate deposit until the time of the drainage) as the extent of the resulting erosion would lead us to assume. That can presumably be ascribed to the fact that only that water surplus disappeared which had already been drained from the domed complexes. In I I.55., the change which had taken place will be further dealt with.

\section{I.49. The DEVELOPMENT OF THE RIVER RUNDE}

We reported in I I.19., p. I6o, that the river Runde would have originated at the area of contact between two highly humified peat complexes, the blue-black complex, described in I I.8., p. I47, and a complex lying to the east of that, which we did not investigate. In our opinion, a clear indication of the fact that we are dealing here with a raised bog river (in the strictest sence of the word) which developed only after c. $3100 \mathrm{BC}$, can be found in the deposit of Menyanthes-Betula peat of faces $\mathrm{O}$ and $\mathrm{P}$, see I I. I 9., p. I6o. We thought that we had found a precursor of the bed of the Runde in the hollows of type EMmen 32 (I I.38., p. 202); there was indeed a water movement which was clearly directed in a northerly direction, but presumably there was still no question of a river bed. This precursor 
can have developed at c. $2500 \mathrm{BC}$ at the earliest (overgrowing of the east-west orientated cover-sand ridge by ombrogenous peat). It actually happened, however, probably only after c. I50o BC (earliest dating for type EMmen 32). The Runde would probably not have been of much significance up to c. 500 BC (drainage of EMMEN I9), since, up to that time, the west-east drainage of the two domed complexes north and south of the contact zone EMmen i 7 and EMMEN I9 (see fig. I6) was still stagnant in this contact zone. We think that it was actually about $500 \mathrm{BC}$ that bog bursts developed, so that the Runde as a river with a bed (not, therefore, exclusively or mainly diffuse water transport) originated.

The drainage of the raised bog lake, EMmen I9, see I I.47.5., p. $22 \mathrm{I}$, is very probably not a special case; enormous erosion also took place c. $500 \mathrm{BC}$ in the bog on the highest-lying places of the Hunze depression, about ro $\mathrm{km}$ south of the investigation area, see EMMEN 34, I I.40., p. 206. The extent of the water displacement at that time in the southern part of Bourtanger Moor, see fig. I, is many times larger than with the drainage of EmmeN 19. The fresh Sphagnum cuspidatum-Scheuchzeria peat deposit (sometimes more than $25 \mathrm{~cm}$ thick) present in this southern part, which lies on the highly humified Sphagnum peat, is interrupted at dozens (possibly hundreds) of places by erosion gulleys of the type discussed in Emmen 34 (fig. 6o, see also i I.40., p. 206). The total erosion area could not be accurately determined, but it comprises, in any case, an area of several $\mathrm{km}^{2}$. Since we are here dealing with a drainage in the highest-lying part of the Hunze depression, it will be clear that the water supplies must have been drained off in a northerly direction, i.e. via the investigation area.

We also found many similar gulleys at the same level in the thick, fresh cuspidatum deposit situated on top of the highly humified Sphagnum peat in an east-west peat-face, some hundreds of metres long, just south of the former "Zwarte Meer" (fig. I7) halfway between Emmen 34 and the investigation area. Enormous movements of water occurred here, too, which can also possibly be dated at c. $5^{00}$ $\mathrm{BC}$.

From our information, the fairly certain conclusion can be drawn that, at c. $500 \mathrm{BC}$, there was a short-lived period of considerable erosion in the southern part of Bourtanger Moor in the Hunze depression, over a distance of more than $10 \mathrm{~km}$, as a result of very large water movements over the surface of the bog. As has already been said above, the masses of water would have been drained off in a northerly direction. We believe that a clear river bed for the 
Runde developed because of this. West-east and east-west contact zones such as in the area of EMmen I 7 and EMmen 19 (see fig. I6) formed side branches of the main drainage river.

The cause of the erosion, which affected the highest-lying parts of the then existing bog surface too, was undoubtedly the presence of large masses of water on this surface, which could no longer be retained by the peat-forming vegetations. One of the streamlets which fed the "Zwarte Meer" up to the time of the artificial drainage of Bourtanger Moor in the previous century can - proceeding from the argument above - be regarded as the real upper reaches of the Runde.

It is very probable that the "Zwarte Meer" developed only well after c. $500 \mathrm{BC}$, as a result of water stagnation due to the further upward growth of the domed complexes to the north. No date for the origin of the lake can be deduced from diagram 3 of the "Zwarte Meer", published by F LORSchürz et al. (1932). These authors assume that the origin of the lake was due to drainage of higher (domed?) bog surfaces to a central point.

\section{The Marginal AREA}

\section{1.50. Emmen 5 (fig. 38), face B, above pit 33}

This section was drawn in by means of a grid with $0.1 \times 0.1 \mathrm{~m}$ squares. Profile ${ }_{5} \mathrm{~B}$ was sampled above pit 34 at about $25 \mathrm{~m}$ east of

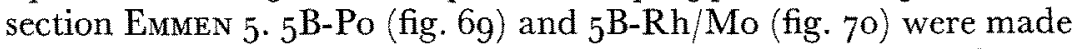
from this. Profile ${ }_{5} \mathrm{C}$ was sampled about i $70 \mathrm{~m}$ east of section EMMEN 5 , and ${ }_{5} \mathrm{C}-\mathrm{Rh} / \mathrm{Mo}$ (fig. $7 \mathrm{O}$ ) was made from it. A secondarily weathered layer which was found in face $B$ is present in the three profiles mentioned $\left(5 \mathrm{~A},{ }_{5} \mathrm{~B},{ }_{5} \mathrm{C}\right)$. The lithology column of profile ${ }_{5} \mathrm{~A}$ which was not investigated is given in the $5 \mathrm{~B}$ diagrams. The stumps present at the foot of the grid belong to the Pinus stump group, Emmen 4 see 10.4., p. $12 \mathrm{I}$.

An originally comparatively dry, highly humified Sphagnum peat developed on the Pinus layer between 15.60 and $15.90 \mathrm{~m}+$ N.A.P., which can be dated at 4500-4000 BC (stump group Munaut E, see ro.5.2., p. 124). After a considerable time (possibly c. $3000 \mathrm{BC}$ ), Scheuchzeria palustris established itself (at about $16.25 \mathrm{~m}+$ N.A.P.) in this Sphagnum peat. Then a less humified peat, rich in Scheuchzeria developed; Spahgnum cuspidatum is still of minor importance here. Highly humified Sphagnum peat remained just above a large stump 
(j, 35-44). Pinus established itself on the moderately humified Scheuchzeria peat (on the level i/j; see EMmen 4, I0.4., p. I2I), possibly as a result of a short-lived slight drying-out of the bog. An increase in the moisture content in the marginal area of the bog which had already become gradually moister - also led to the development of places with open water, in which Sphagnum cuspidatum started to grow (i, I-2 I and i, 45-50). There is moderately humified peat in between these cuspidatum layers. A $20-30 \mathrm{~cm}$ thick layer of highly humified Calluna-rich Sphagnum peat formed over these these rather moist deposits, which must have formed under considerably drier conditions (f/g/h, I- -50). This highly humified deposit was overgrown by a moderately humified peat, in which Eriophorum vaginatum frequently occurs and Calluna is for the most part absent $\left(\mathrm{c} / \mathrm{d} / \mathrm{e} / \mathrm{f}, \mathrm{I}-5^{\mathrm{O}}\right)$. This is possibly an indication of increasing fluctuations in the moisture content.

At the left-hand side of the section, part of a secondarily weathered layer is just visible, and this could still be followed for a few dozen metres in a westerly direction outside the section. This is very likely anthropogenous, as is also the similar layer $\mathrm{b}, \mathrm{I}-5 \mathrm{O}$, which covers the moderately humified peat. From b, $1-9$ and from, b, 35-50, a division can be distinguished in this secondarily weathered layer which is present over the whole section. The layer contains many charcoal remains, especially charred Sphagnum leaves, a lot of very fine organic material, and some sand. The large spread of the fresh Sphagnum imbricatum-papillosum peat and the occurrence of cuspidatum peat containing Scheuchzeria $(\mathrm{a}, \mathrm{I}-\mathrm{a} / \mathrm{b}, 5 \mathrm{o})$ on the layer indicates an overgrowing in a very moist to wet milieu.

The secondarily weathered layer shows rather a high degree of similarity with the "buckwheat layer" observed in many places on the peat-faces, and whose origin is due to the burning of the somewhat dried-out bog surface during the last century. It is possible that here, too, the relatively dry peat (fig. $70,5^{\mathrm{B}-\mathrm{Rh}} / \mathrm{Mo}$, spectra $\mathrm{I}-3$ and ${ }_{5} \mathrm{C}-\mathrm{Rh} / \mathrm{Mo}$, spectrum 4 ) was ploughed and burned, for the purpose of obtaining arable land. One can imagine that, as a result of this custom of burning, evidenced by burnt Sphagna, the peat surface came to lie at a somewhat lower level, due to which the arable land was drowned. The division in the layer, left and right of the section, might perhaps be regarded as attempts to improve the situation by raising the level. Open water must have been present in the part which was not raised ( $b, 10-35)$, at least during part of the year, and, in it, Scheuchzeria and Sphagnum cuspidatum were 
able to establish themselves, but a hummock was also able to develop (b, 28-29).

The fresh peat which overgrew the arable complex could continue growing for only a relatively short time. Desiccation of the bog surface induced a strong expansion of Eriophorum vaginatum-rich hummock vegetations from the small hummock, $b, 28-29$. This moderately humified peat layer, however (at the top of the section), was in turn overgrown by fresh peat (visible from a, I I to a, 35), which is indicative of a short-lived desiccation. The arable layer is situated just in the part of the pollen diagram with the first large Fagus increase (fig. 69, $5 \mathrm{~B}-\mathrm{Po}$ ); the Carpinus percentages present are only low and Corylus drops from c. $25 \%$ to $6 \%$. Because of this the layer can be dated with a rather high degree of certainty at the transition of the Subboreal to the Subatlantic, about 800 BC.

The pollen diagram does not give any information about the nature of possible cultivated crops. There is both a clear Gramineae maximum and an Urtica maximum in spectrum 4, from the arable layer. The absence of Plantago lanceolata from spectrum 7 is striking. The Scheuchzeria maximum and the high Sphagnum percentage in this spectrum can easily be explained stratigraphically. The arable layer lies on moderately humified peat in profile $5 \mathrm{~B}$; there is a thin cuspidatum layer over it, which was overgrown by an off-shoot of a hummock. It appears from ${ }_{5} \mathrm{~B}-\mathrm{Rh} / \mathrm{Mo}$ (fig. 70) that the peat here became much moister only after the arable layer; the Amphitremas attain a considerable increase in spectrum 5. This phenomenon coincides with the establishment of Sphagnum papillosum here.

In profile ${ }_{5} \mathrm{C}$, the layer lies on poorly humified hollow peat. The very moist papillosum peat started to develop here even before the formation of the layer (fig. 7o, $5 \mathrm{C}-\mathrm{Rh} / \mathrm{Mo}$, spectra $\mathrm{I}-4$ ). The decline of Amphitrema flavum and the absence of Sphagnum cuspidatum in spectrum 4, along with the occurrence of Phryganella hemisphaerica and Bullinula indica, provides an indication that the bog surface became drier shortly before the artificial layer was produced. Due to this, perhaps, the winning of arable land became an attractive proposition. After the undoubtedly artificial intervention, as appears from $5 \mathrm{~B}-\mathrm{Rh} / \mathrm{Mo}$ and ${ }_{5} \mathrm{C}-\mathrm{Rh} / \mathrm{Mo}$, the peat growth re-established itself relatively quickly $(5 \mathrm{C}-\mathrm{Rh} / \mathrm{Mo}$, spectra $6-8)$.

\section{I.5I. The PEAT groWTH IN THE MARginal AREA}

The absence of hummocks and hollows from the marginal areas, 
see fig. 16 , can undoubtedly be ascribed, to a very significant extent, to the eutrophication and mineralizing effect of the neighbouring Hondsrug, but also to the clearly distinguishable bog desiccations in the marginal area. As a result of these influences, a generally somewhat more humified peat developed here, which we, however, included in the intermediate deposits, since among them we found clearly less humified layers, whose formation points to a considerably higher moisture level.

A layer of this type is present in the lower part of section EMmen 5 as a moderately humified Scheuchzeria layer, covered by a fresh Scheuchzeria-cuspidatum layer. On stratigraphical grounds, we think that this deposit can be dated between 3000 and $2000 \mathrm{BC}$. The rate of peat accumulation in the marginal area, $130 \mathrm{~cm}$ of peat between 4500-4000 BC (the Middle Atlantic stump layer in EMmEN 5, fig. $3^{8}$, between $\mathrm{I} 5.60$ and $\mathrm{5} 5.90 \mathrm{~m}+$ N.A.P.) and $800 \mathrm{BC}$ (the arable layer, see preceding section) amounts to $3.5 \mathrm{~cm} / \mathrm{r}$ oo years. This is somewhat less than the figure which can be calculated for a corresponding length of time for the ombrogenous peat further inside the bog. It is obvious that we can ascribe this slower peat accumulation to the frequent desiccations (which are also visible in EMMEN 9, see fig. 42). One of those desiccations made the Pinus establishment of Emmen 4 (see Io.4., p. I2I) possible. The water which collected on the surface of the bog after the desiccation made the renewed establishment of e.g. Scheuchzeria palustris and Sphagnum cuspidatum possible. This might be a possible explanation of the Scheuchzeria-rich, moderately humified deposit in EMMEN 5 (fig. $3^{8}$ ), i/j, r-50. The overgrowing by the considerably more humified Calluna-rich peat, which must have been formed under drier conditions $(\mathrm{f} / \mathrm{g} / \mathrm{h} / \mathrm{I}-5 \mathrm{O})$, and then by the Eriophorum-rich peat (c/d/e, I-50) might be an indication of alterations in the drainage of the water surplus in the marginal area; perhaps in connection with the peripheral drainage of the domed complexes which developed at c. ${ }_{1500} \mathrm{BC}$, see 11.48 . 5., p. 227. The Calluna-rich peat might then have been formed before the water in the hollows of type EMMEN 9 had been drained off, i.e. before c. I $500 \mathrm{BC}$; the Eriophorum-rich peat (possibly indicating increasing fluctuations in the moisture content, see the preceding section) might have been formed in a milieu of (but slight) water movement over the bog surface.

If the arable layer in face $B$, pits $33-40$ (see also fig. $3^{8}$ and the preceding section) is indeed the result of more or less successful attempts to make the bog surface suitable for cultivation, its presence presents us with problems to which we have been unable to 
find an answer in the peat investigation. It seems to us that the neighbouring higher sandy soils would probably have been able to offer sufficient arable land, which would undoubtedly have been of better quality than peat arable ground. Furthermore, we do not know of any crops which could have been cultivated on the bog at this time, c. $800 \mathrm{BC}$. It is possible that an attempt to render the peat soil arable was all that was achieved. It appears clearly from diagrams ${ }_{5} \mathrm{~B}-\mathrm{Rh} / \mathrm{Mo}$ and ${ }_{5} \mathrm{C}-\mathrm{Rh} / \mathrm{Mo}$ (fig. $7 \mathrm{o}$ ) that the layer was literally drowned.

If we are dealing with remains of cultivated peat fields here, then we think that it may be concluded that, at the time of the cultivation, the bog surface must have been somewhat drier, see also ${ }_{5} \mathrm{C}-$ $\mathrm{Rh} / \mathrm{Mo}$, spectra 3 and 4 . There are indications present in the bog, too, that, c. $800 \mathrm{BC}$, the bog surface was possibly somewhat drier, or even desiccated, at several places, e.g. EMmeN 9 (11.21., p. 164), EMmen 17 (II.26., p. I 74) and EMmen 22 (Ir.30., p. I85). We have already mentioned (in 1 I.48.I., p. 223) that the available dates do not all possess the same degree of accuracy; moreover, the indications are too vague and too incomplete.

We think we are justified in saying that the bog surface was rather sensitive to slight desiccations between c. I000 and $600 \mathrm{BC}$.

I I.52. ThE OCGURRENCE OF SPHAGNUM PAPILLOSUM LINDBEkG AND SPHAGNUM IMBRICATUM HORNSCHUCH

These two Sphagna are the predominant formers of the fresh Sphagnum peat. It is, however, relevant to include them in a discussion of the intermediate deposit, since the development of the latter was caused, to a significant extent, by their establishment and spread.

The repeated use of the term imbricatum-papillosem peat does not imply that fresh peat is formed exclusively by these two Sphagna, or that they always appear together because of identical ecological requirements. The term is a field name, since it turned out that, in the field, it was not always possible to identify fresh peat further than composed mainly of Sphagna of the Cy mbifolia group. That these are particularly Sphagnum papillosum and S. imbricatum in this raised bog, has been known for a long time. Our investigation has confirmed this again. Their immigration, dated to c. $2000 \mathrm{BC}$ (see I I.35., p. I97), very likely became possible due to an increasing 
humidity as a result of increasing precipitation, see also I I.34.4., p. 193 .

The synchronous establishment of the two types on the brownblack highly humified bog surface might be an indication of relatively little divergence in their ecological requirements. The fact that their establishment on the blue-black highly humified bog surface was considerably delayed, c. I $5^{\circ}$ o $\mathrm{BC}$ (apart from their presence on only one occasion, which can possibly be dated at c. $2000 \mathrm{BC}$, and which is indicated in $22-\mathrm{Rh} / \mathrm{Mo}$, spectrum 2, see fig. 92), indicates a preference for peat surfaces which have formed in an oxidising milieu. Apparently the rather high humidity then already present could not on its own have been sufficient.

In the intermediate deposits, $S$. papillosum appears to be closely connected with hollows, whereas $S$. imbricatum occurs more frequently in hummocks, without, however, being a clear-cut hummock builder. We found clearly more remains of $S$. papillosum than of $S$. imbricatum in the hollows of EMmen ${ }_{5} \mathrm{C}$ (fig. 70, $5 \mathrm{C}-\mathrm{Rh} / \mathrm{Mo}$ ), EMmen 9 (fig. 72, 9A-Rh/Mo), EMmen 15 (fig. 78, ${ }_{15} \mathrm{~B}-\mathrm{Rh} / \mathrm{Mo}$ ), EMmen I7 (fig. 87, I 7 B-macr.) and EMmen 22 (fig. 92, 22-Rh/Mo). Remains of $S$. papillosum were also the most commonly found in those places where the peat formation developed under really wet conditions, such as in EMMEN IgB (fig. 89, IgB-Rh/Mo), EMmen 24 (fig. 94, the redeposited peat in 24A-Rh/Mo), EMmen 28 (fig. 97, 28B-Rh/Mo) and Emmen 34 (fig. I04, 34A-Rh/Mo). Leaves of $S$. imbricatum do, however, occur in the hollow peat, mostly on a somewhat higher level or in smaller quantities. This concerns, at least to a large extent, formations of after c.I500 BC, when the hollows of type EMmeN 9 (I I.35., p. I97) became somewhat drier as a result of the developing peripheral drainage of the domed complexes.

In the diagrams mentioned, it appears that the combination of $S$. cuspidatum $+S$. papillosum occurs more frequently than S. cuspidatum + S. imbricatum. S. imbricatum predominates in the hummocks of EMmen 9 (fig. 72, gB-Rh/Mo), EMmen i5 (fig. $78,{ }_{15} \mathrm{~A}-\mathrm{Rh} / \mathrm{Mo}$ ), EMmen I 7 (fig. 84, I7A-Rh/Mo and fig. 85, I7 C-Rh/Mo) and EMMEN 23 (fig. 92, 23-Rh/Mo). This peat moss would, therefore, have preferred the somewhat drier places, whereas $S$. papillosum would have preferred the wettest places. MüLLER, (1965) reached similar conclusions in his investigation of recent north-west German bog surfaces. Schwickerath (I944), on the contrary, found $S$. imbricatum in the wettest places in the "Hohe Venn".

Both Sphagna occur frequently in the undifferentiated, fresh Sphagnum peat which will be discussed in I1.55., p. 239; it is not 
clear which of the two is predominant. It is clear, however, that, in the one place, more S. papillosum grew (e.g. EMmen ${ }_{5} \mathrm{C}$, fig. 70; EMmen 17B, fig. 87; EMmEN 34A, fig. 104), whereas, in another place, S. imbricatum predominated (e.g. EMmen 9B, fig. 72; EMmen I 7 C, fig. 85; Emmen 28, fig. 97). Pattern-forming possibly occurred because of this, in which fresh imbricatum hummocks alternated with papillosum hollows. However, we do not have any evidence for this.

\section{I.53. The WOODEN TRackways}

Of the four trackways we investigated, only XXI (Bou)*, dated at 2150 BC (see I I.5., EMMEN 33, p. I 43), is situated in highly humified Sphagnum peat; the others lie in or on the intermediate deposit.

The "southern foot path", XVII (Bou), dated to I I 70 BC and to I $195 \mathrm{BC}$ (see table I), lies in the hummock and hollow system, ЕмMEN I 7 (see I i.29., EMmen i6, p. I84), as well as in system EMmen 9. During an excavation of this trackway in May/June, 1967 , it became obvious that prehistoric man had taken measures to make the path more easily negotiable, especially in the hollows of type EMMEN I 7. These measures consisted primarily of taking planks from the hummocks and positioning them in the hollows to raise the levelof the path there, due to which the path gives a more or less disturbed impression. This indicates a higher degree of moisture in the hollows of type EMmen I 7 in comparison with the hollows of EMmEN 9, as we have already observed, see i i.36., p. I 99 .

The use of $\mathrm{I}$ to $\mathrm{I} .5 \mathrm{~m}$ long pins by which both the walking planks and the diagonals were anchored to the peat, see fig. I4, proved, in several places in area EMmeN I 7 , not to have been sufficient to prevent the components of the path from floating away. The "anchoring" appears to have been sufficient in the most westerly part of the path, situated in the area of EMMEN 9. This, too, indicates a greater moisture content in the hollows of type EMmEN I 7, c. I 200 BC. The hummock and hollow formation was scarcely or not at all influenced by the building of the path.

The "northern wooden path", XVI (Bou), dated at 530 BC, see table I, see I I.28., EMmeN I 5, p. I 84, which was already deliberately partly destroyed in prehistoric times (VAN ZEIST I955a, p. 48), contains walking planks which lie clamped between double diagonals connected by pins, see fig. I4. This anchoring has held together less well than that of the southern wooden path. This may be

* Abbreviation for "Bourtanger Moor", see also 2.6., p. 23. 
partly ascribed to the less efficient system of non-anchored walking planks. But, besides this, the very high water content of the peat in the area of EMmEN I 7 , where the wooden path was investigated, would also have been an important factor in the deterioration of the path. From the investigation of the wooden pathways we have also received the impression that the water content in the area of EMmEN I 7 between c. I $200 \mathrm{BC}$ (southern plank path) and $500 \mathrm{BC}$ (northern plank path) increased significantly.

The path of $53^{\circ} \mathrm{BC}$ is overgrown by obviously less humified peat, in comparison with the peat underneath; this is not the case with the path dating from c. I 7o BC. To what extent this is connected with the drainage of the raised bog lake, EMmen 19 (see I I.47. I., p. 218 ), which can be dated at about $500 \mathrm{BC}$, cannot be accounted for without further information.

Path XIV (Bou) which was built without anchoring, (see I I.24., Emmen 7, p. I 72 and I 1.25., Emmen 12, p. I 72, figs. I 4 and I 5), and which is dated at $170 \mathrm{BC}$ (see table I), has remained in its place; presumably the peat in the area of type EMMEN 9 did not have an extremely high water content at that time. This cannot, however, be ascribed only to the drainage of the raised bog lake, Emmen 19 (I I.47.4., p. 220), since, as early as about I200 BC, the hummock and hollow system of EMmen 9 formed a considerably more stable subsoil than the short, strongly pronounced hummocks and hollows of type EMmen i 7 .

The good state of preservation of the elements of these wooden trackways indicates a rapid overgrowing by peat; there can therefore be no question of their having been used for a long time. The absence of traces of wear is in complete agreement with this, but still poses a problem as to the "usefulness" of these paths.

\section{I.54. OTHER VIEWS OF THE INTERMEDIATE DEPOSITS}

With the name, "intermediate deposits", as we have already stated in II.I., p. 138 , we wanted to indicate that we regard the system of highly humified hummocks and fresh hollows and the other synchronous formations with clear differences in humification, as a transition, in both a stratigraphical and a genetic sense, from highly humified Sphagnum peat ( $\left.\mathrm{H}_{7}-9\right)$ to poorly humified Sphagnum peat $\left(\mathrm{H}_{\mathrm{I}}-3\right)$.

The transition from highly humified to fresh peat, and the processes which played a part in this, have often been the subject of study. Several researchers tried to define the stratigraphical pheno- 
menon of the peat growth mechanism by means of a name or short description. There follows below a short description of a number of the best-known ideas in peat investigation which relate to this transition. In this, we will emphasize their usefulness in explaining the phenomena found in our investigation.

\section{Grenzhorizont $(\mathrm{GH})$}

WEBER (I gOo) described the more or less clear-cut contact zone between the highly humified and the poorly humified Sphagnum peat. The stratigraphical nature of the division of the ombrogenous peat deposit which is present here, too, and its supposed synchronous forming in large parts of north-west Europe were often the subject of critical study in later years. VAN ZEIST (1955a) showed that the humification reversal in the investigation area was not simultaneous everywhere, without, however, going in to the stratigraphical characteristics of the transition. VIsscher (I93I) had already reported that WEBER's "grenz" peat layer is not usually present in the raised bog of south-eastern Drenthe, and that the transition often has an undulating course. According to this author, the fresh peat lies discordantly on the highly humified peat. It can be deduced even from this information that the use of the concept, contact surfaces, to explain the transition from highly humified to fresh peat, is a mistaken stand-point.

\section{Recurrence Surfaces (RY-s)}

As in many other north-west European bogs, there were no synchronous humification surfaces of the type described by GRANLund (1932) found here either. All the clear humification transitions in the intermediate deposit have a very localized distribution (e.g. the poorly humified hollow bases), or were caused by local changes, such as the desiccation layer of c. I200 BC in Emmen i7 (I I.26., p. I74), which is absent from EMmen i6 (I I.29., p. I 84). Moreover, the humification transitions often have no clearly layered structure. In the places where this is indeed the case, e.g. the much darker bands in Emmen 9 (fig. 42) which are also visible in Emmen 6 (fig. 39), the extent usually appears to be limited to a few dozen metres. They are undoubtedly the result of local fluctuations in the bog hydrology. Not a single indication has resulted from the investigation that peat growth reacts directly to changes in the precipitation.

Schwarztorf-Weisstorf-Kontakt (SWK)

Averdieck et al. ( I957) suggested giving to the sharp humification 
transition, i.e. the contact zone between the highly humified peat and the poorly humified peat, this purely stratigraphical designation. It is hardly ever possible to determine an SWK in the investigation area. The sharpest humification transitions are to be found in the hollow bases of type Emmen 9 (fig. 42) and of type EMMEN 22 (fig. $5 \mathrm{I}$ ). Both transitions are the result of an increasing water content in the bog area. Neither the period of the transition (a time difference of more than 500 years), nor the reason for the increasing water content (clearly a flooding in EMMEN 22) is the same in these two cases. In practice, the concept, SWK, proved to be unworkable since it was able to indicate neither a definite stage nor a definite level, while the majority of the transitions are concerned with smaller differences in humification.

\section{Humifizierungs-wechsel (HW)}

This term, which was proposed by Olausson (1957) has, in contrast to SWK, such a wide scope that it is not manageable in stratigraphical peat investigation. Humification transitions can be indicated all over the peat-faces in the intermediate deposits. Our field observations, in fact, are based, to an important extent, on the observation of changes in the humification of the bog. These changes can be manifold in nature; moreover, they say nothing about local and regional processes in the bog or about changes in the composition of the peat.

\section{Regeneration complex (RC)}

In contrast to the concepts SWK and HW, which are only intended to convey narrow stratigraphical characteristics (and prove useless for us because of this), this term, suggested by Osvald (1923) tries to define not so much the phenomena, but the processes which caused them. This means that the term implies an interpretation of the observation, too, which must still be proved. We think that we have found sufficient evidence in our investigation to prove that the hummock and hollow forming proceeds from a stable wet/dry mosaic. The upward growth of the bog surface both with hummock and hollow vegetations and with vegetations of the marginal areas, does not go via cyclic processes. The whole system of hummocks and hollows and of marginal area vegetations grew upwards, although the growth rate is variable (I I.2I., EMmen 9 , p. I64). The only clear reversal of a wet/dry pattern which was observed is in EMMEN I 7 (I I.26., p. I74), where one hummockhollow mosaic was replaced by another. This reversal, however, 
was connected with a radical alteration in the drainage pattern, viz. the development of the peripheral drainage of domed complexes. A strong desiccation of the bog surface, however, such as the desiccation in Emmen I 7, dated at c. I 200 BC (see I I.26.) brought about no change in the existing wet/dry pattern. Our observations completely contradict the hypothesis of a cyclic succession.

\section{Fresh Sphagnum Peat \\ I I.55. The FRESH AND BUT SLIGHTLY HUMfFied SPHAGNUM PEAT DEPOSITS}

The discussion of the fresh Sphagnum peat is based on data which have already been the subject of discussion above (p. I62 ff.).

The predominant formers are Sphagnum papillosum and Sphagnum imbricatum, see I I.52., p. 233. There is apparently very little differentiation into hummocks and hollows. This deposit may be regarded as an extension of communities which form fresh Sphagnum peat over communities which form highly humified peat in the intermediate deposits.

The presence of this type of peat in the investigation area was limited as a consequence of the buck-wheat burning cultivation of the I 9 th and 2oth centuries to the lower-most levels of the deposit which undoubtedly was several metres thick, before shrinking. Roughly speaking, all the peat which had formed from the beginning of the ist century $\mathrm{AD}$ has disappeared due to this intervention. Because of this, the surface of the already shrunken peat came to lie about a metre lower. A considerable part of the peat which disappeared due to fire would have consisted of undifferentiated fresh peat. Towards the end of the Middle Ages, however, the peat growth would have come to a virtual stand-still as a result of the artificial drainage of Bourtanger Moor which was started at that time to further the peat digging. This drainage had already progressed so far in the 17 th century, that it was possible to traverse the bog with dykes instead of wooden trackways (Valtherdijk, I6r8 $\mathrm{AD}$ ).

Although shortly before the beginning of the first century AD, the greater part of the bog surface would have consisted of fresh peat, no remains of this peat deposit are present in peat-faces $A, L$ and $N$. This can be ascribed, on the one hand, to the occasional absence of good habitats for this peat, e.g. the well-defined marginal 
area, near the Runde and around raised bog lakes: on the other hand, to the removal of this "bolsterveen" - the upper metre of fresh peat.

The topmost part of the fresh peat which is still present has a high root content (especially of Molinia caerulea and Calluna vulgaris). Remains of the buck-wheat burning layer are still present on several peat-faces, see Emmen 9, fig. 42. When drawing the peat-faces we have reported the topmost secondarily weathered layer as such, without further specification.

The under-side of the fresh peat deposit given in the peat-face drawings is an arbitrary level, see I 1.20., p. I62. We took c. 500 BC as the start of the forming of this deposit, see I I.6., p. 144; this is later along the margin of the bog, see I I.50., EMmen 5, p. 229.

The almost complete absence of differentiation into hummocks and hollows does not mean that a homogenous $S$. imbricatum-papillosum peat was present, see I I.52., p. 233. Moreover, darker bands are in evidence at many places in the fresh peat, and these, just as in the intermediate deposits, indicate slight desiccations of the bog surface, e.g. in EMmen 9 (I I.2 I., p. I64 and fig. 42), EMmen 23 (II. 31., p. 186 and fig. 52), and Emmen 34 (1 I.40., p. 206 and fig. 60). Thin cuspidatum layers occur rather frequently, too, e.g. in EMmEN 22 (fig. 51) and in EMmen 34 (fig. 6o). These phenomena indicate slight fluctuations in the water content of the bog. The bog surface would only locally - depending on the relief - have been respectively somewhat drier or wetter during predominantly very short periods.

Originally there were no large accumulations of water in the fresh peat. In the intermediate deposits, the wet/dry variations are much more pronounced. On the one hand, the more pronounced relief of the hummock and hollow surface would undoubtedly have encouraged these larger variations, on the other hand, the very high water absorption capacity of the imbricatum-papillosum peat would have had a strongly inhibiting effect on the development of sharp dry/wet fluctuations in the fresh peat.

The darker bands in the light-coloured fresh peat are usually concentrations of Ericaceae remains. Eriophorum vaginatum was able to establish itself in various places in these, somewhat drier, growths. It is remarkable that the Amphitrema content in the fresh peat sometimes declines clearly, e.g. I $3-\mathrm{Rh}$ (fig. 75,) spectra $32-34,34 \mathrm{~B}-\mathrm{Rh} / \mathrm{Mo}$ (fig. I04), spectra $7-9$. In $13-\mathrm{Rh}$ (fig. 75), spectrum 33 , the growth of imbricatum-papillosum peat could re-establish itself after a slight desiccation; the milieu, however, became unsuitable for Amphitrema. 
The desiccation in EMmen I 7, which can be dated at c. $300 \mathrm{BC}$, was more extensive (I I.26., p. I 74). Vegetations which form somewhat more highly humified peat, containing Calluna vulgaris, Erica tetralix and Eriophorum vaginatum were able to establish themselves here (fig. 87, 17B-inacr. spectra 74-97), and could maintain their position for a longer time. It is possible that this desiccation induced hummock forming. The most striking point, however, is that, during this process, the wet/dry mosaic which had been present here since c. $1500 \mathrm{BC}$ was altered. This means that we are here dealing with a fundamental change in the (poorly humified) peat growth.

Drainage phenomena in the form of streams, gullies with erosion, etc. are absent from the fresh peat which is still present. The greater part of the precipitation, therefore, would probably have been rather quickly bound up in the peat which was forming - at least till the beginning of the first century $\mathrm{AD}$ - due to which no large collections of water could develop on the bog surface. Moreover, a very large part of the water surplus had disappeared by c. $500 \mathrm{BC}$, see I 1.47.5., p. 22I. The drainage courses of the intermediate deposits, however, perhaps played a part in the drainage of the fresh peat, so that our observations could lead to an incorrect conclusion on this point.

I 1.56. STRATIGRAPHY AND DEVELOPMENT OF THE OMBROGENOUS PEAT

In the Middle Atlantic Pinus forest (c. $4500-4000$ BC, see 10.10., p. 132), suitable habitats for peat-forming Sphagna developed on a large scale, both in the wet Scheuchzeria vegetations in the lowerlying parts of the soil of the forest, and in the somewhat higher, drier parts. The highly humified Sphagnum peat which was forming $\left(\mathrm{H}_{7}-8\right.$, occasionally $\mathrm{H}_{9}$ ) in which Sphagnum rubellum is the main peat-former, overgrew the Pinus forest, thus preserving the lower parts of the trees. Sphagnum cuspidatum could also develop in the wettest places, such as in EMmen I I (I I.3., p. I 4 I, see fig. 75, I I-Rh) The wet/dry pattern of the Middle Atlantic Pinus forest could initially maintain itself. It is possible that Sphagnum molluscum was regularly present; it is not clear which places it occupied on the bog surface. In addition to these Sphagna, Calluna vulgaris, Erica tetralix, Oxycoccus palustris, Andromeda polifolia, Vaccinium spp., Melampyrum spec., Rumex acetosella, Eriophorum vaginatum and Rhynchospora 
alba established themselves here. Polytrichum spec., Aulocomnium palustre and Leucobryum glaucum developed at some places. Drepanocladus spec. would have sought the very moist places.

On the western side of the Sphagnum peat area in the Hunze valley, see fig. 13, a belt of the Pinus forest remained as a transition zone to the Hondsrug. The seepage peat formation continued on the eastern side, see 9.17., p. II 3 and fig. 8. Scheuchzeria communities, at some places extensive, developed in the contact area between the two systems, due to which a layered zone originated in the middle of the bog area, the Scheuchzeria peat contact zone of face J, between pits $33^{1}-336$, see 9.15., p. 104. The highly humified Sphagnum peat forming can be regarded as a continuation of the non-ferruginous fen and fen-wood peat growth, which gradually filled up the Hunze valley, which acted as a drainage gulley for the southern part of the Hunze depression. As long as the east-west orientated cover-sand ridge in the Hunze depression was not yet overgrown, see fig. 3, considerable movements of water would have flowed via its spillway in a northerly direction, even during the ombrogenous peat forming; see the drainage pattern in fig. 6 . This can explain the very moist nature of the highly humified peat in EMmEN 33 (fig. 2), which originated from the area of the spillway, see also I I.5., p. I43. This bog water was undoubtedly very acidic, since the ombrogenous peat growth had developed in the meantime in the southern part of the Hunze depression, see I0.I I., p. I33.

As a result of the somewhat superficial water transport over a relatively long distance, this bog water was well-aerated; due to this, a fairly thorough oxidation of the remains of the plants which had died could take place in the strongly acidic milieu. This fairly thorough oxidation can explain both the rather small peat accumulation $(3.5 \mathrm{~cm} / 100$ years, see also I I.7., p. 145) and the brownblack colour of the desiccated peat visible on the peat-faces (in contrast to the blue-black peat, see i i.8., p. 147).

Probably the peat accumulation procecded originally at an even considerably slower rate; in face $\mathrm{C}$, between the Middle Atlantic stump layer and the "moist phase" which can be dated at c. 2500 BC (II.I 2, p. I 53), a deposit of peat is present which has an average thickness of less than $30 \mathrm{~cm}$. It does not look as if this is an exception. Desiccations several times caused stagnation of the peat growth, due to which Pinus could sometimes re-establish itself on the bog surface. This happened shortly after the overgrowing of the Middle Atlantic Pinus forest, and also long after c. 4000 BC. See the several woodrich levels in the Middle Atlantic stump layer of e.g. face B, pits 
43-50 and face J, pits 296-299 respectively, and along the Scheuchzeria peat contact zone, pits $33^{\mathrm{I}-3} 33^{6}$.

C. $3100 \mathrm{BC}$, the area of the ombrogenous peat growth extended greatly because of the establishment of peat-forming Sphagna taking place on a large scale on the desiccated seepage peat surface, see 9.I4., p. I03. The east-west orientated cover-sand ridge (fig. 3) prevented the acidic bog water flowing out of the southern part of the Hunze depression, due to which the highly humified Sphagnum peat forming took place here in a more strongly reducing milieu (blue-black colour and faster peat accumulation: $7 \mathrm{~cm} /$ Ioo years), see fig. I3, see also I I.8., p. I 47 .

Because of the desiccation of the seepage peat, Pinus also had a chance to establish itself in the bog again. This Pinus forest, consisting of scattered groups of trees (Late Atlantic Pinus forest, see I0.12., p. 135 and fig. 10), was overgrown in a relatively short time by the Sphagnum peat; after c. I 50 years, all the pine trees had disappeared (stump group Munaut A, fig. 105 and 10.5.2., p. 124). This indicates a higher moisture content in the blue-black peatforming milieu than that in the brown-black Sphagnum peat, which overgrew the Middle Atlantic Pinus forest. This higher degree of moisture is also apparent from the occurrence of Scheuchzeria palustris in many places in the lower section of the blue-black Sphagnum peat. This plant did not generally form a real layer of Scheuchzeria peat here, see also i I.39., p. 203.

C. 3000 BC, Empetrum nigrum, which was, however, already present in the bog, increased tremendously. This is possibly the result of an increasing moisture level, both in the brown-black and the blue-black peat. That the moisture level was indeed a factor in this increase can be deduced from the present occurrence of Empetrum in the bog, where the plant is clearly connected with a pronounced wet-dry gradient, see I I.9., p. I 49 .

On the eastern side of the blue-black complex, a MenyanthesBetula peat developed c. $3100 \mathrm{BC}$, in place of a Sphagnum peat, see faces $\mathrm{O}$ and $\mathrm{P}$, see fig. I 3 and I I. 18., p. I 58 . This indicates the presence of water with a somewhat higher mineral content here, which was possibly just not acidic enough for Sphagnum peat growth. The large difference in iron content between this peat and the seepage peat underneath indicates a clear change in the origin of the bog water after the desiccation of the seepage peat c. 3 I 00 BC. The east-west orientated cover-sand ridge (fig. 3), the only mineral elevation in the whole neighbourhood not yet overgrown, cannot be considered as a supplier of water, since, in a shrunken condition, 
the Menyanthes-Betula peat of faces $\mathrm{O}$ and $\mathrm{P}$ were higher than the cover-sand ridge, while this Menyanthes-Betula peat was not present in peat-faces $M$ and $N$, situated between faces $O$ and $P$ on the one hand, and the cover-sand ridge on the other. The relief of the seepage peat surface, see also the schematic cross-section, fig. 34, rules out the existence of a river which could supply the necessary water, since the Menyanthes-Betula peat forms almost the highest part of the desiccated seepage peat surface. Equally unlikely, however, is a northerly origin for the higher mineral content water. In this connection, the difference in height of the base of the Menyanthes-Betula peat can be quoted; in the southerly face $\mathrm{P}$, this lies about $0.5 \mathrm{~m}$ higher than in face $\mathrm{O}$, situated $200 \mathrm{~m}$ to the north. Flow from the Hondsrug, the mineral boundary of the bog, must be considered to be out of the question. Therefore, we must look for the origin of the higher mineral content water in the immediate neighbourhood of the Menyanthes-Betula peat, i.e. in the surrounding highly humified Sphagnum peat deposits. We believe that we may assume that this Menyanthes-Betula peat originated at the line of contact of the two ombrogenous peat complexes; the blue-black complex on the western side and an uninvestigated complex on the eastern side, a fragment of which was found in face Q. The position of this Menyanthes-Betula deposit, at about the highest level of the seepage peat surface, can, in our opinion, be regarded as a pointer in this direction.

Alongside Menyanthes and Betula, Polytrichum could also form rather extensive vegetations, in which Dryopteris and Rumex occur (I I.1 7., p. 157). The transition zone between this carr peat and the highly humified Sphagnum peat complex situated to the east of it (face $\mathrm{O}$, pits $444-446$ and face $\mathrm{P}$, pits $47 \mathrm{I}-473$ ) is only about $30 \mathrm{~m}$ wide. This might indicate both the absence of large movements of water and a comparatively regular supply of the higher mineral content water. If larger variations in the water supply had existed, a considerably wider transition zone would undoubtedly have developed. A number of desiccations did occur in this system, however. One of those was dated at $235^{\circ} \mathrm{BC}$, see II.I 7 . It is possible that this is connected with the desiccation of c. $2500 \mathrm{BC}$, recognisable on faces $\mathrm{H}$ and I as the Sphagnum peat dopplerite layer, see I I. I4.

The drying-out levels in the Menyanthes-Betula peat, characterised particularly by the occurrence of many white pieces of Betula bark, scarcely differ from the leaf remains of Menyanthes trifoliata which dry out white, and this gives the whole peat deposit a striking lightbrown colour. 
C. $2500 \mathrm{BC}$, the large spread of Empetrum nigrum came to an end within a relatively short time, see also I I.9., p. I49. The overgrowing of the Scheuchzeria peat contact zone in face J (9.15., p. 104) and the forming of the moist phase in face G (11.12., p. 153) took place at about the same time. A desiccation was very probably the cause of these phenomena. It is possible that the drainage of the highly humified Sphagnum peat, c. $2500 \mathrm{BC}$, observed in faces $\mathrm{H}$ and $\mathrm{I}$, affected the peat growth over a large surface area.

Sphagnum rubellum is the main peat former in the blue-black peat, too. This peat was probably somewhat less susceptible to desiccations than the brown-black peat, where Pinus sylvestris, sometimes accompanied by Scheuchzeria palustris, was able to establish itself a few times (I0.13.I., p. I36). In I I.39., p. 203, we explained how the occurrence of Scheuchzeria could be related to desiccations of the bog surface. The more laminated stratigraphy of the brown-black peat deposit can probably be ascribed to its more clearly observable reaction to (often slight) desiccations. At a few places in the brownblack peat, there was a large expansion of Calluna vulgaris (I I.ro., p. ${ }_{5} \mathrm{I}$ ), e.g. in face $B$, pits $49-5^{I}$ and face $E$, pits $I_{50}-16 I$. The latter case very probably concerns the drier margin of the "liver peat" of face $E$, which formed under moist to very moist conditions (I1.13., p. 154), and which perhaps developed simultaneously with the spread of Empetrum nigrum, see fig. 86, I 7 B-Rh and fig. 87, I 7 BPo/bog plants, spectra 3-II.

Eriophorum vaginatum occurs frequently at several places in the blue-black peat, e.g. in face $\mathrm{H}$, above pits $224-232$, and face $\mathrm{K}$, above pits $373-383$. The position of this Eriophorum-rich peat, viz. above a rather pronounced relief of the subsoil, leads to the assumption that there is a relationship between this relief and the occurrence of Eriophorum. For that matter, all the blue-black peat became somewhat richer in Eriophorum vaginatum after c. 2500 BC, see e.g. face $\mathrm{M}$, which indicates changes in the peat forming milieu. Possibly larger fluctuations in the moisture level occurred, see I I.I I., p. 152. Eriophorum vaginatum found good habitats along the eastern margin of the Menyanthes-Betula peat, see face $\mathrm{O}$, above pits 444446 and face $P$, above pits $472-474$. This occurrence can be dated from c. 2500 to $2000 \mathrm{BC}$. It is possible that similar vegetations were also present on the western edge of this deposit. The overgrowing of the Menyanthes-Betula peat by highly humified Sphagnum peat, dated to shortly after 2000 BC, see II.1 7., p. I57, took place, as appears from the stratigraphical observations, in a relatively short time. This indicates significant changes in the bog hydrology. Pro- 
bably the bog water became somewhat more acidic, and because of this Sphagna could establish itself on a large scale in this Menyanthes-Betula peat. The cause of this development was perhaps the same change in milieu that caused the development of the intermediate deposits, see I I.34.4., p. I93, among others. This will be discussed later on in this section.

In the brown-black highly humified Sphagnum peat hummocks and hollows developed, at least at some places, see iा.i6., p. ${ }_{5} 6$ and fig. 59, Emmen 33. It seems likely, in our opinion, that their occurrence did not remain limited to the area of the spillway in the east-west orientated cover-sand ridge (fig. 3), but that they were present at many places in the brown-black peat. From the distribution of Eriophorum vaginatum in the blue-black peat, e.g. face $M$, we can conclude that possibly hummocks and hollows do not generally occur in this peat, see also I1.16. Great changes occurred c. 2000 BC in the brown-black bog surface; the highly humified Sphagnum rubellum hollows became so moist that the rubellum growth stagnated. Water could then collect in the hollows. The drier hummock growth continued, as a result of which a clear wet/dry pattern with a slight relief developed on the bog surface (hollows and hummocks, type Emmen 9, see i 1.35., p. I97 and type Emmen 17, see 11.36., p. 199). Even before the phase with open water in the hollows (pools), Sphagnum papillosum and $S$. imbricatum immigrated into the investigation area, see $11.39 .$, p. 203. It is likely that they established themselves on a large scale on the bog surface which was becoming moister, without originally being able to oust the rubellum growth. Their establishment and the development of pools in the bog (in the hollows) indicate increasing precipitation and/or increasing humidity, see 1 r.34.4., p. 193 and I I.52., p. 233.

On the greater part of the bog surface, hummocks and hollows of type EMMEN 9 (fig. 42, and fig. 6r) developed from the wet/dry pattern. In the wet hollows, the extent of which increased as the humidity increased, fresh Sphagnum cuspidatum peat could develop on a large scale.

Hummocks and hollows of the lowermost system of EMmen i 7 developed between two complexes with hummocks and hollows of type Eмmen 9 (i I.36., p. 199, figs. 45, 6r and fig. I6). In this contact zone, the wet/dry pattern contains somewhat larger units and presumably also has a somewhat less pronounced wet-dry division. The hummocks of type EMMEN i 7 consist of moderately humified rubellum peat, without Calluna; the hummocks of EMmen 9 contain highly humified Calluna-rich rubellum peat. 
Between c. 2000 and I 500 BC, the hummocks of both types grew higher, while the hollows filled up with fresh cuspidatum peat. In a I- $1.5 \mathrm{~km}$ wide zone in the western part of the bog surface, some mineralizing of the water of the hollows occurred; Scheuchzeria palustris could establish itself here, see 1 1.39., p. 203. Hummocks of type EMMEN 9 grew upwards rather more quickly, due to which the bog surface became differentiated into a number of domed complexes, see I I.48.5., p. 227. The contact zone running east-west (with type EMMEN I 7) between two of these complexes ended up lying relatively somewhat lower.

These changes did not materialize in large parts of the blue-black highly humified Sphagnum peat; probably the more reducing milieu in this peat had an inhibiting effect on the development of a wet/dry pattern and on the forming of fresh cuspidatum peat. Yet the increasing moisture level, which became discernible c. $2000 \mathrm{BC}$ in the brown-black area (hollows of type EMmen 9 and EMmen I 7), had an effect on the blue-black milieu. The overgrowth of the MenyanthesBetula peat, dated at $1920 \mathrm{BC}$, is an example of this. A few moderately humified cuspidatum layers are present at the top of the highly humified Sphagnum peat of face H, see e.g. Emmen 22 (fig. 51), indicating a relatively higher moisture level. In our opinion, the occurrence of Sphagnum imbricatum in 22-Rh/Mo, spectrum 2, (fig. 92) can also be explained in this way (I I.52., p. 233). In the meantime, the east-west orientated cover-sand ridge in the Hunze depression was also overgrown by Sphagnum peat (fig. 3); this overgrowth can be dated between 2500 and 2000 BC (II.38., p. 202). The extension of the Sphagnum peat area led to great changes in the bog hydrology, see also I I.48.3., p. 225 and fig. 6 (the drainage pattern in the Hunze depression, as this existed, with a few breaks, from the Late-glacial to c. $2000 \mathrm{BC}$ ).

C. $1500 \mathrm{BC}$, doming originated in the areas with hummocks and hollows of type Emmen 9, of such a nature that a peripheral drainage of the domed complexes developed, due to which water flowed via the area of EMmEN I 7 to the lower-lying blue-black bog surface of faces F, G, H and I, among others, see also fig. I6. The water surplus in the hollows of type EMmen 9 disappeared; the cuspidatum peat growth came to a stand-still and Sphagnum papillosum could spread out in the hollows. S. imbricatum, which formed moderately humified peat especially, developed on the hummocks of type EMmEN $9-$ probably on the slopes of the hummocks particularly.

The forming of large, flat-topped, moderately humified hummocks and large hollows of the lowermost system was broken off 
in the area of EMMEN I 7 (fig. 16); at that time, a fairly pronounced pattern emerged with predominantly highly humified, small hummocks and narrow hollows, in which S. cuspidatum spread greatly (1 .36., p. 199). Calluna vulgaris and Eriophorum vaginatum were important constituents in the hummocks. The flooding of the area of faces $\mathrm{F}, \mathrm{G}, \mathrm{H}$ and $\mathrm{I}$ resulted in the development of the extended raised bog lake, EMmen I9 (11.47.2., p. 218), which formed, together with the hummocks and hollows of type EMmen i 7 , a clearcut contact zone, between a few domed complexes containing hummocks and hollows of type EMmen 9, see fig. I6. Sphagnum cuspidatum and Scheuchzeria palustris developed extensively in the acidic and probably somewhat eutrophicated water of the raised bog lake, and due to this, a deposit of fresh peat developed. The presence or the raised bog lake indicates stagnation of the drainage in the contact zone between a number (3) of domed complexes, see also I I. $4^{8}$. 2., p. 224. In a comparatively short time, i.e. within a few centuries, the dimensions of the lake were considerable, although the maximum extent was reached only c. 500 BC. Because of a constant supply of water to the raised bog lake, whose long axis was probably situated somewhat to the north of section EMmEN ig (see fig. I6), a continually increasing part of the bog surface came to lie under water. A "diffuse bank" originated because of this (II.47.3., p. 220): probably a wide marginal area with large hollows which were inundated regularly, for shorter or longer periods. There is such a great distance between the more humified hummocks which are present here, e.g. Emmen 22 (fig. 51) and Emmen 23 (fig. 52), see also fig. $6 \mathrm{r}$, that there is probably no question of the existence of a wet/dry pattern, such as is the cause of types EMMEN 9 and EMMEN I 7 , in the hummocks and hollows of type EMmen 22/23 (I I.37., p. 20 I and figs. $6 \mathrm{I}$ and $\mathrm{r} 6$ ).

The raised bog lake reached the area of sections EMMEN 22 and EMMen 23 (fig. I6) about I $200 \mathrm{BC}$.

From the increasing size of the raised bog lake it can be concluded that the lake was predominantly without drainage. A few times, however, lowering of the water level took place, due to which formers of somewhat less moist peat could establish themselves temporarily in the lake (II.30., p. I85).

In the western margin of the bog (near the Hondsrug), the increase of the moisture content of the peat since c. $2000 \mathrm{BC}$ is certainly discernible; however, no hummocks and hollows developed, but layered deposits of somewhat drier and somewhat moister peat respectively were formed, see II.5I., p. 23 I and fig. 38 . 
Great changes took place on the blue-black bog surface, outside the area of the raised bog lake and the hummocks and hollows of type Emmen 22/23 (fig. 16), too. Analogous with the situation of c. $2000 \mathrm{BC}$ on the brown-black peat, a clear wet/dry pattern originated c. $1500 \mathrm{BC}$ on the eastern part of the blue-black complex from which the hollows and hummocks of type EMmen 32 (fig. $5^{8}$ and fig. I6) developed, see I I.33., p. I88, see also fig. 6I. A flow of water occurred regularly in the hollows (I I.38., p. 202) due to which a few erosion phenomena developed (i I.48.3., p. 225). The occurrence of such hollows, and the area to which this type extended, indicate that forming of type EMMEN 32 took place in a contact zone between domed complexes, see fig. I6. From the occurrence of this type on either side of the east-west orientated cover-sand ridge in the Hunze depression (fig. 3) - which was in the meantime overgrown by ombrogenous peat - it can be concluded that, from $1500 \mathrm{BC}$, the drainage of the southern part of the Hunze depression also proceeded over this cover-sand ridge. This does not mean that around I500 $\mathrm{BC}$ one could already speak of a real drainage river; see below in this section.

The raised bog stream, the Runde, flows over a low, indistinct, south-north cover-sand ridge, see II.19., p. I6o. Above this low sand ridge in the investigation area two highly humified Sphagnum peat complexes are in contact with each other; the blue-black complex and the complex lying to the east of this, which we did not investigate and of which face $Q$ is a fragment. We think that the Runde originated from the drainage of these raised bog complexes. They were in contact just above the low sand-ridge, causing this particular milieu here, in which the Menyanthes-Betula peat (I I.I8., p. I 58; also discussed already in this section, p. 243), was formed. The development of the Runde (I I.49., p. 227) is closely connected with the development of the domed complexes of the intermediate deposits (1 I.48.4., p. 226); its curving course, see fig. I7, can be explained by assuming that the south-north contact zones of the domed complexes formed the bed of the drainage river, see I I.49., p. 227. This would mean that the positioning of the domed complexes, with their diameter of 3 to $4 \mathrm{~km}$, did not take place independently of the mineral subsoil. We think it unlikely that the Runde, as a real drainage river, is just as old as the contact zones of the domed complexes (i.e. from c. I500 BC); presumably the river developed very gradually here, in conjunction with the increase of the water supplies in the bog. We think it rather certain, however, that, since the extensive erosion of the bog surface c. 50o BC, see 
I I.49., p. 227 , the river roughly followed the course (from the "Zwarte Meer") indicated in fig. I 7 .

Although the large supply of water in the bog would strongly delay the desiccations becoming discernible, there are indications that the bog surface was rather susceptible to desiccation $c$. 1000 to $600 \mathrm{BC}$, II.5I. During the period of hummock and hollow formation, prehistoric man made a number of attempts to use the bog surface by building wooden trackways ( $170 \mathrm{BC}$ and $530 \mathrm{BC}$ ) see I I.53., p. 235, and possibly also by trying to make the peat in the marginal area suitable for cultivation (c. 800 BC), see I I.5I., p. 23I, see face $B$, pits $33-43$. These unsuccessful attempts had scarcely any effect on the peat growth.

In all the hummock/hollow types developing, the original, large difference in humification between hummocks and hollows gradually decreases, since the proportion of $S$. imbricatum, which forms mainly less humified peat, increases during the peat growth. The clear wet/dry pattern which was once present became gradually less pronounced in the course of the forming of the intermediate peat, undoubtedly due to the effect of the increasing water content of the bog.

C. $500 \mathrm{BC}$, the bog could no longer contain the water which had collected on the surface; in large parts of the raised bog of south-east Drenthe many lakes emptied (I I.49., p. 227), leaving an enormous trail of erosion, see I I.4O., p. 206. In the investigation area, the water of the raised bog lake, EMMEN I 9, flowed in an easterly direction and emptied into the Runde, see fig. 16 , due to which the underlying highly humified Sphagnum peat was deeply eroded (bog burst). In many places, the peat under the felt-like cuspidatum deposits was washed away, with the result that the layers, thus undermined, were swept into the gulleys, see fig. 48, EMmEN I9, see fig. 6o, EMmEN 34. This thorough drainage was not accompanied by a desiccation of the bog surface; only the surplus of water, in fact, was drained off. The milieu did change, because of the development of, among other things, an accelerated drainage of the domed complexes to the no longer stagnant contact zone, EMmEN 17 and EMmen I9 (fig. I6). This caused scarcely any change in the drainage pattern. Along with the water, many minerals dissolved in it were drained off, due to which, the bog surface, seen as a whole, became clearly more oligotrophic. This greatly favoured the expansion of Sphagnum papillosum and $S$. imbricatum which form a fresh peat, in which scarcely any differentiation into hummocks and hollows takes place. Hardly any collections of water in the form of raised bog 
lakes occur after that on the bog, at least up to the beginning of the Ist century AD.

The surface became somewhat firmer as a result, without, however, its load-carrying capacity being much increased. A hurdle trackway dated at $170 \mathrm{BC}$, see fig. I 5 , laid on peat, in which hummocks can scarcely be distinguished, stayed in place, even without being anchored; see I r.53, p. 235 .

A situation developed c. $300 \mathrm{BC}$ in the undifferentiated fresh peat surface, which enabled more humified peat to form again - at least at places, see i r.26., p. 174. This indicates a clear change in the wet/dry pattern (see also fig. 45, EMMEN I7), which leads to the suggestion that the peat-forming milieu had changed radically, see II.55., p. 239. Such a change is not present in Emmen 9 (II.2 I., p. I64 and fig. 42); it was possibly restricted to the contact zone between the domed complexes. The development of the fresh peat cannot be followed further after the beginning of the ist century $\mathrm{AD}$, as a result of the disappearance of a peat deposit, about $\mathrm{I} \mathrm{m}$ thick, due to the buck-wheat burning in the $19^{t h}$ and 20 th centuries.

\section{CHAPTER 12.: REGAPITULATION}

I 2. I. General

In Chapter I. (pp. I-I4), the history of peat investigation was first outlined roughly; for this, we used a classification by OvERBECK ( 1963 ) into four periods. The most recent period (from $19 \mathrm{I} 6$ ) was discussed somewhat more deeply. Attention was paid to the diversity of views concerning the relative importance of the different factors which affect the peat growth (climate, mineral ground water level, vegetation processes).

The principal motive for this peat study was, on the one hand, the availibility of potentially good sources of information in the form of fine peat-faces which were on the point of disappearing c. I 960 , and on the other hand, the lack of any study, based on modern methods of investigation, of the peat area east of EMmEN, to the west of the Dutch-German border (part of the Bourtanger Moor). A few of these methods of investigation were also discussed in this chapter. The pollen-analytical investigation was directed especially towards the dating of phenomena in the peat, the drawing-up of correlations and the obtaining of an understanding into the composition of types of peat. The use of rhizopod analysis enabled 
us to determine more precisely the characteristics of the ombrogenous peat-forming milieu - especially the degree of moisture. Mention was also made in the first chapter of the investigation of types of peat - of importance in describing the growth mechanisms - as an addition to pollen analysis and rhizopod analysis.

In Chapter 2. (pp. 14-29), the geographical position of the peat area - situated in the ice-marginal valley of the Hunze, see fig. I - was outlined; this chapter contains some geological and meteorological information and a brief survey of archaeological finds in the investigation area and its surroundings. In the description of the peat area, the destruction of the bog as a result of the continually further-reaching human intervention in the course of the past five centuries, was outlined. This destruction led to the landscape we found with desiccated blocks of peat. A detailed description was given of the way in which the investigation methods were applied (field investigation with surveying, drawing, sampling, excavation, borings; and laboratory investigation: pollen analysis, rhizopod analysis, moss determination, determination of macroscopic remains, dendrochronology and ${ }^{14} \mathrm{C}$-determinations).

\subsection{The INVESTIGATION}

In Chapter 3. (pp. 29-44), a description was given of the 17 peat-faces which were drawn in and of the sections taken from peatfaces which were not drawn in $\left({ }^{14} \mathrm{C}\right.$-diagram, EmMererfscheidenveEn I, EMmen 32, Emmen 33 and EMmen 34). The types of peat which were differentiated in the drawings of the peat-faces were described here.

In Chapter 4. (pp. 44-52), on the basis of a few pollen diagrams, a survey of the vegetational history of the investigation area since the end of the last Ice Age was given. In Chapter 5. (pp. 52-55), we reported on which sort of subsoil (sand and fluvial loam) the peat deposits are situated. In Chapter 6. (pp. 55-65), we discussed the deposits which were formed in the Late-glacial and which lie in the Hunze valley (Braunmoostorf, brown gyttja, loess and a layer of birch twigs). In Chapter 7. (pp. 65-69), two gyttjas (orange gyttja and grey gyttja) were under discussion, which were formed during the Boreal, to the east of the Late-glacial deposits. Chapter 8. (pp. 70-8o) deals with the non-ferruginous fen and fen-wood peat present in the Hunze valley, which was formed from the Preboreal to half-way in the Atlantic. In Chapter 9. (pp. 8I- 
I4), we discussed the ferruginous seepage peat, situated to the east of the non-ferruginous fen and fen-wood peat, which was formed during the Atlantic. The Pinus stump layers were dealt with in Chapter 1o. (pp. I 14-1 38). Three important Pinus establishments were observed, viz. one at the beginning of the Atlantic, one in the middle of the Atlantic (both establishments in the non-ferruginous fen and fen-wood peat) and one at the end of the Atlantic (in the seepage peat area). Information was also given in this chapter about the dendrochronological investigation by MUNAUT (MUNAUT and Casparie, I97I) of the stumps of these establishments. The ombrogenous peat is the subject of Chapter I I. (pp. I38-25I). In this peat, a differentiation was made between a highly humified Sphagnum peat deposit, an intermediate deposit and a deposit of fresh Sphagnum peat. A Menyanthes-Betula peat deposit found between two highly humified Sphagnum peat complexes, and the raised bog rivulet, the Runde, were also discussed in this chapter.

In most of the chapters, usually in the last section, the genesis of the peat deposit was dealt with in detail.

In the following section, a synopsis of the genesis of all the investigated peat deposits will be given. The diagrammatic cross-section of the peat given in fig. 34 will be explained. In fig. 36 , two curves are given, by means of which an attempt is made to indicate the moisture level (water content) of the peat during its entire development. The left-hand curve refers to the area where the base of the peat dates from the Late-glacial; the right-hand curve to the area where Boreal gyttja lies on the base of the seepage peat. The description of the different terms, "dry", "rather dry", etc. is given in the context of the peat investigation, see the lower part of fig. 36 . It will be obvious that the curves were not composed from direct observation and therefore may not be regarded as an exact reflection of the water content present during the peat growth.

As a clarification of this synopsis, the peat growth since the Lateglacial has been illustrated in two diagrams in fig. 35 . In the lefthand diagram, the height was made the vertical axis, in which only average thicknesses were indicated for the deposits. The righthand diagram has time as the vertical axis (same scale as in fig. 36). The adjusted time scale was plotted against the height (lefthand diagram), and the appropriate heights were plotted against the time axis (right-hand diagram). Comparison of the two diagrams gives, among other things, information about the rate of growth of the various peat deposits. The two curves 
of fig. $3^{6} \mathrm{can}$, as it were, be projected on the right-hand diagram of fig. 35 , the left-hand curve near the I $\mathrm{km}$ point of the horizontal scale, the right-hand curve at about $2.3 \mathrm{~km}$.

In the following synopsis, numbers appear in brackets after the names of the types of peat. These numbers refer to the symbols for these peat types which were indicated in fig. I9. These symbols were described in 3.1.2., p. 30 .

\section{I2.3. Synthesis of THE genesis of THE BOG COMPLEXES EAST OF EMMEN}

Shortly before the beginning of the Allerød, Hypnaceae (including Scorpidium scorpioides and Calliergon sarmentosum), together with several Cyperaceae, established themselves on a large scale in the Hunze valley (the almost $2 \mathrm{~km}$ wide western part of the Hunze depression) which was becoming more moist (fig. $3^{6}$ ). From this, a deposit of Braunmoostorf developed (IIa). A brown gyttja was deposited on the wettest places (IIb). For the distribution of the deposits, see fig. 5. In the course of the Allerød, a considerable part of the Hypnaceae deposit was blown over by loam which came from the Hondsrug (western edge of the Hunze depression). The Hypnaceae communities were smothered by this loess sedimentation which ended shortly after the beginning of the Late Dryas. Towards the end of this period, this loess deposit (IIc), (for its distribution, see fig. 5), had a vegetation with probably predominantly small birches, which caused the development of a thin layer of twigs (IId). In the Preboreal, possibly even at the beginning of this period, a non-ferruginous fen peat (IVa) formed in depressions in the Lateglacial deposits, and its extent gradually increased till the end of the Boreal (fig. 7). Pinus was possibly able to establish itself several times after desiccations in this rather moist sedge peat (fig. 36 ) containing Betula and Menyanthes, among others.

On the southern and eastern flanks of the fen peat deposit which was forming, drainage water stagnated in the Hunze valley to an increasing extent, due to which some gulleys were inundated here during the Boreal, as also happened later to the intervening Iow sand plateaux (fig. 36). An orange gyttja (IIIa) developed originally, then a sandy grey gyttja (IIIb); for their distribution, see fig. 7. C. $5300 \mathrm{BC}$, both the non-ferruginous fen peat and the gyttja dried out, since the supply of water from the southern part of the Hunze depression, via the spillway in the east-west orientated cover-sand ridge in the Hunze depression near Nieuw Dordrecht (fig. 5), 
stagnated. Pinus (IVf) established itself on the desiccated non-ferruginous fen peat surface, and it was able to continue growing till c. $5000 \mathrm{BC}$.

To the east of the non-ferruginous fen peat area in which Pinus occurred, ferruginous seepage (fig. 36 ) developed at the beginning of the Atlantic from at least three centres, as a result of which a ferruginous Hypnaceae peat growth $(\mathrm{Va})$ developed over a considerable part of the Hunze depression to the east of Emmen (fig. 8). Shortly before $5000 \mathrm{BC}$, the supply of water to the Hunze valley via the spillway developed again. Alnus established itself on a massive scale in the Pinus forest which was rapidly becoming more moist. A fast-growing fen-wood peat (IVb), containing mainly Alnus at first, but later, more Betula, developed. The very high degree of moisture (see the left-hand curve between 5000 and $4500 \mathrm{BC}$ in fig. 36 ) is evidenced by, among other things, the frequent occurrence of Menyanthes, Nymphaea and possibly several Sparganium species in this peat. Scheuchzeria palustris could establish itself here and there. The non-ferruginous fen peat area changed as a result of the development of seepage; the eastern border shifted westwards (fig. 7). The supply of seepage water made especially seepage peat formation possible near the seepage centres and in a number of south-north orientated drainage flows. Above the sand-ridges situated between the drainage flows and shallow gulleys, the seepage peat is rather less ferruginous and contains rather more Alnus remains. These are possibly the last, overgrown remains of the Alnus forest, which covered this part of the Hunze depression at the beginning of the seepage. The supply of non-ferruginous drainage water in the Hunze valley decreased around $45^{\circ 0} \mathrm{BC}$ (fig. 36); the forming of non-ferruginous fen-wood peat came to a stand-still. The fen-wood peat deposit shrank a bit, due to which the subsoil relief was reflected in the peat surface. Pinus could establish itself on the higher places (VIa); on the lower-lying parts, Scheuchzeria (VIc), was present as well. At about the same time, the siderite formation (Vc) developed in the seepage peat area. Siderite developed mostly near the seepage centres and in south-north drainage flows in isodiametrical lenses, up to ro $m$ diameter, in a reducing milieu. The latter indicates anaerobic processes during the development. The supply of seepage water was so great, that a flooding occurred c. $4500 \mathrm{BC}$, probably from the most westerly seepage centre, into the non-ferruginous fen-wood peat area. Due to this, a stream with ferruginous water formed in the Pinus forest (fig. II) which covered the non-ferruginous fen peat, and this stream remained in existence for several centuries. 
Highly humified peat-forming Sphagna established themselves on a large scale in the Pinus forest (VIIc), probably Sphagnum rubellum in particular, and due to this the forest was gradually smothered. C. $4000 \mathrm{BC}$, all that remained of the originally uninterrupted forest was some pine trees at a few places. At some places in the contact area between the non-ferruginous peat and the seepage peat, a large expansion of Scheuchzeria took place (VIb), see fig. 8.

The seepage stopped c. $3^{\text {Ioo }} \mathbf{B C}$; the seepage peat dried out thoroughly (fig. 36 ) and numerous drying cracks appeared in the peat which possessed little elasticity. This desiccated peat was superficially affected by erosion at only one place. Pinus could establish itself in those places where the iron content was somewhat lower, i.e. above sand-ridges in the subsoil. The rest of the desiccated surface, which became very moist again within a short time, provided good habitats for peat-forming Sphagna, especially Sphagnum rubellum, and for Scheuchzeria, although the latter could not maintain its growth. Within I50 years, the highly humified Sphagnum peat (VIIc) overgrew the Pinus forest (fig. I I) which consisted of small, scattered groups of trees. Later, dopplerite precipitated on the transition from the seepage peat to the highly humified Sphagnum peat, due to which the seepage peat dopplerite layer $(\mathrm{Vd})$ is present at this level. This highly humified Sphagnum peat formed in a more reducing milieu (blue-black complex) than the highly humified Sphagnum peat, which developed from shortly after $4500 \mathrm{BC}$ in the Pinus forest on the non-ferruginous fen peat (brown-black complex). Empetrum nigrum developed extensively in both complexes (seefig. 13) from c. $3000 \mathrm{BC}$ to c. $2500 \mathrm{BC}$. Calluna-rich peat formed at places in the brown-black complex (VIIf); Pinus (VIa) was able to establish itself again a few times sometimes together with Scheuchzeria, (VIc).

Since the Boreal, a belt of Pinus forest was present in the western marginal area, where desiccations occurred more frequently than further inwards in the bog. In the course of the Atlantic, Pinus could establish itself a few times a little further removed from the edge of the bog, and it could maintain this position, together with Scheuchzeria, till well into the Subboreal.

A somewhat eutrophicated milieu developed at the highest level of the desiccated seepage peat surface in the contact area of the blue-black complex and the highly humified Sphagnum peat complex situated to the east of it, as a result of drainage towards the edges of this two bog complexes. The bog water which collected here was not acidic enough for Sphagnum growth. The Menyanthes-Betula peat 
(VIIa), see fig. I3, developed here, indicating a high degree of moisture.

At 2500 BC, part of the blue-black Sphagnum peat was drained via the drying cracks in the seepage peat. Pinus could establish itself close to the desiccation area and then Empetrum nigrum declined sharply. It is possible that, as a result of the somewhat changed milieu, Eriophorum vaginatum could increase sharply. Later, the Sphagnum peat dopplerite layer (VIIh) precipitated on the desiccation level of c. $2500 \mathrm{BC}$.

About $2000 \mathrm{BC}$ the Menyanthes-Betula peat growth gave way to highly humified Sphagnum peat growth. At the same time, water collected in the hollows of the brown-black highly humified Sphagnum peat, as a result of which the formation of Sphagnum rubellum peat stagnated there, and was replaced by growth of fresh Sphagnum cuspidatum peat. Sphagnum imbricatum and Sphagnum papillosum immigrated into this bog area. The highly humified Sphagnum peat growth was maintained in the hummocks. The clear-cut wet/dry pattern manifests itself as a mosaic of poorly humified hollows and highly humified hummocks (hummocks and hollows of type EMmen 9), see fig. 16: the intermediate deposit (VIId). In a comparatively narrow zone (c. $300 \mathrm{~m}$ wide) between areas with hummocks and hollows of type EMmen 9, a less-pronounced wet/dry pattern is present, from which fresh hollows and highly humified hummocks also evolved (type EMmen 17), see fig. 16.

The peat surface in the areas with hummocks and hollows of type EMMEN 9 grew upwards more rapidly than the surface with type EmMEN 17 and the blue-black highly humified Sphagnum peat, due to which doming developed on the peat surface. C. $1500 \mathrm{BC}$, the water in the hollows of type Emmen 9 began to drain off, via the zone with type EMMEN I7, to the lower-lying, blue-black, highly humified peat surface, which is situated between three complexes with type Emmen 9. The milieu in the area of Emmen I 7 changed because of this to such an extent that a new, considerably more pronounced wet/dry pattern developed here. Where water collected on the blue-black bog surface, there developed an elongated lake, which was practically without outlet, the raised bog lake, EMmEN I 9 (fig. I6). As a result, the blue-black peat became so much more acidic here, that fresh Sphagnum cuspidatum could form in the lake. The raised bog lake was the lowest-lying and the wettest part of the contact zone between domed complexes, which had a diameter of $3-4 \mathrm{~km}$.

The lake had an extensive marginal area, with very large hollows 
and low hummocks (type EmMen 22/23, see fig. I6), which form a diffuse bank. In the north-south contact zones of the domed complexes a slight, northwards-directed drainage developed; hummocks and hollows of type Emmen 32 evolved here (fig. I6). This northsouth contact zone coincides with the eastern margin of the blueblack complex, where the Menyanthes-Betula peat is present.

After about $1500 \mathrm{BC}$, the hollows of type EMMEN 9 filled up with mainly Sphagnum papillosum; hardly any additional $S$. cuspidatum formed here. Cuspidatum peat was still developing in the hollows of type Emmen 17, Emmen 22/23 and Emmen 32, i.e. in the contact zones. The highly humified Sphagnum peat growth, with Sphagnum rubellum, Calluna and Eriophorum vaginatum, could initially continue growing in the hummocks of the intermediate deposit, but S. imbricatum could gradually increase there, forming less humified bog. The moisture content of the peat continuously increased (see also the curves in fig. $3^{6}$ ), due to which the water level constantly rose further, especially in the contact zones without outlet, such as the raised bog lake, Emmen 19. C. $500 \mathrm{BC}$, the bog could no longer contain the water which had collected on the surface. In the bog area east of EMmEN, the raised bog lake EMmEN ig drained in an easterly direction into the bog rivulet, the Runde, (fig. 17 ), which had developed from the north-south contact zones of six domed complexes. The underlying highly humified Sphagnum peat was extensively eroded by this drainage. Numerous lakes and pools in a large part of the raised bog of south-eastern Drenthe emptied in this way, resulting in an enormous trail of erosion.

Since only the water surplus which had already flowed from the domed complexes disappeared, the bog surface was not desiccated by this drainage. Many minerals, however, were removed with the water, as a result of which the bog surface, considered as a whole, became clearly more strongly oligotrophic. This was highly favourable to an increase of Sphagnum papillosum and S. imbricatum. These then formed a fresh peat (VIIe), in which scarcely any differentiation occurs between hummocks and hollows. The wet/dry pattern, clearly present c. $2000 \mathrm{BC}$, which became considerably less pronounced in the period after $\mathrm{c}$. Iooo $\mathrm{BC}$, was then present to only a very slight extent. The wet/dry pattern in the contact zone of EMmen I 7 probably altered c. $300 \mathrm{BC}$, which might indicate a radical change in the peat-forming milieu in the contact zones. 


\section{BIBLIOGRAPHY}

Aario, R., - Ig65 - Entwicklung des Moores Harjulansuo. Comptes Rendus de la Soc. géol. de Finlande Nr. XXXVII: $131-148$.

Aletsee, L., - 1959 - Zur Geschichte der Moore und Wälder des nördlichen Holsteins. Nova Acta Leopoldina Nr. 139. Bd. 21: I- 5 1.

Atlas van Nederland, - $1963-$ r 969 - Topografische Dienst, Delft.

Averdieck, F. R., - I957a-Ein Moorprofil sagt über die Vegetationsgeschichte seiner Umgebung aus. Harburger 7. b. 7: $109-122$.

Averdieck, F. R., - I957b-Zur Geschichte der Moore und Wälder Holsteins. Nova Acta Leopoldina N. F. Nr. I30, Bd. I9: I-I 52.

Averdieck, F. R. \& H. Döbling, - 1959-Das Spätglazial am Niederrhein. Fortschr. Geol. Rheinld. u. Westf. 4: 341-362.

Baden, W. \& G. Grosse-Brauckmann, - 1964 - Einige für Wasserwirt und Landwirt wichtige moorkundliche Begriffe. Wasser und Boden 16 . Jhrg, $\mathrm{H}$. 5: $155-159$.

Bahnson, H., - 1968 - Kolorimetriske bestemmelser af Humificeringstal i Højmosetørv fra Fuglsø mose på Djursland. Medd. Dansk Geol. Foren. Bd. I8, H. I: $55-63$.

VAN BAREN, J., - 1910 - Zur Frage nach der Entwicklung des postglazialen Klimas in den Niederlanden. Postglaziale Klimaveränderungen Stockholm: $25-31$.

VAn Baren, J.3 - 1913 - Die Hochmoore der Niederlande. Die Ernährung der Pflanze. 9e-Jhrg., Nr. I: $1-8$.

Van Baren, J., - I927 - De bodem van Nederland. Bd. II. Het Kwartair. S. L. Van Looy, Amsterdam. 1365 pp.

BARKMAN, J.J. \& V. WESTHOFF, - I 969 - Botanical evaluation of the Drenthian District. Vegetatio I9: $330-388$.

BeHre, K. E., - 1966 - Untersuchungen zur spätglazialen und frühpostglazialen Vegetationsgeschichte Ostfrieslands. Eiszeitalter u. Gegenwart Bd. I7: $69-84$.

Berre, K. E., - 1967 - The Late Glacial and Early Postglacial History of Vegetation and Climate in Northwestern Germany. Rev. Palaeobotan. Palynol., 4: $149-\mathrm{I} 6 \mathrm{I}$.

BEHRE, K. E., - 1970 - Die Entwicklungsgeschichte der natürlichen Vegetation im Gebiet der unteren Ems und ihre Abhängigkeit von den Bewegungen des Meeresspiegels. Probleme der Küstenforschung 9: 13-48.

Van Bemmelen, J. M., - I895 - Over de samenstelling, het voorkomen, en de vorming van sideroze (witte klien) en van vivianiet in de onderste darglaag der hoogveenen van Zuidoost-Drenthe. Verh. Kon. Ned. Akad. Wet., re sectie, 3: $\mathrm{I}-16$.

Beijerinck, W., - 1934 - Sphagnum en Sphagnetum. Meded. nr. 6, Nederlandsch Biologisch Station. Versluys, Amsterdam. i $16 \mathrm{pp}$.

Beyerinck, W., - 1947 - Zadenatlas der Nederlandsche flora. Meded. nr. 30, Biol. Stat. Wijster. Wageningen. 316 pp.

BrRKs, HrLARY H., - I970 - Studies in the vegetational history of Scotland. I. A pollen diagram from Abernethy Forest, Inverness-Shire. F. Ecol. $5^{8}$ : $827-846$.

Borgman, A. - I89o-De Hoogvenen van Nederland. Diss. Groningen, 179 pp.

Bos, P. R. \& J. N. Niermeyer, - I955-Atlas der gehele aarde. J. B. Wolters, Groningen. 
Von BüLow, K., - I929 — Handbuch der Moorkunde. I. Allgemeine Moorgeologie. Berlin. $308 \mathrm{pp}$.

Bult, P., - 1963 - Twee haarvlechten. Een veenvondst uit 1894 . Nieuwe Drentse Volksalmanak 81: 213-215.

ButLer, J. J., - I960 - Drie Bronsdepots van Bargeroosterveld. Nieuwe Drentsche Volksalmanak 78: 205-23I.

Casparie, W. A., - 1962 - Mest uit het veen in het Schoonebeekerveld. Nieure Drentse Volksalmanak 80: 2 I9-222.

Casparie, W. A., - 1969 - Bult- und Schlenkenbildung in Hochmoortorf. Vegetatio I9, : 146-I80.

Casparie, W. A. \& W. Van Zeist, - ig6o-A Late-glacial Lake Deposit near Waskemeer (Prov. of Friesland). Acta Botan. Neerl. 9: ig I-Ig6.

Glason, A. T., - 1961 - Twee oerosschedels uit Drenthe. Nieuwe Drentse Volksalmanak 79: $183-188$.

CLAson, A. T., - Ig63-Het Bolleveen bij Taarloo. Sporen van voorhistorische turfwinning in Drenthe. Nieuwe Drentse Volksalmanak 81: $23 \mathrm{I}-240$.

Coles, J. M. \& F. A. Hrabert, - 1968 - Prehistoric Roads and Tracks in

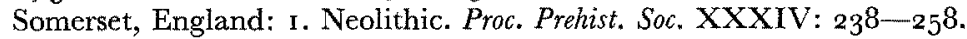

Coles, J. M., F. Alan Hibbert \& C. F. Clement, - 1970 - Prehistoric Roads and Tracks in Somerset, England: 2. Neolithic. Proc. Prehist. Soc. 36: 125I5I.

Conol.ty, A. P. \& J. H. Drckson, - 1969 - A note on a Late-Weichselian Splachnum Capsule from Scotland. New Phytol. 68: 197-I99.

Damblon, F.s - 1969 - Etude palynologique comparée de deux tourbières du plateau des Hautes Fagnes de Belgique: la Fagne Wallonne et la Fagne de Clefay, Bull. Nat. Plantentuin Belg. 39: 17-45.

Daniet.s, A. G. H., - 1964 - A contribution to the investigation of the Holocene history of the beech in Eastern Netherlands. Acta Botan. Neerl. 13:66-75.

Diederichs, R., - i 894 - Ueber die fossile Flora der mecklenburgischen Torfmoore. Güstrow, Rostock. 34 pp.

Dixox, H. N., - 1924 - The student's handbook of British mosses; third ed. Sumfield \& Day, Eastbourne. $5^{82}$ pp.

DONNER, J. J., - I97I - Towards a stratigraphical division of the Finnish Quaternary. Commentationes Physico-Mathematicae $4 \mathrm{l}: 28 \mathrm{I}-305$.

VAN Duinen, L. \& W. VAN Zeist,-I I6 I-Some pollen Diagrams from the Clay district in the Provinces of Groningen, Friesland and North-Holland (Netherlands), Palaeohistoria VIII: $127-137$.

Edelman, C. H. \& G. C. MaArleveld - 1958-Pleistozän-geologische Ergebnisse der Bodenkartierung in den Niederlanden. Geol. Jb., Bd. 73:639-684.

EllenBerg, H., - 1963 - Waldfreie Flach- und Zwischenmoore im Vergleich zu anderen Moortypen. in: Vegetation Mitteleuropas mit den Alpen, pp. 410-45I. Eugen Ulmers, Stuttgart.

ERnst, O., - 1934 - Zur Geschichte der Moore, Marschen und Wälder Nordwest-Deutschland IV: Untersuchungen in Nordfriesland. Schr. Natur. Ver. Schleswe. Holst., 20: 209-334.

Eshuis, H. J. - 1936 - Untersuchungen an Niederländischen Mooren. Recueil Trav. Bot. Nérl. vol. XXXIII: $688-704$.

Eshurs, H. J., - I946 - Palynologisch en Stratigrafisch Onderzock van de Peelvenen. Diss. Utrecht, I $43 \mathrm{pp}$.

Faber, F. J., - 1960 - Geologie van Nederland. Aanvullende hoofdstukken, IV. J. Noorduyn en Zn., Gorinchem. 607 pp. 
FAegri, K., J. Iversen, \& H. T. WAterbolk, - I964 - Textbook of pollenanalysis; 2nd ed. Munksgaard, Copenhagen 237 pp.

Firbas, F. - I 949 - Spät- und nacheiszeitliche Waldgeschichte Mitteleuropas nördlich der Alpen. Bd. I, Allgemeine Waldgeschichte, Jena. 480 pp.

Firbas, F., K. O. Münnich, \& W. Wittke, - $195^{8}-{ }^{14} \mathrm{C}$-Datierungen zur Gliederung der nacheiszeitlichen Waldentwicklung und zum Alter von Rekurrenzflächen im Fichtelgebirge. Flora Bd. I46: 512-520.

Florschürz, F., - I 933 - Résumé van de op 29 Juli I 933 voor de Subcommissie der Commissie van Advies voor den Proefpolder bij Andijk gehouden lezing over Veenonderzoek in het algemeen en dat in den Wieringermeerpolder in het bijzonder. Stencil I $6 \mathrm{pp}$.

Florschüтz, F., - $193^{8}$ - Archaeologie en Palaeobotanie. Nederlandsche Anthropologische Vereeniging. E. J. Brill, Leiden pp. I 2-I5.

Frorschütz, F., - r $94 \mathrm{I}$ - Wordingswijze en botanische samenstelling van eenige Nederlandsche veensoorten. Uit de verzameling "Inleidingen" tot de bespreking van "Het veen en zijn ontginning", gehouden in de Elfde Wetenschappelijke Bijeenkomst der Sectie Nederland van de Internationale Bodemkundige Vereeniging te Utrecht. Stencil I I pp.

FLoRschütz, F. \& E. L. VAN OYE, - $193^{8}$ - Over de ouderdomsbepaling van de "vijvers" op het plateau van het Belgisch Hoogveen. Tijdschr. Kon. Ned. Aardr. Gen. LV, 3: 454-46r.

FLORSCHÜTZ, F. \& E. C. WAssinK, - I935 - Untersuchungen an niederländischen Mooren. Recueil Trav. Bot. Neerl. vol. XXXII: 438-452.

Florschütz, F. \& E. C. WASSINK, - I94I - Untersuchungen an niederländischen Mooren. Recueil Trav. Bot. Neerl. vol. XXXVIII: I-I6.

Florschütz, F., G. Vermeulen., M. H. Van RaAlte., E. C. Wassink, \& W. H. VAN DobBen, - I932 - Resultate von Untersuchungen an einigen niederländischen Mooren. Recueil Trav. Bot. Neerl. vol. XXIX: I-I 7 .

Geological Nomenclature - I959-Ed. A. A. G. Schiteferdecker. J. Noorduijn en Zoon N.V., Gorinchem. 523 pp.

Geologische geschiedenis van Nederland. - 1956 - Ed. A. J. Pannekoek. Staatsdrukkerij, 's Gravenhage. I 54 pp.

VAN Giffen, A. E., - I9I3 - De Buinerbrug en het steenen voetpad aldaar. Oudh. Meded. Rijksmus. Oudh. Leiden VII: 5I-9o.

VAN Grffen, A. E., - I925 - De ligging der archaeologica in het hoogveen. in: Hand. XXe Ned. Nat. Geneesk. Congr., 3 pp. Groningen.

Glasbergen, W., - 1956 - De dolk van Bargeroosterveld, I. Vondstomstandigheden \& beschrijving. Nieuwe Drentsche Volksalmanak 74: 19I-198.

Glasbergen, W., - I956 - Der römische Münzschatz von Bargercompascuum (Drenthe). I. Die Entdeckung. Palaeohistoria 5, 77-79.

Godwin, H., - I954 - Recurrence-Surfaces. Danmarks Geol. Undersegelse II Raekke. Nr. 80: 23-3o.

Godwin, H., - I955 - Studies of the Post-Glacial History of British Vegetation. XIII. The Meare Pool Region of the Somerset Levels. Phil. Trans. Roy. Soc. London, Ser. B. 662, vol. 239: I6 I-1 90.

Godwin, H., - I956 - The history of the British flora. Univ. Press., Cambridge. $3^{8} 4 \mathrm{pp}$.

Godwin, H., - ${ }^{1967}$ - Discoveries in the Peat near Shapwick Station, Somerset. Proc. Somersetshire Arch, and Natural History Soc. vol. I I I: 20-23.

Godwin, H., - Ig68 - Studies of the Post-Glacial History of British Vegetation 
XV. Organic Deposits of Old Buckenham Mere, Norfolk. New Phytol. 67: $95-107$.

Godwin, H., - 1968 - Terneuzen and Buried Forests of the East Anglian Fenland. New Phytol. 67: 733-738.

Granlund, E., - 1932 - De Svenska Högmossarnas Geologi. Sverig. Geol. Undersökn. $\mathrm{C}_{373}$, Ârsbok 26: 1-193.

Groenman-Van WaAteringe, W., - ig68 - The Elm decline and the first appearance of Plantago Maior. Vegetatio I5, 292-296.

GrofrNe, U., - I952 - Zur Daticrung der Küstenmoore zwischen Jadebusen und Dollart. Abhandl. Naturwiss. Ver. Bremen 33: $12 \mathrm{I}-\mathbf{1} 32$.

Grospietsch, TH., - 1952 - Die Rhizopodenanalyse als Hilfsmittel der Moorforschung. Naturwissenschaften 39: $3^{18}-323$.

Grospretsch, TH., - I955 - Die testaceen Rhizopoden der Hochmoore und ihre Bedeutung für die Moorforschung. Gewässer und Abwässer Heft 6:5-19.

Grospiersch, TH., - 1958 - Wechseltierchen (Rhizopoden). Kosmos. Gesellschaft der Naturfreunde Franckh'sche Verlagshandlung, Stuttgart, $80 \mathrm{pp}$.

Gross, H., - I930 - Das Problem der nacheiszeitlichen Klima- und Florenentwicklung in Nord- und Mitteleuropa. Bot. Centralbl. Bd. XLVII, Abt. II. Heft I: I-I Io.

Grosse-Brauckmann, G., - rg61 - Unterlagen und Daten zur allgemeinen Moorkunde und Moorbotanik. Stencil. Bremen. ro pp.

Grosse-Brauckmann, G., - 1961 - Zur Terminologie organogener Sedimente. Geol. 7b. 79: 1 I 7-I 44 .

Grosse-Bradokmann, G., - 1962 - Moorstratigraphische Untersuchungen im Niederwesergebiet (Uber Moorbildungen am Geestrand und ihre Torfe). Veröffentl. Geobotan. Inst. Rübel, Zürich 37: roo-i I 9.

Grosse-Brauckmann, G., - rg62 - Zur Moorgliederung und -ansprache. Zeitschrift für Kulturtechnik, 3.Jhrg., H. I: 6-29.

Grosse-Brauckmann, G., - I 963 - Über die Artenzusammensetzung von Torfen aus dem Nordwestdeutschen Marschen-Randgebiet. Vegetatio In: $325-341$.

Grosse-Brauckmann, G., - 1964 - Einige wenig beachtete Pflanzenreste in nordwestdeutschen Torfen und die Art ihres Vorkommens. Geol. $7 b .81$ : $621-644$.

Grosse-Brauckmann, G., - r964 - Über die beiden Weberschen MoorprofilSchemata. Stencil. Bremen. 5 pp.

Grosse-Brauckmann, G., - 1965 - Vom Hochmoor und seiner Pflanzenwelt. Materia Medica Nordmark, 4: 3-26.

Grosse-BrauckmanN, G., - 1967 - Über die Artenzusammensetzung einiger nordwestdeutscher Torfe. Pflanzensaziologie und Palynologie: $160-180$.

Grosse-Brauckmann, G., - 1967 - Die Moore in der Bundesrepublik Deutschland. Natur und Landschaft 42, H. 9: 195-198.

Grosse-Brauckmann, G., - 968 - Einige Ergebnisse einer vegetationskundlichen Auswertung botanischer Torfuntersuchungen, besonders in Hinblick auf Sukzessionsfragen. Acta Bot. Neerl. i 7 ( I): 59-69.

Grosse-Brauckmann, G., - rg69-Zur Zonierung und Sukzession im Randgebiet eines Hochmoores. Vegetatio i 7: 33-49.

Grosse-Brauckmann, G. \& D. Puffe, - I 964 - Untersuchungen an TorfDünschnitten aus einem Moorprofil vom Teufelsmoor bei Bremen. Soil Micromorphology: $83-93$.

HAFSTEN, U.,-I958-Boreal pine trunks from Oddernes (Vest-Agder, Norway). 
Demonstration of the Tapes-transgression. Norsk geologisk tidsskrift, Bd. $3^{8}$, h. $3-4: 313-325$.

Hahne, H., - I918 - Die geologische Lagerung der Moorleichen und Moorbrücken. Veröff. Provinzialmus. z. Halle, Bd. I, H. I: I-48.

HALBERTSMA, H., - I $962 / 1963$ - Veenbruggen en hun gebruik; naar aanleiding van een beschrijving uit het jaar I6I9. Ber. Rijksdienst Oudheidk. Bodemonderzoek I2-I3: 193-209.

Van Der Hammen, T., - r 949 - De Allerød-oscillatie in Nederland. Pollenanalytisch onderzoek van cen laatglaciale meerafzetting in Drente. Proc. Kon. Ned. Akad. Wetensch. Vol. LII, Nrs. I \& 2: 2-16.

Van Der Hammen, T., - I95 I - Late-glacial flora and periglacial phenomena in the Netherlands. Leidse Geol. Meded. I 7: I 7-1 83 .

Hardy, E. M., - I 939 - Studies of the Post-Glacial History of British Vegetation. V. The Shropshire and Flint Maelor Mosses. New Phytol., vol. XXXVIII, Nr. 4: $364-396$.

Harnisch, O., - 1925- Studien zur Oekologie und Tiergeographie der Moore. Zool. Jahrb. (Hist.) $5 \mathrm{I}: \mathrm{I}-\mathrm{I} 66$.

Harnisch, O., - I 929 - Die Biologie der Moore. in: Die Binnengewässer VII. ed. A. Thienemann, I 46 pp. E. Schweitzerbart, Stuttgart.

Harnisch, O., - I948 - Rhizopodenanalyse der Moore. Biol. Zentralbl. Bd. 67: $55 \mathrm{I}-562$.

HARNisch, O., - I 949 - Älterer und jüngerer Sphagnumtorf; ein rhizopodenanalytische Studie an nordwesteuropäischen Hochmooren. Biol. Zentralbl. Bd. 68: 398-412.

Harnisch, O., - r959 - Rhizopoda. in: Die Tierwelt Mitteleuropas, ed. P. Brohmer Bd. I, Lief. Ib: I-75.

HaYen, H. - Ig66 - Moor und Torf. Heinz Holzberg Verlag, Oldenburg. $\mathrm{I}-\mathrm{I} 6$.

HAYeN, H., - I957 - Zur Bautechnik und Typologie der vorgeschichtlichen, frühgeschichtlichen und mittelalterlichen hölzernen Moorwege und Moorstrassen. Oldenb. $7 b$. Bd. 56, Teil 2: 83- 7 7o.

Hayen, H., - rg6oa - Erhaltungsformen der in den Mooren gefundenen Baumreste. Oldenb. 76 . Bd. 59, Teil 2: 2 I-49.

HAYen, H., - Ig6ob - Vorkommen der Eibe (Taxus baccata L.) in oldenburgischen Mooren. Oldenb. 7b. Bd. 59, Teil 2: 5I-67.

Hayen, H., - I961 - Zwei hölzerne Moorwege aus dem Fundgebiet Ipwegermoor B, Kreis Ammerland i. Oldbg. Neue Ausgrabungen und Forschungen in Niedersachsen 15 : I I3-I31.

Hayen, H., - I 1965 - Menschenförmliche Holzfiguren neben dem Bohlenweg XLII (Ip) im Wittemoor. Oldenb. Frb. 64: $1-25$.

Hayen, H., - I965 - Der Bohlenweg I (Bou) in der Dose zwischen Sprakel und Tinnen (Kreis Meppen, Reg. -Bez. Osnabrück). Die Kunde I6: 74-94.

Hayen, H., - Ig66 - Moorbotanische Untersuchungen zum Verlauf des Niederschlagsklimas und seiner Verknüpfung mit der menschlichen Siedlungsstätigkeit. Neue Ausgrabungen und Forschungen in Niedersachsen, 3: 280-307.

Hayen, H., - 1968 - "Isernbarg". Ein Eisenverhüttungsplatz in Streekermoor (Gemeinde Hatten, Landkreis Oldenburg). Oldenb. $\mathfrak{f} b . \mathrm{Bd} .87$ : $133^{-1} 73$.

Hayen, H., - I968 - Moore als Geschichtsquelle. Möglichkeiten und Forderungen der Moorarchäologie. Jahrb. für Naturschurz und Landschaftspflege I8: 3 -I2.

HAYEN, H., - 1969 - Ein Kiefernwaldhorizont im Südteil des Ipweger Moores 
(Gemeinde Mooriem, Kreis Wesermarsch). Neue Ausgrabungen und Forschungen in Niedersachsen 4: 329-347.

Heinselman, M. L. - ig63 - Forest sites, bog processes, and peatland types in the glacial lake Agassiz, region Minnesota. Ecological Monographs 33: $327-374$.

Heukels, H. \& S. J. VAN Ooststroom, - I962 - Flora van Nederland, geillu-

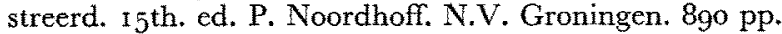

Van Heuveln, B., - $195^{8}$ - Minerale afzettingen in het smeulveen. Boor en Spade IX: $38-53$.

VAN HeUvei.N, B., - I959- Ouderdomsbepalingen van humus in een humuspodzolprofiel onder veen volgens de ${ }^{14} \mathrm{C}$-methode. Boor en Spade $\mathrm{X}: 27-3^{8}$.

VAN Heuveln, B., - 1962 - Organic $B$ in high moor peat and high moor peat reclamation soils. Boor en Spade XII: $169-177$.

Hol, J. B. L., - I949 - Geomorfologie. in: Handboek der geografie van Nederland, deel I. pp. $240-319$. J. J. Tijl, Zwolle.

HoogenRaAd, H. R., - I 934 - Studien über die Sphagnicolen Rhizopoden der niederländischen Fauna. Diss. Utrecht. roo pp.

HoogenraAd, H. R. \& A. A. De Groot, - r940 - Zoetwaterrhizopoden en -Heliozoën (A la). in: Fauna van Nederland IX, Sythoff, Leiden. 303 pp.

Houwrnck, R., - rgr3 - Het laagveen in de provincie Drente. Nieuwe Drentsche Volksalmanak 31: $40 \mathrm{pp}$.

IVERsen, J., - I941 - Landnam i Danmarks Stenalder. Danmarks Geol. Unders. II. R., Nr. 66: 7-68.

Iversen, J., - 1949 - The Influence of Prehistoric Man on Vegetation. Danmarks Geol. Unders. IV. R. Bd. 3, Nr. 6:4-25.

JANSSEN, C. R., - 1959 - Alnus as a disturbing factor in pollendiagrams. Acta Bot. Neerl. 8: $55-58$.

JAnssen, G. R., - I960 - On the Late-Glacial and Post-Glacial Vegetation of South Limburg (Netherlands). Wentia 4: I-I 12.

Janssen, G. R. \& H. A. Tan Hove., - I971 - Some Late-Holocene pollen diagrams from the Peel raised bogs (Southern Netherlands). Rev. Palaeobot. Palynol. I I: 7-53.

Jasnowski, M., J. Jasnowska, \& St. Markowski, - 1968 - Vanishing raised and transition peat bogs in the Baltic Region of Poland. Ochrona Przyrody $R$. 33: $69-\mathrm{r} 24$.

Jessen, K., - I934 - Preliminary Report on Bog Investigations in Ireland. Ir. Nat. 7. vol. V, Nr. 6: i 30-r 34 .

JESSEN, K., - I935 - Archaeological dating in the history of North Jutland's vegetation. Acla Archaeologica 5: r $85-2$ I4.

JeSSEN, K., - 1949 - Studies in Late Quaternary deposits and flora-history of Ireland. Proc. Roy. Irish Acad., Sect. B., vol. 52, No. 6: 85-29o.

Jongmans, W. J., - $193^{2}$ - De ontwikkeling der Palaeobotanie en haar verband met botanie en geologie. D. v. d. Marck, Heerlen. 28 pp.

Katz, N. J., - $193^{\circ}$ - Zur Kenntnis der oligotrophen Moortypen des europäischen Russlands. Bot. Centralbl. Bd. XLVII, Abt. II, Heft I: 177-210.

KLAus, W., - I960 - Pollendiagramme der Moore des niederösterreichischen Waldviertels. Verhandl. Geol. Bundesanstalt $H$. 1: $72-77$.

Klaus, W., - 1961 - Pollendiagramme der Moore des niederösterreichischen Waldviertels. II. Das Schremser Moor (Schwarzinger Torfstich). Verh. Geol. Bundesanstalt H. 2: $128-\mathrm{r} 30$.

Koperowa, W., - 1962 - The History of the Late-Glacial and Holocene 
Vegetation in Nowy Targ Basin. Acta Palaeobotan., Polsk. Akad. Nauk. II, Nr. 3: $3-62$.

Korinsky, N. A., - I97I - The problem of the boundary horizon, with special reference to the Shuvaloff peat bog. Appendix to guide for field route no. I-B., III international palynological conference. USSR Academy of Sciences, Moscow: $41 \mathrm{pp}$.

KrisAr, R., - I965 - Pflanzensoziologische Untersuchungen in Lungauer Mooren. Verh. Zool. Bot. Ges. Wien 105/106: 94-136.

Krisar, R., - $197^{0}$ - Pollenanalytische Notizen aus dem Lungau. Mitt. Ostalp. -Dinar. Sek. d. Int. Ver. f. Veg. kunde, H. 1o/2: $34-45$.

KuBrTzKI, K., - I96o- Moorkundliche und pollenanalytische Untersuchungen am Hochmoor "Esterweger Dose". Schr. Naturw. Ver. Schlesw. Holst. Bd. 30: $12-28$.

Kubitzki, K. \& K. O. Munnich, - ig6o - Neue ${ }^{14}$ C-Datierungen zur nacheiszeitlichen Waldgeschichte Nordwestdeutschlands. Ber. Deut. Botan. Ges., Bd. LXXIII, H. 4: $137-146$.

KukLA, St., - 1965 - The development of the Spring Bogs in the regions of North-East Poland. in: Zagadnienia Torfoznawcze, no. 57; 395-483. P.W.R.i.l., Warszawa.

KulczyŃski, St., - I930 - Stratigraphie der Moore von Polesie. Prace Biura Meljoracji Polesia, Tom I, Zeszyt 2: $1-84$.

Van Leeuwen, Chr. G., - $1962-$ De Hoogvenen van Twente. Wetens. Meded. Kon. Ned. Natuurh. Ver. Nr. 43: 2 I-38.

LEsEmanN, B., - 1969 - Pollenanalytische Untersuchungen zur Vegetationsgeschichte des Hannoverschen Wendlandes. Flora, Abt. B, Bd. I 58: 480-5I9.

Ligtering, G. H., - 1954-De Hondsrug en het dal van de oer-Eems. Tijdschr. Kon. Ned. Aardr. Gen. 71: 105-120.

LoRIÉ, J., - 1894 - Iets over de Hoogvenen van Drenthe. Nieurve Drentsche Volksalmanak i $3: 82-97$.

MaArleveld, G. C., - 1960 - Wind directions and cover sands in the Netherlands. Biuletyn Peryglacjalny, Nr. 8: $49-58$.

Mamakowa, K., - 1962 - The Vegetation of the Basin of Sandomierz in the Late-Glacial and Holocene. Acta Palaeobotan., Polsk. Akad. Nauk III, Nr. 2: $3-57$.

MarkK, S., - r965 - Biology and Stratigraphy of the Alder Bogs in Poland. in: Zagadnienia Torfoznawcze, no. 57: 5-303. P.W.R.i.L., Warszawa.

Markgraf, V., - I969 - Moorkundliche und vegetationsgeschichtliche Untersuchungen an einem Moorsee an der Waldgrenze im Wallis. Bot. $\mathcal{7 b}$. 89, Nr. I: $\mathrm{r}-63$.

Maute, K. - Moorrast. - Das Teufelsmoor und Worpswede im Landkreis Osterholz. Verkehrsverband für den Kreis Osterholz: $3-8$.

Mrkkelsen, V. M., - i943 - Bidrag til Lille Vildmoses Stratigrafi og Vegetationshistorie. (Contributions to the Stratigraphy and the Vegetational History of Lille Vildmose (Jutland) ). Meded. Dansk. Geol. Foren., Bd. Io, H. $3: 329-364$.

Mrtahezl, G. F., - 1951 - Studies in Irish Quaternary Deposits: No. 7. Proc. Roy. Irish Acad., Sect. B, vol. 53, No i I: I I I-206.

Mrtaheld, G. F., - I956 - Post-Boreal pollen-diagrams from Irish raised bogs. Proc. Roy. Irish Acad., Sect. B, vol. 57, No 14: 185-251.

MrrchelL, G. F., - I965 - Littleton Bog, Tipperary: An Irish Vegetational Record. The Geol. Soc. of America, Inc. Special Paper 84: I-16. 
Moore, J. J., - 1963 - Summary report of the International Symposium on Anthropogenous Vegetation held at Stolzenau/Weser, 27-30 March 1961. Vegetatio 11: $136-139$.

Moore, J.J., - $1967-$ Zur Entstehung und Entwicklung der terrainbedeckenden Moore Westirlands. Symposion über Gesellschafts-Entwicklung. Stencil, Rinteln.

Morrison, M. E. S., - 1955-The Water Balance of the Raised Bog. Ir. Nat. J., Vol. XI, No 1I: $303-308$.

Morrison, M. E. S., - 1959 - The Ecology of a Raised Bog in Co. Tyrone, Northern Ireland. Proc. Roy. Irish Acad. Sect. B, vol. 6o, Nr. 9: 29r-3o8.

Mulder, G. J. A., - I9I I - Literatuur. Tijdschr. Kon. Nederl. Aardr. Gen. ze Ser. dI. XXVIII, Afl. $6: 967-98$ I.

Müller, K., - I965 - Zur Flora und Vegetation der Hochmoore des nordwestdeutschen Flachlandes, Schr. Naturwiss. Ver. Schleswig-Holstein, Bd, 36:30-77.

MÜller, K., - 1968 - Ökologische-vegetationskundliche Untersuchungen in ostfriesischen Hochmooren. Ber. Deut. Botan. Ges. Bd. 81, H. 6: 22I-237.

Munaur, A. V., - rg66a - Recherches Dendrochronologiques sur Pinus silvestris. I. Étude de 45 pins sylvestres récents originaires de Belgique. Agricultura (Louvain) 14, 2e Série, no 2: 193-232.

Munaut, A. V., - Ig66b - Recherches Dendrochronologiques sur Pinus silvestris. II. Premiére application des méthodes dendrochronologiques à l'étude de pins sylvestres sub-fossiles (Terneuzen, Pays-Bas). Agricultura (Louvain) I4, 2e série, no $3: 361-389$.

Munaut, A. V., - 1967 - Etude paléo-écologique d'un gisement tourbeux situé à Terneuzen (Pays-Bas). Ber. Rijksdienst Oudheidk. Bodemond.. 17: $7-27$.

Munaut, A. V., - 1967 - La forêt ensevelie de Terneuzen. in: Industrie: 7 pp. Fed. Ind. Belges, Bruxelles.

Munaut, A. V., - Ig69 - L'affleurement tourbeux du Braakman (Flandre Zélandaise). Les Naturalistes Belges 50-10: 564-571.

Munaut, A. V. \& W. A. Casparie, - I97I - Etude dendrochronologique des Pinus sylvestris L. subfossiles provenant de la tourbière d'Emmen (Drenthe, Pays-Bas). Rev. Palaeobot. Palynol. I I : 20 I-226.

Nichols, H., - 1969 - Chronology of peat growth in Canada. Palaeography, Palaeocolimatol., Palaeoecol. 6: 6r-65.

NiLsson, T.,-196r - Ein neues Standardpollendiagramm aus Bjärsjöholmssjön in Schonen. Lunds Univ. Arsskr. N. F. (2) 56: 3-34.

Nirsson, T., - $\mathrm{r}_{964 \mathrm{a}}$ - Standardpollendiagramme und ${ }^{14} \mathrm{C}$-Datierungen aus dem Ageröds Mosse im mittleren Schonen. Lunds Univ. Arsskr. N. F. (2) 59:5-52.

Nirsson, T., - $1964 \mathrm{~b}$ - Entwicklungsgeschichtliche Studien im Ageröds Mosse, Schonen. Lunds Univ. Arsskr. N. F. (2) 59:5-34.

Olausson, E., - I957-Das Moor Roshultsmyren; eine geologische, botanische und hydrologische Studie in einem südwestschwedischen Moor mit exzentrisch gewölbten Mooselementen. Lunds Univ. Arsskr. N. F. (2) $53: \mathrm{I}-72$.

Osvald, H., - 1923 - Die Vegetation des Hochmoores Kosmosse. Svenska Växtsoc. Sallsk. Handl. I: I-266.

Osvaid, H., - 1950 - The raised bog Komosse. Excursion Guide. Seventh International Botanical Congress, Stockholm, Section: A II b 2, : I-2I.

Overbeck, F., - 1950 - Die Moore. in: Das Känozoikum in Niedersachsen 4. Abteilung. Geologie und Lagerstätten Niedersachsens. Niedersächs. Amt Landesplanung u. Statistik, Reihe A I Bd 3: 5- I 12. 
Overbeck, F., - 1952 - Das Grosse Moor bei Gifhorn im Wechsel hygrokliner und xerokliner Phasen der nordwestdeutschen Hochmoorentwicklung. Niedersächs. Amt Landesplanung u. Statistik, Reihe A I, Bd. 4I: I-63.

Overbeck, F., - I957b - Das Alter des Grenzhorizonts norddeutscher Hochmoore nach Radiocarbon-Datierungen. Veröffentl. Geobot. Inst. Rübel, Zürich, H. 34: $118-120$.

Overbeck, F., - I957/58 - Erläuterung zur Tafel "Entwicklung eines Hochmoores in Niedersachsen"s. Neues Archiv für Niedersachsen Bd. 9 (14), H. 5: $400-401$.

Overbeck, F., - 1963 - Aufgaben botanisch-geologischer Moorforschung in Nordwestdeutschland. Deut. Botan. Ges. B. 76, 1: 2-12.

Overbeck, F. \& I. Griéz,-I954-Mooruntersuchungen zur Rekurrenzflächenfrage und Siedlungsgeschichte in der Rhön. Flora 14I: 5 I-94.

Overkeck, F. \& H. HapPach, - I956 - Über das Wachstum und den Wasserhaushalt einiger Hochmoorsphagnen. Flora 144: 335-402.

Overbeck, F., K. O. Münnich, L. Aletsee, \& F. R. Averdieck, - 1957 - Das Alter des "Grenzhorizonts" norddeutscher Hochmoore nach RadiocarbonDatierungen. Flora 145: 37-71.

Van Oye, E. L., - $193^{6}$ - Een veen-profiel uit Drente. Ned. Kruidk. Archf. $4^{6:} 52 \mathrm{I}-524$.

Ploeger, P. L. \& W. Groenman-Van Waateringe, - 1964 - Late Glacial Pingo and valley development in the Boorne region near Wijnjeterp, Province of Friesland, Netherlands. Biuletyn Peryglacjalny, 13: 199-233.

Polak, B., - 1963-A buried Allerød Pine-forest. Acta Botan. Neerl. 12:533- 538.

Poore, M. E. D. \& D. Walker, - I958/59 - Wybunbury Moss, Cheshire. Mem. and Proc. Manch. Lit. and Phil. Soc. ro1: 1-24.

Von Post, L., - 1916 - Forest tree pollen in south Swedish peat bog deposits. Pollen et Spores 9, nr. 3, I967: 375-40 .

Praglowski, J., - Ig68 - Rekurrenzflächen und Humifizierungsgrad. Pollenanalytische Untersuchung in Snöroms-Moor. Pollen et Spores, Vol. X, Nr. I: $73-$ II 5 .

Prange, W., - 1963 - Das Holozän und seine Datierung in den Marschen des Arlau-Gebietes, Nordfriesland. Meyniana Bd. 13, $47-76$.

Puffe, D. \& G. Grosse-Brauckmann, - 1963 - Mikromorphologische Untersuchungen an Torfen. Zeitschrift für Kulturtechnik Flurbereinigung 4 Jhrg., H. 3: $159-188$.

Van RaAlte, H. M. \& E. C. Wassink, - 1932 - Resultate von Untersuchungen an einiger niederländischen Hochmooren; B. Zwartemeer. Rec. trav. bot. néerl. 29: 6-12.

Ratcliffe, D. A. \& D. Walker, - 1958 - The Silver Flowe, Galloway, Scotland. F. Ecol. $46: 407-445$.

Reinders, G., - I896 - Het voorkomen van gekristalliseerd ferrocarbonaat (Siderit) in moerasijzererts, en eene bijdrage tot de kennis van het ontstaan van dit erts in den Nederlandschen bodem. Verh. Kon. Akad. Wet. $2 \ell$ sectie, 5: I-40.

Reinders, G., - I902 - Mededeeling omtrent de verspreiding van het deels poedervormig deels pijpvormig ijzeroer in de provinciën Groningen en Drente. Verh. Kon. Akad. Wet. ae sectie, 9: I- 18.

Du Rretz, G. E., - 1950 - Phytogeographical Mire Excursion to the BillingenFalbygden District in Västergötland (Southwestern Sweden). Seventh International Botanical Congress Stockholm, Section: PHG: $1-54$. 
Rudolp, H., - 1963 - Die Kultur von Hochmoor-Sphagnen unter definierten Bedingungen. Beilräge zur Biologie der Pflanzen. Bd. 39, H. 2: 153-177.

Rybníček, K. \& E. RyBničkovÁ, - ig68 - The History of Flora and Vegetation on the Blato mire in southeastern Bohemia, Czechoslovakia (Palaeoecological Study). Folia geobot, phytotax., Praha 3: 117-1 42.

SAEBø, S., - 1968 - The Autecology of Rubus chamaemorus L. I. Phosphorus economy of Rubus chamaemorus in an ombrotrophic mire. Sci. Rep. Agr. Coll. Norway $47,(\mathrm{I}): \mathrm{I}-67$.

Saebo, S., - r 969 - On the mechanism behind the effect of freezing and thawing on dissolved phosphorus in Sphagnum fuscum peat. Sci. Rep. Agr. Coll. Norway $48,(\mathrm{r} 4)$ : I- 10.

Sahierbeek, A., - igr 7 - De studie der venen. Tijdschr. Kon. Ned. Aardr. Gen. 2e Ser. dl. XXXIV, Afl. 4: 505-545.

SchLüter H., - 1969 - Hochmoorgesellschaften im Thüringer Wald. Mitt. flor, -soz. Arbeitsgem. N. F. : $346-364$.

Schmiтz, H., - 1952 - Moortypen in Schleswig-Holstein und ihre Verbreitung. Schr. Naturw. Ver. Schleswig-Holstein, Band XXVI, H. I: 64-68.

Schnezkloth, H., - I963a - Das Hohe Moor bei Scheessel (Kreis Rotenburg/ Hannover). Beih. geol. 7 b. 55: 1-104.

SchneEkloth, H., - I $963 \mathrm{~b}$ - Das Weisse Moor bei Kirchwalsede (Kreis Rotenburg/Hannover). Beih. geol. $7 b .55: 105-138$.

Schinemzoth, H., - 1965 - Die Rekurrenzfläche im Grossen Moor bei Gifhorn - eine zeitgleiche Bildung? Geol. $7 b, 83: 477-496$.

SchNeEKLOTH, H., - I968-Altersunterschiede des Schwarz-/Weisstorfkontaktes im Kehdinger Moor. Geol. 7 b. 85: $477-496$.

Schneider, S. \& H. U. SteckHAN, - Ig63 - Das Grosse Moor bei Barnstorf (Kreis Grafschaft Diepholtz). Beih. geol. 7b. 55: 139-192.

Schröder, D., - r934 - Eine Calluna-Heide unter der Zuiderzee. Abh. Nat. Ver. Bremen, Schütte-Festschrift: $83-88$.

SchÜtrumpF, R:, - 1956 - Die Moore Schleswig Holsteins. Geolog. Landesamt Schlesw. Holst., Kiel: $40 \mathrm{pp}$.

SchwaAR, J., - I969 - Die Gerolsteiner Moss, Eifel, in moor- und vegetationskundlicher Sicht. Ber. Dtsch. Bot. Ges. Bd. 82, H. 3/4: 249-264.

SchwaAr, J., - r970 - Nachwärmezeitliche Vegetationsgeschichte des Salmwaldes/Eifel. Ber. Dtsch. Bot. Ges. Bd. 833/4: 89-107.

Sernander, R., - igro - Die schwedische Torfmoore als Zeugen postglazialer Klimaschwankungen. in: Die Veränderungen des Klimas seit dem Maximum der letzten Eiszeit: $197-246$. Herausgegeben von dem Exekutivkomitee des I1. Internationalen Geologenkongress, Stockholm.

DE Smet, L. A. H. \& A. E. KLUNGeL, - I965-De ouderdom van veenpaketten en gliedelagen in de Groninger Veenkoloniën. Boor en Spade, XIV: $28-4 \mathrm{I}$.

Smrth, A. G., - 1958 - Pollen Analytical Investigations of the Mire at Fallahogy TD., Co. Derry. Proc. Roy. Irish Acad., Sect. B, vol. 59, No. 16: $329-343$.

Van der Spoel-Walvius, M. R., - I964- Pollen analytical Studies on Disc Wheels. With a Reference to the Radiocarbon Dates. Palaeohistoria X: 147-1 56 .

TALlis, J. H., - 1962 - The identification of Sphagnum spores. Trans. Brit. bryol. Soc. 4, Part 2: 209-213.

TAluis, J. H. \& H. J. B. Birks, $-1965-$ The past and present distribution of Scheuchzeria palustris L. in Europe. J. Ecol. 53: 287-298. 
Teunissen, D., - ig69 - Verslag van de excursie naar Drenthe. Stencil Nijmegen, $15 \mathrm{pp}$.

Teunissen, D., - ig65 - Verslag Palynologisch Practicum ig63-1964. Stencil Nijmegen, 7 pp.

Teunissen, D., - I966 - Verslag van het Palynologisch Practicum 1965-1966. Stencil Nijmegen, 7 pp.

Tolpa, St., M. Jasnowski, A. PAzczyński, - r 967 - System der genetischen Klassifizicrung der Torfe Mitteleuropas. Zeszyty Problemowe Postepów Nauk Rolniczych 76: 9-99.

Tolonen, K., - ig66 - Stratigraphic and rhizopod analyses on an old raised bog, Varrassuo, in Hollola, South Finland. Ann. Bot. Fenn. 3: 147-166.

Tolonen, K., - I971 - On the regeneration of Northeuropean bogs. I. Klaukkalan Isosuo in S. Finland. Acta Agraria Fennica 43: 143- 66.

Versluys, J., - rgr9 - Verslag der excursie naar de venen van Drente en de Fosfaatgroeven bij Ootmarsum op I, 2 en 3 mei. Geol. Mijnbouw. 9 pp.

Villaret-Von Rochow, M., - I957 - Altersbestimmung eines Torfes aus dem Untergrund des Löwenplatzes in Luzern. Ber. Geobotan. Forschungsinst. Rübel, Zürich: f. 1956: 56 -66.

Visscher, J., - 1931 - Das Hochmoor von Südost Drente. Diss. Utrecht. 108 pp.

Visscher, J., - I 949 - Veenvorming. Noorduyn's Wetenschappelijke Reeks. no. 33: i 5 pp., Gorinchem.

Vogel, J. C. \& H. T. WAterbolk, - I963-Groningen Radiocarbon Dates IV. Radiocarbon 5: 163-202.

Vogel, J. C. \& H. T. WAterbolk, - I967 - Groningen Radiocarbon Dates VII. Radiocarbon 9: 107-I55.

Vogel, J. C., W. A. Casparie, \& A. V. Munaut, - I969 - Carbon-I4 Trends in Subfossil Pine Stubs. Science I66: I 143 - I 145.

De VRIES, H. \& H. T. WATERbolK, - 1958 - Groningen Radiocarbon Dates III. Science 128: I550- 1556 .

De Vries, H., G. W. Barendsen, \& H. T. Waterbolk, - I958 - Groningen Radiocarbon Dates II. Science 127: I 29-I37.

VRoman, M., - I952 - Study of a peat profile on the Frisian Coast of the former "Zuiderzee". Acta Botan. Neerl. I(2): 250-258.

VAN DER WAALS, J. D., - 1963 - Kroniek van Opgravingen en Vondsten in Drenthe in $196 \mathrm{I}$. Nieuwe Drentse Volksalmanak 81 : 248-26r.

Van Der Waals, J. D. - 1964 - Prehistoric Disc Wheels in the Netherlands. Diss. Groningen. 103 pp.

Walker, D., - I961 - Peat Stratigraphy and bog regeneration. Proc. Linnean Soc. London Pt. I: 29-33.

WaLker, D., - 1966 - The Late Quaternary History of the Cumberland Lowland. Phil. Trans. Roy. Soc. London, Ser. B, 770, vol. 251: I-210.

WALker, D. \& P. M. WALKeR, - I96I - Stratigraphic evidence of regeneration in some Irish Bogs. F. Ecol. 49: 169-185.

WARnstorf, G., - I9I I - Sphagnales - Sphagnaceae (Sphagnologia universalis). Das Pflanzenreich: $274-275$.

WAs, St. - I965 - Genesis, Succession and Mechanism of development of Moss Peat Layers. in: Zagadnienia Torfoznawcze, no. 57: 305-393. P.W. R.i.L., Warszawa.

Waterbolx, H. T., - I954 - De Praehistorische mens en zijn milieu. Een Palynologisch Onderzoek naar de menselijke invloed op de plantengroei van de diluviale gronden in Nederland. Diss. Groningen. I 53 pp. 
Waterbolk, H. T. \& W. Van Zeist, - I96 I - A Bronze Age Sanctuary in the Raised Bog at Bargeroosterveld (Dr.). Helinium I: 5- I9.

WEBER, C. A., - Igoo - Uber die Moore, mit besonderer Berücksichtigung der zwischen Unterweser und Unterelbe liegenden. Jahres-Bericht der Männer von Morgenstern 3: 3-23.

Weber, C. A., - 1902 - Uber die Vegetation und Entstehung des Hochmoors von Augstumal. Paul Parey, Berlin. 252 pp.

Weber, C. A., - 1908 - Die Entwicklung der Moorkultur in den letzten 25 Jahren. in: Festschrift zur Feier des 25 jährigen Bestehens des. Vereins zur Förderung der Moorkultur im Deutschen Reich, Berlin: 80-1or.

Weber, C. A., - Igro - Was lehrt die Aufbau der Moore Nordwestdeutschlands uber den Wechsel des Klimas in postglazialer Zeit? Zeitschr. deutschen Geol. Ges. 62: $143-162$.

WEBER, C. A., - 1924 - Das Moor des Steinkammergrabes von Hammah. Praehistorischen Zeitschrift XV: 40-52.

WEber, C. A., - 1926a-Die Entwicklungsgeschichte unserer Moore. Ver. Förd. Moorkult. Deutsch. Reich. Berlin, 9 pp.

Weber, C. A., - 1926b-Grenzhorizont und Klimaschwankungen. Abh. Nat. Ver. Bremen, Bd. XXVI, H. I: 98-106.

Weber, C. A., - r930 - Grenzhorizont und Älterer Sphagnumtorf. Abh. Nat. Ver. Bremen, Bd. XXVIII, H. I: $57-65$.

Ter Wee, M. W., - 1962 - The Saalian Glaciation in the Netherlands. Mededel. Geol. Sticht., N. Ser. 1 5: 57-76.

Welten, M., - Ig64 - La Tourbière de Genevez. Mitt. Naturforschenden Gesellschaft Bern, N. F. 21: $67-73$.

WesselinK, W. H. A., - I 924 - De veenbrug te Emmercompascuum. Tijdschr. Kon. Ned. Aardr. Gen. 2. Serie, 4r: 234-242.

WeST, R., - 1964 - Pleistocene geology and biology. With special reference to the British Isles. Longmans, Green and Co Ltd. $377 \mathrm{pp}$.

WesthofF, V., - rg67 - Rapport van het internationale symposion over Vegetatie-dynamiek (syndynamica), gehouden te Rinteln/Weser, 20-23 maart. Stencil: 12 pp.

WrermanN, R., - rg62 - Botanisch-moorkundliche Untersuchungen in Nordfriesland. Meyniana Bd. 12: 97-146.

Willutzki, H., - I962 - Zur Waldgeschichte und Vermoorung sowie über Rekurrenzflächen im Oberharz. Nova Acta Leopoldina N. F. 160, (25): I-52.

Wijmstra, T. A., A. Smit, T. Van der Hammen \& B. Van Geel, - I97I Vegetational succession, fungal spores and short-time cycles in pollen diagrams from the Wietmarscher Moor. Acta Bot. Neerl. 20: 401-410.

ZAGwijn, W. \& R. PAEPE, - ig68 - Die Stratigraphie der weichselzeitlichen Ablagerungen der Niederlande und Belgiens. Eiszeitalter u. Gegenwart ig: $129-146$.

VAN ZEIST, W., - I955a - Pollen analytical investigations in the northern Netherlands; with special reference to archaeology. Diss. Utrecht. 8I pp.

VAN ZEIST, W., - $1955 \mathrm{~b}$ - Some Radio-carbon dates from the Raised bog near Emmen (Netherlands). Palaeohistoria IV: I $13-$ I 18.

Van ZeIst, W., - 1956 - Die Palynologische Bearbeitung des Münzfundes von Bargercompascuum. Palaeohistoria V: 93-99.

VAN Zeist, W., - $195^{8}$ - De Valtherbrug. Nieute Drentse Volksalmanak 76 : $2 \mathrm{I}-49$. 
Van ZeIsT, W., - 1959 - Studies on the Post-Boreal Vegetational History of South-eastern Drenthe (Netherlands). Acta Botan. Neerl. 8: $156-185$.

VAN ZEIST, W. \& H. T. WATERBoLK, - 1960 - Een houten gebouwtje uit de Bronstijd in het veen bij Bargeroosterveld. Nieuze Drentse Volksalmanak 78 : I99-204.

Zimmermans, W. H., - in the press - Moor- und Flussfunde vom Neolithikum bis zur Völkerwanderungszeit in niederländischen-norddeutschen Flachland zwischen Rhein und Elbe. Göttingen.

Zondervan, H., - I925 - Een geografisch-geologische excursie naar de veenstreek. Tijdschr. Kon. Ned. Aardr. Gen. 2e Serie, dl. XLII, Afl. 4: 54 I-55o. 